



\section{GUIDELINES: friend or foe?}

Opportunities for improvement of cardiovascular pharmacotherapy based on evidence from real-world observational data

Willemien Kruik-Kollöffel 



\title{
GUIDELINES: FRIEND OR FOE?
}

\section{OPPORTUNITIES FOR IMPROVEMENT OF CARDIOVASCULAR PHARMACOTHERAPY BASED ON EVIDENCE FROM REAL-WORLD OBSERVATIONAL DATA}

\author{
Proefschrift
}

\author{
ter verkrijging van \\ de graad van doctor aan de Universiteit Twente, \\ op gezag van de rector magnificus, \\ prof.dr. T.T.M. Palstra, \\ volgens besluit van het College voor Promoties \\ in het openbaar te verdedigen \\ op woensdag 29 mei 2019 om 14.45 uur
}

door

Wilhelmina Joanneke Kruik-Kollöffel

geboren op 5 april 1965

te Utrecht 
Dit proefschrift is goedgekeurd door:

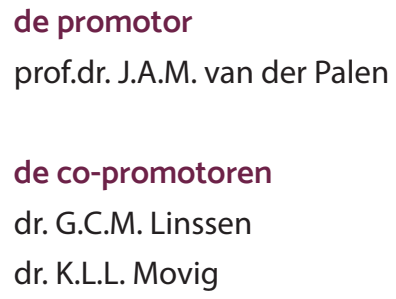

De meeste data die gebruikt zijn in de analyses beschreven in dit proefschrift, zijn verkregen uit het PHARMO Database Network. De auteur wil graag het PHARMO Instituut bedanken en alle zorgverleners die informatie leveren aan het Database Network.

Het drukken van dit proefschrift is financieel ondersteund door de Raad van Bestuur Ziekenhuisgroep Twente, de Saxenburgh Groep - Röpcke-Zweers ziekenhuis Hardenberg en CARDION U.A.

Ontwerp omslag: Esther Scheide, www.proefschriftomslag.nl

Lay-out: $\quad$ Esther Scheide, www.proefschriftomslag.nl

Druk: $\quad$ Ridderprint BV

ISBN: $\quad$ 978-90-365-4732-1

DOI: $\quad 10.3990 / 1.9789036547321$

(c) Willemien Kruik-Kollöffel, Enschede, The Netherlands, 2019

All rights reserved. No parts of this thesis may be reproduced, stored in a retrieval system or transmitted in any form or by any means without permission of the author. Alle rechten voorbehouden. Niets uit deze uitgave mag worden vermenigvuldigd, in enige vorm of op enige wijze, zonder voorafgaande schriftelijke toestemming van de auteur. 
Promotie commissie

Voorzitter/secretaris prof.dr. Th.A.J. Toonen, Universiteit Twente, BMS

Promotor prof.dr. J.A.M. van der Palen, Universiteit Twente, BMS

Co-promotoren dr. G.C.M. Linssen, Ziekenhuisgroep Twente

dr. K.L.L. Movig, Medisch Spectrum Twente

Leden

prof.dr. C. von Birgelen, Universiteit Twente, BMS

prof.dr. J.G. Grandjean, Universiteit Twente, ET

prof.dr. E.N. van Roon, Rijksuniversiteit Groningen

prof.dr. O.H. Klungel, Universiteit Utrecht

prof.dr. P. van der Meer, Universitair Medisch Centrum Groningen 



\section{Contents}

Chapter 1 General introduction

Chapter 2 Prescription behaviour for gastroprotective drugs in new users as a result of communications regarding clopidogrel - proton pump inhibitor interaction

Chapter 3 Decrease in switches to "unsafe" proton pump inhibitors after communications about interactions with clopidogrel

Chapter 4 Effects of European Society of Cardiology guidelines on medication profiles after hospitalisation for heart failure in 22,476 Dutch patients: from 2001 till 2015

Chapter 5 Association between heart failure medication at discharge and heart failure readmission

Chapter 6 Association between cardiovascular medication and readmission in heart failure patients

Chapter 7 Risk of readmission for heart failure associated with non-cardiovascular medication: an observational cohort study

Chapter 8 General discussion

Chapter 9 Summaries

Summary

Nederlandse samenvatting

Samenvatting voor het publiek

Dankwoord

Curriculum Vitae

List of publications 166

Bij de voorpagina 


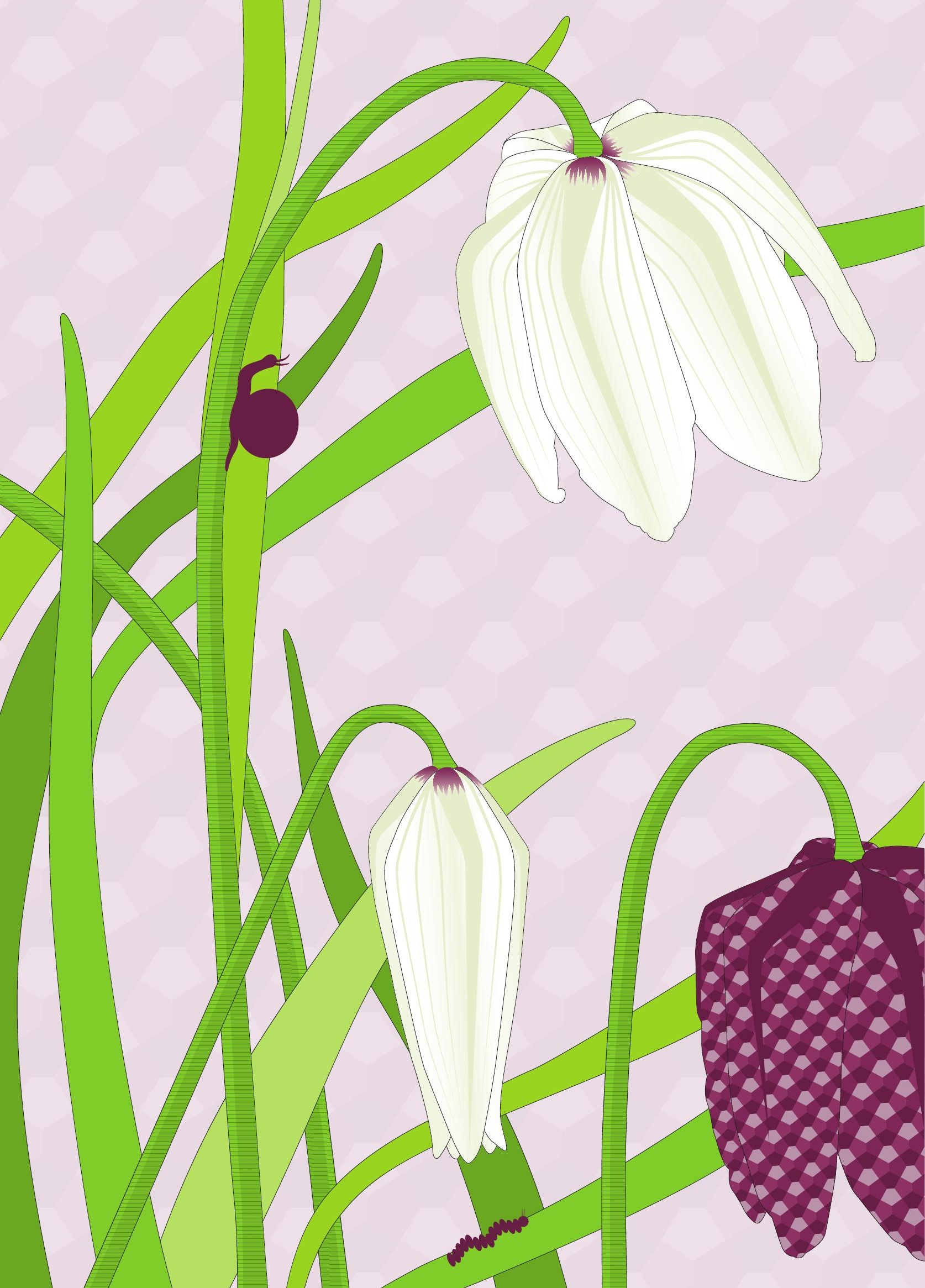




\section{Chapter 1}

General introduction 


\section{DR. A. CIOHTIA'S LEHRBUCH \\ DER \\ ARZNEIMITTELLEHRE \\ UND \\ ARZNEIVERORDNUNGSLEHRE.}

ACHTE, VERBESSERTE UYD VERMEHRTE AUFLAGE

HERATSGEGEBEN

voN

DR. WILHELM FILEHNE,

1 ORD. PROFESSOR DER PHARMAKOLOGIE ETC. UND DIRECTOR DES PHARMAKOLOGISCHEN INSTITUTS DER UNIVERSITITT BRESLAU.

\section{FREIBURG I. B. UND LEIPZIG 1893.}

AKADEMTSCHE VERLAGSBUCHHANDLUNG VON J. C. B. MOHR (PAUL SIEBECK). 


\section{Guideline development and position}

For almost 750 years we know of pharmacists in the Netherlands." Anselmus, "Anselmus van Utrecht", is the first, mentioned in a document dated 1276 in the archives of the city of Utrecht: "nostro anselmo apotekario". Probably most of his medicines were extracts of herbs, meticulously prepared to keep the medicinal ingredients and to eliminate malicious by-products. He will have cherished his recipes and have tried to ameliorate them day-today. His recipes were his guidance and his friends.

In 1893 the eighth edition of Dr Cloetta's "Lehrbuch der Arzneimittellehre und Arzneiverordnungslehre" was published. ${ }^{2}$ This book describes the possible side effects of various drugs. For example in the chapter about morphin: "regelmässig Stuhlverstopfung" and "Appetitverminderung" as well as the risk of "Der chronische Morphinmissbrauch". Not only the use of the preparations was described, but also in detail, like the recipe of a master chef, the preparation of Tinctura Valerianae aetherea from Radix Valerianae.

There have always been similarities between the preparation of medicines and the art of cookery. Recipes are like guidelines: good friends, guaranteeing high quality medicines. Nowadays, guidelines from scientific specialist associations are not by everybody considered as good friends. Working with guidelines has been called "cookbook-medicine". No need for thinking, just follow the recipe. However, in the art of cookery as well as in medicine, the amateur cannot become a professional, just by working from the book. For being a good health care professional, as well as a good chef, expert craftsmanship is needed as well as knowledge of the matter.

When, in 1972, Archie Cochrane, the name giver of the Cochrane society, reproached the medical profession for not having critical summaries of all randomised controlled trials, about 14 reports of trials were being published per day. ${ }^{3}$ In 2010 the counter was on 75 trials published every day and 11 systematic reviews of trials. Since then, this number has risen even further. For an individual professional it is far beyond his or her reach to try to read, interpret and implement all this scientific news. The composition of clinical practice guidelines by the scientific specialist associations is therefore necessary. ${ }^{4}$ The translation of all this scientific information into guidelines, has nowadays resulted in about 525 clinical practice guidelines in the Netherlands. This number has been stable for a long time already and each year about 50 guidelines are updated.

The composing of guidelines has evolved into the concept of "evidence-based medicine", a term introduced in 1991. ${ }^{5}$ Guyatt described the requirements for evidence-based medicine: skills of literature retrieval, critical appraisal, and information synthesis. It also requires judgment of the applicability of evidence to the patient at hand and systematic approaches to make decisions when direct evidence is not available. Guidelines are seen as the mainstay to practice evidence-based medicine. 
The last decade, however, criticism on guidelines and evidence-based medicine has been growing, internationally ${ }^{6,7}$ as well as in the Netherlands. ${ }^{8}$ The main criticism is related to the focus on scientific evidence, especially from randomised clinical trials, instead of a focus on the patient. Because of the overflow of information from scientific research nowadays, the risk arises that we lose sight of the interest of the individual patient. The time-consuming work of the updating of guidelines can take years in which the patients do not take advantage of new insights and might receive out-dated care. In 2016 the British Medical Journal introduced the BMJ Rapid Recommendations", which aim is "to promptly translate emerging research to user friendly and trustworthy recommendations, evidence summaries, and decision aids".

\section{Guidelines from national authorities}

Another book now, from the year 1946: "Ars praescribendi voor den Medicus".10 This book describes the rule of Bürgli: drugs with a similar effect give an additive outcome, if they have the same pharmacological site of action. This might be considered medication surveillance in the making, drug duplication, i.e. the inappropriate use of two drugs from the same therapeutic class. Drug duplication is nowadays considered as one of the main themes in drug safety alerting by pharmacists, besides drug interactions, surveillance of contraindications and dose control. The author of "Ars praescribendi voor den Medicus" also describes some financial directions a physician has to abide by. For example how to avoid having to pay back the National Health Insurance Fund for their patients, or the way to determine the wages for the preparation of drugs for the various classes of private patients. Not every physician in 1946 will have liked this interference with his or her prescription behaviour. Prescription guidelines as rule, or law, by an external interfering authority. Not a friend, but a foe?

The involvement of regulatory authorities, apart from administrative instructions, dates from the sixties, when the letter to the editor of $\mathrm{McBride}^{11}$ preluded the extensive publicity about the mutagenic characteristics of thalidomide. In the Netherlands on the market as Softenon ${ }^{\circledR}$ since 1957 , this was also called the "Softenon-affair". As far as McBride knew, congenital abnormalities were present in approximately $1.5 \%$ of babies, whereas he observed an incidence of almost $20 \%$ in babies delivered of women who were given this drug during pregnancy as an antiemetic or sedative.

THALIDOMIDE AND CONGENITAL ABNORMALITIES

SIR,-Congenital abnormalities are present in approximately $1.5 \%$ of babies. In recent months I have observed that the incidence of multiple severe abnormalities in babies delivered of women who were given the drug thalidomide ('Distaval') during pregnancy, as an antiemetic or as a sedative, to be almost $20 \%$.

These abnormalities are present in structures developed from mesenchyme-i.e., the bones and musculature of the gut. Bony development seems to be affected in a very striking manner, resulting in polydactyly, syndactyly, and failure of development of long bones (abnormally short femora and radii).

Have any of your readers seen similar abnormalities in babies delivered of women who have taken this drug during pregnancy?

Hurstville, New South Walts.

W. G. MCBRIDE. Insufficient animal research was performed in the preclinical phase, while a supervisory authority was non-existent. ${ }^{12}$ The first Dutch Medicines Act came into effect in 1958 and the Dutch Medicines Evaluation Board (MEB) was founded in 1963. 
The MEB is the Dutch independent authority that regulates the quality, efficacy and safety of medicines, and encourages better use of medicines for the right patient. Their core business is to look at the entire lifecycle of medicines, from early development through to their use in practice. One of their spearheads is pharmacovigilance: the science and activities relating to the identification, assessment, understanding, and prevention of adverse effects and health problems, which are related to the use of medicinal products. One of the tools available to them is the Direct Healthcare Professional Communication (DHPC). ${ }^{13}$

A DHPC, or "Dear doctor-letter," is a single, additional risk minimisation measure used to directly inform healthcare professionals about new, important information about a medicinal product. DHPCs are sent by the marketing authorisation holder of the product, to healthcare providers in consultation with the MEB. The MEB publishes the DHPCs on its website, together with a message containing advice for healthcare professionals and patients. New and important information about the usage of a medicinal product is a possible reason to issue a DHPC, for example new contra-indications, important new sideeffects, changes in the dosage, et cetera. The initiative for distributing a DHPC can come from the European or national competent authorities, or from the marketing authorisation holder. The contents of the letter and the communication plan are determined by the marketing authorisation holder and the competent authorities.

The Policy Document "Direct Healthcare Professional Communication"14 describes the procedure for the implementation of DHPCs in the Netherlands, and provides instructions for translating the DHPC, identifying the target groups, and their distribution. The starting point is supposed to be that the information in the DHPCs is optimally consistent with the usability for healthcare providers, which should improve the effectiveness of this additional risk minimisation measure. A serious omission (personal opinion) is the fact that the concerning content of a DHPC has hardly been discussed with practicing health care professionals or the concerned scientific specialist associations.

On 29 May 2009'15, the European Medicines Agency (EMA) published a statement on the possible interactions between clopidogrel and (es)omeprazole, a proton pump inhibitor (PPI). In August 2009, a DHPC was sent to the concerned groups of professionals. The scientific proof, however, underpinning the statement on omeprazole or esomeprazole, was not without dispute. In 2008 for the first time Gilard et al. ${ }^{16}$ observed decreased levels of the active metabolite of clopidogrel and an increased platelet reactivity in patients coadministered a PPI. Focks et al. ${ }^{17}$ published a systematic review of all following publications on the impact of the addition of PPIs to clopidogrel on platelet function and cardiovascular outcome. They stated that the emerging evidence from recent prospective studies did not support the statement that the addition of a PPI in patients who used clopidogrel should be considered harmful with regard to the decreased efficacy of clopidrogel. In the years 
2008-2011, clopidogrel was almost exclusively prescribed by cardiologists in combination with aspirin. In the Netherlands, more than 100,000 patients were prescribed clopidogrel in 2009. The physician and pharmacist had to choose the lesser of two evils. On the one hand switching the gastroprotection to a less effective one on the basis of doubtful scientific evidence and the burden of medication change, with on the other hand, medicolegal aspects and the theoretical risk of diminished efficacy of clopidogrel.

On July $5^{\text {th }}, 2018$, the medical and pharmaceutical world was startled by a press release of the EMA about the finding of impurities in tablets valsartan from a certain company. ${ }^{18}$ The subsequent recall of valsartan containing tablets concerned at least 160,000 of 225,000 patients. If 8,000 patients would swallow the maximum dosage of valsartan of $320 \mathrm{mg}$ for four years, an estimated one extra patient might develop cancer during his lifetime caused by the quantity of the impurity in the polluted tablets. ${ }^{19}$ Physicians, pharmacists and patients have been quite occupied with valsartan since then: so risk communication is a complicated field of work!

Guidelines, especially if proclaimed by a national authority without a clear approval mark of a scientific specialist associations, can easily become a foe for health care professionals, instead of a friend.

\section{Implementation of guidelines}

"Between the health care that we now have and the health care that we could have lies not just a gap, but a chasm", was one of the main quotes of the 2001 report of the United States Institute of Medicine "Crossing the quality chasm: a new health system for the $21^{\text {st }}$ century".20 The gap between on the one hand scientific evidence and guidelines and on the other hand the practice of evidence-based medicine is wide.

Various models have been developed to describe the road from scientific theory to daily practice. One of those ${ }^{21}$ characterizes the sequential cognitive and behavioural steps, which have to be taken to adhere to guidelines with 4 A's: awareness, agreement, adoption and adherence. Physicians, who are initially unaware of a specific guideline, must first become aware of it, then intellectually agree with it, next decide to follow it in their practice (adopt it), and finally actually succeed in following it at appropriate times (adhere to it). Based on their research into paediatric vaccine recommendations, this model seems to hold for physicians' voluntary compliance with guidelines. In cases where guideline compliance is "forced", further efforts to promote agreement become less relevant, whereas interventions to enhance adoption and adherence remain important. From the nursing discipline ${ }^{22}$, emanate two statements 1) getting the evidence straight and 2) getting the straight evidence used. The 4-stage awareness-to-adherence model is then extended to include some extra elements, in particular, patient involvement. 
In the field of guideline implementation in heart failure, an editorial was published in the Journal of the American College of Cardiology with the daring title ${ }^{23}$ : "Are Guidelines Merely Suggestions?". The editorial starts off with a quote by W. Clement Stone ${ }^{22}$ : "The natural law of inertia: Matter will remain at rest or continue in uniform motion in the same straight line unless acted upon by some external force". This definition of inertia refers to the factors for inertia with the clinician, the patient and system input in the field of heart failure management. According to this editorial the implementation of guideline directed therapies can be improved and the heart failure associated morbidity and mortality reduced, by addressing these modifiable factors. For the clinicians the factors are lack of awareness, limited time, limited experience in the management of complex heart failure patients and the creed "my patient is doing fine". The modifiable factors in the system are insurance, understaffed clinics and remote locations with paucity of specialists, although this last factor is less relevant in the Netherlands. Finally, the factor patient: reluctance to change, poor adherence, comorbidities and being uninformed may play a role.

Scientific specialist associations become more and more aware that the work is not finished once the guideline is in press. On the contrary, most of the work still has to be done. Summary cards, apps, ready to present webcasts, toolkits, risk charts, etc. are developed. And last but not least, the patient gets more and more involved, not only on the level of participation in guideline composing, but also in the clinic on an individual basis through shared decision making.

A guideline is a friend to a patient, once there is space for the needs of this individual patient. There are plenty of example available. Such as home treatment with intravenous furosemide or dobutamine in end-of-life heart failure care and the increasing use of genetic testing prior to the prescription of clopidogrel in the USA, which has resulted in the test being funded via Medicare. Other examples are monitoring at home for patients with heart failure and patient oriented internet-sites by specialist associations. Hot topics of this decennium are: personalized care, patient oriented care, individualized care. With the patient at the table, the criticism on guidelines and evidence-based medicine, not being applicable for an individual patient, can be set at rest.

\section{Real-world data and real-world evidence}

John Snow ${ }^{25}$ is considered one of the fathers of modern epidemiology, in part because of his work in tracing the source of a cholera outbreak in Soho, London, in 1854. By talking to local residents he identified the source of the outbreak as the public water pump on Broad Street. His studies of the pattern of the disease were convincing enough to persuade the local council to disable the well pump by removing its handle. Snow's study was a major event in the history of public health and geography. It is regarded as the founding event of the science of epidemiology. 
Snow used real-world data as evidence, just as for hundred years the development of new medical treatments relied on real-world evidence from real-world data. Real-world evidence in medicine means evidence obtained from real-world data, which are observational data obtained outside the context of randomized controlled trials (RCTs) and generated during routine clinical practice. James Lind $^{26}$ was the first to study the effect of citrus fruit by a systematic experiment in 1747. It ranks as one of the

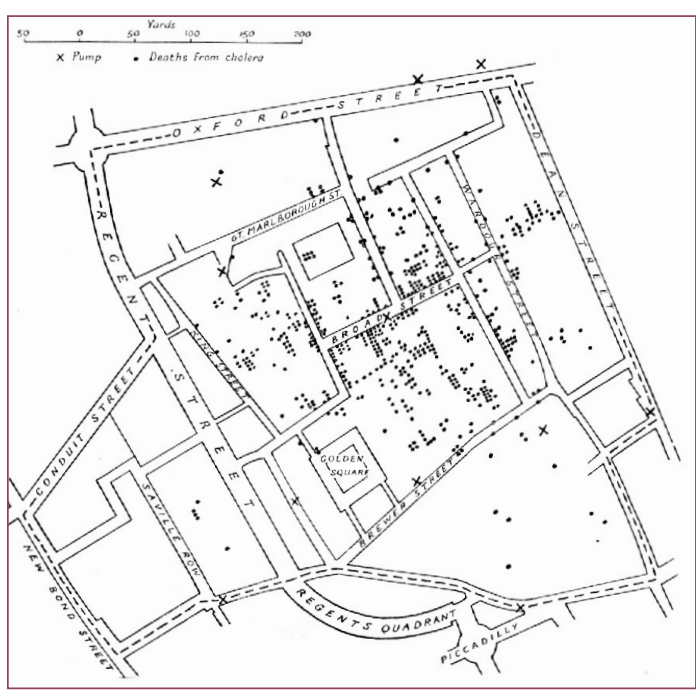
first reported, controlled, clinical experiments in the history of medicine. Although based on real-world evidence since antiquity in various parts of the world, and since the 17th century in England, it had been known that citrus fruit had an antiscorbutic effect. ${ }^{27}$

Traditionally RCT are recognized as "golden standard". However, if a patient is younger than, sicker than, older than, taller, shorter, thinner, or in any way different from the patient in a RCT, can the results from this RCT transferred to this particular patient? Real-world data are capable of measuring for example the effectiveness of a certain drug in a realworld setting, detect rare side-effects on long-term, or evaluate the implementation of guidelines. Real-world evidence might be considered as a bridge between the structured research setting of a RCT and everyday medical practice. Data gathered in everyday practice could be used to generate new knowledge and answer a variety of research questions.

$E_{M A}{ }^{28}$ as well as the U.S. Food and Drug Administration (FDA) ${ }^{29}$ have embraced realworld evidence to monitor post-marketing safety and adverse events. Regulatory decisions can be based upon real-world data. Between 1 January 2005 and 31 December 2013, 392 products received a positive report for their market authorisation by EMA. Analyses demonstrated that 31 registries were required for those products..$^{30} 71 \%$ Of the registries had a primary safety objective. Thirteen of the registries had not been started. Only 9 of the registries reported no problems. A low accrual rate was reported in 13 of the registries started, a delayed start and a requirement of a protocol amendment were both reported in 9 registries. This study ${ }^{30}$ will enable the EMA to adjust their real-world evidence policy on the request for registries in the context of post-marketing surveillance.

Real-world data can be obtained from patient registries, healthcare databases (including electronic health records), pharmacy and health insurance databases, social media and patient-powered research networks. ${ }^{31}$ There are, however, some limitations to the use of 
real-world data. First, data are not collected for research purposes. As they are collected during daily clinical practice, the data collection process may not be clear and may result in imprecise, incorrect or incomplete data entry. Second, data collection with the aim of good patient care might bring along invalid, incorrect or incomplete data. For example, recording of pain scores might stop if the pain is under control. Third, the quality and completeness of the data will vary. Especially if data is recorded by various health care professionals working with the patients in various settings and in the situation where more databases have to be combined, quality checks should be performed the get an idea of the over-all quality of the data. A procedure for correction or deletion of data is necessary. And last but not least a privacy-question might arise if more data are collected than necessary. Especially with pharmacy records the question arises whether one is interested in prescription of a drug, dispensing or actual use by the patient. In addition, over-the-counter drugs might not be registered as well as drugs distributed through other channels, like a hospital pharmacy.

Next to the limitations, there are also advantages of real-world evidence compared to $\mathrm{RCT}^{32,33}$ In case data are already available, no time is needed to recruit and enrol patients and real-world evidence enables shortening of the duration of the research. Real-world evidence can guide the direction for further RCT-based research. Research that cannot be performed with RCT is possible, like in children or high-risk groups, and the detection of rare side-effects is within reach. Some real-world data are more easily accessible and retrievable.

\section{Outline and scope of this thesis}

The main objective of this thesis is to search for opportunities for improvement of cardiovascular pharmacotherapy based on evidence from real-world observational data.

Clopidogrel is a pro-drug. The active metabolite blocks P2Y12-ADP-receptor irreversibly and prevents adenosine diphosphate induced aggregation of platelets. During the period 2008-2011 clopidogrel was in the Netherlands mainly used in cardiology, for patients with acute coronary syndromes (ACS) and/or undergoing percutaneous coronary interventions, and it was used mostly in combination with aspirin, also a platelet aggregation inhibitor. In the Netherlands in 2017 40,938 percutaneous coronary intervention procedures were performed, for stable coronary artery disease or ACS. ${ }^{34}$ ACS can present itself as a myocardial infarction or unstable angina pectoris. Patients with unstable angina do not experience myocardial necrosis, have a substantially lower risk of death and appear to derive less benefit from intensified antiplatelet therapy as well as early invasive strategy. ${ }^{35}$ In 2017 23,003 men and 11,144 women were admitted to a hospital with myocardial infarction, respectively with a mean age of 66 and 71 years. ${ }^{34}$

As the combination of two platelet aggregation inhibitors is associated with an increased risk of gastrointestinal bleeding, measurements to reduce the risk of gastrointestinal bleeding 
have to be taken. The prescription of a PPI is the most powerful instrument. Safety concerns of the concomitant use of clopidogrel and PPI in general at first and later (es)omeprazole in particular, were announced by the EMA and the FDA, and a DHPC was published, see above. In Chapter 2 we investigated the association between the various communications and the effect on the prescription pattern of a PPI for patients starting on gastroprotective drugs. The changes in prescriptions for gastroprotective drugs in patients already on gastroprotection were analysed in Chapter 3.

In the Netherlands in 2017 an estimated 230,200 patients have heart failure. ${ }^{34}$ Heart failure is responsible for $20 \%$ of cardiovascular mortality. The impact of heart failure on the micro-level, a patient and his or her surroundings, as well as the macro-level, use of health care system and effect on society in general, is extensive. It is therefore of utmost importance to diagnose and treat heart failure on the basis of all available evidence. In 1987 the Consensus trial ${ }^{36}$ was published, which for the first time incontrovertibly demonstrated that the -at that time- poor outcome of patients with heart failure can be markedly improved with medical therapy. The first European guideline on the treatment of heart failure was published in $1997^{37}$, followed by revised guidelines in $2001^{38}, 2005^{39}, 2008^{40}$, $2012^{41}$ and $2016 .{ }^{42}$ In Chapter 4 we analysed in real-world data to what extent the European Society of Cardiology guidelines influenced prescription behaviour at discharge after a first hospital admission for heart failure, between 2001 and 2015. The focus was on core heart failure medication: angiotensin-converting-enzyme inhibitors (ACEI)/angiotensin-receptor blockers (ARB), beta-blockers (BB), mineralocorticoid-receptor antagonists (MRA) and diuretics.

\section{The New England Journal of Medicine}

OCopyright, 1987, by the Massachusetts Medical Society

\begin{tabular}{llr}
\hline Volume 316 & JUNE 4, 1987 & Number 23 \\
\hline
\end{tabular}

EFFECTS OF ENALAPRIL ON MORTALITY IN SEVERE CONGESTIVE HEART FAILURE

Results of the Cooperative North Scandinavian Enalapril Survival Study (CONSENSUS)

The GONSENSUS Trial Study GRouP*

Hospital admission for heart failure is a marker of a poor prognosis. ${ }^{42}$ In 2017 in the Netherlands 16,283 men and 14,702 women were admitted to a hospital because of heart failure. ${ }^{34}$ After a first admission, between 2008 and 2010 respectively 13\%, 32\% and 64\% of the men had died within 30 days, 1 year and 5 year. For women these percentages were 
respectively $15 \%, 33 \%$ and $65 \%$. Titration of disease-modifying medications (ACEI/ARB, BB and MRA) should start during hospital admission in patients with heart failure especially with reduced ejection fraction, as they reduce the risk of hospital admission for heart failure and death..$^{42}$ Diuretics are indispensable for most patients with heart failure with reduced ejection fraction as well as heart failure with preserved ejection fraction. In Chapter $\mathbf{5}$ we assessed over a 15-year period the association between the prescription of ACEI/ARB, BB, MRA and diuretics and heart failure readmissions in a real-world, large, unselected group of patients after a first hospital admission for heart failure.

Once the foundation for heart failure optimal medical therapy is laid, the work of the heart failure specialist is not yet finished. Specific groups of patients, on the one hand, need additional heart failure medication, like an angiotensin receptor neprilysin inhibitor, ivabradine, digoxin, or the combination of hydralazine/isosorbide dinitrate. Some of these drugs are also used for other indications, like digoxin for atrial fibrillation. On the other hand, cardiovascular comorbidities are common in heart failure and their associated cardiovascular medication can interfere with optimal medical therapy resulting in undesirable side-effects, or even heart failure exacerbation. In Chapter 6 we investigated the association between additional heart failure medication and non-heart failure cardiovascular medication, and readmissions for heart failure in the same cohort as in Chapter 5. Finally we performed in Chapter 7 a hypothesis generating study to estimate the risk of readmission for heart failure, associated with the non-cardiovascular medication present at the moment of discharge. This medication is not that "close to the heart" of a cardiologist as the cardiovascular medication, but might for example aggravate heart failure symptoms and further impair quality of life, or affect the use of treatments for heart failure. ${ }^{42}$ The comorbidity for which the non-cardiovascular medication is intended, can interfere with diagnosis and management of heart failure as well.

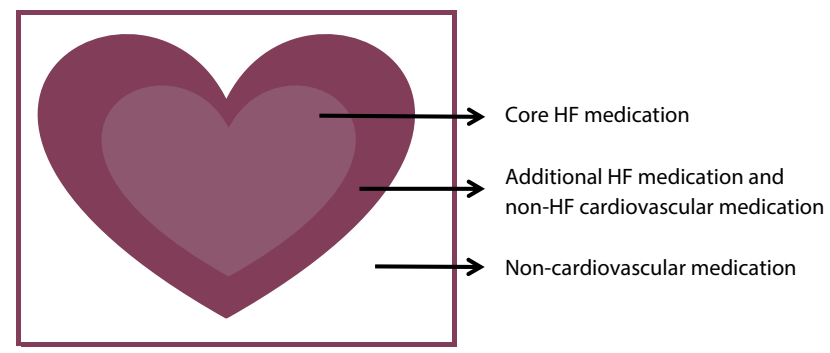

The general discussion is presented in Chapter 8. The main findings are put in a broader perspective. Implications and considerations for both clinical practice and future studies will be discussed. 


\section{References}

1. Wie was Anselmus? http://www. anselmuscolloquium.org/anselmuswie/. Accessed 1 February 2019.

2. Lehrbuch der Arzneimittellehre und Arzneiverordnungslehre, eighth edition. Filehne W (ed). Akademische Verlagsbuchhandlung von JCB Mohr, Freiburg, Leipzig, 1893.

3. Bastian H, Glasziou P, Chalmers I. Seventyfive trials and eleven systematic reviews a day: how will we ever keep up? PLoS Med 2010;7(9): e1000326.

4. Federatie Medisch Specialisten. Medischspecialistische richtlijnen. Wat, voor wie en waarom? https://www.demedischspecialist. nl/sites/default/files/FMS_faq.Medischspecialistische\%20-richtlijnen_v05.pdf. Accessed 1 February 2019.

5. Guyatt GH. Evidence-based medicine. ACP J Club 1991;114:A16.

6. Elwyn G, Wieringa S, Greenhalgh T. Clinical encounters in the post-guidelines era. BMJ 2016;353:i3200.

7. Greenhalgh T, Howick J, Maskrey N. Evidence based medicine: a movement in crisis? BMJ 2014;348:g3725.

8. Raad voor Volksgezondheid en Samenleving. Zonder context geen bewijs. Over de illusie van evidence-based practice in de zorg. Den Haag, juni 2017. https://www.raadrvs.nl/ documenten/publicaties/2017/06/19/zondercontext-geen-bewijs. Accessed 1 February 2019.

9. Siemieniuk RA, Agoritsas T, Macdonald H, Guyatt GH, Brandt L, Vandvik PO. Introduction to $\mathrm{BMJ}$ rapid recommendations. BMJ 2016;354:i5191.

10. Ars praescribendi voor den medicus, second edition. Blok CJ (ed). De erven F Bohn NV, Haarlem, 1946.

11. McBride WG. Thalidomide and congenital abnormalities. Lancet 1961;7216:1358.

12. College ter Beoordeling van Geneesmiddelen. Wat doet het College ter Beoordeling van Geneesmiddelen, 1 April 2015. https://www. cbg-meb.nl/documenten/vergaderstukk en/2015/04/01/150401-patientconsumentverslag-bijlage1. Accessed 1 February 2019.

13. College ter Beoordeling van Geneesmiddelen. Direct Healthcare Professional Communication https://english.cbg-meb.nl/topics/mah-directhealthcare-professional-communication-dhpc. Accessed 1 February 2019.

14. College ter Beoordeling van Geneesmiddelen. MEB 44: Direct Healthcare Professional Communication. https://english.cbg-meb.nl/ topics/mah-direct-healthcare-professionalcommunication-dhpc/documents/policydocuments/2019/01/01/meb-44-directhealthcare-professional-communicationsdhpcs. Accessed 1 February 2019.

15. European Medicines Agency (EMA). News and press release archive. Public statement on possible interaction between clopidogrel and proton pump inhibitors, May 29, 2009. http://www.ema.europa.eu/ema/ index.jsp?curl=pages/news_and_events/ news/2009/11/news_detail_000194. jsp\&mid=WC0b01ac058004d5c1. Accessed 4 February 2017.

16. Gilard M, Arnaud B, Cornily JC, Le Gal G, Lacut K, Le Calvez G. Influence of omeprazole on the antiplatelet action of clopidogrel associated with aspirin: the randomized, double-blind OCLA (Omeprazole CLopidogrel Aspirin) study. J Am Coll Cardiol 2008;51(3):256-260.

17. Focks JJ, Brouwer MA, Van Oijen MG, Lanas A, Bhatt DL, Verheugt FW. Concomitant use of clopidogrel and proton pump inhibitors: impact on platelet function and clinical outcome- a systematic review. Heart 2013;99(8):520-527.

18. European Medicines Agency (EMA). EMA reviewing medicines containing valsartan from Zhejiang Huahai following detection of an impurity: some valsartan medicines being recalled across the EU, 5 July 2018. https://www.ema.europa.eu/en/news/emareviewing-medicines-containing-valsartanzhejiang-huahai-following-detectionimpurity-some. Accessed 1 February 2019.

19. Nederlands Huisartsen Genootschap. Update: terugroepactie medicijnen met valsartan. https://www.nhg.org/actueel/nieuws/updateterugroepactie-medicijnen-met-valsartan. Accessed 1 February 2019.

20. United States Institute of Medicine. Crossing the quality chasm: a new health system for the $21^{\text {st }}$ century, March 2001. https://www. nap.edu/catalog/10027/crossing-the-qualitychasm-a-new-health-system-for-the. Accessed 1 February 2019. 
21. Pathman DE, Konrad TR, Freed GL, Freeman VA, Koch GG. The awareness-to-adherence model of the steps to clinical guideline compliance. The case of pediatric vaccine recommendations. Med Care 1996;34(9):873-889.

22. Glasziou P, Haynes B. The paths from research to improved health outcomes. Evid Based Nurs 2005;8(2):36-38.

23. Jefferies $\mathrm{JL}$, Ibrahim NE. Are guidelines merely suggestions? J Am Coll Cardiol 2018;72(4):367369.

24. Clement Stone quotes. AZQuotes. http:// www.azquotes.com/quote/776478. Accessed 1 February 2019.

25. John Snow. Wikipedia. https://en.wikipedia. org/wiki/John_Snow. Accessed 1 February 2019.

26. James Lind. Wikipedia. https://en.wikipedia. org/wiki/James_Lind. Accessed 1 February 2019.

27. Scurvy. Wikipedia. https://en.wikipedia.org/ wiki/Scurvy. Accessed 1 February 2019.

28. European Medicines Agency (EMA). Harnessing the potential of real world data through a "learning healthcare system", 27 September 2018. https://www.ema.europa. eu/en/news/harnessing-potential-real-worlddata-through-learning-healthcare-system. Accessed 1 February 2019.

29. U.S. Food and Drug Administration (FDA). Real world evidence. https://www.fda. gov/scienceresearch/specialtopics/ realworldevidence/default.htm. Accessed 1 February 2019.

30. Bouvy JC, Blake K, Slattery J, de Bruin ML, Arlett $P$, Kurz X. Registries in European postmarketing surveillance: a retrospective analysis of centrally approved products, 2005-2013. Pharmacoepidemiol Drug Saf 2017;26(12):1442-1450.

31. Real-world evidence (RWE) navigator. https:// rwe-navigator.eu. Accessed 1 February 2019.

32. Kim HS, Lee S, Kim JH. Real-world evidence versus randomized controlled trial: clinical research based on electronic medical records. J Korean Med Sci 2018;33(34):e213.

33. Corrigan-Curay J, Sacks L, Woodcock J. Realworld evidence and real-world data for evaluating drug safety and effectiveness. JAMA 2018;320(9):867-868.
34. Nederlandse Hartstichting. Hart- en vaatziekten in Nederland 2018. Den Haag, november 2018. https://www.hartstichting. nl/getmedia/a6e15c10-2710-41b9-bcf88185feaf54b2/cijferboek-hartstichting-hartvaatziekten-nederland-2018.pdf. Accessed 1 February 2019.

35. Roffi M, Patrono C, Collet JP, Mueller C, Valgimigli M, Andreotti F, et al. 2015 ESC Guidelines for the management of acute coronary syndromes in patients presenting without persistent ST-segment elevation: task force for the management of acute coronary syndromes in patients presenting without persistent ST-segment elevation of the European Society of Cardiology (ESC). Eur Heart J. 2016;37(3):267-315.

36. The CONSENSUS trial study group. Effects of enalapril on mortality in severe congestive heart failure. Results of the cooperative North Scandinavian enalapril survival study (CONSENSUS). N Engl J Med 1987;316:14291435.

37. Task force of the working group on heart failure of the European Society of Cardiology. The treatment of heart failure. Eur Heart J 1997;18(5):736-753.

38. Remme WJ, Swedberg K. Guidelines for the diagnosis and treatment of chronic heart failure. Eur Heart J 2001;22(17):1527-1560.

39. Swedberg K, Cleland J, Dargie H, Drexler H, Follath F, Komajda M, et al. Guidelines for the diagnosis and treatment of chronic heart failure: executive summary (update 2005): the task force for the diagnosis and treatment of chronic heart failure of the European Society of Cardiology. Eur Heart J 2005;26(11):11151140.

40. Dickstein K, Cohen-Solal A, Filippatos G, McMurray JJ, Ponikowski P, Poole-Wilson PA, et al. ESC Guidelines for the diagnosis and treatment of acute and chronic heart failure 2008: the task force for the diagnosis and treatment of acute and chronic heart failure 2008 of the European Society of Cardiology. Developed in collaboration with the Heart Failure Association of the ESC (HFA) and endorsed by the European Society of Intensive Care Medicine (ESICM). Eur Heart J 2008;29(19):2388-2442. 
41. McMurray JJ, Adamopoulos S, Anker SD, Auricchio A, Bohm M, Dickstein K, et al. ESC Guidelines for the diagnosis and treatment of acute and chronic heart failure 2012: The task force for the diagnosis and treatment of acute and chronic heart failure 2012 of the European Society of Cardiology. Developed in collaboration with the Heart Failure Association (HFA) of the ESC. Eur Heart J 2012;33(14):1787-1847.

42. Ponikowski P, Voors AA, Anker SD, Bueno H, Cleland JG, Coats AJ, et al. 2016 ESC Guidelines for the diagnosis and treatment of acute and chronic heart failure: The task force for the diagnosis and treatment of acute and chronic heart failure of the European Society of Cardiology (ESC). Developed with the special contribution of the Heart Failure Association (HFA) of the ESC. Eur J Heart Fail 2016;18(8):891-975. 



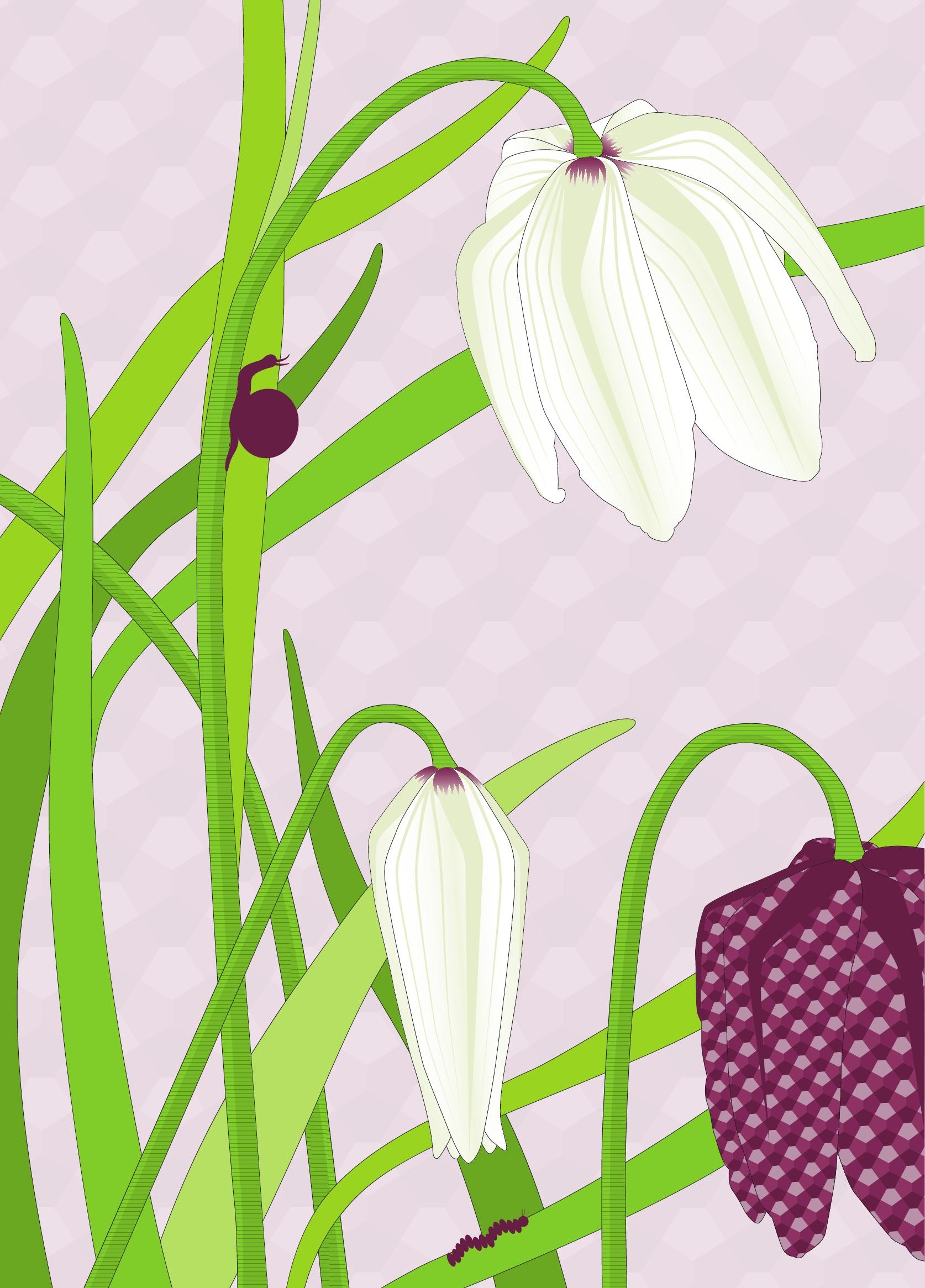




\section{Chapter 2}

Prescription behavior for gastroprotective drugs in new users as a result of communications regarding clopidogrel-proton pump inhibitor interaction

Willemien J. Kruik-Kollöffel Job van der Palen

H. Joost Kruik Myrthe P. P. van Herk-Sukel Kris L. L. Movig 


\section{Abstract}

Safety concerns of the concomitant use of clopidogrel and proton pump inhibitors (PPIs) were published in 2009 and 2010 by the medicines regulatory agencies, including a direct healthcare professional communication. We examined the association between various safety statements and prescription behavior for gastroprotective drugs in naive patients in the Netherlands during the years 2008-2011. Data from the PHARMO Database Network were analyzed with interrupted time series analyses to estimate the impact of each communication on drug prescriptions. Dispensings were used as a proxy variable for prescription behavior.

After the early communication in January $2009,15.5 \%$ (95\% Cl $7.8 \%$ to $23.4 \%)$ more patients started concomitantly with (es)omeprazole and $13.8 \%$ (95\% Cl 6.5\% to $21.2 \%$ ) less with other PPIs. Directly after the first statement in June 2009, we found a steep increase in histamine 2-receptor antagonists (H2RA) peaking at 25\%, placing those patients at risk for gastrointestinal events. This effect for H2RA faded away after a few months. In February 2010, when the official advice via an adjusted statement was to avoid (es)omeprazole, we found a decrease of $11.9 \%(95 \% \mathrm{Cl} 5.7 \%$ to $18.2 \%)$ for (es)omeprazole and an increase of $+16.0 \%$ (95\% Cl $10.3 \%$ to $21.7 \%$ ) for other PPIs. Still $22.6 \%$ (95\%Cl $19.5 \%$ to $25.7 \%$ ) of patients started on (es)omeprazole in February 2010, placing them at risk for cardiovascular events.

Advices of regulatory authorities were followed, however, reluctantly and not fully, probably partly because of the existing scientific doubt about the interaction. 


\section{Introduction}

Clopidogrel is mainly used in cardiology - especially during the period 2008-2011 in the Netherlands - for patients with acute coronary syndromes or undergoing percutaneous coronary intervention. As platelet aggregation inhibitors, clopidogrel alone, aspirin alone, as well as their combination, are all associated with increased risk of gastrointestinal (GI) bleeding. The Expert Consensus Document of the American College of Cardiology Foundation on the concomitant use of proton pump inhibitors (PPIs) and thienopyridines recommends PPIs to reduce Gl bleeding among patients with a history of upper GI bleeding. ${ }^{1}$ The Dutch Harm-Wrestling Task Force published in 2008 recommended to apply the same recommendations to clopidogrel as to aspirin, to err on the safe side of caution. ${ }^{2}$ PPIs are appropriate in patients with multiple risk factors for GI bleeding, who require antiplatelet therapy. The risk of Gl bleeding increases as the number of risk factors increases and is also dependent on ethnic differences. In patients with serious coronary heart disease treated with clopidogrel, concurrent PPI use was associated with reduced incidence of hospitalizations for gastroduodenal bleeding. ${ }^{3}$

In 2009 and 2010, various official statements about the safety of the concomitant use of clopidogrel and PPIs were published:

I Early communication. In the United States, the U.S. Food and Drug Administration (FDA) posted an early communication on 26 January 2009 to notify healthcare professionals that studies were going to be conducted to obtain additional information on the effects of genetic factors and certain drugs (especially the PPIs) on the effectiveness of clopidogrel. ${ }^{4}$

II First statement. On 29 May 2009, the European Medicines Agency (EMA) published a public statement on the possible interactions between clopidogrel and PPIs. ${ }^{5}$ On 3 June 2009, the Dutch Medicines Evaluation Board (MEB) concluded in an official statement that the combination of clopidogrel and omeprazole was not recommended unless the combination was indispensable according to the prescriber. ${ }^{6}$ In August 2009, a direct healthcare professional communication (DHPC or "Dear Doctor" letter) was sent to the concerned groups of professionals. The FDA on 17 November 2009 discouraged the use of omeprazole for gastroprotection and was not able to give specific information on the use of other PPIs. ${ }^{7}$

III Adjusted statement. On 16 February 2010, the statement was adjusted by MEB not to combine clopidogrel with (es)omeprazole because of the effect on clopidogrel's active metabolite levels and anticlotting activity. ${ }^{8}$ The EMA followed on 17 March 2010. ${ }^{9}$ 
The last warning dated from 27 October 2010, and is a reminder by the FDA to avoid concomitant use of clopidogrel and omeprazole, where pantoprazole could be an alternative. $^{10}$

The scientific proof underpinning the statement on omeprazole or esomeprazole is not without dispute. Gilard et al. ${ }^{11}$ first found decreased levels of the active metabolite of clopidogrel and an increased platelet reactivity in patients coadministered a PPI. Focks et al. ${ }^{12}$ published a systematic review of all following publications on the impact of the addition of PPIs to clopidogrel on platelet function and cardiovascular (CV) outcome. They state that the emerging evidence from recent prospective studies does not support the statement that the addition of PPIs in patients who use clopidogrel should be considered harmful.

Safety monitoring of drugs is a regulatory responsibility and the effectiveness of DHPCS in achieving the desired clinical behavior has been questioned, especially in light of the new pharmacovigilance legislation from $2012 .{ }^{13}$ Several studies looked into this, and there is a clear need for more research to understand the impact of different ways of safety communication. ${ }^{14-17}$ While the annual number of DHPCs is rising, studies demonstrate that the intended and unintended impact of the instrument itself is not always self-evident and the safety information does not always reach the healthcare professionals. ${ }^{18}$ In the case of the hypothesized interaction between clopidogrel and PPIs, safety communications, including those by the regulatory authorities, caused a lot of turmoil.

The objective of our study was to investigate the association between the various communications on the safety of the combined use of clopidogrel and PPIs on the prescribing behavior as deduced from dispensing records following DHPCs and EMA press releases in the EU member state the Netherlands in the years 2008-2011 for patients starting on gastroprotective (GP) drugs.

\section{Materials and Methods}

\section{Design and data}

Data were retrieved from the out-patient pharmacy database of the PHARMO Database Network, which comprises general practitioner or specialist prescribed healthcare medication dispensed by out-patient pharmacies. ${ }^{19}$ We used dispensing data as a proxy variable for prescribing. The dispensing records include information on the type of the product, date, strength, dosage regimen, quantity, route of administration, prescriber specialty, and costs. Drug dispensings are coded according to the WHO Anatomical Therapeutic Chemical (ATC) Classification System. Out-patient pharmacy data cover a catchment area representing 3.6 million (>20\%) residents throughout the Netherlands. Healthcare coverage regarding the reimbursement of concerned drugs was similar for all Dutch citizens and they were all equally included. Only patients 18 years and older 
were included, in accordance with the marketing authorization for clopidogrel (ATC code B01AC04 and B01AC30).

We divided the study into four separate periods. The first period started in January 2008 and ended by the end of January 2009, when the FDA early communication was posted on 26 January 2009. ${ }^{4}$ The public statements of the EMA ${ }^{5}$ (29 May 2009) and MEB ${ }^{6}$ (3 June 2009) made the second period to start in February 2009 and end by the end of May 2009. The third period lasted from June 2009 till the end of February 2010, since the adjusted statement by EMA $^{8}$ was published in 16 February 2010. The data collection ended in December 2011. In June 2009, as a result of the statements of the EMA and MEB, the interaction was integrated into the Dutch national drug-drug interaction database (G-standard), which is used by almost all pharmacies in the Netherlands. As a result, pharmacists started to contact prescribers in case of a combined prescription for PPI and clopidogrel. We therefore chose June 2009 as intervention month instead of August 2009, when the DHPC was sent, dated 6 August 2009.

Dispensings were clustered into episodes of continuous use of the same chemical entity based on the date and amount of dispensing, accepting a 30-day gap between following dispensings as described by Catalan and LeLorier. ${ }^{20}$ Dispensing of a GP drug (histamine 2-receptor antagonists [H2RA] ATC code A02BA, PPIs ATC code A02BC) started a new episode of use. Clopidogrel will usually be prescribed for 3 up to 12 months. If a patient was included in the PHARMO Database Network less than 120 days before the first dispensing of clopidogrel, we excluded this patient for the analysis of first use, as the maximum prescribing period for a drug is 90 days. Patients who started using a GP drug at least 2 weeks before the start of clopidogrel, were classified as prior users. These patients were not included in our analysis of choice for GP because their choice of GP drug was made in the absence of clopidogrel. Concomitant users started a GP drug 2 weeks before until 4 weeks after the start of clopidogrel, the first episode of use in this time frame is analyzed. If the GP drug was started four or more weeks after the start of clopidogrel, we used the first episode of use for the analysis of post users. For these two groups we analyzed the choice of GP drug. PPIs were fully reimbursed in the years 2008 until 2011. H2RA for GP use must be prescribed by a physician in a double dose in order to be reimbursed. We therefore assume all dispensings for H2RA in our study were done for gastroprotection. Theoretically some patients could enter our study cohort twice; by starting clopidogrel twice in our study, we expected this to be minimal.

\section{Analysis}

The observational research file was created using SAS programs organized within SAS Enterprise Guide version 4.3 (SAS Institute Inc., Cary, NC) and conducted under Windows using SAS version 9.2. Statistical analysis was performed using SPSS software version 22 (IBM SPSS Statistics, Armonk, New York, USA). 
Descriptive statistics were used to summarize the characteristic of the study cohort. Means for age were compared between the 4 years with analysis of variance (ANOVA) and Tukey's Honestly Significant Difference (HSD) as post hoc test. Gender distribution over the years was tested with a chi-square test for nominal variables. A chi-square test for trend was used to assess a trend over time in use of GP medication. We used interrupted time series analyses (segmented linear regression analyses) to estimate the impact of each event on the dispensing of GP drugs, as described by the Cochrane Collaboration. ${ }^{21}$ Statistical significance was set at $P \leq 0.05$.

\section{Results}

Demographic characteristics and use of GP drugs are presented in Table 1. The average age in our study was 67 years and $64 \%$ was male.

During the study period (2008-2011), 40\% of the patients did not use GP drugs at all. Approximately a quarter of the patients (27\%) were already using GP drugs prior to the start of clopidogrel. About the same percentage (23\%) started GP drugs and clopidogrel concomitantly. During the study period, about $10 \%$ of the patients started GP drugs at least 4 weeks after the start of clopidogrel. The percentage of patients without GP at the start of clopidogrel decreased from $55 \%$ to $42 \%$. A small number of patients were using H2RA at the moment they started clopidogrel. A considerable part of the patients was using (es) omeprazole, decreasing from around 20\% (2008 and 2009) to about 15\% (2010 and 2011).

Table 1 also presents the use of GP drugs at the start of clopidogrel use in relation to age. The percentage of patients without GP drug at the start of clopidogrel decreased from $55 \%$ in the total study population in 2008 to $29 \%$ in 2011 if the age group was 80 years or older. 


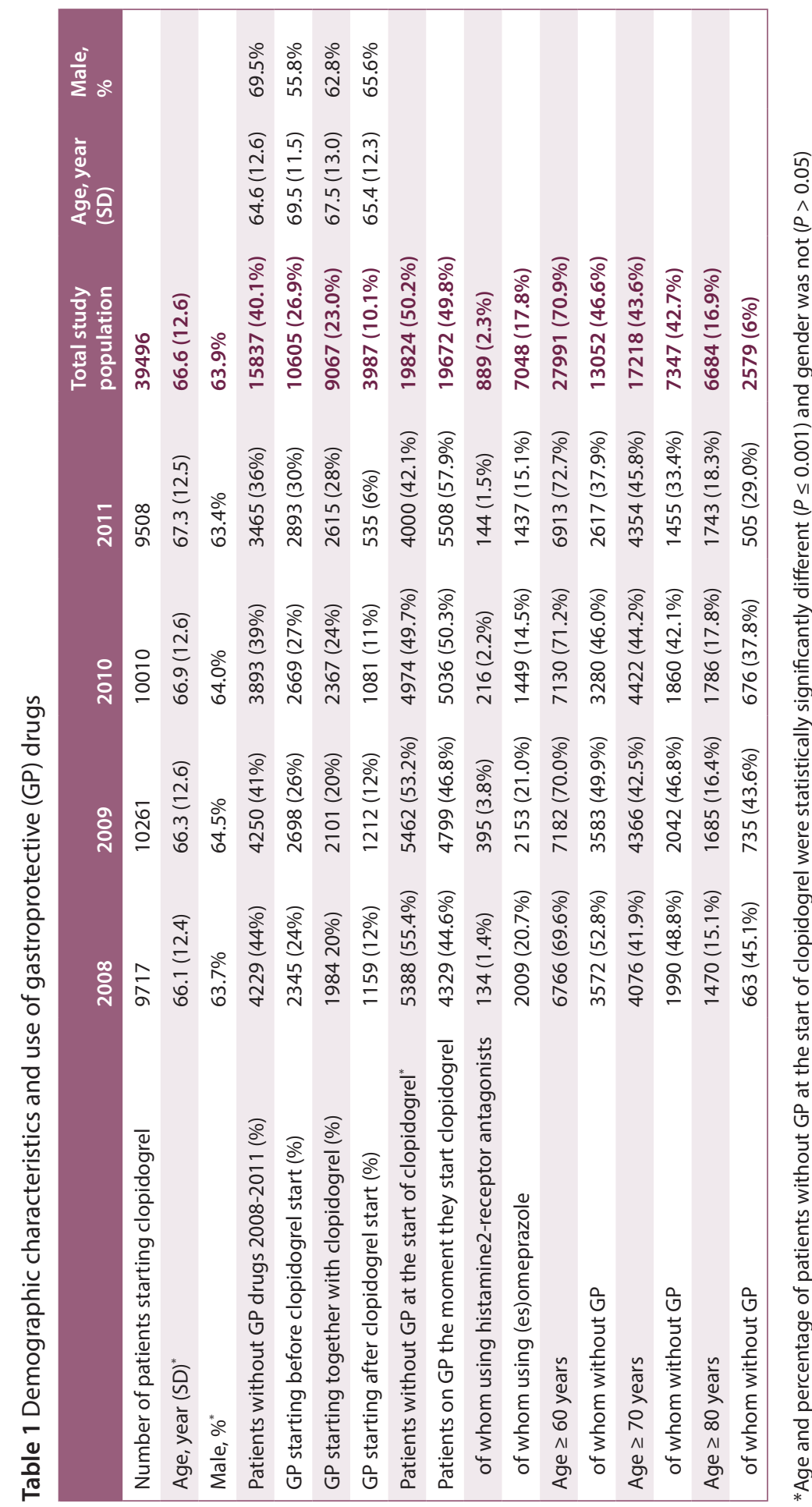


In Figure 1 the group of patients is described who started a GP drug and clopidogrel concomitantly. Before the early communication of the FDA an average of $40 \%$ of the patients started on (es)omeprazole. This percentage decreased significantly after the safety statements, reaching a new steady level around $20 \%$. The percentage of patients starting on other PPIs rose from $60 \%$ to about $80 \%$. A small percentage of the patients started on H2RA, with the exception of the period immediately after the first statements of the FDA and MEB and the introduction in the Dutch interaction database, where a short but significant increase is shown for a few months. After the early communication, a statistically significant $(P \leq 0.05)$ jump in slope and intercept is seen for all groups, except the jump in intercept for H2RA. The jump in intercept for (es)omeprazole was $+15.5 \%(95 \% \mathrm{Cl} 7.8 \%$ to $23.4 \%)$, and for other PPIs it was $-13.8 \%(95 \% \mathrm{Cl}-21.2 \%$ to $-6.5 \%)$. After the adjusted statement, the jump in intercept is statistically significant $(P \leq 0.05)$ for (es)omeprazole $(-11.9 \% ; 95 \% \mathrm{Cl}-18.2 \%$ to $-5.7 \%$ ) and the other PPIs (+16.0\%; $95 \% \mathrm{Cl} 10.3 \%$ to $21.7 \%)$.

Figure 1 Choice of gastric protection in patients starting concomitantly with clopidogrel and (es)omeprazole $(\triangle)$, other proton pump inhibitor (PPI) (o), or histamine 2-receptor antagonist (H2RA) ( $\square)$

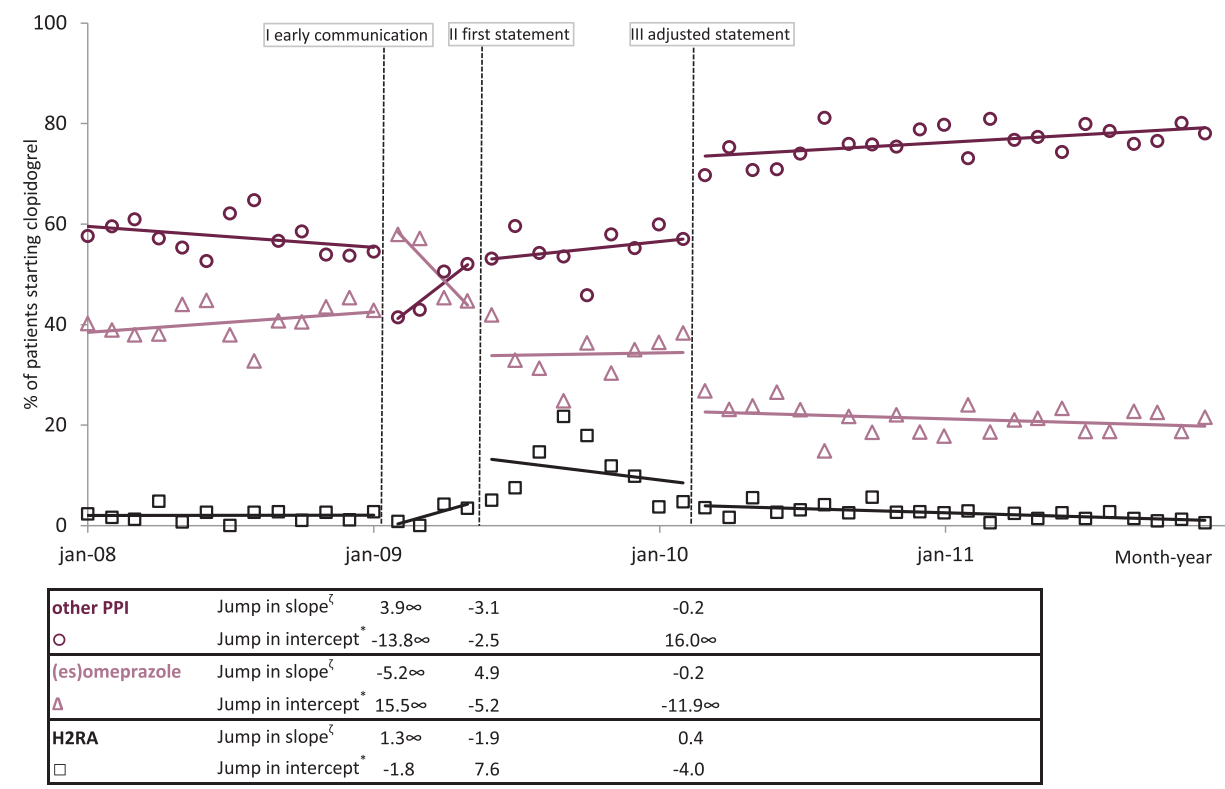

Monthly, on average, 183 patients start clopidogrel without prior use of medication for gastric protection. I, Early communication to re-evaluate need for PPl; II, first statement to avoid combination with PPI; III, adjusted statement to avoid combination with (es)omeprazole $\zeta$ indicates jump in slope from the previous to the following period * indicates jump from the predicted $\%$ just infinitely close to that month to the predicted \% for becoming the first month of the next period $\infty$ statistically significant $(P \leq 0.05)$ 
In Figure 2, data on patients who started with a GP drug at least 4 weeks after the start of clopidogrel are presented. In this Figure we removed the first 6 months, because the number of patients was too small. Roughly the patterns were similar to those in Figure 1: a decrease in starting on (es)omeprazole to about $20 \%$, an increase in other PPIs to $80 \%$, and a temporarily but obvious shift to more dispensing of H2RA. After the early communication, the jump in intercept was statistically significant $(P \leq 0.05)$ for other PPIs $(-5.9 \%$; $95 \% \mathrm{Cl}$ $-11.7 \%$ to $-0.2 \%)$. After the adjusted statement, the jumps in intercept for all three groups were statistically significant $(P \leq 0.05)$, for (es)omeprazole it was $-12.8 \%(95 \% \mathrm{Cl}-21.3 \%$ to $-4.4 \%)$, for other PPIs $+22.4 \%(95 \% \mathrm{Cl} 14.7 \%$ to $30.2 \%)$, and for $\mathrm{H} 2 \mathrm{RA}-9.7 \%(95 \% \mathrm{Cl}-16.5 \%$ to $-2.9 \%)$.

Figure 2 Choice of gastric protection in patients starting at least 4 weeks after clopidogrel with (es)omeprazole $(\Delta)$, other proton pump inhibitor (PPI) (o), or histamine 2-receptor antagonist ( $\square)$

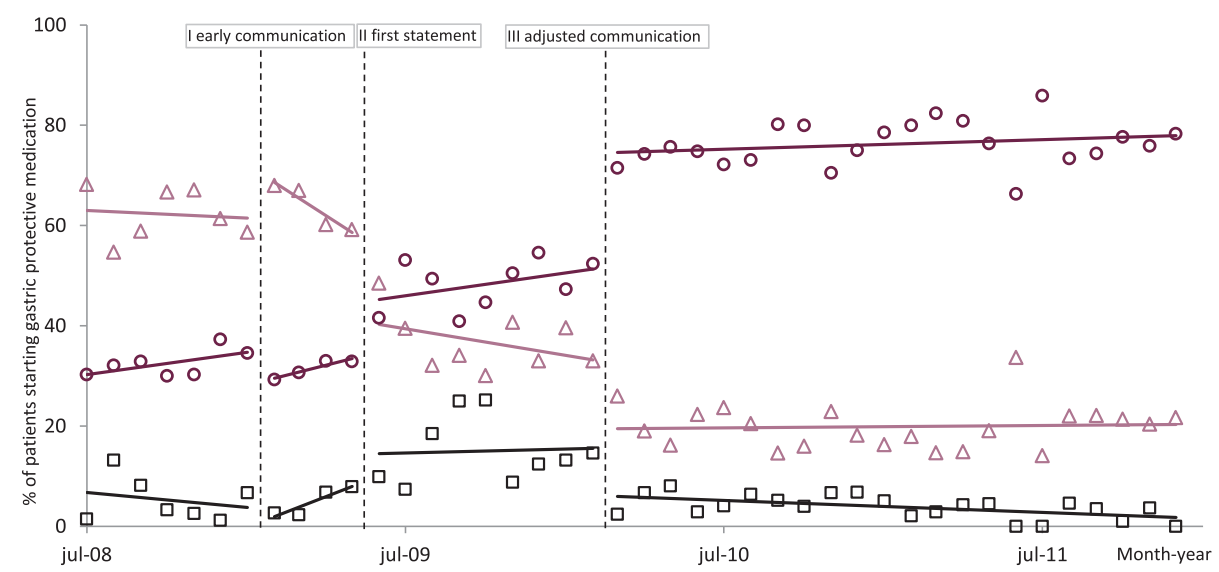

\begin{tabular}{|llrrl|}
\hline other PPI & Jump in slope $^{\zeta}$ & 0.6 & -0.5 & -0.6 \\
0 & Jump in intercept $-5.9 \infty$ & 10.5 & $22.5 \infty$ \\
\hline (es)omeprazol Jump in slope & -3.1 & 2.4 & 0.9 \\
$\Delta$ & Jump in intercept 7.3 & -15.0 & $-12.8 \infty$ \\
\hline H2RA & Jump in slope & 2.5 & -1.9 & -0.3 \\
$\square$ & Jump in intercept -1.3 & 4.5 & $-9.7 \infty$ \\
\hline
\end{tabular}

After June 2008, monthly, on average, 92 patients start clopidogrel without prior use medication for gastric protection. I, Early communication to re-evaluate need for PPI; II, first statement to avoid combination with PPI; III, adjusted statement to avoid combination with (es)omeprazole $\zeta$ indicates jump in slope from the previous to the following period * indicates jump from the predicted \% just infinitely close to that month to the predicted $\%$ for becoming the first month of the next period $\infty$ statistically significant $(P \leq 0.05)$ 
If a patient without previous GP use started clopidogrel, the physician had to decide whether to prescribe a GP drug, or not. A patient was on average 67.5 years if a GP drug was started on that moment, and 64.7 years if started later or did not start at all in our study $(P \leq 0.001)$. Each year the probability of being prescribed a GP drug increased by a factor 1.016 , corrected for gender. The probability of being prescribed a GP drug, however, was $1.2(95 \% \mathrm{Cl} 1.14$ to 1.27$)$ larger for a female patient to start a GP drug at the same age.

Notable is the difference in the first period between patients who start a GP drug and clopidogrel concomitantly (Figure 1) and patients who start a GP drug later (Figure 2). In patients who start clopidogrel and GP drug concomitantly, other PPIs than (es)omeprazole were favored, whereas in patients who start later with a GP drug, (es)omeprazole was preferred. In Figure 3, we investigated this topic by splitting both groups into omeprazole and esomeprazole. For patients who started later with GP drugs, more omeprazole was prescribed in comparison with those who started at the same time.

Figure 3 Choice for omeprazole or esomeprazole in concomitant starters (o) and post starters ( $\square)$

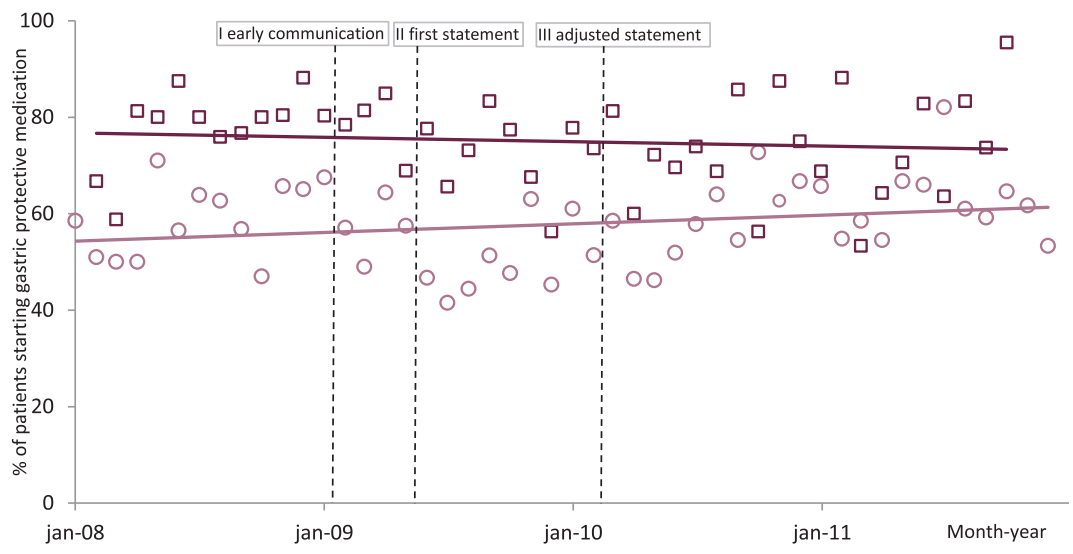

Percentage of omeprazole as part of total (es)omeprazole for patients who started concomitantly or at least 4 weeks after the start of clopidogrel. I, Early communication to re-evaluate need for proton pump inhibitor (PPI); II, first statement to avoid combination with PPI; III, adjusted statement to avoid combination with (es) omeprazole

\section{Discussion}

We were able to demonstrate a significant effect on prescription and subsequent dispensing behavior in the EU member state the Netherlands due to the various statements and DHPCs by the regulatory agencies. Directly after the first statement in June 2009, we found a shift 
in prescribing of $\mathrm{H} 2 \mathrm{RA}$ peaking at $25 \%$. In February 2010, when the adjusted statement became to prescribe non(es)omeprazole, still $22.6 \%$ of patients started on (es)omeprazole. The effect was hesitant, not fully complying to the official advices. In the case of clopidogrel there was not one single abrupt change, because there were multiple statements over time. The early communication of the FDA in January 2009 was a precursor to the later statements. The DHPC in August 2009 came 2 months after the statement of the EMA and the introduction in the Dutch interaction database. The solitary effect of the DHPC can therefore not be examined, and we designed the study with three breaking points.

Not being prescribed a GP drug if needed could be considered to be an unintended effect of the safety warnings. Patients are unnecessarily at risk for Gl side effects of clopidogrel. Although the Harm-Wrestling report published in the Netherlands in 2008 was quite clear in their recommendations for adequate gastric protection with a PPI, a considerable percentage of the patients did not receive a GP drug at all or a less effective one, namely a H2RA. ${ }^{2}$ According to the guideline of the Dutch College of General Practitioners of January 2013, H2RA double dosing is no longer considered adequate GP.22 We suppose a greater proportion of the patients qualify for GP than is observed in our study. Partially this might be caused by the uncertainty among physicians and pharmacists caused by the supposed interaction between clopidogrel and PPIs, and partly by the time needed to integrate the recommendations into daily practice. This is demonstrated by the increase of PPI users in the Netherlands in the years 2002 till 2012 with a factor 2.6. ${ }^{23}$

In the age group of 80 years or older, we found that on average in $39 \%$ clopidogrel was not combined with a PPI or H2RA. Most of the patients in our population -at least those 70 years or older - should probably be prescribed GP drugs. According to the Dutch HarmWrestling Task Force published in 2008, adequate gastroprotection was recommended above the age of 80 , for patients older than 70 if they were treated simultaneously with one other medication that increased the risk of Gl complications, and for patients older than 60 if they were treated simultaneously with two or more other medications that increased the risk of Gl complications. ${ }^{2}$ In the years 2008-2011, clopidogrel was almost exclusively prescribed by cardiologists in combination with aspirin. A considerable part of the patients in our study therefore was at risk for Gl events.

The present study shows that a significant part of the patients is prescribed (es)omeprazole when they start clopidogrel (Figures 1,2). Those patients are at risk for not being protected effectively for CV events, if the scientific proof of the combination clopidogrel with (es)omeprazole is valid. We believe that only a minority of the cardiologists was informed of the supposed interaction by the beginning of June 2009, because there was no attention at all in general medicine or cardiology journals in the Netherlands (e.g., Medisch Contact, Nederlands Tijdschrift voor Geneeskunde, Netherlands Heart Journal). The integration in the Dutch drug database is supposed to be the starting point for the 
change in prescription and dispensing behavior. This lack of change in behavior can have three different sources: the prescriber, the patient, or the factors outside those two. Because we studied dispensing data, a lack of change can be caused by the prescriber-pharmacist combination or the type of prescriber (general practitioner or specialist). The prescriber might not have received the information about the interaction, not "believe" in it, or did not think it is the cardiologists' duty to think about gastroprotection. It does not feel right to withhold an otherwise advisable drug because it might harm the patient. On the other hand, could an individual professional be liable if he has not stuck to this kind of official statement by EMA, FDA, and MEB in case a patient experiences side effects in view of those statements. A change in medication is a risk factor for reduced medication adherence, which might be one of the reasons why not all hospitals changed the GP medication when a patient with (es)omeprazole was admitted to a hospital. Besides communicated safety issues, other factors such as the introduction of new drugs, type of prescriber and patient's characteristics can influence prescribing and dispensing patterns. Unfortunately, these data are not adequately available in the PHARMO database.

As shown in Figure 3, in patients who started later with GP drugs, more omeprazole was prescribed in comparison with those who started at the same time. We hypothesize that later starters are prescribed a PPI by a general practitioner, who are more cost conscious, and omeprazole being the cheaper drug.

Characteristics for age and gender correspond to those found in the CURE study, the major study for the market authorization of clopidogrel. ${ }^{24}$ In that study mean age was 64 years and $61 \%$ of the clopidogrel users were male.

We observed a striking difference with regard to gender. The risk of starting a GP drug together with clopidogrel was $1.2(95 \% \mathrm{Cl} 1.14$ to 1.27$)$ greater for a female patient. Patients with a history of upper Gl events should be a prescribed GP drug. Women present more frequent with nausea and vomiting when presenting with acute coronary events. ${ }^{25}$ Those symptoms could be mistaken for upper Gl events while in fact being the preceding symptoms of the following acute coronary syndromes for which they will be prescribed clopidogrel. Another possible explanation for the observed difference in prescribing GP drugs to women could be the incidence of risk factors being unequally distributed among male and female. For example, for female patients the prescription of serotonin reuptake inhibitors in 2014 increased twofold, a risk factor in gastroprotection as well as use of corticosteroids (factor 1.35). ${ }^{23}$ We concluded gender to be a confounder in our study.

\section{Strengths and limitations}

Our results are limited to the Dutch situation, although we believe our conclusions will hold true for other countries because of the international nature of the discussion. Changes in use of GP drugs are caused by the various communications and not by - for example - 
the reimbursement rules in the Netherlands, because those were equal for PPIs and H2RA. Zeitoun et al. ${ }^{26}$ demonstrated substantial inconsistencies in making safety communications in four European member countries, being a source for possible confusion among patients and physicians. Because we had to design the study with three breaking points, the solitary effect of the DHPC cannot be examined. We were not able to gather sufficient data points in all periods for a solid interrupted time series analysis, especially for the period after the early communication. However, trends are clear, due to the large number of patients included in the study. We limited our study to patients not using GP drugs the moment they start clopidogrel. New use is known to be a more sensitive measure than overall use, because changes in prescribing behaviour are more likely with new users. ${ }^{27}$ We limited our statistical analysis of demographic characteristics and use of GP drugs (Table 1) to clinically relevant parameters: age, gender, and percentage of patients without GP drugs at the start of clopidogrel. However, proceeding statistical significance is not very meaningful given the extremely large numbers of patients involved. The interaction of antiplatelet drugs with (es) omeprazole is limited to clopidogrel. Ticagrelor and prasugrel - both not yet available in the Netherlands in 2008-2011 - do not interact with (es)omeprazole. Among persons treated with clopidogrel, carriers of a reduced-function CYP2C19 allele had significantly lower levels of the active metabolite of clopidogrel, diminished platelet inhibition, and a higher rate of major adverse CV events, including stent thrombosis, than did noncarriers. ${ }^{28}$ Incidence of this reduced-function allele varies between $1 \%$ and $6 \%$ in the Caucasian population, and between $12 \%$ and $23 \%$ in the Asian population. Due to this high percentage, current European and American guidelines (European Society of Cardiology, American College of Cardiology Foundation/American Heart Association) prefer other antiplatelet drugs beside aspirin.

\section{Conclusions}

Lessons learned in this study should be applied to managing drug safety information in general. Although the place in therapy of clopidogrel will be repositioned to specific smaller - groups of patients, prescribing the drug still needs to be done in a safe way, taking into account all available safety information and weighing pros and cons of the message. We suggest that an official statement from regulatory authorities followed by a DHPC could have had more impact on prescribing behavior if the scientific doubt was absent or negligible, the specialist associations had supported it, an alternative treatment had been available and actively promoted, and those statements were regularly updated to conform to new evidence. The MEB is working on a new directive for DHPCs, which provides an opportunity to close the gap between regulatory authorities and healthcare professionals and make a DHPC have an impact. 


\section{References}

1. Abraham NS, Hlatky MA, Antman EM, Bhatt DL, Bjorkman DJ, Clark CB, et al. ACCF/ACG/ AHA 2010 expert consensus document on the concomitant use of proton pump inhibitors and thienopyridines: a focused update of the ACCF/ACG/AHA 2008 expert consensus document on reducing the gastrointestinal risks of antiplatelet therapy and NSAID use. A report of the American College of Cardiology Foundation Task Force on Expert Consensus Documents. J Am Coll Cardiol 2010;56:20512066.

2. Warle-van Herwaarden MF, Kramers $C$, Sturkenboom MC, Van den Bemt PM, De Smet PA. Targeting outpatient drug safety: recommendations of the Dutch HARMWrestling Task Force. Drug Saf 2012;35:245259.

3. Ray WA, Murray KT, Griffin MR, Chung CP, Smalley WE, Hall K, et al. Outcomes with concurrent use of clopidogrel and protonpump inhibitors: a cohort study. Ann Intern Med 2010;152:337-345.

4. U.S. Food and Drug Administration (FDA). Drug Safety Information for Healthcare Professionals. "Early Communication about an Ongoing Safety Review of clopidogrel bisulfate (marketed as Plavix)", January 26, 2009.

Available at: http://www.fda.gov/Drugs/DrugSafety/PostmarketDrugSafetylnformationforPatientsandProviders/DrugSafetylnformationforHeathcareProfessionals/ucm079520.htm. Accessed 7 November 2015.

5. European Medicines Agency (EMA). News and press release archive. "Public statement on possible interaction between clopidogrel and proton pump inhibitors", May 29, 2009. Available at: http://www.ema.europa.eu/ema/ index.jsp?curl=pages/news_and_events/ news/2009/11/news_detail_000194. jsp\&mid=WC0b01ac058004d5c1. Accessed 7 November 2015.

6. Dutch Medicines Evaluation Board (MEB). Direct Healthcare Professional Communications "Standpunt CHMP en CBG over interactie clpidogrel met protonpompremmers", June 3, 2009. Original link has been removed from the internet, but mentioned in Pharm Weekbl 2009;144:7. Accessed 7 November 2015.

7. U.S. Food and Drug Administration (FDA). Drug Safety Information for Healthcare
Professionals. "Update to the labeling of Clopidogrel Bisulfate (marketed as Plavix) to alert healthcare professionals about a drug interaction with omeprazole (marketed as Prilosec and Prilosec OTC)", November 17, 2009. Available at: http://www.fda.gov/Drugs/DrugSafety/PostmarketDrugSafetylnformationforPatientsandProviders/DrugSafetylnformationforHeathcareProfessionals/ucm 190787.htm. Accessed 7 November 2015.

8. Dutch Medicines Evaluation Board (MEB). Direct Healthcare Professional Communications "Herzien standpunt interactie clopidogrel met protonpompremmers", February 16, 2010. Original link has been removed from the internet, but mentioned in Pharm Weekbl 2010;145:8-9. Accessed 7 November 2015.

9. European Medicines Agency (EMA). News and press release archive. "Public statement on interaction between clopidogrel and proton-pump inhibitors", March 17, 2010. Available at: http://www.ema.europa.eu/ema/ index.jsp?curl=pages/news_and_events/ news/2010/03/news_detail_001008. jsp\&mid=WC0b01ac058004d5c1. Accessed 7 November 2015.

10. U.S. Food and Drug Administration (FDA). Drug Safety Information for Healthcare Professionals. "Information on Clopidogrel Bisulfate (marketed as Plavix)", October 27, 2010. Available at: http://www.fda.gov/Drugs/ DrugSafety/PostmarketDrugSafetylnformationforPatientsandProviders/ucm 190836.htm. Accessed 7 November 2015.

11. Gilard M, Arnaud B, Cornily JC, Le Gal G, Lacut K, Le Calvez G, et al. Influence of omeprazole on the antiplatelet action of clopidogrel associated with aspirin: the randomized, double-blind OCLA (Omeprazole CLopidogrel Aspirin) study. J Am Coll Cardiol 2008;51:256-260.

12. Focks JJ, Brouwer MA, Van Oijen MG, Lanas A, Bhatt DL, Verheugt FW. Concomitant use of clopidogrel and proton pump inhibitors: impact on platelet function and clinical outcome- a systematic review. Heart 2013;99:520-527.

13. European Parliament and the European Council. Directive 2010/84/EU. Available at: http://eur-lex.europa.eu/LexUriServ/ LexUriServ.do?uri=OJ:L:2010:348:0074:0099:E N:PDF. Accessed 8 November 2015. 
14. Mol PG, Straus SM, Piening S, De Vries JT, De Graeff PA, Haaijer-Ruskamp FM. A decade of safety-related regulatory action in the Netherlands: a retrospective analysis of direct healthcare professional communications from 1999 to 2009. Drug Saf 2010;33:463-474.

15. Piening $\mathrm{S}$, Haaijer-Ruskamp FM, De Vries JT, Van der Elst ME, De Graeff PA, Straus SM, et al. Impact of safety-related regulatory action on clinical practice: a systematic review. Drug Saf 2012;35:373-385.

16. Piening S, Reber KC, Wieringa JE, Straus SM, De Graeff PA, Haaijer-Ruskamp FM, et al. Impact of safety-related regulatory action on drug use in ambulatory care in the Netherlands. Clin Pharmacol Ther 2012;91:838-845.

17. Ruiter R, Visser LE, Van Herk-Sukel MP, Geelhoed-Duijvestijn PH, De Bie S, Straus SM, et al. Prescribing of rosiglitazone and pioglitazone following safety signals: analysis of trends in dispensing patterns in the Netherlands from 1998 to 2008. Drug Saf 2012;35:471-480.

18. Gispen-de Wied CC, Leufkens HG. From molecule to market access: drug regulatory science as an upcoming discipline. Eur J Pharmacol 2013;719:9-15.

19. Herings R, Pederson L. Pharmacy-based medical record linkage systems. Pp. 270286 in B. Strom, S. Kimmel and S. Hennessy, eds. Pharmacoepidemiology. 5th ed. WileyBlackwell, Oxford, UK, 2012.

20. Catalan VS, LeLorier J. Predictors of long-term persistence on statins in a subsidized clinical population. Value Health 2000;3:417-426.

21. Cochrane Collaboration. Effective Practice and Organisation of Care (EPOC). Interrupted time series (ITS) analyses, 2013. Available at: http://epoc.cochrane.org/sites/epoc.cochrane. org/files/uploads/21\%20Interrupted $\% 20$ time $\% 20$ series\%20analyses\%202013\%20 08\%2012_2.pdf. Accessed 16 May 2016.

22. Numans $M$, De Wit N, Dirven JAM, HeemstraBorst CG, Hurenkamp G, Scheele ME, et al. NHG-Standaard Maagklachten. The Dutch College of General Practitioners [2013] Available at: https://www.nhg.org/ standaarden/volledig/nhg-standaardmaagklachten-derde-herziening. Accessed 7 November 2015.
23. Drug Information System of National Health Care Institute. Available at: https://www. gipdatabank.nl/. Accessed 7 November 2015.

24. Yusuf S, Zhao F, Mehta SR, Chrolavicius S, Tognoni G, Fox KK. Effects of clopidogrel in addition to aspirin in patients with acute coronary syndromes without ST-segment elevation. N Engl J Med 2001;345:494-502.

25. Dey S, Flather MD, Devlin G, Brieger D, Gurfinkel EP, Steg PG, et al. Sex-related differences in the presentation, treatment and outcomes among patients with acute coronary syndromes: the Global Registry of Acute Coronary Events. Heart 2009;95:20-26.

26. Zeitoun JD, Lefevre JH, Downing N, Bergeron $\mathrm{H}$, Ross JS. Inconsistencies among European Union pharmaceutical regulator safety communications: a cross-country comparison. PLoS One 2014;9:e109100.

27. Reber KC, Piening S, Wieringa JE, Straus SM, Raine JM, De Graeff PA, et al. When direct health-care professional communications have an impact on inappropriate and unsafe use of medicines. Clin Pharmacol Ther 2013;93:360-365.

28. Holmes MV, Perel P, Shah T, Hingorani AD, Casas JP. CYP2C19 genotype, clopidogrel metabolism, platelet function, and cardiovascular events: a systematic review and metaanalysis. JAMA 2011;306:2704-2714. 


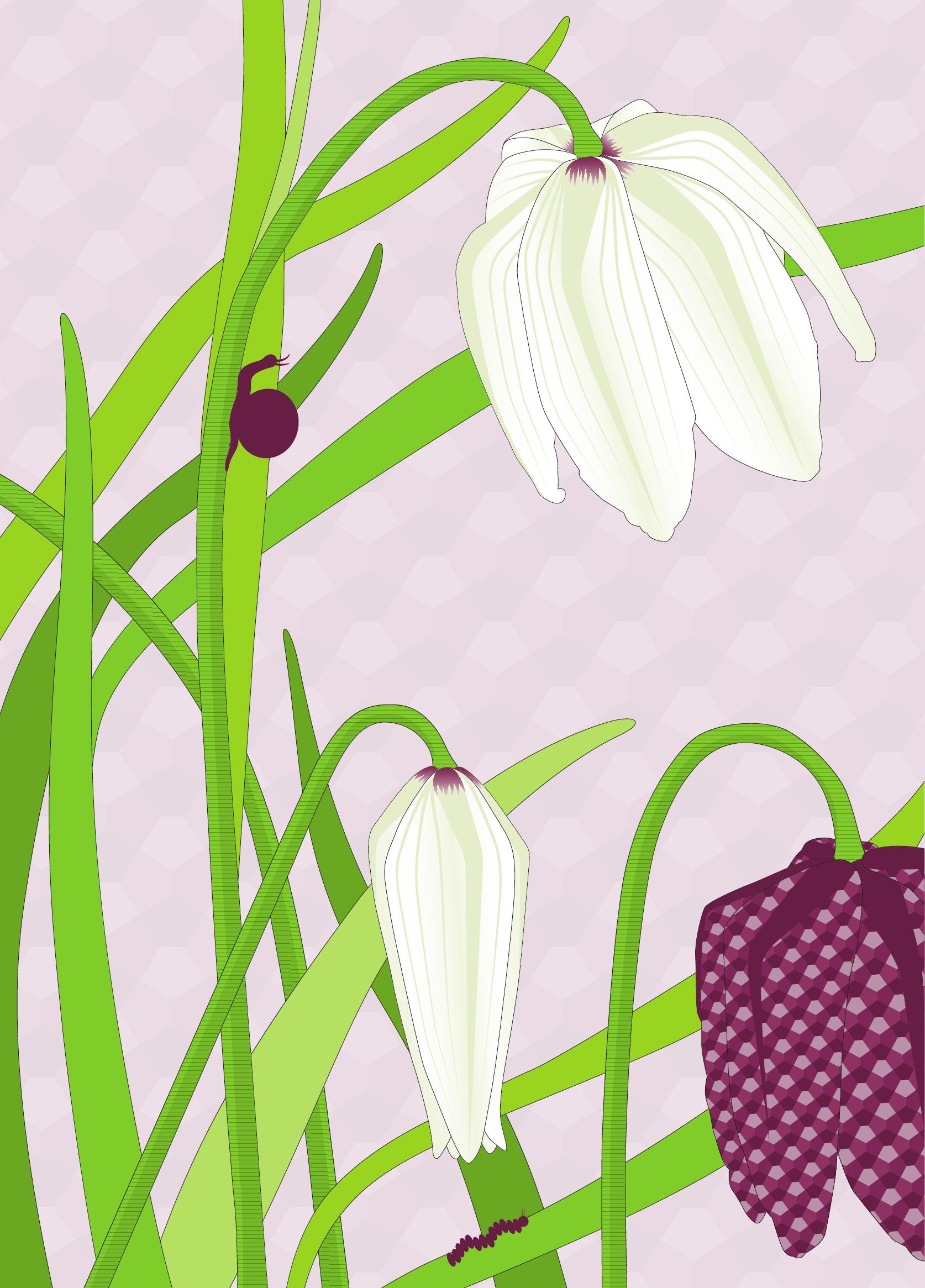




\title{
Chapter 3
}

Decrease in switches to "unsafe" proton pump inhibitors after communications about interactions with clopidogrel

\author{
Willemien J. Kruik-Kollöffel \\ Job van der Palen \\ Myrthe P. P. van Herk-Sukel \\ H. Joost Kruik \\ Kris L. L. Movig
}




\section{Abstract}

\section{Background}

In 2009 and 2010 medicines regulatory agencies published official safety statements regarding the concomitant use of proton pump inhibitors and clopidogrel. We wanted to investigate a change in prescription behaviour in prevalent gastroprotective drug users (2008-2011).

\section{Methods}

Data on drug use were retrieved from the Out-patient Pharmacy Database of the PHARMO Database Network. We used interrupted time series analyses (ITS) to estimate the impact of each safety statement on the number of gastroprotective drug switches around the start of clopidogrel and during clopidogrel use.

\section{Results}

After the first statement (June 2009), significantly fewer patients switched from another proton pump inhibitor to (es)omeprazole $(-14.9 \% ; 95 \% \mathrm{Cl}-22.6 \%$ to $-7.3 \%)$ at the moment they started clopidogrel compared to the period prior to this statement. After the adjusted statement in February 2010, the switch percentage to (es)omeprazole decreased further $(-4.5 \% ; 95 \% \mathrm{Cl}-8.1 \%$ to $-0.9 \%)$. We observed a temporary increase in switches from proton pump inhibitors to histamine 2-receptor antagonists after the first statement; the decrease in the reverse switch was statistically significant $(-23.0 \% ; 95 \% \mathrm{Cl}-43.1 \%$ to $-2.9 \%)$.

\section{Conclusions}

With ITS, we were able to demonstrate a decrease in switches from other proton pump inhibitors to (es)omeprazole and an increase of the reverse switch to almost $100 \%$. We observed a partial and temporary switch to histamine 2-receptor antagonists. This effect of safety statements was shown for gastroprotective drug switches around the start of clopidogrel treatment. 


\section{Introduction}

Safety concerns with regard to the concomitant use of clopidogrel and proton pump inhibitors (PPIs) were published in 2009 and 2010 by the medicines regulatory agencies, including a direct healthcare professional communication (DHPC). Concerns originated from a publication by Gilard et al. ${ }^{1}$ In 2008 they reported increased in vitro platelet reactivity and decreased levels of the active metabolite of clopidogrel in patients administered clopidogrel as well as a PPI. These communications caused considerable turmoil among physicians, and the scientific evidence was discussed extensively. Especially in the year following the regulatory agencies' statements, scientists retrospectively explored existing databases and several articles were published in the international literature. In 2013 Focks et al. ${ }^{2}$ published a systematic review of all publications on the impact of the addition of PPIs to clopidogrel on platelet function and cardiovascular outcome. They stated that the suggestion that the potential adverse effect should especially be considered if omeprazole is prescribed is based on pharmacological assumptions and laboratory measurements, but is contradicted by the available clinical evidence. The study by Gilard et al. ${ }^{1}$ should be considered as hypothesis generating and not confirmation of a clinically relevant interaction. Unfortunately, the regulatory authorities have not given an update after all these reports. Indeed, the statements have altogether been removed from the site of the Dutch regulatory authorities because the usual period of five years since publication has passed.

We examined the association between various safety statements and prescription behaviour for gastroprotective (GP) drugs in patients naïve to these drugs who were prescribed clopidogrel in the Netherlands from 2008 to $2011 .^{3}$ We were able to demonstrate statistically significant shifts in the prescription of GP drugs when those statements were launched. In January 2009, after the early communication to re-evaluate the need for a PPI, 15.5\% more patients were started concomitantly with (es)omeprazole and $13.8 \%$ fewer with other PPIs. In June 2009, directly after the first statement to avoid combinations with a PPI, we measured a steep increase in histamine 2-receptor antagonists (H2RA), peaking at $25 \%$. This effect for H2RA faded away after a few months. An adjusted statement in February 2010 was to avoid (es)omeprazole, and we then found a decrease of $11.9 \%$ for (es)omeprazole and an increase of $16.0 \%$ for other PPIs. Still, $22.6 \%$ of patients started on (es)omeprazole in February 2010. During our study period, a significant proportion of the patients received prescriptions against the advice of regulatory agencies. We philosophised about this discrepancy in an earlier publication. ${ }^{3}$

Research into changes in prescribing behaviour as a result of safety communications by regulatory authorities is usually performed in new use, because new use is a more sensitive measure than overall use. ${ }^{4}$ In patients already on a GP drug, an extra hurdle has to be taken to follow the official advice. A physician has to change the patient's GP drug when 
starting clopidogrel or summon a patient to come to the office to change it. A change in treatment is a therapy-related factor that can negatively affect adherence according to the WHO report "Adherence to long-term therapies, evidence for action". ${ }^{5}$ According to this report, adherence averages $50 \%$ and is therefore a serious threat to effective and efficient treatment, resulting in the WHO calling for action in 2003. It is therefore to be understood that physicians feel reluctant to change medication therapy on the basis of doubtful scientific evidence. We were anxious to know whether we could nonetheless demonstrate a change in prescription behaviour when the statements were published on patients who were already using GP drugs at the time they started clopidogrel treatment.

\section{Methods}

\section{Design}

In 2009 and 2010, various official statements about the safety of the concomitant use of clopidogrel and PPIs were published:

I. Early communication by the US Food and Drug Administration (FDA, 26 January 2009) to re-evaluate the need for a PPI. ${ }^{6}$

II. First statement by the European Medicines Agency (EMA, 29 May 2009) ${ }^{7}$ and the Dutch Medicines Evaluation Board (MEB, 3 June 2009) ${ }^{8}$ to avoid the combination of clopidogrel and a PPI. As a result of those statements, the interaction was integrated into the Dutch national drug-drug interaction database (G-standard), and pharmacists started to contact prescribers in case of a combined prescription for PPI and clopidogrel.

III. Adjusted statement by the Dutch MEB (16 February 2010) ${ }^{9}$ and EMA (17 March 2010) ${ }^{10}$ to avoid the combination of clopidogrel and (es)omeprazole.

We included patients in our study who started clopidogrel in 2008 until 2011. Those three statements divided the study into four separate periods.

\section{Data collection and analysis}

Data were retrieved from the Out-patient Pharmacy Database of the PHARMO Database Network, which comprises general practitioner or specialist prescribed healthcare medication dispensed by out-patient pharmacies. ${ }^{11}$ We used dispensing data as a proxy variable for prescribing. The Out-patient Pharmacy Database of the PHARMO Database Network covers a catchment area representing 3.6 million ( $>20 \%$ of the population) residents throughout The Netherlands. Healthcare coverage regarding the reimbursement of concerned drugs was similar for all Dutch citizens and they were all included on an equal basis.

In patients who already used a GP drug for at least 2 weeks before the start of clopidogrel, we determined whether a switch in GP drug was made from 2 weeks before the start of clopidogrel (anticipating the start of clopidogrel) until 4 weeks after the start of clopidogrel, 
i.e. a concomitant switch. A switch in GP drug was defined as a change from one group of GP drugs to another: (es)omeprazole (ATC code A02BC01 and A02BC05), another PPI (ATC code $\mathrm{A} 02 \mathrm{BC}$, not $\mathrm{A02BC01}$ or $\mathrm{A02BC05}$ ) or H2RA (ATC code $\mathrm{A02BA}$ ). The first switch from one group of GP drugs to another was analysed. Specialities and generics are combined.

We used interrupted time series analyses (ITS, segmented linear regression analyses) to estimate the impact of each event on the dispensing of GP drugs, as described by the Cochrane Collaboration. ${ }^{12}$ Statistical significance was set at $P \leq 0.05$.

More details on the design, data collection and analysis are described in our earlier publication. $^{3}$

\section{Results}

The numbers of patients using and switching GP drugs at the start of are shown in Table 1.

Table 1 Numbers of patients using and switching gastroprotective (GP) drugs

\begin{tabular}{|c|c|c|c|c|c|}
\hline & 2008 & 2009 & 2010 & 2011 & $\begin{array}{l}\text { Total study } \\
\text { population }\end{array}$ \\
\hline $\begin{array}{l}\text { Patients already using GP drug } \\
\text { and starting clopidogrel }\end{array}$ & 2345 & 2698 & 2669 & 2893 & 10605 \\
\hline $\begin{array}{l}\text { Patients switching GP drug } \\
\text { when starting clopidogrel, } \mathrm{n}(\%)\end{array}$ & $222(9 \%)$ & $566(21 \%)$ & $884(33 \%)$ & 1049 (36\%) & $2721(26 \%)$ \\
\hline \multicolumn{6}{|c|}{ Histamine 2-receptor antagonist (ATC-code), n (\%)* } \\
\hline Cimetidine (A02BA01) & $15(1 \%)$ & $13(0 \%)$ & $7(0 \%)$ & $10(0 \%)$ & $45(0 \%)$ \\
\hline Ranitidine (A02BA02) & $136(6 \%)$ & $143(5 \%)$ & $135(5 \%)$ & $113(4 \%)$ & $527(5 \%)$ \\
\hline Famotidine (A02BA03) & $4(0 \%)$ & $6(0 \%)$ & $7(0 \%)$ & $2(0 \%)$ & $19(0 \%)$ \\
\hline Nizatidine (A02BA04) & $4(0 \%)$ & $1(0 \%)$ & $0(0 \%)$ & $0(0 \%)$ & $5(0 \%)$ \\
\hline \multicolumn{6}{|c|}{ Proton pump inhibitor (ATC code), $n(\%)^{*}$} \\
\hline Omeprazole (A02BC01) & $960(40 \%)$ & $1231(46 \%)$ & $1249(47 \%)$ & $1463(51 \%)$ & $4903(46 \%)$ \\
\hline Pantoprazole (A02BC02) & $767(33 \%)$ & $763(28 \%)$ & $769(29 \%)$ & $773(27 \%)$ & $3072(29 \%)$ \\
\hline Lansoprazole (A02BC03) & $37(2 \%)$ & $28(1 \%)$ & $26(1 \%)$ & $39(1 \%)$ & $130(1 \%)$ \\
\hline Rabeprazole (A02BC04) & $78(3 \%)$ & $70(3 \%)$ & $71(3 \%)$ & $59(2 \%)$ & $278(3 \%)$ \\
\hline Esomeprazole (A02BC05) & $344(15 \%)$ & $443(16 \%)$ & $405(15 \%)$ & $434(15 \%)$ & $1626(15 \%)$ \\
\hline
\end{tabular}

*First use of GP drug

Figure 1 shows the switches from (es)omeprazole to another PPI and vice versa. There was a statistically significant decline in the number of switches from another PPI to (es) omeprazole after the first statement $(-14.9 \% ; 95 \% \mathrm{Cl}-7.3 \%$ to $-22.6 \%)$ and after the adjusted statement $(-4.5 \% ; 95 \% \mathrm{Cl}-8.3$ to -0.9$)$. The decrease in the slope for switches from (es) omeprazole to another PPI was statistically significant after the adjusted statement (-2.3; $95 \% \mathrm{Cl}-3.8$ to -0.7$)$. In January 2008 , the percentage of patients switching from another PPI 
to (es)omeprazole was $11.7 \%$ (starting point of the regression line). At the end of our study in December 2011, still 2.6\% of patients switched from another PPI to (es)omeprazole (end point of the regression line). This was in contrast to the percentage of patients switching from (es)omeprazole to another PPI, which increased in the same period from $63.1 \%$ to $94.0 \%$.

Figure 1 Patients with prior gastroprotection switching at the start of clopidogrel to other proton pump inhibitor (PPI) ( $\square$ ) or (es)omeprazole $(\diamond)$

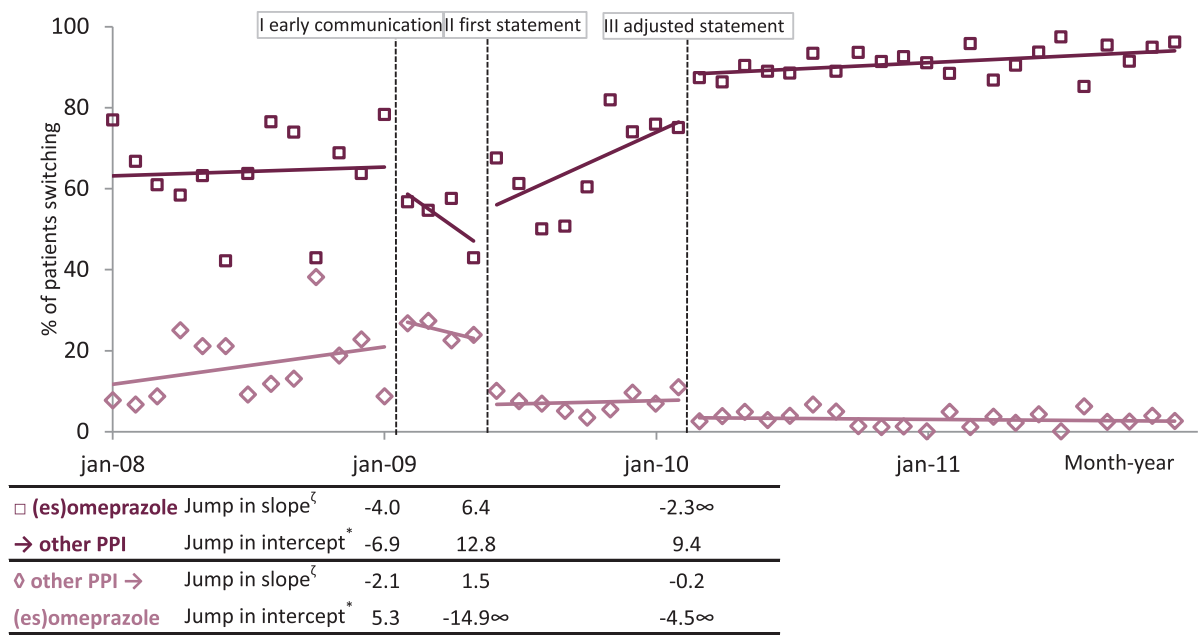

I Early communication to re-evaluate need for PPI; II first statement to avoid combination with PPI; III adjusted statement to avoid combination with (es)omeprazole. ' Jump in slope from the previous to the following period *Jump from the predicted \% just infinitely close to that month to the predicted \% for becoming the first month of the next period $\infty$ Statistically significant $(P \leq 0.05)$.

Figure 2a describes the group of patients who switched from a PPI to an H2RA or vice versa in each month. Only the decline in the number of switches from an H2RA to a PPI after the first statement was statistically significant $(-23.1 \% ; 95 \% \mathrm{Cl}-43.1 \%$ to $-2.9 \%)$. In general, no more than $30 \%$ of patients who started clopidogrel switched from an H2RA to a PPI or vice versa, except for a distinct increase in the switch from a PPI to an H2RA after the first statement, reaching a peak of about $41 \%$ of patients switching their GP drug when starting clopidogrel. This increase faded away in subsequent months to percentages below $5 \%$. Figure $2 \mathrm{~b}$ shows an enlargement of this part. 
Figure 2a Patients with prior gastroprotection switching at the start of clopidogrel to histamine2-receptor antagonist (H2RA) (o) or proton pump inhibitor (PPI) ( $\Delta$ )

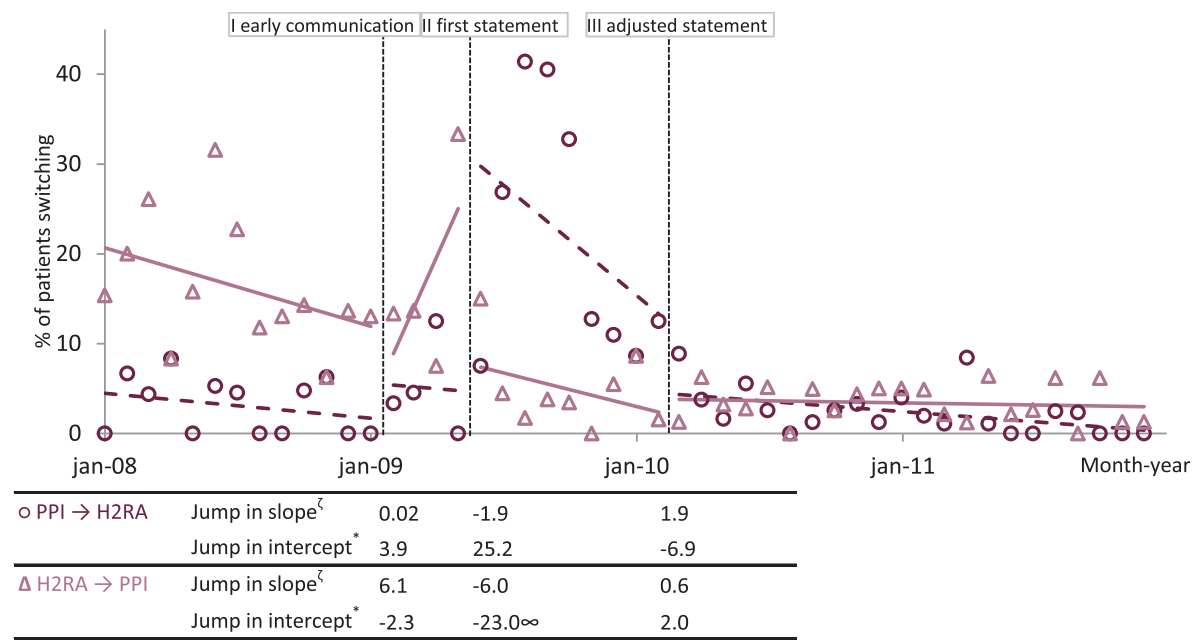

I Early communication to re-evaluate need for PPI; II first statement to avoid combination with PPI; III adjusted statement to avoid combination with (es)omeprazole. ' Jump in slope from the previous to the following period *Jump from the predicted \% just infinitely close to that month to the predicted \% for becoming the first month of the next period $\infty$ Statistically significant $(P \leq 0.05)$

Figure $2 \mathrm{~b}$ Augmentation of Figure $2 \mathrm{a}$, patients switching from proton pump inhibitor to histamine2-receptor antagonist

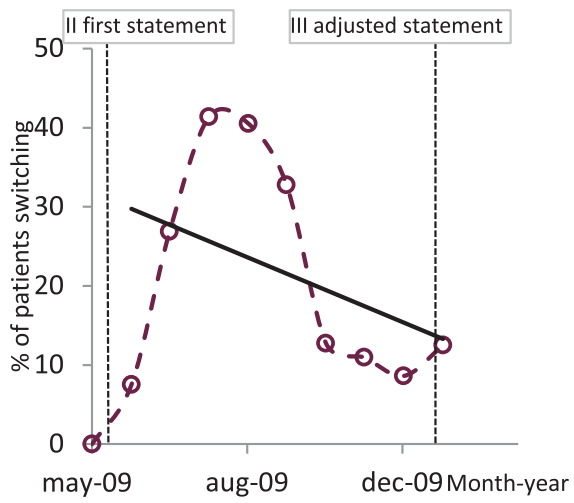

Regression line and connecting line 


\section{Discussion}

In our study, we were able to demonstrate an increase in switches from (es)omeprazole to other PPIs and a decrease of the reverse switch to almost none, following statements by the medicines regulatory agencies. Switches to other PPIs were almost exclusively to pantoprazole, as this is also theoretically the least likely PPI to interact with clopidogrel. ${ }^{13}$ Lansoprazole and rabeprazole were seldom used in our study as well as in the Netherlands in general. ${ }^{14}$ The percentage of patients switching to another PPI was close to $100 \%$ by the end of 2011. We observed a temporary large increase in switches from PPIs to an $\mathrm{H} 2 \mathrm{RA}$, although this change did not reach statistical significance $(25.2 \% ; 95 \% \mathrm{Cl}-13.1 \%$ to $63.5 \%)$. Although this increase seems radical, the absence of statistical significance can be explained by the high variability following the first statement, as shown in Figures 2a, $2 \mathrm{~b}$. The number of reverse switches at that moment, i.e. from an H2RA to a PPI, did reach statistical significance $(-23.0 \% ; 95 \% \mathrm{Cl}-43.1 \%$ to $-2.9 \%)$. The distribution among the various PPIs in our study before the start of clopidogrel is in accordance with the use of PPIs in the Netherlands. ${ }^{14}$ In our study $71 \%$ of the patients used (es)omeprazole in 2008-2011; in the Netherlands these two drugs were used by $72 \%$ of patients.

The effect of safety statements on prescription behaviour was shown for GP drug switches around the start of clopidogrel treatment. Although a minority of the changes were statistically significant, the evidence according to the graphic reflection is evident. The percentage of patients being switched from an H2RA to a PPI or vice versa was less than 5\%, which reflects an overall decrease in H2RA use in the Netherlands in the period from 2002 (402,512 patients) to 2012 (90,870 patients). ${ }^{14}$ This trend was confirmed by the revised guidelines of the Dutch College of General Practitioners of January 2013, in which H2RA double dosing was no longer considered adequate gastroprotection. ${ }^{15}$

We observed an increasing percentage of patients being switched from 2008 through 2011 (Table 1), showing that the advice of regulatory authorities was at least partly accepted. As already discussed in our previous study ${ }^{3}$, official advice on this supposed interaction was followed reluctantly and not fully. As a rule, physicians, including cardiologists, are sensitive to up-to-the-minute reported evidence. Safety statements are usually delayed from the latest information. Doubtful scientific evidence has probably been the cause in the delay in the case of clopidogrel-(es)omeprazole. As can be seen from the Figures, the deflection of the curves starts when the statements are published. Cabana ${ }^{16}$ described that, to achieve a change in behaviour, various hurdles have to be overcome: knowledge, attitudes and behaviour. With regard to knowledge, Piening et al. ${ }^{17}$ investigated by means of a questionnaire in December 2009 and January 2010 the level of knowledge on safety information on four specific drugs (rimonabant, moxifloxacin, clopidogrel and etoricoxib) among general practitioners, internists, community pharmacists and hospital pharmacists; $88 \%$ indicated that they were aware of the safety issues for clopidogrel. The 
trustworthiness of the source of the safety information is an aspect that determines the factor attitude. In the case of clopidogrel, the source, i.e. the Dutch MEB, is considered to be very trustworthy. The power of the message could have been augmented, in our opinion, by adding another trustworthy source, i.e. the professional associations. No attention was given to this issue in general medicine or cardiology journals in the Netherlands (e.g. Medisch Contact, Nederlands Tijdschrift voor Geneeskunde, Netherlands Heart Journal). With regard to behaviour, the healthcare professionals reported to have taken action (e.g. adjusting therapy, informing colleagues, discussion with patients) in response to $29 \%$ of the DHPCs, ranged from $23 \%$ of internists to $37 \%$ of community pharmacists. ${ }^{17}$ In the case of the interaction of clopidogrel with GP drugs, this was probably partly because of the existing scientific doubt about the interaction. ${ }^{2}$

The clinical implication of not complying with the official advice is unknown, because the scientific evidence of the interaction is in doubt. The Cogent study group ${ }^{18}$ concluded that there was no apparent cardiovascular interaction between clopidogrel and omeprazole, but could not rule out a clinically meaningful difference in cardiovascular events in a group of patients prescribed clopidogrel with or without omeprazole. However, the prophylactic use of omeprazole reduced the rate of upper gastrointestinal (GI) bleeding. In 2011 Fernando et al. ${ }^{19}$ recommended in a review that only patients with previous Gl bleeding or multiple risk factors for Gl bleeding should be prescribed a GP drug. With regard to the pharmacologic basis of the interaction, (es)omeprazole is the most potent inhibitor of the liver enzyme CYP2C19 of all PPIs. It could interfere with clopidogrel metabolism and reduce exposure to the active metabolite of clopidogrel. ${ }^{19}$ Not complying with the official advice could have legal complications in a case where a patient has adverse effects from inadequate clopidogrel dosing. On the other hand, following the advice could result in gastrointestinal events in patients prescribed no GP drug at all or, as we now know, a less effective H2RA. If a PPI is indicated, a consideration could be to switch to pantoprazole when starting clopidogrel.

In our study, about $40 \%$ of patients did not use a GP drug at all. Not being prescribed a GP drug if needed could be considered an unintended effect of safety warnings. We discussed this point in our earlier publication. ${ }^{3}$ It would have been interesting to add the clinical outcomes of these patients. Unfortunately, our database-based study does not have this information. The uncertainty among physicians and pharmacists about the supposed interaction could have led to the instruction to patients to interrupt the use of GP drugs. This effect is hard to deduce from our data based on dispensing information. However, a more pronounced effect would have been seen in patients not starting a GP drug at all. The percentage of patients without gastroprotection in our cohort decreased from $44 \%$ to $36 \%{ }^{3}$ We suppose that a greater proportion of these patients would have qualified for GP drugs according to the guidelines implemented in those years, such as the 
Expert Consensus Document of the American College of Cardiology Foundation on the concomitant use of PPIs and thienopyridine ${ }^{20}$ and the report of the Dutch Harm-Wrestling Task Force. $^{21}$

Our study is the only one, as far as we know, to study changes in PPI prescription at the individual patient level, using data from over 10,000 patients, aggregated by monthly level before and after the three safety statements. Some other groups studied the effect of the communications on the prescription of PPI. In 398 Spanish patients discharged in 2012 after acute coronary syndrome who were prescribed clopidogrel as well as a GP drug, $36 \%$ were prescribed (es)omeprazole and $45 \%$ pantoprazole. ${ }^{22} \mathrm{~A}$ minority of $11 \%$ were prescribed H2RA (ranitidine). At admission 71\% were using (es)omeprazole. A large US cohort identified patients using clopidogrel and a PPI. ${ }^{23}$ After 17 November 2009 58\% of the PPIs prescribed in combination with clopidogrel were (es)omeprazole. No information on H2RA use is given. A Canadian group focussed on the changes in the prescription of pantoprazole, which rapidly became the most commonly prescribed PPI in $52 \%$ of the patients by the end of 2009 (24\% in the final quarter of 2008) and $71 \%$ by the end of $2013 .{ }^{24}$ The use of omeprazole was decreased further and $4.4 . \%$ of the patients received an H2RA. In a Qatar hospital in 2012, in 300 patients rabeprazole and lansoprazole were prescribed after acute coronary syndrome in $81 \%$ and $13 \%$, respectively. ${ }^{25}$ Omeprazole and esomeprazole were the least prescribed PPIs with 4 and $2.6 \%$, respectively, of the total utilisation.

We had to deal with three very distinct breaking points of variable length, and we were not able to gather sufficient data points in all periods for a solid ITS, especially for the period after the early communication. For example, of our total study population of 39,496 patients, in August 2008, 177 patients started clopidogrel and were already using a GP drug. Of those 177 patients, only 17 switched: 13 from (es)omeprazole to another PPI, two from another PPI to (es)omeprazole and two from an H2RA to a PPI. The statistical results depend upon the slopes of the lines (as the regression line is steeper, the probability of statistical significance increases), the number of points used in each regression line (after the early communication, we had only 4 months to use in our analysis) and the spread around the regression line (which is among other factors determined by a small amount of patients switching in a certain month to a certain group of drugs). In Figure $2 b$, an enlargement of a part of Figure $2 \mathrm{a}$ is shown, which demonstrates the limitations of ITS in some situations: the trend is very clear, but calculating a regression line obscures the true effect. Nevertheless, the trends are clear, mainly due to the large number of patients included in the study. As already shown by Piening et al. ${ }^{26}$, ITS is the best available study design to evaluate the impact of policy changes on prescription behaviour. However, to prove an effect in prevalent users is complicated, because, as stated by Reber et al. ${ }^{4}$, new use is a more sensitive measure than overall use. In a publication in 2013 , this group systematically evaluated the determinants 
of the impact of 59 DHPCs for 46 drugs issued in the Netherlands, all in new drug users. We also examined the changes in prescribing behaviour at first in new users. ${ }^{3}$ Additionally, in the present analysis, we were able to show an effect in prevalent users. In such a group of patients, regulatory authorities would logically have to use more convincing strategies to achieve a change in prescription behaviour, such as collaboration with professional associations and assessing all the existing evidence.

\section{Conclusion}

With ITS, we were able to demonstrate an effect of safety statements on the prescription of GP drugs in patients already on GP drugs. Although the place in therapy of clopidogrel is repositioning to specific, smaller groups of patients, the lessons learned in this study should be applied to managing drug safety information in general. 


\section{References}

1. Gilard M, Arnaud B, Cornily JC, Le Gal G, Lacut K, Le Calvez G, et al. Influence of omeprazole on the antiplatelet action of clopidogrel associated with aspirin: the randomized, double-blind OCLA (Omeprazole CLopidogrel Aspirin) study. J Am Coll Cardiol 2008;51(3):256-260.

2. Focks JJ, Brouwer MA, Van Oijen MG, Lanas A, Bhatt DL, Verheugt FW. Concomitant use of clopidogrel and proton pump inhibitors: impact on platelet function and clinical outcome- a systematic review. Heart 2013;99(8):520-527.

3. Kruik-Kollöffel WJ, van der Palen J, Kruik HJ, van Herk-Sukel MP, Movig KL. Prescription behavior for gastroprotective drugs in new users as a result of communications regarding clopidogrel - proton pump inhibitor interaction. Pharma Res Per 2016;4(4):e00242.

4. Reber KC, Piening S, Wieringa JE, Straus SM, Raine JM, de Graeff PA, et al. When direct health-care professional communications have an impact on inappropriate and unsafe use of medicines. Clin Pharmacol Ther 2013;93:360-365.

5. World Health Organization (WHO). Adherence to long-term therapies: evidence for action. Geneva; January 2003. http://apps.who.int/ iris/bitstream/10665/42682/1/9241545992. pdf. Accessed 4 February 2017.

6. U.S. Food and Drug Administration (FDA). Drug Safety Information for Healthcare Professionals. "Early Communication about an Ongoing Safety Review of clopidogrel bisulfate (marketed as Plavix)", January 26, 2009: http://www.fda.gov/Drugs/DrugSafety/PostmarketDrugSafetylnformationforPatientsandProviders/DrugSafetylnformationforHeathcareProfessionals/ucm079520.htm. Accessed 4 February 2017.

7. European Medicines Agency (EMA). News and press release archive. "Public statement on possible interaction between clopidogrel and proton pump inhibitors", May 29, 2009: http://www.ema.europa.eu/ema/ index.jsp?curl=pages/news_and_events/ news/2009/11/news_detail_000194. jsp\&mid=WC0b01ac058004d5c1. Accessed 4 February 2017.

8. Dutch Medicines Evaluation Board (MEB). Direct Healthcare Professional
Communications "Standpunt CHMP en CBG over interactie clopidogrel met protonpompremmers", June 3, 2009. Original link has been removed from the internet, but mentioned in Pharm Weekbl 2009;144(24):7. Accessed 7 November 2015.

9. Dutch Medicines Evaluation Board (MEB). Direct Healthcare Professional Communications "Herzien standpunt interactie clopidogrel met protonpompremmers", February 16, 2010. Original link has been removed from the internet, but mentioned in Pharm Weekbl 2010;145(7):8-9. Accessed 7 November 2015.

10. European Medicines Agency (EMA). News and press release archive. "Public statement on interaction between clopidogrel and proton-pump inhibitors", March 17, 2010: http://www.ema.europa.eu/ema/ index.jsp?curl=pages/news_and_events/ news/2010/03/news_detail_001008. jsp\&mid=WC0b01ac058004d5c1. Accessed 4 February 2017.

11. Herings R and Pederson L. Pharmacybased Medical Record Linkage Systems. In: Pharmacoepidemiology, Fifth Edition. Strom B, Kimmel S and Hennessy S. (eds). Wiley Blackwell, Oxford, UK, 2012:270-286.

12. Cochrane Collaboration. Effective Practice and Organisation of Care (EPOC). Interrupted time series (ITS) analyses. Oslo; 2013. http:// epoc.cochrane.org/sites/epoc.cochrane.org/ files/uploads/21\%20Interrupted $\% 20$ time $\% 20$ series\%20analyses\%202013\%2008\%2012_2. pdf. Accessed 4 February 2017.

13. Cuisset T, Frere C, Quilici J, Poyet R, Gaborit $B$, Bali L, et al. Comparison of omeprazole and pantoprazole influence on a high 150mg clopidogrel maintenance dose the PACA (Proton Pump Inhibitors And Clopidogrel Association) prospective randomized study. J Am Coll Cardiol 2009;54(13):1149-1153.

14. Drug Information System of National Health Care Institute. https://www.gipdatabank.nl/. Accessed 3 July 2016.

15. Numans M, De Wit N, Dirven JAM, HeemstraBorst CG, Hurenkamp GJB, Scheele M, et al. NHG-Standaard Maagklachten. The Dutch College of General Practitioners. 2013. https:// www.nhg.org/standaarden/volledig/nhgstandaard-maagklachten-derde-herziening Accessed 4 February 2017. 
16. Cabana MD, Rand CS, Powe NR, Wu AW, Wilson $\mathrm{MH}, \mathrm{Abboud} \mathrm{PA}$, et al. Why don't physicians follow clinical practice guidelines? JAMA 1999; 282(15):1458-1465.

17. Piening $S$, Haaijer-Ruskamp FM, De Graeff PA, Straus SM, Mol PG. Healthcare professionals' self-reported experiences and preferences related to direct healthcare professional communications. Drug Saf 2012;35(11):1061-1072.

18. Bhatt DL, Cryer BL, Contant CF, Cohen M, Lanas A, Schnitzer TJ, et al. Clopidogrel with or without omeprazole in coronary artery disease. N Engl J Med 2010;363(20):1909-1917.

19. Fernando H, Dart AM, Peter K, Shaw JA. Proton pump inhibitors, genetic polymorphisms and response to clopidogrel therapy. Thromb Haemost 2011;105(6):933-944.

20. Abraham NS, Hlatky MA, Antman EM, Bhatt DL, Bjorkman DJ, Clark CB, et al. ACCF/ACG/ AHA 2010 expert consensus document on the concomitant use of proton pump inhibitors and thienopyridines: a focused update of the ACCF/ACG/AHA 2008 expert consensus document on reducing the gastrointestinal risks of antiplatelet therapy and NSAID use. A report of the American College of Cardiology Foundation Task Force on Expert Consensus Documents. J Am Coll Cardiol 2010;56(24):2051-2066.

21. Warle-van Herwaarden MF, Kramers C, Sturkenboom MC, van den Bemt PM, de Smet PA. Targeting outpatient drug safety: recommendations of the Dutch HARMWrestling Task Force. Drug Saf 2012;35(3):245259.

22. Lozano I, Sanchez-Insa E, De Leiras SR, Carrillo P, Ruiz-Quevedo V, Pinar E, et al. Acute coronary syndromes, gastrointestinal protection, and recommendations regarding concomitant administration of proton-pump inhibitors (omeprazole/esomeprazole) and clopidogrel. Am J Cardiol 2016; 117(3):366368.

23. Guérin A, Mody R, Carter V, Ayas C, Patel H, Lasch K, et al. Changes in practice patterns of clopidogrel in combination with proton pump inhibitors after an FDA safety communication. PloS One 2016;11(1):e0145504.

24. Juurlink DN, Gomes T, Paterson JM, Hellings C, Mamdani MM. Trends in the coprescription of proton pump inhibitors with clopidogrel: an ecological analysis. CMAJ Open 2015;3(4):E428-431.

25. Awaisu A, Hamou F, Mekideche L, El Muabby N, Mahfouz A, Mohammed S, et al. Proton pump inhibitor co-prescription with dual antiplatelet therapy among patients with acute coronary syndrome in Qatar. Int J Clin Pharm 2016;38(2):353-361.

26. Piening $S$, Haaijer-Ruskamp FM, De Vries JT, van der Elst ME, de Graeff PA, Straus SM, et al. Impact of safety-related regulatory action on clinical practice: a systematic review. Drug Saf 2012;35(5):373-385. 


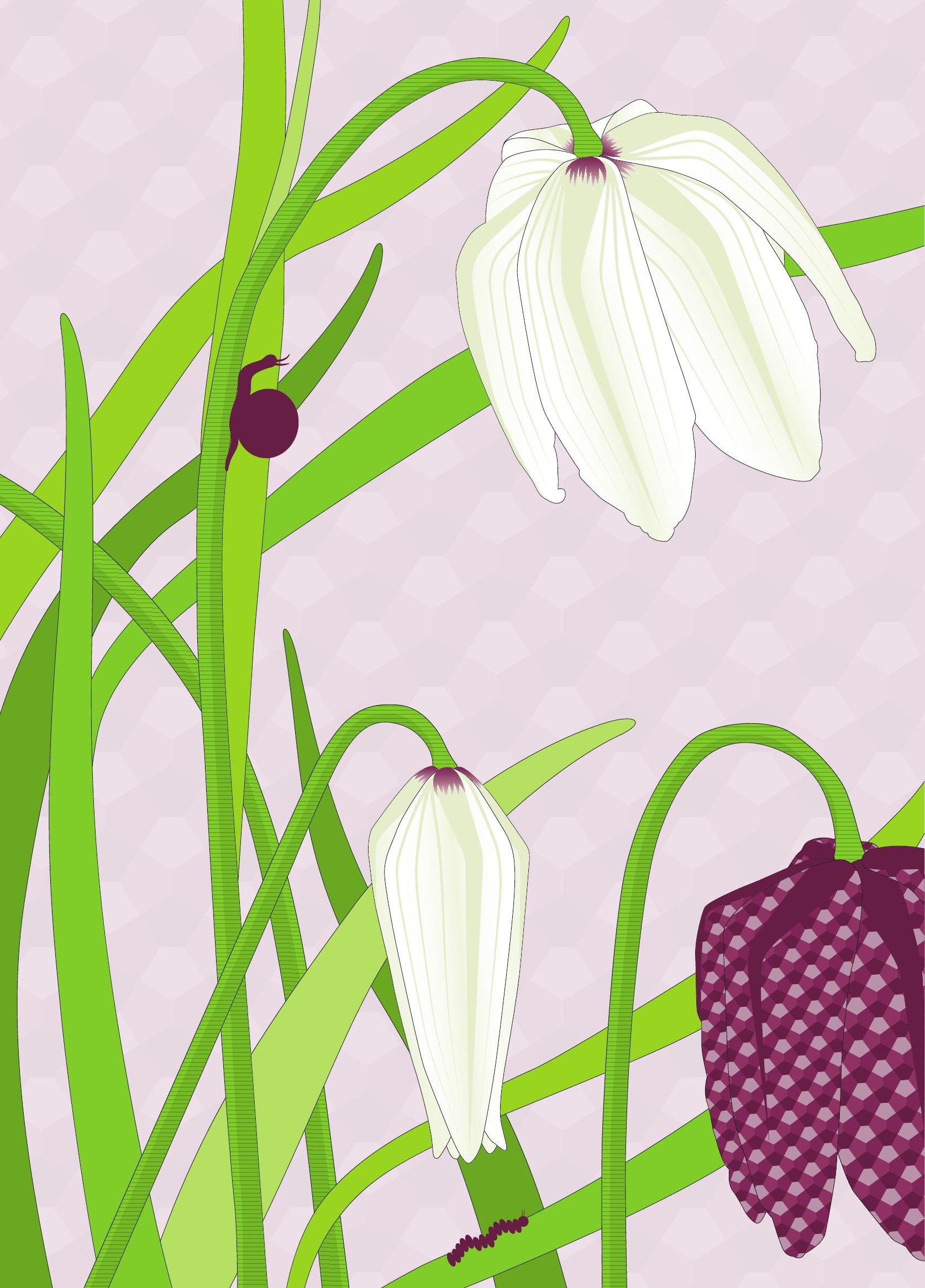




\section{Chapter 4}

Effects of European Society of Cardiology guidelines on medication profiles after hospitalization for heart failure in 22,476 Dutch patients: from 2001 till 2015

Willemien J. Kruik-Kollöffel

Gerard C.M. Linssen

H. Joost Kruik

Kris L.L. Movig

Edith M. Heintjes

Job van der Palen

Accepted for publication in Heart Fail Rev 


\section{Abstract}

Aims

Prescriber-adherence to guideline-recommended medication in patients with heart failure (HF) in clinical practice is suboptimal. We analysed how evolving guideline recommendations influenced medication profiles after a first HF hospitalization.

Methods and results

We extracted medication profiles from the Dutch PHARMO Database Network for 22,476 patients with a diagnosis of HF at hospital discharge between 2001 and 2015. The percentage of patients prescribed the combination of a beta-blocker (BB) and an angiotensinconverting-enzyme inhibitor (ACEI) or angiotensin-receptor blocker (ARB) increased from $24 \%$ to approximately $45 \%$ within this 15 -year period. The percentage of patients who also used a mineralocorticoid-receptor antagonist (MRA) reached approximately $20 \%$. The probability of being prescribed these combinations decreased with increasing age. As a consequence of the policy change in the ESC guideline 2001, the use of BB increased from less than $40 \%$ in 2001 to about $70 \%$ by 2015 . The percentage of patients prescribed an ACEI and/or an ARB, an MRA or a diuretic was about stable, at respectively $63 \%, 37 \%$ and $82 \%$. Although the 2012 ESC guideline also advised MRA in New York Heart Association (NYHA) class II, there was no increase in MRA prescriptions.

\section{Conclusions}

Compliance with the ESC guidelines varied for the individual recommendations. Remarkably, there was no significant increase in MRA prescriptions. At the same time developments were demonstrated, which were not instigated by the guidelines, like the shift from ACEI to ARB. Although the exact HF classification of our patients was unknown, given a relatively stable case-mix, our data provide insight into "real-world" pharmacological management. 


\section{Introduction}

Despite substantial advances of medical therapy in the past two decades, morbidity and mortality of patients with heart failure (HF) remain high. ${ }^{1}$ Specific disease-modifying HF drugs have been incorporated into the European (ESC) practice guidelines. However, use of advocated medication in real-world clinical practice is still suboptimal. ${ }^{2-6}$ Jefferies et al. ${ }^{7}$ talk about the concept of the "therapeutic inertia". Identifying facilitators and barriers to implementation are important to improve the penetration of guidelines and are a priority for the heart failure field to make a significant step forward. Analyses of real-world data of $\mathrm{HF}$ therapies may enhance our understanding of optimal medical therapy.

Angiotensin-converting-enzyme inhibitors (ACEI) are important in the treatment of HF. The key evidence for the use of ACEl is outlined in the 2016 ESC guidelines ${ }^{1}$, a firm position they had acquired already in the ESC guideline 1997. ${ }^{\circ}$ The angiotensin-receptor blockers (ARB) were first mentioned in the ESC guideline $2001^{\circ}$ and were recommended since then for patients unable to tolerate an ACEl. Beta-blockers (BB) are recommended since the ESC guidelines 2001 and reduce mortality and morbidity in symptomatic patients with HF with reduced ejection fraction (HFrEF), even on top of treatment with an ACEI. ${ }^{1,9}$ Spironolactone, a mineralocorticoid-receptor antagonist (MRA), was only mentioned in the section of diuretics in the 1997 guideline. ${ }^{8}$ In the guidelines of 2001, 2005 and 2008, it obtained an independent position in the treatment of patients with HF NYHA III and IV.9-11 In the 2012 guidelines ${ }^{12}$, due to the EMPHASIS-HF trial ${ }^{13}$, MRA were also advised in symptomatic HF patients NYHA class II. ${ }^{1}$ These historic developments have led to ACEI/ARB, BB and MRA nowadays forming the cornerstone of pharmacological treatment in patients with HFrEF. ${ }^{1}$ According to the 2016 ESC guideline, only slightly fewer patients with HF with preserved ejection fraction (HFpEF) and HF with mid-range ejection fraction (HFmrEF) appear to receive $A C E I / A R B, B B$ an MRA. ${ }^{1}$ In HFpEF, according to the United States guideline for $\mathrm{HF}^{14}$, $B B, A C E I / A R B$ and MRA could be prescribed to a considerable proportion of these patients. Diuretics are the cornerstone of management of congestion, despite the emergence of ACEI, BB and MRA, although evidence of large, well-controlled clinical trials is lacking.

We reviewed the penetration of guidelines on the basis of the prescription of evidencebased medication in a large cohort of patients at discharge after a first hospital admission for HF in the Netherlands between 2001 and 2015, a period in which major progress is made in the treatment of HF. We analysed the relationship between guideline-directed recommendations over a 15-year period and actual trends or changes in medication after a first HF hospitalisation. The focus was on ACEI/ARB, BB, MRA, and diuretics. Although the exact HF classification of our patients was unknown, our large database still provides a valid insight in how the guidelines with respect to HF medical therapy were adhered to from 2001 till 2015. After all, according to the 2016 ESC guideline, only slightly fewer patients with HFpEF and HFmrEF appear to receive ACEI/ARB, BB, MRA and diuretics. ${ }^{1}$ Our specific questions are presented in Table 1. 


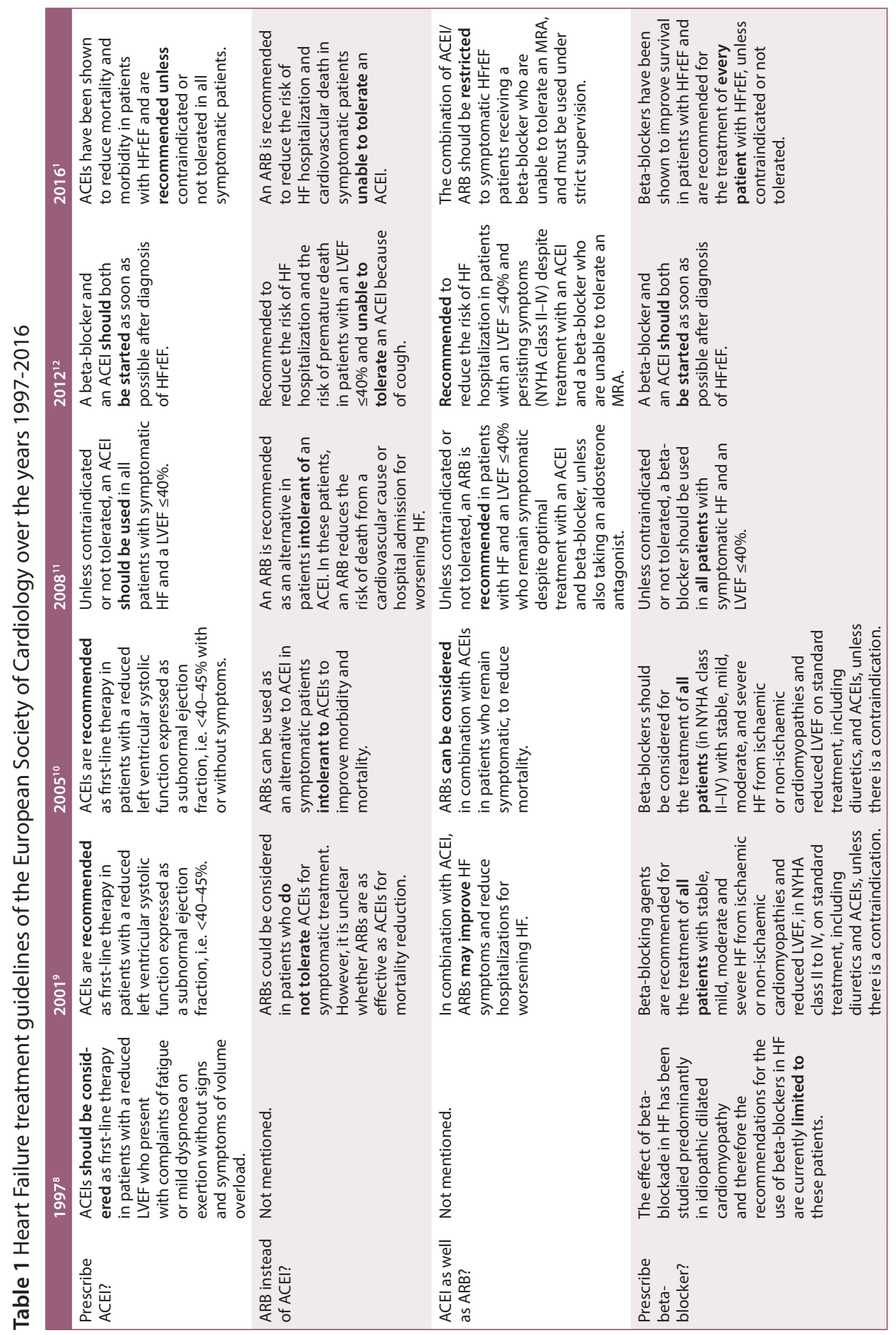




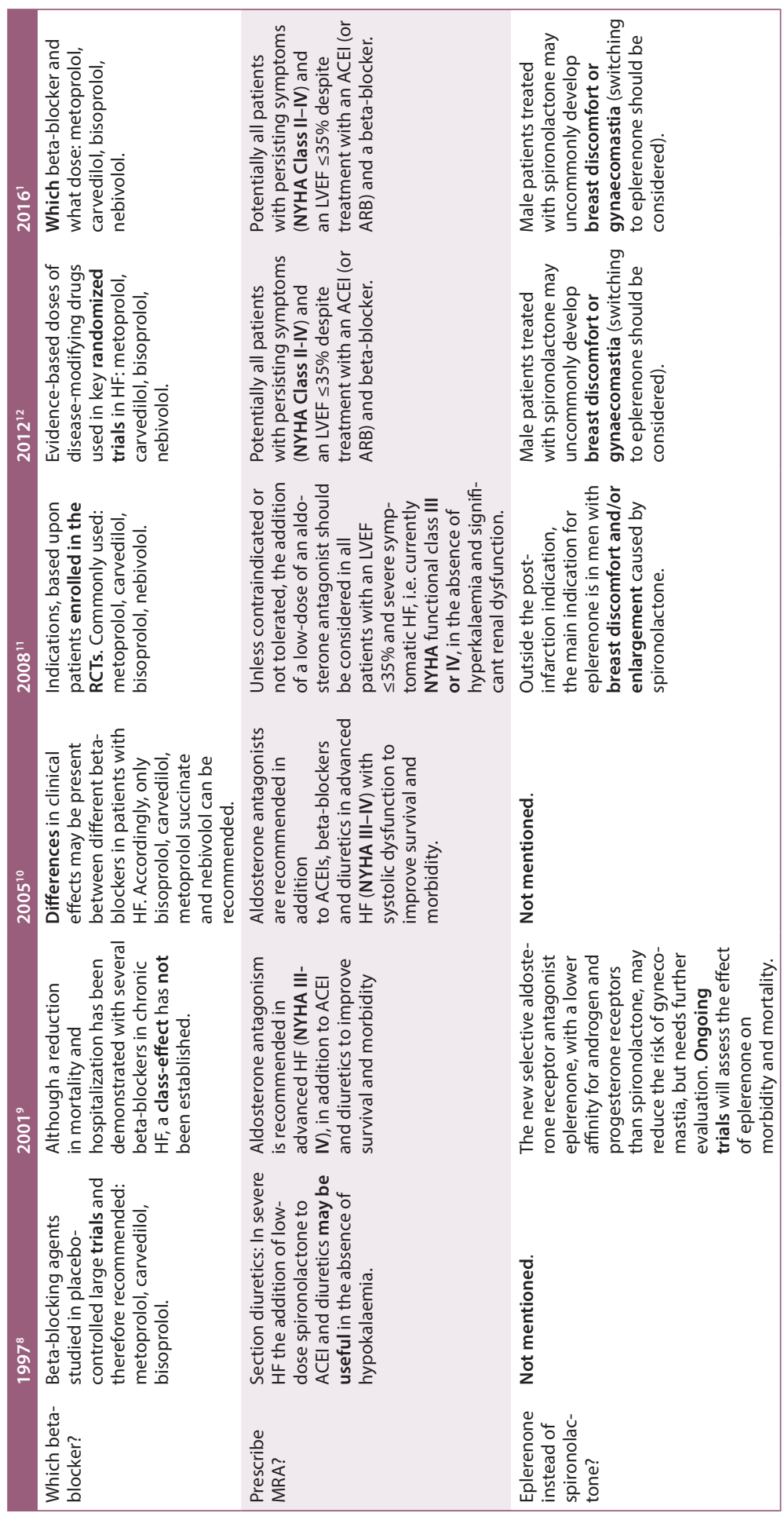




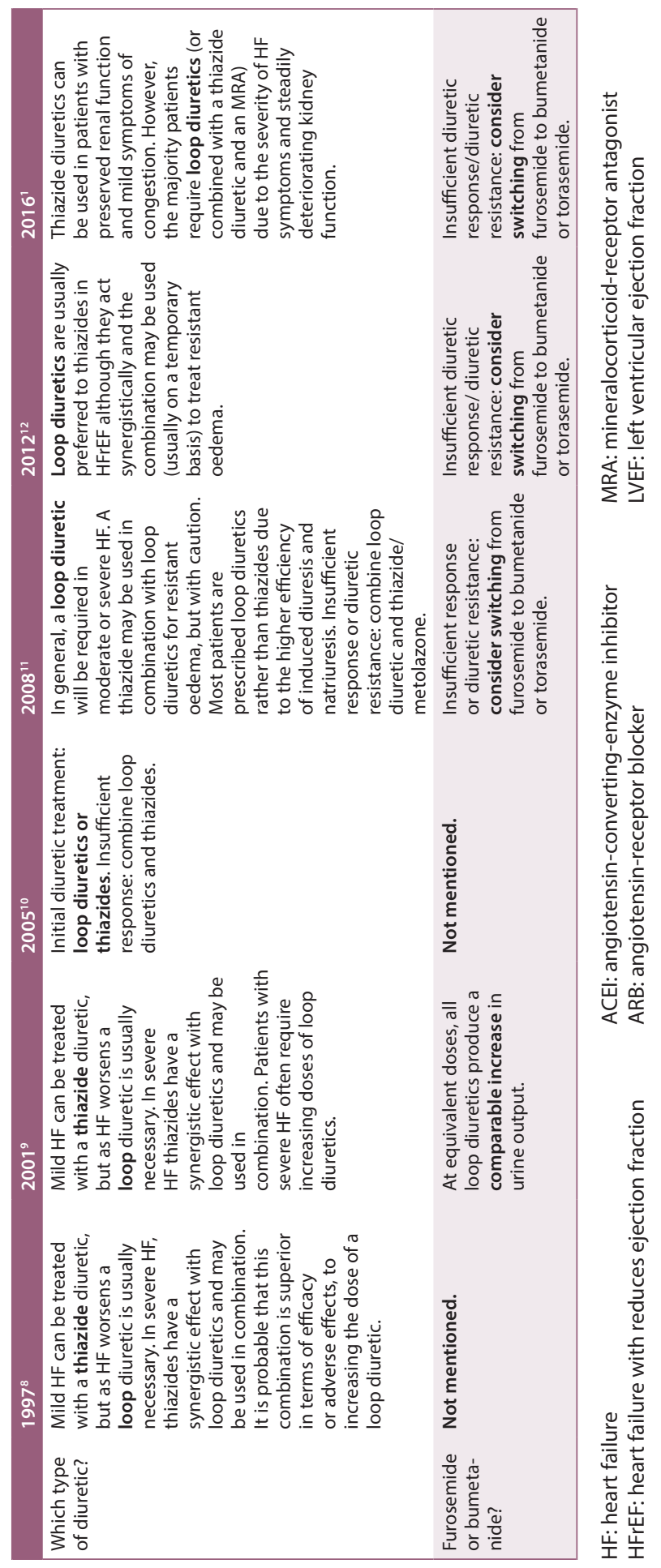




\section{Methods}

We extracted from the PHARMO Database Network 22,476 patients in the Hospitalisation Database with a diagnosis of HF or hypertensive heart disease with (congestive) HF at hospital discharge with their medication from the linked Out-Patient Pharmacy Database, in the Netherlands, between 2001 and 2015. The PHARMO Database Network is a population-based, medical record linkage system covering more than four million Dutch inhabitants. It's linkage algorithms have been validated and the Database Network forms a representative sample of the Dutch population. . $^{15,16}$

The linked Hospitalization Database of PHARMO comprises hospital admissions for more than 24 hours and admissions for less than 24 hours for which a bed is required. PHARMO has access to data of over $80 \%$ of the hospitals in the Netherlands from the national Dutch Hospital Data Foundation. The records include information on hospital admission and discharge dates, discharge diagnoses and procedures. Primary diagnoses are coded in a standardized way after discharge by trained employees according to the WHO International Classification of Diseases.

\section{Patient population}

We included patients with a first discharge diagnosis of HF (ICD-9 428; ICD-10 I50) or hypertensive heart disease with (congestive) HF (ICD-9 402; ICD-10 I11.0) between 2001 and 2015. Patients in both diagnosis groups were clustered for analyses. Patients with rheumatic heart disease with HF (ICD-9 398.91; ICD-10 109.81) or hypertensive heart \& renal disease with HF (some subgroups of ICD-10 I13) represented less than $0.05 \%$ within this group and were therefore excluded. For a planned admission for HF, i.e. pacemaker implantation, different ICD-codes are applicable. It was considered to be the first admission for $\mathrm{HF}$ if there was no known previous admission in at least three years, assuming one expects a patient in the Dutch health care system to be admitted to the same hospital with a rehospitalization for HF. Only patients 18 years and older were included. Information on HF etiology, comorbidities, left ventricular function, e.g. HFrEF or HFpEF or functional class (NYHA) was not available.

Prescription data were retrieved from the linked Out-Patient Pharmacy Database of PHARMO, which comprises drug dispenses from primary and secondary care prescriptions, dispensed by out-patient pharmacies, representing 3.8 million residents throughout the Netherlands. Drug dispenses are coded according to the WHO Anatomical Therapeutic Chemical (ATC) Classification System. Healthcare coverage regarding the reimbursement of concerned drugs was similar for all Dutch citizens. Dispenses from four months before HF hospital admission until four months after discharge were collected.

Hospital data were available up to and including 2015. For each patient periods of uninterrupted use around the time of the hospitalization were formed prior to analysis, based 
on periods of uninterrupted data availability for both pharmacy and hospitalization data. Completeness of available data was influenced by changes in data governance per hospital and pharmacy. It is relevant to know that in the Netherlands healthcare coverage regarding the reimbursement of concerned drugs or hospitalisations is similar for all Dutch citizens.

\section{Data processing and statistical analysis}

The major developments in the ESC guidelines with regard to HF medical treatment during the study period are represented in Table 1. The recommendations of each class of diseasemodifying HF drug and diuretics have been specified from 1997 till 2016.

Dispensing data were used as a proxy variable for prescribing and usage of drugs. Analyses of drug use were performed on the lowest available level of the ATC classification 2017, preferably the $5^{\text {th }}$ level (chemical substance). Alterations in ATC classifications during our study period were accounted for. Based on the last dispensing of a drug before hospital admission and the first dispensing after discharge, the medication profile on discharge was established, accepting a 30-day gap between consecutive dispensings as uninterrupted use of a specific class of drugs. ${ }^{17} \mathrm{~A}$ new drug started at discharge should be dispensed between one day before and seven days after discharge to be assigned to the medication profile on discharge. Dispensings with ATC group V ("Various") were deleted, with the exception of V03 (i.e. "all other therapeutic products", like iron chelating agents and drugs for treatment of hypercalcemia). Only patients with drug dispenses before as well as after admission were included, including at least one cardiovascular drug (ATC group C, cardiovascular system) at discharge.

Characteristics of the study cohort are presented as means (SD) or medians (interquartile range) for continuous variables and frequencies (\%) for categorical variables.

The observational research file was created using SAS programs organized within SAS Enterprise Guide version 7.1 (SAS Institute Inc., Cary, NC) and conducted under Windows using SAS version 9.4. Statistical analysis was performed using SPSS software version 24 (IBM SPSS Statistics, Armonk, New York, USA). Descriptive statistics were used to summarize the characteristics of the study cohort. To assess the relation between age and the probability to follow the guidelines, logistic regression was used.

\section{Results}

Baseline characteristics of our cohort, comprising 22,476 Dutch HF patients over a 15-year period are presented in Table 2. The mean age was 76.8 years, $50.9 \%$ were females. The percentage of females was lowest in 2008 (48.5\%) and highest in 2015 (54.2\%) and there seems to be a slight increase in the percentage of females over time. The mean number of drugs prescribed on discharge was 7.6, and was lowest in 2001 (mean 6.9) and highest in 2011 (mean 8.0). The most prescribed drugs ( $2^{\text {nd }}$ level ATC group) were diuretics in $82.1 \%$ 
of the patients (C03), antithrombotic agents in $66.3 \%$ (B01) and agents acting on the reninangiotensin system in $62.8 \%$ (C09). Drugs for acid related disorders (A02) were the most prescribed non-cardiovascular drugs. The median length of hospital-stay decreased from 8 to 5 days, while the mean age on admission increased from 75.3 years to 78.6 years (SD 10.9 years). The prescription rates for all four classes of drugs are shown in Figure 1.

Table 2 Characteristics of the study cohort

\begin{tabular}{|c|c|}
\hline \multicolumn{2}{|l|}{ Patient characteristics } \\
\hline Total number of patients & 22476 \\
\hline Number of patients/study year (SD) & $1498(455)$ \\
\hline Age: mean (SD) & $76.8(10.9)$ \\
\hline Gender: female \% & $50.9 \%$ \\
\hline \multicolumn{2}{|l|}{ Characteristics of the hospital admission } \\
\hline \multicolumn{2}{|l|}{ Discharge diagnosis: } \\
\hline heart failure (HF) & 22241 \\
\hline hypertensive heart disease with (congestive) HF & 235 \\
\hline Length of stay in days: median (interquartile range) & $6(3.0-11.0)$ \\
\hline \multicolumn{2}{|l|}{ Medication profile on discharge } \\
\hline Number of drugs (SD) & $7.57(3.56)$ \\
\hline ACEI/ARB & $62.7 \%$ \\
\hline Betablocker & $59.6 \%$ \\
\hline HF-betablocker & $51.2 \%$ \\
\hline MRA & $37.0 \%$ \\
\hline Diuretics excluding MRA & $81.8 \%$ \\
\hline Diuretics including MRA & $83.8 \%$ \\
\hline Beta-blocker + ACEI/ARB & $40.4 \%$ \\
\hline Beta-blocker + ACEI/ARB + MRA & $17.1 \%$ \\
\hline \multicolumn{2}{|l|}{ Top 10 prescribed therapeutic subgroups } \\
\hline \multicolumn{2}{|l|}{ ATC group: } \\
\hline Diuretics (CO3) & $82.1 \%$ \\
\hline Antithrombotic agents (B01) & $66.3 \%$ \\
\hline Agents acting on the renin-angiotensin system (C09) & $62.8 \%$ \\
\hline Beta blocking agents (CO7) & $59.6 \%$ \\
\hline Cardiac therapy (CO1) & $46.8 \%$ \\
\hline Drugs for acid related disorders (A02) & $39.1 \%$ \\
\hline Lipid modifying agents (C10) & $38.9 \%$ \\
\hline Psycholeptics (N05) & $26.9 \%$ \\
\hline Drugs used in diabetes (A10) & $25.5 \%$ \\
\hline Drugs for obstructive airway diseases (R03) & $20.1 \%$ \\
\hline
\end{tabular}

ACEI/ARB: angiotensin-converting-enzyme inhibitor (ACEI) or angiotensin-receptor blocker (ARB) HF-betablocker: bisoprolol, carvedilol, metoprolol or nebivolol; MRA: mineralocorticoid-receptor antagonist 
Figure 1 Prescription of groups of heart failure medication

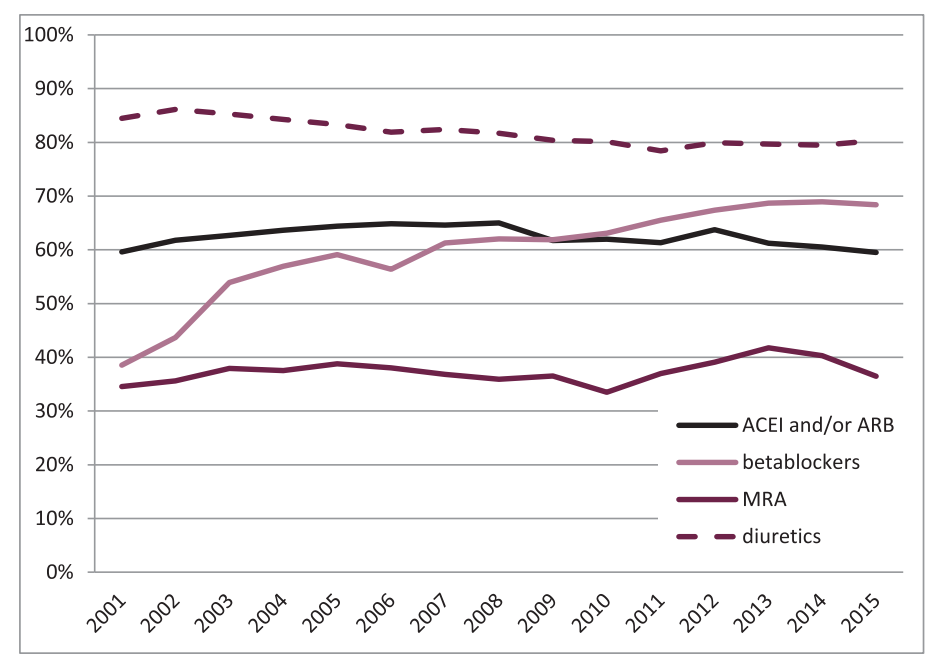

ACEl: angiotensin-converting-enzyme inhibitor; ARB: angiotensin-receptor blocker; MRA: mineralocorticoidreceptor antagonist

Figure 2 shows that $63 \%$ of the patients were prescribed an ACEI, an ARB or both. The contribution of ARB increased, while the percentage of the patients using ACEI as well as ARB increased till 2008 and decreased thereafter, not reaching 3\% of the patients.

Figure 2 Prescription of ACEl and/or ARB

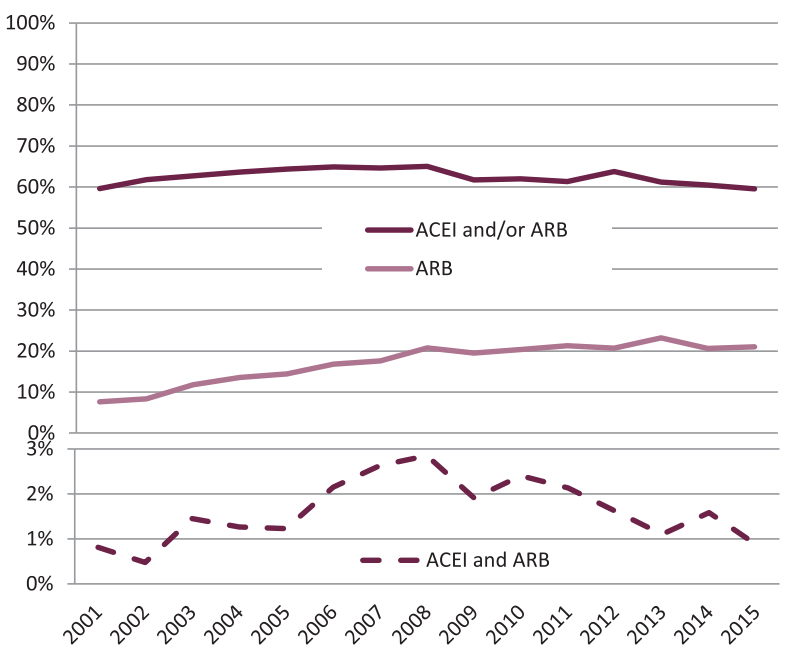

ACEl: angiotensin-converting-enzyme inhibitor; ARB: angiotensin-receptor blocker 
The use of BB increased from less than $40 \%$ in 2001 to about $70 \%$ at the end of our study period, as shown in Figure 3. The BB with a market authorisation for HF and mentioned in the ESC guidelines dominated, in particular metoprolol. Sotalol accounted for $4.6 \%$ and other BB for only $4.1 \%$.

Figure 3 Prescription of betablockers

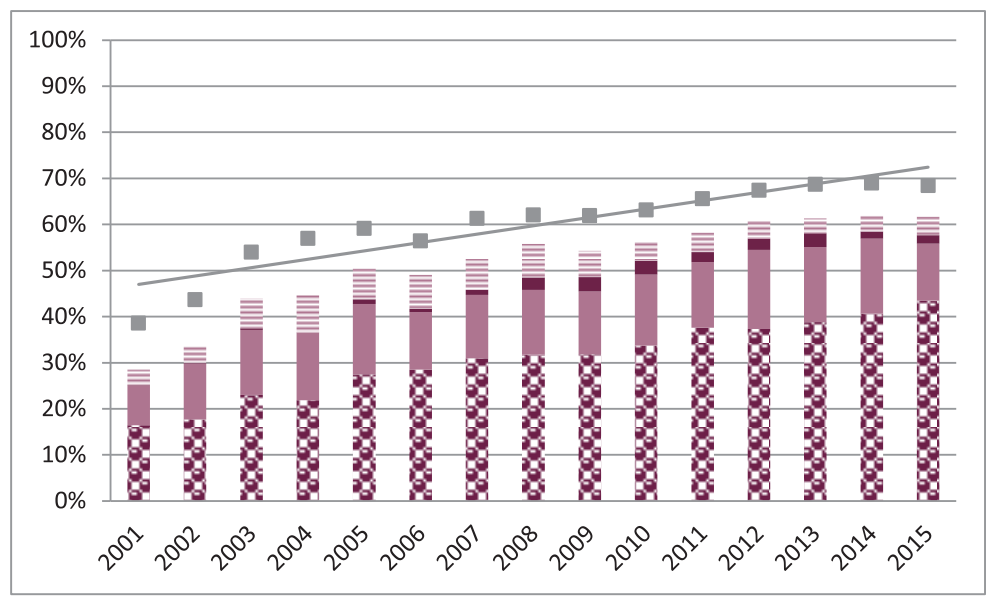

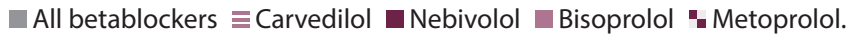

During 2001-2015 a stable $37 \%$ of the patients used MRA, which did not change during that 15-year period. In 2001 the percentage was 34.6\%, in 2015 36.5\%, range over the 15-year period $33.5 \%-41.8 \%$. Eplerenone, introduced in the Netherlands in 2004, was prescribed to $2-4 \%$ of the patients.

More than $80 \%$ of the patients were prescribed a diuretic drug. The loop diuretic were prescribed most frequently, in $71.8 \%$ of the patients as monotherapy and to $4.9 \%$ of the patients combined with thiazides (low-ceiling diuretics) and/or a potassium-sparing agent. Other diuretics or combinations of diuretics were prescribed considerably less. The use of furosemide versus bumetanide, the only two loop diuretics available in the Netherlands during the study period, was stable, about $65 \%$ and $35 \%$, respectively.

The percentage of patients prescribed $a B B$ and an ACEI or ARB, the first step in the treatment of symptomatic HFrEF according to the guideline $2016^{1}$, increased from $24 \%$ to approximately $45 \%$, see Figure 4 . The percentage of patients who also used an MRA reached approximately $20 \%$. Data for men and women were very similar. With each additional year of age, the chance of being prescribed ACEI/ARB and BB decreased by $2 \%$, while being prescribed an MRA as well decreased by $1.5 \%$ with each year that patients are older, see Figure 5 . 
Figure 4 Patients prescribed optimal medical therapy

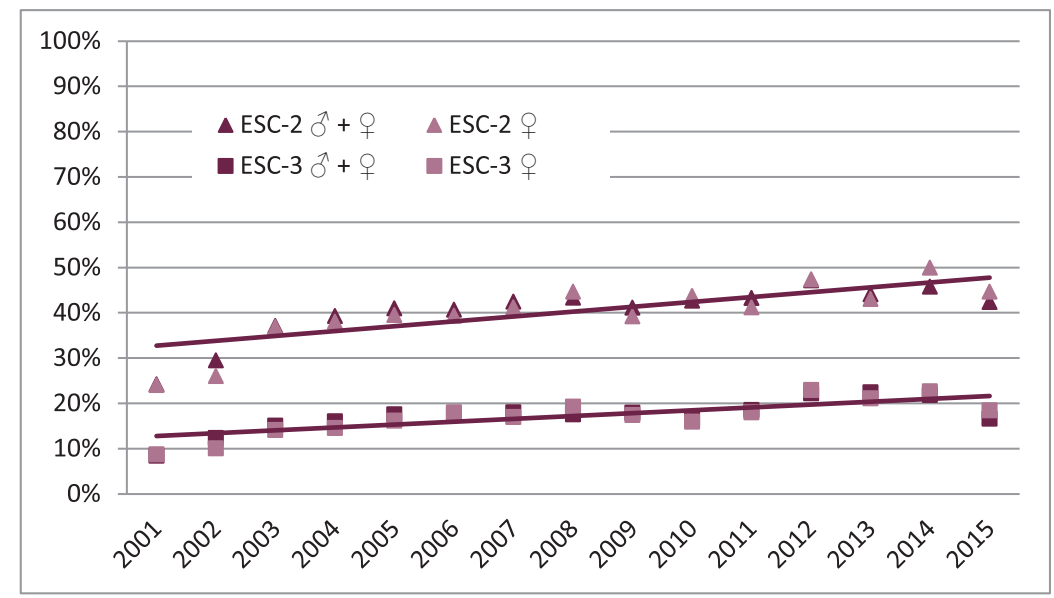

ESC-2: Betablocker + (angiotensin-converting-enzyme inhibitor and/or angiotensin-receptor blocker)

ESC-3: Betablocker + (angiotensin-converting-enzyme inhibitor and/or angiotensin-receptor blocker) + mineralocorticoid-receptor antagonist

Figure 5 Propability of being prescribed HF medical treatment

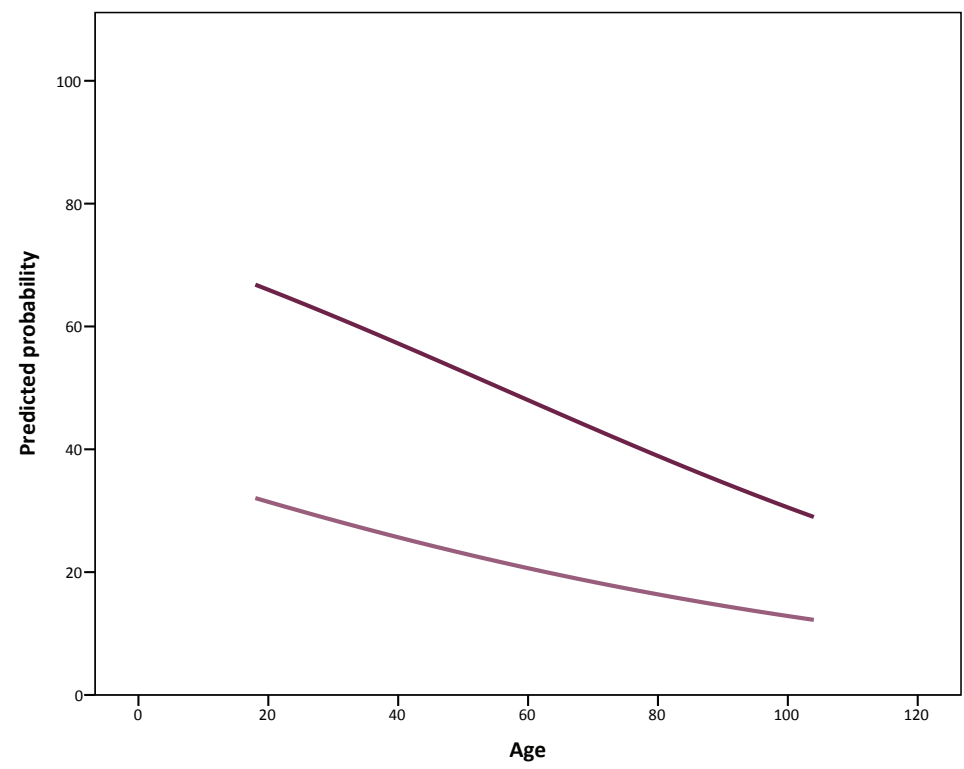

ESC-2: Beta-blocker + (angiotensin-converting-enzyme inhibitor and/or angiotensin-receptor blocker) ESC-3: Beta-blocker + (angiotensin-converting-enzyme inhibitor and/or angiotensin-receptor blocker) + mineralocorticoid-receptor antagonist 


\section{Discussion}

Our study showed the evolving pattern over 15 years in the medication profile at discharge after a first hospitalization for HF in the Netherlands. This reflects the developments in evidence-based HF medication and the ESC guidelines, respectively. Other studies covered a (much) shorter time frame (3-12 years) and were (much) smaller ( $N=1,825-16,052){ }^{2-6,18}$ The mean age, gender distribution and co-medication in our study were comparable to those studies, which may imply that our results are representative for a typical HF population.

\section{Angiotensin-converting-enzyme inhibitors and angiotensin-receptor blockers} In our cohort the percentage of patients prescribed an ACEI and/or an ARB did not rise considerably above $60 \%$ during the 15 -year study period. However the ratio of ACEI and ARB did change: more patients were prescribed an ARB instead of an ACEl in the course of the years, whereas the position of ARB in the guidelines from 2001 until 2016 remained unchanged "in patients unable to tolerate ACEI". In 2001, 13\% of ACEI and/or ARB were for an ARB, while this percentage has risen to $35 \%$ in 2015 . A similar trend was seen in the Dutch population in general, as these numbers rose from $28 \%$ to $45 \% .{ }^{19}$ The combination of ACEI and ARB for HFrEF had been recommended in a selected group of patients up to and including the 2012 guidelines. ${ }^{12}$ This combination was reviewed by the European Medicines Agency in $2014^{20}$, which suggested that benefits are thought to outweigh risks only in selected patients with HFrEF in whom other treatments are unsuitable. The 2016 ESC guidelines were adapted accordingly. The combination of ACEI and ARB did not rise above $3 \%$ of the patients in our study in 2008 and thereafter dropped. Bouvy et al. ${ }^{2}$ concluded that ACEl were still not initiated in many subjects who might benefit from them. In their study of an earlier cohort of the same PHARMO Database in the 90's, the percentage of patients being prescribed ACEls 6 months after discharge after a first hospital admission for HF rose from $49.8 \%$ to $54.8 \%$, which matches our numbers. In other studies (Eschalier ${ }^{3}$, Koudstaal ${ }^{5}$, Maggioni ${ }^{6}$ and Tavazzi ${ }^{18}$ ) observed percentages were between $61.4 \%$ and $78.0 \%$. Gilstrap et al. ${ }^{4}$ found in their "Get with the Guidelines Heart Failure", a North-American quality improvement initiative, percentages reaching up to $90.5 \%$.

\section{Beta-blockers}

Only four BB have been tested in key randomized clinical trials in HFrEF and received market approval of regulatory authorities. Bisoprolol ${ }^{21}$, metoprolol ${ }^{22}$ and nebivolol ${ }^{23}$ are selective $\beta 1$-blocking agents, whereas carvedilol ${ }^{24}$ is both an alpha- and beta-blocking agent, although the $\beta$-blocking effect is 10 times greater. There is no clinical evidence that other BB reduce mortality. Sotalol, a BB without market authorisation for HF was probably prescribed to patients with cardiac arrhythmias together with HF. The prescription percentages of the four BB with market authorisation rose in our study from 38.5\% in 2001 
to $68.4 \%$ in 2015. In the aforementioned study by Bouvy et al. ${ }^{2}$ the percentage of patients prescribed BB rose from $11.3 \%$ to $28.7 \%$ in 1998. From other studies (Eschalier ${ }^{3}$, Koudstaal ${ }^{5}$, Maggioni ${ }^{6}$ and Tavazzi $^{18}$ percentages between $50.7 \%$ and $71.8 \%$ were published. Only Koudstaal and coworkers ${ }^{5}$ reported on separate percentages for all BB (34.6\%) and BB with a market authorisation for HF (22.2\%). Our figures resemble those found in other studies, although we do not know the type of HF of our patients.

\section{Mineralocorticoid-receptor antagonists}

The percentage of patients prescribed an MRA in our study remained on average $37 \%$ during the 15-year period, although the position of MRA in the guidelines evolved from the use as an additional diuretic to prevent or treat diuretic-induced hypokalaemia ${ }^{8}$ into the prominent one it achieved in the 2012 guideline. ${ }^{12}$ At the introduction of the ESC guidelines the importance of thorough implementation of guidelines was emphasized, so it was therefore remarkable that we could not find an effect on prescription behaviour of this considerable change in the guidelines for MRA, based on the results of the EMPHASISHF trial. ${ }^{13}$ Others (Eschalier ${ }^{3}$, Koudstaal ${ }^{5}$, Maggioni ${ }^{6}$, Tavazzi ${ }^{18}$ and Ferreira ${ }^{25}$ ) observed percentages between $14.2 \%$ and $56 \%$. Once again our $37 \%$ is in the middle of this range, although we do not know the type of HF of our patients. Ferreira et al. studied the determinants and pattern of use of MRA in HFrEF. ${ }^{25}$ Patients who were prescribed an MRA at baseline were younger, more often male, had higher body mass index, lower sodium, higher proportion of hypertension history and ACE/ARB prescription. They concluded that MRA were largely under-prescribed and frequently discontinued. Therefore, although the percentage we found does not differ from other studies, we can only speculate about the explanation for the absence of a rise in prescriptions for MRA during the course of years. A possible explanation may be the conservative strategy to prescribe an MRA to a vulnerable group of HF patients, already treated with an ACE/ARB, BB and in most cases also a diuretic. Savarese et al. recently speculated about this same phenomenon. ${ }^{26}$ The increasing age of the patients (i.e. mean age on admission increased from 75 years to almost 79 years) can only explain this finding to a limited extent. Eplerenone did not reach meaningful percentages of patients and its use is therefore probably limited to patients with specific side-effects on spironolactone, as described in Table 1.

\section{Diuretics}

In a recent review of diuretic treatment in $\mathrm{HF}^{27}$ the primary focus is on loop diuretics, of which only furosemide and bumetanide are available in the Netherlands during the study period. Diuretics are prescribed in more than $80 \%$ of our patients. Most of the patients require loop diuretics, as recommended in the ESC guidelines. ${ }^{1}$ Thiazides as monotherapy could be prescribed for hypertension. Other investigators reported the same percentages 
for the prescription of diuretics (Bouvy ${ }^{2}$, Koudstaal ${ }^{5}$, Maggioni ${ }^{6}$ and Tavazzi ${ }^{18}$ ). There was no shift from furosemide to bumetanide or vice-versa during the course of the study period.

\section{HF medical treatment}

ACEI, BB and - in patients with NYHA class II HF - MRA have shown to improve survival in patients with HFrEF and are recommended nowadays for the treatment of every patient with HFrEF, unless contraindicated or not tolerated.' In our study however the percentage of patients prescribed an ACEI (or ARB) and a BB rose only to a percentage of about $45 \%$. The percentage of patients who also used an MRA reached approximately $20 \%$. Importantly, data for men and women were very similar in our study, which is remarkable considering the conflicting data in other reported studies. ${ }^{5,28}$ Also, strikingly, with increasing age, disease modifying drugs like ACEI/ARB, BB and MRA are less prescribed. This might be due to the increased incidence of comorbidities and co-medication in elderly patients or to the greater prevalence of HFpEF amongst older patients..$^{29}$ This trend has also been demonstrated in a recently published cross-sectional registry in $\mathrm{HF}$ outpatient clinics in the Netherlands (CHECK-HF). ${ }^{30}$

Furthermore, real-world patients tend to be older and have more contraindications than patients in clinical trials. Over the years, in our cohort, patients were older and the length of hospital stay decreased. Other investigators found percentages of $37.2 \%$ for the combination of BB and MRA and $8.4 \%$ or $42 \%$ for the combination ACEI/ARB, BB and MRA $8.4 \%$ or $42 \% .3,31$ In the ESC Heart Failure Long-Term Registry ${ }^{6}$, the reasons for nonadherence to the guidelines were investigated. A considerable part of the non-use in their study could be explained by contraindications or intolerance. Only in $3.2 \%, 2.3 \%$, and $5.4 \%$ of the cases for respectively ACEI/ARB, BB and MRA, the undertreatment was unexplained.

\section{Strengths and limitations}

Although the exact HF classification of our patients was unknown, our large database provided insights in real-world HF medical therapy from 2001 till 2015. The mean age, gender distribution and co-medication of our study cohort are comparable to other studies. Although the proportion of HFpEF in the total population of HF patients has increased from 43.0\% (period 1995-2004) to $56.2 \%$ (period 2005-2014) 32 , that probably did not influence the trends we observed. However, those trends should be interpreted with caution due to the change in case-mix. Also, there is relatively little difference in the medical treatment of $\mathrm{HFrEF}$ versus HFpEF which makes it likely that the change in case-mix was not the driver for little changes in medical treatment over time. ${ }^{1}$ The lack of more detailed information on the patient or the type of HF is a significant issue. The databases in the PHARMO Database Network do not contain this information. Due to privacy legislation there was no option to retrieve this information afterwards. This information would have made our conclusions 
much more robust. Also, we have no data on the doses of the prescribed HF drugs. Some studies seem to prove the importance of the right (i.e. maximally tolerated) dose, while others are not able to support this, or even refute it. ${ }^{33}$

The probabilistic linkage by PHARMO between the Hospitalisation Database and the Outpatient Pharmacy Database has been validated previously ${ }^{15}$, and has an accuracy of about $95 \%$. As it is highly unlikely that HF patients did not receive at least one drug in anatomical main group $C$ in the medication profile, we only included patients with dispenses before as well as after a hospitalization and at least one drug in anatomical main group $C$ in the medication profile on discharge to eliminate likely mislinked patients.

A part of the patients will still be in the start-up phase of disease modifying therapy, because it is their first hospital admission for HF. We chose to investigate the medication profile at discharge and not to include new prescriptions once a patient had been discharged, because of the potential for rapid deterioration of the disease. The Italian Network on Heart Failure study reported data not only at discharge, but also one year later. ${ }^{18}$ The prescription for ACEI/ARB increased in that year by $1 \%, \mathrm{BB}$ increased by $3 \%$, MRA decreased by $4 \%$, and diuretics decreased by $2 \%$. These figures suggest the aspect of uptitration is marginal. However, the CHECK-HF registry reported considerably higher prescription percentages for ACEI/ARB (84\% as compared to $72.7 \%$ in our cohort), BB $(86 \%$ versus $59.6 \%$ ) and MRA (56\% versus $37.0 \%){ }^{30}$ The vast majority of patients in that registry (77\%) had HFrEF.

\section{Conclusions}

Our study showed to what extent the ESC guidelines influenced prescription behaviour at discharge after a first hospitalization for heart failure, during 2001 - 2015 . However, the compliance with the guidelines varied for the individual recommendations. Remarkably, there was no significant increase in MRA prescription. At the same time some developments were demonstrated, which were not instigated by the guidelines, like the shift from ACEI to ARB. Our data provide insight into "real-world" pharmacological management in an unselected HF population during a 15-year period. As far as we know this study is unique given the number of patients it pertains and the duration of the study-period. Further research is needed to elucidate the reasons for non-adherence and to develop strategies for improvement. Especially the elderly HF patient might benefit from more widespread prescription of disease-modifying drugs.

\section{Acknowledgement}

The authors would like to thank all the healthcare providers contributing information to the PHARMO Database Network. 
1. Ponikowski P, Voors AA, Anker SD, Bueno H, Cleland JG, Coats AJ, et al. 2016 ESC Guidelines for the diagnosis and treatment of acute and chronic heart failure: The Task Force for the diagnosis and treatment of acute and chronic heart failure of the European Society of Cardiology (ESC). Developed with the special contribution of the Heart Failure Association (HFA) of the ESC. Eur J Heart Fail 2016;18(8):891-975.

2. Bouvy ML, Heerdink ER, Leufkens HG, Hoes AW. Patterns of pharmacotherapy in patients hospitalised for congestive heart failure. Eur J Heart Fail 2003;5(2):195-200.

3. Eschalier R, Chenaf C, Mulliez A, Yalioua A, Clerfond G, Authier N, et al. Impact of clinical characteristics and management on the prognosis of unselected heart failure patients. Cardiovasc Drugs Ther 2015;29(1):89-98.

4. Gilstrap LG, Fonarow GC, Desai AS, Liang L, Matsouaka R, DeVore AD, et al. Initiation, continuation, or withdrawal of angiotensinconverting enzyme inhibitors/angiotensin receptor blockers and outcomes in patients hospitalized with heart failure with reduced ejection fraction. J Am Heart Assoc 2017;6(2):e004675.

5. Koudstaal S, Pujades-Rodriguez M, Denaxas S, Gho JMIH, Shah AD, Yu N, et al. Prognostic burden of heart failure recorded in primary care, acute hospital admissions, or both: a population-based linked electronic health record cohort study in 2.1 million people. Eur J Heart Fail 2017;19(9):1119-1127.

6. Maggioni AP, Anker SD, Dahlstrom U, Filippatos G, Ponikowski P, Zannad F, et al. Are hospitalized or ambulatory patients with heart failure treated in accordance with European Society of Cardiology guidelines? Evidence from 12,440 patients of the ESC Heart Failure Long-Term Registry. Eur J Heart Fail 2013;15(10):1173-1184.

7. Jefferies JL, Ibrahim NE. Are Guidelines Merely Suggestions? J Am Coll Cardiol 2018;72(4):367-369.

8. Task Force of the Working Group on Heart Failure of the European Society of Cardiology. The treatment of heart failure. Eur Heart J 1997;18(5):736-753.

9. Remme WJ, Swedberg K. Guidelines for the diagnosis and treatment of chronic heart failure. Eur Heart J 2001;22(17):1527-1560.
10. Swedberg K, Cleland J, Dargie H, Drexler H, Follath F, Komajda M, et al.Guidelines for the diagnosis and treatment of chronic heart failure: executive summary (update 2005): the task force for the diagnosis and treatment of chronic heart failure of the European Society of Cardiology. Eur Heart J 2005;26(11):1115-1140.

11. Dickstein K, Cohen-Solal A, Filippatos G, McMurray JJ, Ponikowski P, Poole-Wilson PA, et al. ESC Guidelines for the diagnosis and treatment of acute and chronic heart failure 2008: the task force for the diagnosis and treatment of acute and chronic heart failure 2008 of the European Society of Cardiology. Developed in collaboration with the Heart Failure Association of the ESC (HFA) and endorsed by the European Society of Intensive Care Medicine (ESICM). Eur Heart J 2008;29(19):2388-2442.

12. McMurray JJ, Adamopoulos S, Anker SD, Auricchio A, Bohm M, Dickstein K, et al. ESC Guidelines for the diagnosis and treatment of acute and chronic heart failure 2012: The Task Force for the Diagnosis and Treatment of Acute and Chronic Heart Failure 2012 of the European Society of Cardiology. Developed in collaboration with the Heart Failure Association (HFA) of the ESC. Eur Heart J 2012;33(14):1787-1847.

13. Zannad F, McMurray JJ, Krum H, van Veldhuisen DJ, Swedberg K, Shi H, et al. Eplerenone in patients with systolic heart failure and mild symptoms. N Engl J Med 2011;364(1):11-21.

14. Yancy CW, Jessup M, Bozkurt B, Butler J, Casey DE, Jr., Colvin MM, et al. 2017 ACC/AHA/ HFSA Focused Update of the 2013 ACCF/ AHA Guideline for the Management of Heart Failure: A Report of the American College of Cardiology/American Heart Association Task Force on Clinical Practice Guidelines and the Heart Failure Society of America. J Am Coll Cardiol 2017;70(6):776-803.

15. Herings RMC, Pedersen L. PharmacyBased Medical Record Linkage Systems. In: Strom BL, Kimmel SE, Hennessy S, ed. Pharmacoepidemiology, 5th ed. Oxford: WileyBlackwell; 2012. p. 270-286.

16. Pharmo. PHARMO Database Network. https:// www.pharmo.nl/what-we-have/pharmodatabase-network/. Accessed 4 November 2018. 
17. Catalan VS, LeLorier J. Predictors of long-term persistence on statins in a subsidized clinical population. Value Health 2000;3(6):417-426.

18. Tavazzi L, Senni M, Metra M, Gorini M, Cacciatore G, Chinaglia A, et al. Multicenter prospective observational study on acute and chronic heart failure: one-year follow-up results of IN-HF (Italian Network on Heart Failure) outcome registry. Circ Heart Fail 2013;6(3):473-481.

19. The Drug Information System of National Health Care Institute. https://www gipdatabank nl/. Accessed 4 November 2018.

20. European Medicines Agency (EMA). PRAC recommends against combined use of medicines affecting the reninangiotensin (RAS) system, 11 April 2014. http://www.ema.europa.eu/ema/index. jsp?curl=pages/news_and_events/ news/2014/04/news_detail_002066. jsp\&mid=WC0b01ac058004d5c1. Accessed 4 November 2018.

21. Packer $M$, Fowler MB, Roecker EB, Coats AJ, Katus HA, Krum H, et al. Effect of carvedilol on the morbidity of patients with severe chronic heart failure: results of the carvedilol prospective randomized cumulative survival (COPERNICUS) study. Circulation 2002;106(17):2194-2199.

22. CIBIS-II Investigators and Committees. The Cardiac Insufficiency Bisoprolol Study II (CIBIS-II): a randomised trial. Lancet 1999;353(9146):9-13.

23. Flather MD, Shibata MC, Coats AJ, van Veldhuisen DJ, Parkhomenko A, Borbola J, et al. Randomized trial to determine the effect of nebivolol on mortality and cardiovascular hospital admission in elderly patients with heart failure (SENIORS). Eur Heart J 2005;26(3):215-225.

24. MERIT-HF Study Group. Effect of metoprolol $\mathrm{CR} / \mathrm{XL}$ in chronic heart failure: Metoprolol $\mathrm{CR} / \mathrm{XL}$ Randomised Intervention Trial in Congestive Heart Failure (MERIT-HF). Lancet 1999;353(9169):2001-2007.

25. Ferreira JP, Rossignol P, Machu JL, Sharma A, Girerd N, Anker SD, et al. Mineralocorticoid receptor antagonist pattern of use in heart failure with reduced ejection fraction: findings from BIOSTAT-CHF. Eur J Heart Fail 2017;19(10):1284-1293.
26. Savarese G, Carrero JJ, Pitt B, Anker SD, Rosano GMC, Dahlstrom U, et al. Factors associated with underuse of mineralocorticoid receptor antagonists in heart failure with reduced ejection fraction: an analysis of 11 215 patients from the Swedish Heart Failure Registry. Eur J Heart Fail 2018;20(9):1326-1334.

27. Ellison DH, Felker GM. Diuretic Treatment in Heart Failure. N Engl J Med 2017;377(20):19641975.

28. Hoes AW. Beta blockers for heart failure. BMJ 2016;353(8054):i2074.

29. Komajda M, Hanon O, Hochadel M, LopezSendon JL, Follath F, Ponikowski P, et al. Contemporary management of octogenarians hospitalized for heart failure in Europe: Euro Heart Failure Survey II. Eur Heart J 2009;30(4):478-486.

30. Brunner-La Rocca HP, Linssen GC, Smeele FJ, van Drimmelen AA, Schaafsma HJ, Westendorp PH, et al. Contemporary drug treatment of chronic heart failure with reduced ejection fraction: the CHECK-HF registry. JACC Heart Fail 2019;7(1):13-21.

31. British Society for Heart Failure. National Heart Failure Audit, April 2014-March 2015. https://www.ucl.ac.uk/nicor/audits/ heartfailure/documents/annualreports/ heartfailurepublication14_15. Accessed 4 November 2018.

32. Vasan RS, Xanthakis V, Lyass A, Andersson C, Tsao C, Cheng S, et al. Epidemiology of left ventricular systolic dysfunction and heart failure in the Framingham study: an echocardiographic study over 3 decades. JACC Cardiovasc Imaging 2018;11(1):1-11.

33. Ambrosy AP, Gheorghiade M. Real-world dosing of evidence-based medications for heart failure: embracing guideline recommendations and clinical judgement. Eur J Heart Fail 2017;19(11):1424-1426. 



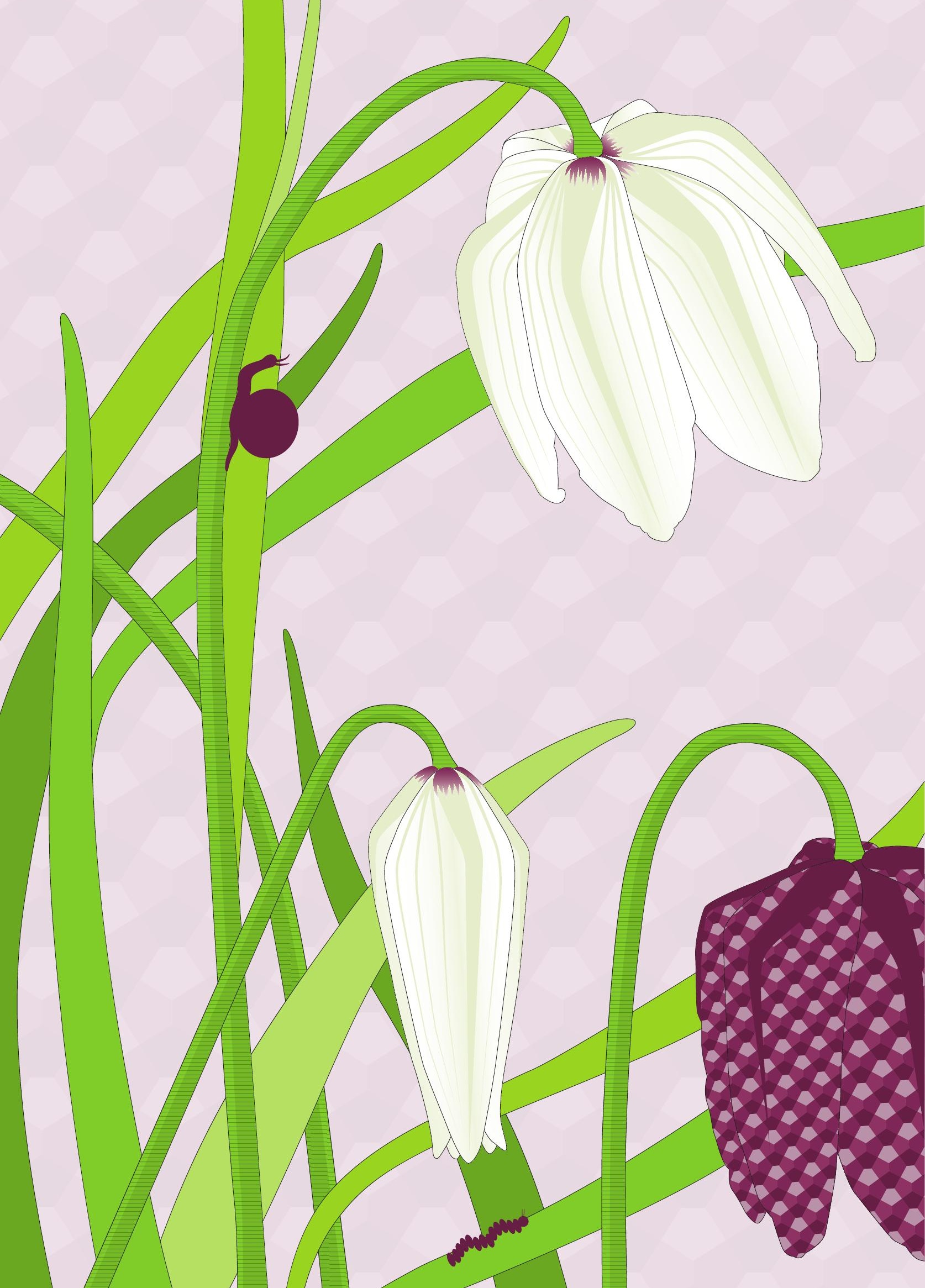




\section{Chapter 5}

Association between heart failure medication at discharge and heart failure readmission

Willemien J. Kruik-Kollöffel Job van der Palen

Carine J.M. Doggen

H. Joost Kruik

Edith M. Heintjes

Kris L.L. Movig

Gerard C.M. Linssen

Submitted 


\section{Abstract}

\section{Aims}

The aim of this large population-based cohort study is to compare hospital readmission rates of patients with heart failure (HF), prescribed core HF medications versus non-use in a real-world scenario. Angiotensin-converting-enzyme inhibitors (ACEI), angiotensinreceptor blockers (ARB), beta-blockers (BB) and mineralocorticoid-receptor antagonists (MRA) have demonstrated in randomized clinical trials in selected groups of HF patients to reduce the risk of readmission for HF. Diuretics, being indispensable for most patients with $\mathrm{HF}$, are also investigated.

\section{Methods and results}

Medication at hospital discharge was determined on the basis of dispensing data from the Dutch PHARMO Database Network including 22,476 patients with a diagnosis of HF between 2001 and 2015. Median follow-up was 29.3 months. One third of all patients were readmitted for HF. Propensity scores were calculated as a proxy for comorbidities and hazard ratios were adjusted (HRadj) accordingly. ACEI and ARB were not associated with readmission. Only $\beta 1$-selective BB (sBBHF; bisoprolol, metoprolol and nebivolol) decreased risk of readmission (HRadj 0.94; 95\% Cl 0.90-0.99). Carvedilol, a $\beta$ - and partly a1-blocking agent, (HRadj 1.25; 95\%Cl 1.14-1.38), MRA (HRadj 1.09; 95\%Cl 1.03-1.15) and diuretics (HRadj 1.14; 95\% Cl 1.06-1.23) were associated with an increased risk of readmission.

\section{Conclusion}

Based on our results, sBBHF should be preferred to the non-selective BB carvedilol, whereas these are considered equivalent in current guidelines. Further investigations are necessary to confirm our results in other real-world HF patients. 


\section{Introduction}

Hospital admission is a marker for worse prognosis in patients with heart failure (HF)., ${ }^{1,2}$ Patients discharged after a hospital admission for HF have a high risk of HF readmission. The 1-year follow-up of the European Society of Cardiology (ESC) HF long-term registry showed that $22.2 \%$ of patients is readmitted for $\mathrm{HF}$ and all-cause mortality is $26.0 \% .^{1,3}$ Other research groups reported comparable results. ${ }^{4,5}$ Especially since the $2001 \mathrm{HF}$ guidelines of the ESC, major advances in pharmacotherapy to reduce the frequency of hospital admissions were made., ${ }^{6,7}$ Angiotensin-converting-enzyme inhibitors (ACEI) are recommended as first-line-therapy, and angiotensin-receptor blockers (ARB) as an alternative for patients who do not tolerate an ACEl. Beta-blockers (BB) are recommended for most patients. Mineralocorticoid-receptor antagonists (MRA) are advised for patients with NYHA class III and IV, which was expanded to NYHA class II in 2012. The position for diuretics remained unchanged: indispensable for most patients. Titration of disease-modifying medications (ACEI/ARB, BB and MRA) in patients with reduced left ventricular ejection fraction (HFrEF) should start during hospital admission, because in patients with chronic $\mathrm{HF}$, mortality risk is highest early after hospital discharge..$^{8-10}$ The right medication at the right dose should start as soon as possible.

The evidence for the use of the classes of HF medication, however, is based upon large randomized clinical trials. These trials were performed in a relative healthy patient group, carefully selected based on in- and exclusion criteria, thoroughly monitored and all relevant patient characteristics known. This results into a homogeneous group of patients, suitable for testing specific medication. However, this group does not resemble daily clinical practise of HF patients. Comorbidities, especially in HF patients, are common.

The aim of this study was to assess over a 15-year period the association between the prescription of ACEI/ARB, BB, MRA and diuretics and HF readmission in a real-world, large, unselected group of patients after a first hospital admission for HF. We were particularly interested in differences in readmission rates relative to non-use for $A C E l$ versus $A R B$ and for $\beta 1$-selective BB (sBBHF: bisoprolol, metoprolol and nebivolol) versus carvedilol, a $\beta$ - and partly a1-blocking agent, as these medications are to some extent interchangeable.

\section{Methods}

\section{Patient population and medication}

In a cohort of 22,476 patients the association between HF medication at discharge after a first hospital admission for HF between January 1, 2001 and December 31, 2015 and readmission rate was analysed. All data are extracted from the PHARMO Database Network, a population-based, medical record linkage system covering more than four million Dutch inhabitants. ${ }^{11}$ Its linkage algorithms have been validated and the Database Network forms a representative sample of the Dutch population. ${ }^{12}$ 
Patients with a first discharge diagnosis of HF (ICD-9 428; ICD-10 I50) or hypertensive heart disease with (congestive) HF (ICD-9 402; ICD-10 I11.0) were included. Data includes cardiovascular as well as non-cardiovascular medication, the latter which provides proxy information about co-morbidities, as well as age at time of first hospital admission, gender and the year of admission and time to readmission or end of follow-up. Last date of followup for readmissions 1 January 2015, for medication 1 September 2016. More details were previously reported. ${ }^{?}$

\section{Data processing and statistical analyses}

Dispensing data were used as a proxy variable for medication use. Medication dispenses from primary and secondary care prescriptions, dispensed by out-patient pharmacies, are included. Medication dispenses are coded according to the WHO Anatomical Therapeutic Chemical (ATC) Classification System. ${ }^{13}$ Beta-blockers included were the ones recommended in the HF guidelines in Europe and the US: $\beta 1$-selective BB (sBBHF: bisoprolol (C07AB07), metoprolol (C07AB02) and nebivolol (C07AB12)) and carvedilol (C07AG02), a $\beta$ - and partly a1-blocking agent. ${ }^{1,14,15}$ Furthermore, ACEl (C09A and C09B), ARB (C09C and C09D), MRAs (C09DA) and diuretics (mainly loop diuretics ${ }^{7}$, C03CA) are investigated.

Descriptive statistics were used to compare patients with and without a readmission. Data are presented as means (SD) or medians (interquartile range) for continuous variables and frequencies (\%) for categorical variables. Differences in continuous variables between patients that were readmitted or not were compared using the $t$-test for independent samples or the Mann-Whitney $U$ test, as appropriate. Between-group differences in categorical variables were compared using the Chi-square test. The risk of readmission associated with the various medications versus non-use was analysed using Kaplan-Meier analysis with the log-rank test. Time-to-first event was either time to readmission or end of follow-up. Hazard Ratio's (HR) with a $95 \%$ confidence interval $(95 \% \mathrm{Cl})$ were calculated. A $P$-value of $\leq 0.05$ was considered to indicate statistical significance. Statistical analysis was performed using SPSS software version 24 (IBM SPSS Statistics, Armonk, New York, USA).

We dealt with confounding by indication, and adjusted for this using propensity scores. ${ }^{16}$ The propensity score estimates the risk of a certain patient to be prescribed certain medication. The HR (see below) was adjusted (HRadj) for this propensity score. Propensity scores were calculated using logistic regression analyses that included the co-medication, as a proxy for comorbidities, and baseline characteristics, i.e. age, gender, total number of unique medications and year of hospital admission. The propensity score included the medication on identifying level, in general on second level ATC group, i.e. the therapeutic subgroup. Based on mode of action and therapeutic use, however, on the third level ATC group, i.e. pharmacological subgroup, were included medication used in diabetes A10, 
non-steroid anti-inflammatory and antirheumatic products M01, psycholeptics N05 and psychoanaleptics N06.

A multivariable Cox regression model for each HF medication versus non-use was constructed to calculate the adjusted hazard ratio (HRadj). The Cox models were adjusted for baseline characteristics and propensity scores to adjust for confounding by indication. ${ }^{16}$ The HRadj and 95\% confidence intervals are all graphically displayed in a Forest-plot. The area under the curve of the ROC-curve (AUC) was determined to give an estimation of the extent to which the propensity scores were adequately estimated. Finally, as a sensitivity analysis, propensity trimming was performed to remove extreme propensity scores, i.e. patients with very high or very low probability of receiving a specific medication, complemented with an analysis after trimming the $5^{\text {th }}, 10^{\text {th }}$ and $20^{\text {th }}$ percentiles, respectively. ${ }^{16}$

Carvedilol and sBBHF are to some extent interchangeable, as well as ACEI and ARB. However, the profile of a patient to whom a sBBHF is prescribed, may differ from the profile of a patient to whom carvedilol is prescribed. The probability for being prescribed specific medication is calculated in the propensity score. The propensity score therefore gives an impression of -for example- the carvedilol-profile of the patient: what is his or her probability of being prescribed carvedilol. We introduced this carvedilol-profile, i.e. the propensity score for carvedilol, into the Cox model of sBBHF. This model than consists of sBBHF, baseline characteristics and the propensity score of carvedilol. This modified Cox model for SBBHF is meant to give an impression of the readmission risk being prescribed a sBBHF, adjusted for the probability of being prescribed carvedilol. Vice versa a modified Cox-model for carvedilol was built including carvedilol, baseline characteristics and the propensity score of sBBHF. Similarly, this method was used for the pair ACEI versus ARB.

\section{Results}

Baseline characteristics of this population-based cohort, comprising 22,476 HF patients over a 15-year period are presented in Table 1. The mean age was 76.8 years (SD 10.9 years), and $50.9 \%$ were women. The mean number of medications prescribed at hospital discharge was 7.6 (SD 3.6), after a median length of stay of 6 days (interquartile range 3-11 days). Thirty percent of the patients was readmitted for HF. Readmitted patients were younger, more often men, their initial hospital stay was longer, and they used more medications, although differences were small between patients with or without a readmission. Except for the use of metoprolol and bisoprolol, all groups of HF medication were prescribed more frequently to patients with a readmission. Median follow-up time to end of follow-up or readmission was 29.3 months (interquartile range 7.4-69.7 months). 
Table 1 Characteristics of the study cohort for 22,476 heart failure patients

\begin{tabular}{|c|c|c|c|c|}
\hline & All patients & Readmitted & Without readmission & $P$-value* \\
\hline Number of patients & 22476 & 6713 & 15763 & \\
\hline Age: mean (years, SD) & $76.8(10.9)$ & $76.3(10.5)$ & $76.9(11.1)$ & $P<0.001$ \\
\hline Gender: female (\%) & $11449(50.9 \%)$ & $48.2 \%$ & $52.1 \%$ & $P<0.001$ \\
\hline $\begin{array}{l}\text { Length of stay in days: median } \\
\text { (interquartile range) }\end{array}$ & $6(3-11)$ & $7(3-11)$ & $6(3-11)$ & 0.020 \\
\hline \multicolumn{5}{|l|}{ Medication profile on discharge } \\
\hline Number of medications: mean (SD) & $7.57(3.56)$ & $7.77(3.50)$ & $7.48(3.58)$ & $P<0.001$ \\
\hline ACEI/ARB: & $14096(62.7 \%)$ & & & \\
\hline ACEI (\%) & $10599(47.2 \%)$ & $3268(48.7 \%)$ & $7331(46.5 \%)$ & 0.003 \\
\hline ARB (\%) & $3898(17.3 \%)$ & 1225 (18.2\%) & $2673(17.0 \%)$ & 0.019 \\
\hline Beta-blocker: & $13406(59.6 \%)$ & & & \\
\hline Metoprolol (\%) & $6847(30.5 \%)$ & $1983(29.5 \%)$ & $4864(30.9 \%)$ & 0.050 \\
\hline Bisoprolol (\%) & $3156(14.0 \%)$ & $928(13.8 \%)$ & $2228(14.1 \%)$ & 0.540 \\
\hline Nebivolol (\%) & $374(1.7 \%)$ & $120(1.8 \%)$ & $254(1.6 \%)$ & 0.345 \\
\hline Carvedilol (\%) & $1224(5.4 \%)$ & $470(7.0 \%)$ & 754 (4.8\%) & $P<0.001$ \\
\hline MRA: & $8317(37.0 \%)$ & & & \\
\hline Spironolactone (\%) & $7940(35.3 \%)$ & $2500(37.2 \%)$ & $5440(34.5 \%)$ & $P<0.001$ \\
\hline Eplerenone (\%) & $393(1.7 \%)$ & $134(2.0 \%)$ & $259(1.6 \%)$ & 0.065 \\
\hline Diuretics (\%) & $18384(81.8 \%)$ & $5649(84.2 \%)$ & $12735(80.8 \%)$ & $P<0.001$ \\
\hline Beta-blocker + ACEI/ARB (\%) & $9088(40.4 \%)$ & $2810(41.9 \%)$ & $6278(39.8 \%)$ & 0.005 \\
\hline Beta-blocker + ACEI/ARB + MRA (\%) & $3850(17.1 \%)$ & $1219(18.2 \%)$ & $2631(16.7 \%)$ & 0.008 \\
\hline
\end{tabular}

*Differences in characteristics between readmitted patients and patients without readmission, compared using the Chi-square test, the t-test for independent samples or the Mann-Whitney $U$ test; MRA: mineralocorticoid-receptor antagonist; ACEI/ARB: angiotensin-converting enzyme inhibitor (ACEI) and/or angiotensin receptor blocker (ARB)

Kaplan-Meier curves for time to readmission or end of follow-up are shown in Figure 1. Patients on carvedilol, MRA and diuretics have an increased risk of readmission (HR between 1.14 and 1.30, all $P<0.001$ ). For all medications (Table 2, Figure 2 ), except sBBHF, the use of the particular medication was associated with an increased risk of readmission, but not all risks were statistically significant. The percentage of patients readmitted to hospital is higher with that medication and the unadjusted HR for time to event is increased. 
Figure 1 Readmission for HF medication in 22,476 patients
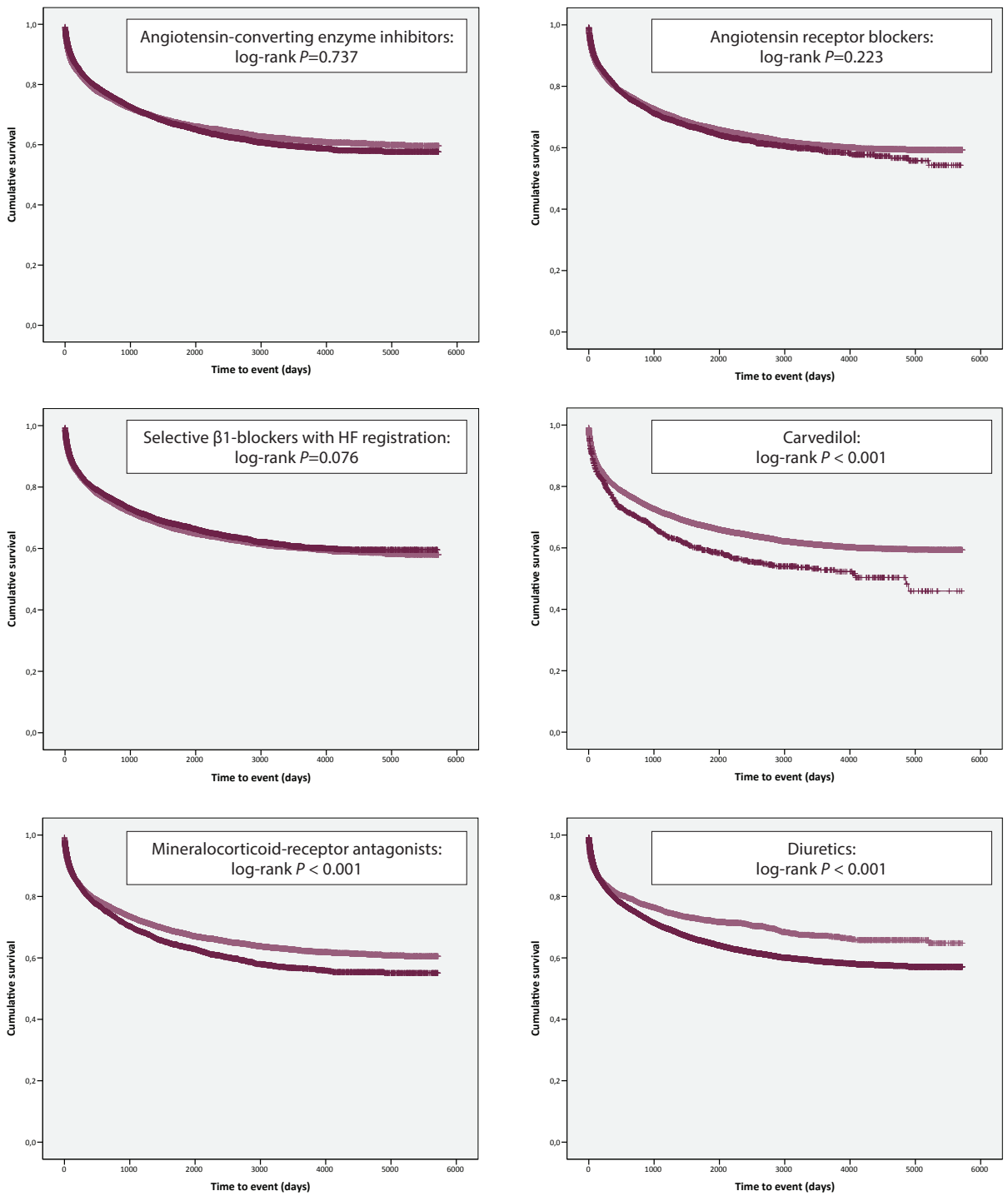

- patients without medication patients on medication

MRA: mineralocorticoid-receptor antagonist

The AUC, calculated to estimate the reliability of the propensity score, i.e. how good the estimation of the risk for a certain patient to be prescribed certain medication was, ranges from 0.67 for sBBHF and 0.68 for MRA, up to 0.79 for ARB and 0.78 for diuretics. The AUC for ACEl and carvedilol were in between: 0.74 and 0.75 . 
Table 2 Risk of readmission associated with HF medication

\begin{tabular}{|c|c|c|c|c|c|}
\hline Medication & $\begin{array}{l}\text { Number of } \\
\text { patients (\%) }\end{array}$ & $\begin{array}{l}\text { Numer of patients } \\
\text { users }\end{array}$ & $\begin{array}{l}\text { s readmitted (\%) } \\
\text { non-users }\end{array}$ & $\begin{array}{l}\text { Unadjusted HR } \\
(95 \% \mathrm{CI})\end{array}$ & $\begin{array}{l}\text { Adjusted HR } \\
(95 \% \mathrm{Cl})^{*}\end{array}$ \\
\hline ACEI & 10599 (47.1\%) & $3268(30.8 \%)$ & 3445 (29.0\%) & $1.01(0.96-1.06)$ & $0.97(0.92-1.02)$ \\
\hline ARB & 3898 (17.3\%) & 1225 (31.4\%) & $5488(29.5 \%)$ & $1.04(0.98-1.11)$ & $1.01(0.95-1.09)$ \\
\hline sBBHF & 10344 (46.0\%) & 3019 (29.2\%) & 3694 (30.4\%) & $0.96(0.91-1.00)$ & $0.94(0.90-0.99)$ \\
\hline Carvedilol & $1224(5.4 \%)$ & $470(38.4 \%)$ & $6243(29.4 \%)$ & $1.30(1.18-1.42)$ & $1.25(1.14-1.38)$ \\
\hline MRA & 8317 (37.0\%) & $2628(31.6 \%)$ & 4085 (28.9\%) & $1.14(1.09-1.20)$ & 1.09 (1.03-1.15) \\
\hline Diuretics & $18384(81.8 \%)$ & 5649 (30.7\%) & $1064(26.0 \%)$ & $1.26(1.18-1.34)$ & $1.14(1.06-1.23)$ \\
\hline
\end{tabular}

ACEl: angiotensin-converting enzyme inhibitor; ARB: angiotensin receptor blocker; sBBHF: Selective beta1receptor blocker with a market authorisation for heart failure; MRA: mineralocorticoid-receptor antagonist; HR: hazard ratio comparing patients with versus without the particular medication; *HR adjusted for age, gender, number of drugs (excl particular drug), year of admission, propensity score of particular medication (based on baseline characteristics and co-medication)

Figure 2 Hazard ratios* of heart failure readmission and heart failure medication

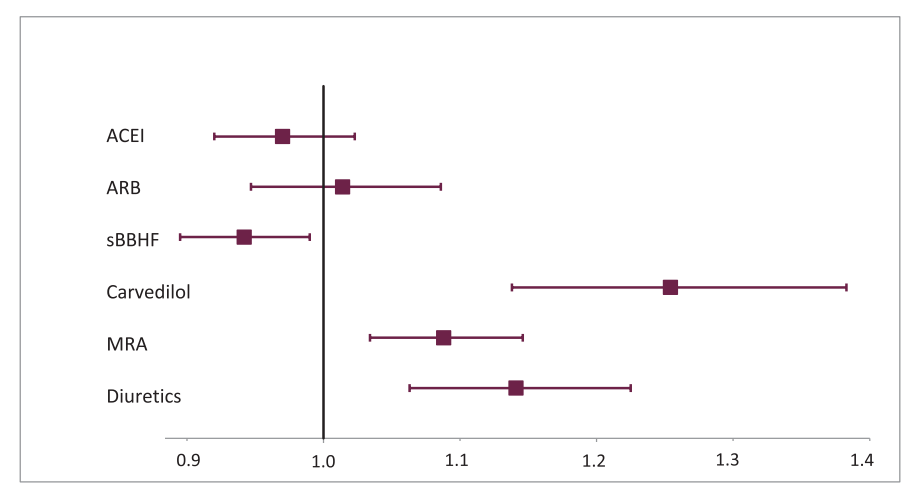

*HR versus non-use adjusted for age, gender, number of drugs (excl particular medication), year of admission, propensity score of particular medication (based on baseline covariates and co-medication); ACEl: angiotensin-converting enzyme inhibitor; ARB: angiotensin receptor blocker; sBBHF: selective beta1receptor blocker with a market authorisation for heart failure; MRA: mineralocorticoid-receptor antagonist

After adjustment for age, gender, number of medications, year of admission and the propensity score, all HRs reduced to some extent. The HRadj for ACEI and ARB were respectively $0.97(95 \% \mathrm{Cl} 0.92-1.02)$ and $1.01(95 \% \mathrm{Cl} 0.95-1.09)$. The HRadj of carvedilol (1.25; $95 \% \mathrm{Cl} 1.14-1.38), \mathrm{MRA}(1.09 ; 95 \% \mathrm{Cl} 1.03-1.15)$ and diuretics $(1.14 ; 95 \% \mathrm{Cl} 1.06-1.23)$ were increased. The results for SBBHF deviate from the other HF medications, as the percentage of patients readmitted to hospital is decreased for sBBHF users and the HR even lower in the adjusted analysis $(0.94 ; 95 \% \mathrm{Cl} 0.90-0.99)$. The analyses using propensity score trimming showed similar results (data not shown). 
As carvedilol and sBBHF are to some extent interchangeable, the probability of being prescribed carvedilol, the propensity score of carvedilol, was introduced into the Cox model of sBBHF. This modified Cox model for sBBHF was meant to give an impression of the readmission risk of a sBBHF prescribed to a patient with a certain probability of being prescribed carvedilol. When carvedilol is prescribed to a patient after adjustment for the propensity score of carvedilol, the HRadj is 1.25 , as mentioned above. However, in the modified Cox model for sBBHF with the propensity score for carvedilol in the sBBHF model, the risk is not increased ( $\mathrm{HR} 0.98 ; 95 \% \mathrm{Cl} 0.93-1.03)$. Vice versa, for a patient with a certain probability of being prescribed a sBBHF (estimated by the propensity score of SBBHF), the prescription of a sBBHF, is associated with a lower rate of readmission (HRadj 0.94), as mentioned above. At the same time, for this patient with a certain probability of being prescribed sBBHF, the use of carvedilol in the modified Cox model for carvedilol, results in a HRadj of 1.33 (95\%Cl 1.21-1.46).

The same method was used for ACEI versus ARB. Given a certain probability of being prescribed an ACEI (as estimated by the propensity score of ACEI), the prescription of an ACEI results in a HRadj of 0.97 , as mentioned above, while the prescription of an ARB to this patient with an ACEI-profile, was associated with an increased risk of readmission (HRadj 1.39; 95\%Cl 1.23-1.58). Vice versa, based on the ARB-profile, as estimated by the propensity score of ARB, the actual prescription of an ARB resulted in a HRadj of 1.01 (see above), while the prescription of an ACEl to this patient resulted in a HRadj of 1.21 (95\% Cl 1.09-1.33).

\section{Discussion}

In this large observational cohort study, we clearly observed a reduced risk of HF readmission if prescribed a BB. However, carvedilol, a non-selective BB, showed to have an increased risk of readmission, even after adjusting for confounding by indication. Similarly, MRA and diuretics increased risk, which ranged from a 1.14 to 1.30-fold. The evidence for a reduced hospital admission rate while using one of the four main groups of HF medication, is based upon clinical trials including relative healthy patients. In our real-world, large, unselected group of HF patients being discharged from hospital, not all these results could be reproduced.

The most probable explanation is the large number of comorbidities in our patients inherent to the real-world scenario, demonstrated for example by the large number of medications (7.6) per HF patient prescribed at hospital discharge. In trials, on which the guidelines are based, mostly relatively uncomplicated, selected patients are included. In practice, each HF patient has on average three to four comorbidities. ${ }^{17}$ As we have cardiovascular as well as non-cardiovascular medication, we were able to combine all this information to determine the risk of each HF medication. After adjusting for comorbidities by proxy approach, the risk of readmission decreased to only a limited extent. 


\section{Beta-blockers}

We found that sBBHF decreased the risk of readmission, after adjusting for propensity scores. In contrast, the use of carvedilol was associated with an (adjusted) 1.25-fold increased risk of HF readmission.

The only randomized clinical trial comparing two beta-blockers is the COMET trial, comparing metoprolol and carvedilol. ${ }^{18}$ The authors suggested that the non-selective BB carvedilol extends survival compared with the selective BB metoprolol. However, the supposedly added effect of $\beta 2$-blockade has caused discussion. ${ }^{19}$ In the editorial accompanying the COMET-trial ${ }^{20}$ three reasons contradicted these findings. First, the fact that the negative effect of BB on the myocardium is solely caused by $\beta 1$-blockade. Secondly, it was pointed out that molecular effects of carvedilol and metoprolol are similar when equipotent doses are used. Two retrospective studies support this statement on equipotency and showed no benefit for carvedilol on the point of readmissions and mortality. ${ }^{21,22}$ In 2013 in a meta-analysis of 21 randomized trials no differences between selective and non-selective BB were observed. ${ }^{23}$ Recently, the role of $\beta$-selectivity was once again not found to be relevant in 5242 patients with multiple exclusion criteria. ${ }^{24}$ Third, the fact that there were no supportive outcome data from large clinical trials in heart failure for benefit of a1-blockade. ${ }^{20}$ Moreover, the ALLHAT-study ${ }^{25}$ showed that a-receptor blockers had a $25 \%$ increased risk of combined cardiovascular disease events, including twice the risk of developing congestive heart failure. This negative effect of a1-blockade might be a plausible explanation for the increased risk of readmission we found for carvedilol.

Carvedilol is presumably more often prescribed to patients with more severe HF, because of the placebo-controlled COPERNICUS-study ${ }^{26}$ in which patients with moderate to severe HFrEF were included. This study was the major clinical trial for market authorisation of carvedilol. We attempted to adjust for this confounding by indication with the propensity score, which still resulted in an increased risk of readmission. Thereafter, the carvedilolprofile, the probability of being prescribed carvedilol, was introduced into the Cox model of $\mathrm{sBBHF}$, which did not increase the risk. For a patient with a certain probability of being prescribed a sBBHF, the prescription of carvedilol results in an increased HRadj. Based on our real-world results, all patients, irrespective of their probability of being prescribed carvedilol or SBBHF, i.e. irrespective of their comorbidities, are at lower risk of readmission if they use a sBBHF compared with carvedilol. However, there might be subgroups of patients, for whom carvedilol is a more appropriate BB.

\section{Angiotensin-converting-enzyme inhibitors and angiotensin-receptor blockers}

According to the 2016 ESC guideline, ARB have not been consistently proven to reduce mortality in patients with HFrEF and their use should be restricted to patients intolerant of an ACEl or those who take an ACEl but are unable to tolerate an MRA. ${ }^{1}$ In our study, 
after adjusting for propensity scores, $A C E I$ and $A R B$ do not increase risk. If the probability of being prescribed an $A C E l$, was introduced into the Cox model of $A R B$, the prescription of ARB resulted in a 1.39-fold increased risk. ACEl are therefore, more favourable for patients with the ACEI-profile, based on the probability being prescribed an ACEI. Vice versa, based on the ARB-profile, the actual prescription of an ARB did not result in an increased risk, while the prescription of an ACEI to this patient with a certain probability for being prescribed an ARB, resulted in a 1.21-fold increased risk. From our results one could conclude that the choice for ACEI or ARB seems to match the respective patient profiles. This statement is supported by the fact that $27 \%$ of the patients on ACEI or ARB, is prescribed an ARB. ACEI induced cough is reported in up to $20 \%$ of the patients and angioedema in $<1 \% .{ }^{14}$ In the CHARM-Alternative trial, patients intolerant to ACEI were able to tolerate an ARB. ${ }^{27}$

\section{Mineralocorticoid-receptor antagonists and diuretics}

The fact that MRA had a 1.09-fold increased risk of readmission in our study is not in line with other studies, like the EMPHASIS-HF, where a $42 \%$ reduction in HF admission rate compared to placebo was reported..$^{28}$ For diuretics the increased risk was 1.14-fold, which could be explained by residual confounding. Diuretics are recommended to reduce the symptoms of congestion. In the sickest patients these might not be able to suppress congestion, leading to HF readmission. It is disputed whether diuretics are disease severity markers or true risk factors. ${ }^{29}$

\section{Strengths and limitations}

A major strength of our study is the number of patients and the fact that not only the cardiovascular medication is available, but non-cardiovascular medication as well, which we used as a proxy for comorbidities. As the population of HF patients ages and the number of comorbidities increases, results of carefully designed clinical trials become more and more difficult to translate to daily clinical practise. The high prevalence of comorbidities in a real-world scenario is illustrated in a large Danish cohort including 317,161 patients, between 2008 and 2012. ${ }^{30}$ The percentage of patients with moderate, severe, and very severe co-morbidities was $21 \%, 16 \%$, and $16 \%$, respectively, categorised according to the Charlson Comorbidity Index.

One may expect confounding by indication, because prescription or withholding of $\mathrm{HF}$ medication at discharge is not done at random as in a clinical trial. The prescription of particular medication can result in a higher probability of readmission, but this can also be because patients that have a higher probability of readmission, due to more severity or comorbidities are prescribed this specific medication. ${ }^{16}$ This phenomenon is called confounding by indication or confounding by severity. Therefore, we used propensity scores analyses. Although we did try to adjust for confounding by indication by using 
propensity scores, probably residual confounding is still present, especially as we calculated propensity scores using logistic regression analyses based on limited information of the patient and no information on HF aetiology, comorbidities, left ventricular function, e.g. HF with preserved (HFpEF) or mid-range (HFmrEF) left ventricular ejection fraction or HFrEF, or functional class (NYHA). To obtain a measure of the quality of the propensity scores, the AUC was calculated. As illustrated by the AUC (mean 0.74), we seem to have been acceptable successful in constructing these propensity scores for ACEI, ARB, carvedilol and diuretics. The AUC for sBBHF and MRA were, however, somewhat disappointing. The adjustment with propensity scores might therefore not have been adequate enough.

Finally, the use of the investigated groups of HF medication is evidence-based for HFrEF, not for HFpEF or HFmrEF. ${ }^{1}$ Although this exact HF classification of the patients in our cohort is unknown, according to the 2016 ESC guideline, only slightly fewer patients with HFpEF and $\mathrm{HFmrEF}$ receive $\mathrm{ACEI} / \mathrm{ARB}, \mathrm{BB}, \mathrm{MRA}$ and diuretics. ${ }^{1}$

\section{Conclusion}

We have investigated the association between HF medication and readmission for HF in daily clinical practise in a group of patients being discharged from hospital after a first admission for HF. Use of carvedilol, MRA and diuretics was associated with an increased risk of HF readmission. Only the prescription of sBBHF resulted in a decreased risk of readmission. Based on our results, sBBHF should be preferred to the non-selective BB carvedilol. The choice for ACEI or ARB seems to match the respective patient profiles. Further investigations are necessary to confirm our results.

\section{Acknowledgement}

The authors would like to thank all healthcare providers contributing information to the PHARMO Database Network. 
1. Ponikowski $P$, Voors $A A$, Anker SD, Bueno H, Cleland JG, Coats AJ, et al. 2016 ESC Guidelines for the diagnosis and treatment of acute and chronic heart failure: the task force for the diagnosis and treatment of acute and chronic heart failure of the European Society of Cardiology (ESC). Developed with the special contribution of the Heart Failure Association (HFA) of the ESC. Eur J Heart Fail 2016;18:891-975.

2. Goldgrab D, Balakumaran K, Kim MJ, Tabtabai SR. Updates in heart failure 30day readmission prevention. Heart Fail Rev;doi:10.1007/s10741-018-9754-4. Published online ahead of print 28 November 2018.

3. Crespo-Leiro MG, Anker SD, Maggioni AP, Coats AJ, Filippatos G, Ruschitzka F, et al. European Society of Cardiology heart failure long-term registry (ESC-HF-LT): 1-year followup outcomes and differences across regions. Eur J Heart Fail 2016;18:613-625.

4. Eschalier R, Chenaf C, Mulliez A, Yalioua A, Clerfond G, Authier N, et al. Impact of clinical characteristics and management on the prognosis of unselected heart failure patients. Cardiovasc Drugs Ther 2015;29:89-98.

5. Gilstrap LG, Fonarow GC, Desai AS, Liang L, Matsouaka R, DeVore AD, et al. Initiation, continuation, or withdrawal of angiotensinconverting enzyme inhibitors/angiotensin receptor blockers and outcomes in patients hospitalized with heart failure with reduced ejection fraction. J Am Heart Assoc 2017;6:e004675.

6. Remme WJ, Swedberg K. Guidelines for the diagnosis and treatment of chronic heart failure. Eur Heart J 2001;22:1527-1560.

7. Kruik-Kollöffel WJ, Linssen GCM, Kruik HJ, Movig KLL, Heintjes EM, van der Palen J. Effects of European Society of Cardiology guidelines on medication profiles after hospitalization for heart failure in 22,476 Dutch patients: from 2001 till 2015. Accepted for publication in Heart Fail Rev.

8. Desai AS, Stevenson LW. Rehospitalization for heart failure: predict or prevent? Circulation 2012;126:501-506.

9. Solomon SD, Dobson J, Pocock S, Skali H, McMurray JJ, Granger CB, et al. Influence of nonfatal hospitalization for heart failure on subsequent mortality in patients with chronic heart failure. Circulation 2007;116:1482-1487.

10. Chun S, Tu JV, Wijeysundera HC, Austin PC, Wang $X$, Levy D, et al. Lifetime analysis of hospitalizations and survival of patients newly admitted with heart failure. Circ Heart Fail 2012;5:414-421.

11. PHARMO Database Network. https://www. pharmo.nl/what-we-have/pharmo-databasenetwork/. Accessed 25 January 2019.

12. van Herk-Sukel MP, van de Poll-Franse LV, Lemmens VE, Vreugdenhil G, Pruijt JF, Coebergh JW, et al. New opportunities for drug outcomes research in cancer patients: the linkage of the Eindhoven Cancer Registry and the PHARMO Record Linkage System. Eur J Cancer 2010;46:395-404.

13. WHO ATC/DDD Index. https://www.whocc.no/ atc_ddd_index/. Accessed 25 January 2019.

14. Yancy CW, Jessup M, Bozkurt B, Butler J, Casey DE Jr., Colvin MM, et al. 2017 ACC/AHA/ HFSA Focused update of the 2013 ACCF/ AHA guideline for the management of heart failure: a report of the American College of Cardiology/American Heart Association task force on clinical practice guidelines and the Heart Failure Society of America. J Am Coll Cardiol 2017;70:776-803.

15. Yancy CW, Jessup M, Bozkurt B, Butler J, Casey DE Jr., Drazner MH, et al. 2013 ACCF/ AHA guideline for the management of heart failure: a report of the American College of Cardiology Foundation/American Heart Association task force on practice guidelines. J Am Coll Cardiol 2013;62:e147-e239.

16. Austin PC. An introduction to propensity score methods for reducing the effects of confounding in observational studies. Multivariate Behav Res 2011;46:399-424.

17. Wolsk E. Heart failure and co-morbidity revisited; the elephant in the room. Eur J Heart Fail 2018;20:1267-1268.

18. Poole-Wilson PA, Swedberg K, Cleland JG, Di LA, Hanrath P, Komajda M, et al. Comparison of carvedilol and metoprolol on clinical outcomes in patients with chronic heart failure in the carvedilol or metoprolol European trial (COMET): randomised controlled trial. Lancet 2003;362:7-13. 
19. Bristow MR, Feldman AM, Adams KF Jr., Goldstein S. Selective versus nonselective beta-blockade for heart failure therapy: are there lessons to be learned from the COMET trial? J Card Fail 2003;9:444-453.

20. Dargie HJ. Beta blockers in heart failure. Lancet 2003;362:2-3.

21. Go AS, Yang J, Gurwitz JH, Hsu J, Lane $\mathrm{K}$, Platt R. Comparative effectiveness of beta-adrenergic antagonists (atenolol, metoprolol tartrate, carvedilol) on the risk of rehospitalization in adults with heart failure. Am J Cardiol 2007;100:690-696.

22. Pasternak B, Svanstrom H, Melbye M, Hviid A. Association of treatment with carvedilol vs metoprolol succinate and mortality in patients with heart failure. JAMA Intern Med 2014;174:1597-1604.

23. Chatterjee $S$, Biondi-Zoccai G, Abbate A, D'Ascenzo F, Castagno D, van Tassell B, et al. Benefits of beta blockers in patients with heart failure and reduced ejection fraction: network meta-analysis. BMJ 2013;346:f55.

24. Paolillo S, Mapelli M, Bonomi A, Corra U, Piepoli M, Veglia F, et al. Prognostic role of beta-blocker selectivity and dosage regimens in heart failure patients. Insights from the MECKI score database. Eur J Heart Fail 2017;19:904-914.

25. Major cardiovascular events in hypertensive patients randomized to doxazosin vs chlorthalidone: the antihypertensive and lipid-lowering treatment to prevent heart attack trial (ALLHAT). ALLHAT Collaborative Research Group. JAMA 2000;283:1967-1975.

26. Packer M, Fowler MB, Roecker EB, Coats AJ, Katus HA, Krum H, et al. Effect of carvedilol on the morbidity of patients with severe chronic heart failure: results of the carvedilol prospective randomized cumulative survival (COPERNICUS) study. Circulation 2002;106:2194-2199.

27. Granger CB, McMurray JJ, Yusuf S, Held P, Michelson EL, Olofsson B, et al. Effects of candesartan in patients with chronic heart failure and reduced left-ventricular systolic function intolerant to angiotensin-convertingenzyme inhibitors: the CHARM-Alternative trial. Lancet 2003;362:772-776.

28. Zannad F, McMurray JJ, Krum H, van Veldhuisen DJ, Swedberg K, Shi H, Vincent J,
Pocock SJ, Pitt B. Eplerenone in patients with systolic heart failure and mild symptoms. $\mathrm{N}$ Engl J Med 2011;364:11-21.

29. Kapelios CJ, Malliaras K, Kaldara E, Vakrou S, Nanas JN. Loop diuretics for chronic heart failure: a foe in disguise of a friend? Eur Heart $J$ Cardiovasc Pharmacother 2018;4:54-63.

30. Schmidt M, Ulrichsen SP, Pedersen L, Botker $\mathrm{HE}$, Sorensen HT. Thirty-year trends in heart failure hospitalization and mortality rates and the prognostic impact of co-morbidity: a Danish nationwide cohort study. Eur J Heart Fail 2016;18:490-499. 



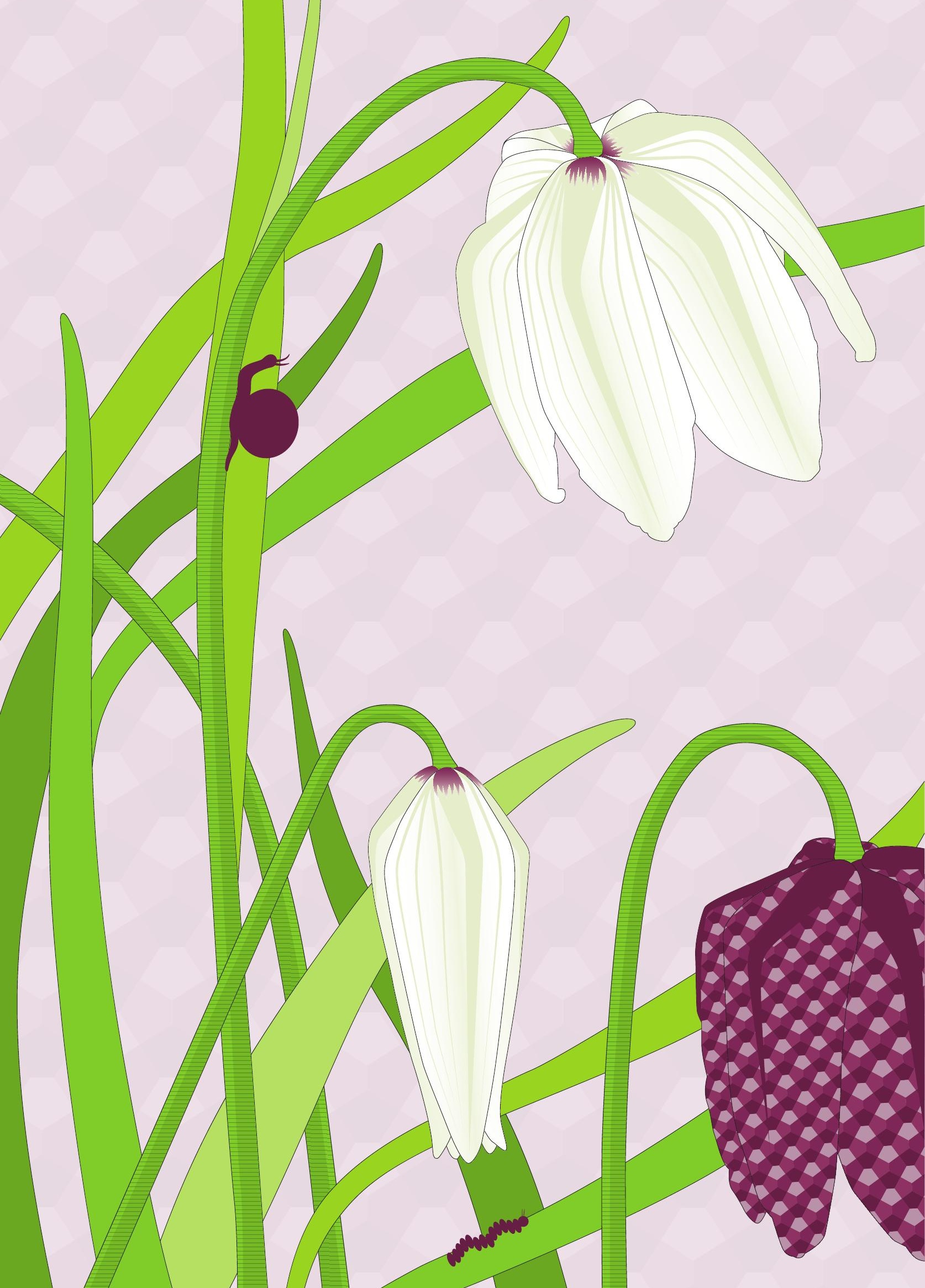




\section{Chapter 6}

Association between cardiovascular medication and readmission in heart failure patients

Willemien J. Kruik-Kollöffel Gerard C.M. Linssen

H. Joost Kruik Edith M. Heintjes

Kris L.L. Movig Carine J.M. Doggen Job van der Palen

Submitted 


\section{Abstract}

Aims

Patients discharged after an admission for heart failure (HF) have a high risk of HF readmission. The aim of this population-based cohort study was to compare hospital readmission rates of HF patients using additional HF medication and/or non-HF cardiovascular (CV) medication versus patients not using the particular additional HF medication and/or nonHF CV medication in a real-world scenario.

\section{Methods and results}

Medication at hospital discharge was determined on the basis of dispensing data from the Dutch PHARMO Database Network including 22,476 patients with a diagnosis of HF between 2001 and 2015. Median follow-up was 29.3 months. Thirty percent of patients were readmitted for HF. Propensity scores were calculated as a proxy for comorbidities and hazard ratios were adjusted (HRadj) accordingly. The prescription of digoxin was associated with a decreased readmission risk (HRadj 0.93; 95\% Cl 0.87-0.99), as well as aspirin monotherapy (HRadj 0.90; 95\% Cl 0.85-0.95), whereas P2Y12 inhibitor monotherapy with an increased risk (HRadj 1.26; 95\%Cl 1.07-1.49). The risks of readmission for statins, nitrates and amiodarone were all significantly increased, with HRadj between 1.18 and 1.31.

\section{Conclusion}

Use of digoxin, added in selected HF patients on top of core HF medication according to the guidelines, was associated with a lower risk of HF readmission. In view of the lower risk of HF readmission, aspirin monotherapy should be preferred to P2Y12 inhibitor monotherapy, which depends on the indication of the prescription. The risk of readmission for patients on statins, nitrates and amiodarone is increased, compared to patients not prescribed these drugs. 


\section{Introduction}

Medical therapy, especially for heart failure (HF) with reduced ejection fraction (HFrEF), nowadays consists of angiotensin-converting-enzyme inhibitors or angiotensin-receptor blockers, beta-blockers, mineralocorticoid-receptor antagonists and diuretics, forming the core HF medication. ${ }^{1}$ Angiotensin-converting-enzyme inhibitors or angiotensin-receptor blockers and beta-blockers should be started as early as possible. Mineralocorticoid-receptor antagonists are indicated in symptomatic patients with HFrEF New York Heart Association class II-IV. The addition of diuretics to these disease-modifying agents is indispensable for most HF patients to reduce congestion.

Furthermore, in specific groups of patients additional HF medication is recommended according to the European Society of Cardiology (ESC) guideline ${ }^{1}$ : an angiotensin receptor neprilysin inhibitor, ivabradine, digoxin, or the combination of hydralazine and isosorbide dinitrate. Notably, cardiovascular comorbidities are common in HF and other (non-HF) cardiovascular medication, e.g. antiarrhythmic agents, antithrombotic agents and calciumchannel blockers, is necessary, which can interfere with optimal HF medical therapy resulting in adverse side-effects, or even HF exacerbation. To illustrate, in 323 episodes of worsening of chronic HF, $15 \%$ of the patients used antiarrhythmic agents in the past 48 hours, and $13 \%$ of those used calcium-channel blockers. ${ }^{2}$

The objective of our study was to investigate, in a large observational cohort, using data from 2001 through 2015, the association between hospital readmission rates after a first HF admission of patients using additional HF medication and/or non-HF cardiovascular medication versus patients not using this particular additional HF medication and/or nonHF cardiovascular medication.

\section{Methods}

\section{Patient population}

In a cohort of 22,476 patients the association between additional HF and non-HF cardiovascular medication at discharge after a first hospital admission for HF between January 1, 2001 and December 31, 2015 and readmission rate was analysed. All data were extracted from the PHARMO Database Network, a population-based, medical record linkage system covering more than four million Dutch inhabitants. ${ }^{3}$ Its linkage algorithms have been validated and the Database Network forms a representative sample of the Dutch population. ${ }^{4,5}$ Patients with a first discharge diagnosis of HF (ICD-9 428; ICD-10 I50) or hypertensive heart disease with (congestive) HF (ICD-9 402; ICD-10 I11.0) were included. Data on both cardiovascular and non-cardiovascular medication were collected, which provides proxy information about comorbidities, as well as age at time of first hospital admission, gender and the year of admission and time to readmission or end of follow-up. Last date of follow-up for readmissions 1 January 2015, for medication 1 September 2016. More details were previously reported. ${ }^{6}$ 


\section{Medication}

Dispensing data were used as a proxy variable for usage of medication. Medication dispenses from primary and secondary care prescriptions, dispensed by out-patient pharmacies, were included. Drug dispenses are coded according to the WHO Anatomical Therapeutic Chemical (ATC) Classification System. ${ }^{7}$ The following ATC groups were investigated: cardiac therapy (C01); other hypertensives (C02); calcium-channel blockers (C08); lipid modifying agents (C10), and antithrombotic agents (B01). The medication was split into two groups.

A) Additional HF medication, prescribed on top of or instead of core HF medication. ${ }^{1}$ Additional HF medications were ivabradine (C01EB17), digoxin (C01AA05), or the combination of hydralazine and isosorbide dinitrate (C02DB02 and C01DA08). The angiotensin receptor neprilysin inhibitor was introduced in the Netherlands in 2016.

B) Non-HF cardiovascular medication, which included antithrombotic agents (B01) and miscellaneous cardiovascular medication. Data were combined if therapeutic and pharmacological properties were comparable into: statins, dihydropyridines, heparins, non-vitamin $\mathrm{K}$ antagonists oral anticoagulants (NOAC), vitamin $\mathrm{K}$ antagonists and $\mathrm{P} 2 \mathrm{Y} 12$ inhibitors. For aspirin monotherapy patients using aspirin without vitamin Kantagonist or P2Y12 inhibitors were included, disregarding the use or non-use of dipyridamole. For vitamin $\mathrm{K}$ antagonist monotherapy patients using vitamin $\mathrm{K}$ antagonist without aspirin or P2Y12 inhibitors were included. Patients prescribed a P2Y12 inhibitor without vitamin $\mathrm{K}$ antagonist or aspirin were considered as using P2Y12 inhibitor monotherapy. Patients categorised as using dual antiplatelet therapy (DAPT), were prescribed aspirin and a P2Y12 inhibitor. Patients using combinations with vitamin $\mathrm{K}$ antagonist and aspirin and/or P2Y12 inhibitors were considered as a separate group.

\section{Data processing and statistical analysis}

Characteristics of the study cohort are presented as means (SD) or medians (interquartile range) for continuous variables and frequencies (\%) for categorical variables. Differences in continuous variables between patients who were readmitted to the hospital or not were compared using the $t$-test for independent samples. Between-group differences in categorical variables were compared using the Chi-square test. In the descriptive analyses medication was described if used by at least 200 patients, or 40 patients and a $P$-value of $\leq 0.25$ for the association with readmissions for HF. Time-to-first event was either time to readmission or end of follow-up. Hazard Ratio's (HR) with a $95 \%$ confidence interval $(95 \% \mathrm{Cl})$ were calculated. A $P$-value of $\leq 0.05$ was considered as statistically significant. Statistical analysis was performed using SPSS software version 24 (IBM SPSS Statistics, Armonk, New York, USA). 
To handle confounding by indication we adjusted the analyses by using propensity scores. ${ }^{8}$ The propensity score estimates the risk of a certain patient to be prescribed certain medication. The HR (see below) was adjusted (HRadj) for this propensity score. Propensity scores were calculated using logistic regression analyses that included the co-medication, as a proxy for comorbidities, and baseline characteristics, i.e. age, gender, total number of unique medications, and year of admission. The propensity score included the medication on identifying level, in general on second level ATC group, i.e. the therapeutic subgroup. Based on mode of action and therapeutic use, however, the third level ATC group, i.e. pharmacological subgroup, included medication used in diabetes A10, non-steroid antiinflammatory and antirheumatic products M01, psycholeptics N05, and psychoanaleptics N06. The area under the curve of the ROC-curve (AUC) was determined to estimate the extent to which the propensity scores were adequately estimated in a logistic regression analysis (online supplementary Table S1).

Multivariable Cox regression models calculating the HRadj of use versus non-use for each medication were constructed. The Cox models were adjusted for baseline characteristics and propensity scores to adjust for confounding by indication. ${ }^{8}$ The HRadj and $95 \% \mathrm{Cl}$ are all graphically displayed in a Forest-plot. Finally, as a sensitivity analysis, propensity trimming at the $5^{\text {th }}, 10^{\text {th }}$ and $20^{\text {th }}$ percentiles was performed to remove extreme propensity scores, i.e. patients with very high or very low probability of receiving specific medication. ${ }^{8}$

Results

Baseline characteristics of this population-based cohort, comprising 22,476 HF patients over a 15-year period, are presented in Table 1. The mean age was 76.8 years (SD 10.9 years), and $50.9 \%$ were women. The majority of patients were prescribed core HF medication: angiotensin-converting-enzyme inhibitors or angiotensin-receptor blockers (62.7\%), betablockers (59.6\%), mineralocorticoid-receptor antagonists (37.0\%) and diuretics (81.8\%). The mean number of medications prescribed at hospital discharge was 7.6 (SD 3.6), after a median stay of 6 days (interquartile range 3-11 days). Median follow-up time to end of follow-up or readmission was 29.3 months (interquartile range 7.4-69.7 months). Thirty percent of all patients were readmitted for HF.

Table 2 shows additional HF medication and non-HF cardiovascular medication and their association with readmissions for HF. Statins were prescribed the most frequent, in $38.4 \%$ of the patient. Digoxin, vitamin K antagonist monotherapy, aspirin monotherapy and nitrates were all used by $21.5 \%$ up to $28.6 \%$ of the patients. The readmission percentages for patients not prescribed these medications varied between $27.7 \%$ and $30.3 \%$. Table 3 shows the multivariable Cox regression models for the medications that were in univariate analyses significantly associated with readmission rate. HRadj vary between 0.68 and 1.64 (online supplementary Table S1). The HRadj are all graphically displayed in a Forest-plot (Figure 1). 
Table 1 Characteristics of the study cohort for 22,476 heart failure patients

\begin{tabular}{|ll|}
\hline Demographic characteristics & \\
\hline Number of patients & 22476 \\
Number of patients readmitted (\%) & $6713(29.9 \%)$ \\
Age: mean (years, SD) & $76.8(10.9)$ \\
Gender: female (\%) & $11449(50.9 \%)$ \\
Length of stay in days: median (interquartile range) & $6(3-11)$ \\
\hline Medication profile on discharge & $7.57(3.56)$ \\
\hline Number of medications: mean (SD) & $14096(62.7 \%)$ \\
ACEl/ARB (\%) & $13406(59.6 \%)$ \\
Beta-blocker (\%) & $8317(37.0 \%)$ \\
MRA (\%) & $18384(81.8 \%)$ \\
Diuretics excluding MRA (\%) & $9088(40.4 \%)$ \\
Beta-blocker + ACEI/ARB (\%) & $3850(17.1 \%)$ \\
\hline Beta-blocker + ACEI/ARB + MRA (\%) & \\
\hline
\end{tabular}

ACEI/ARB: angiotensin-converting enzyme inhibitor (ACEI) and/or angiotensin receptor blocker (ARB) MRA: mineralocorticoid-receptor antagonist

Figure 1 Hazard ratios* of heart failure readmission and cardiovascular medication

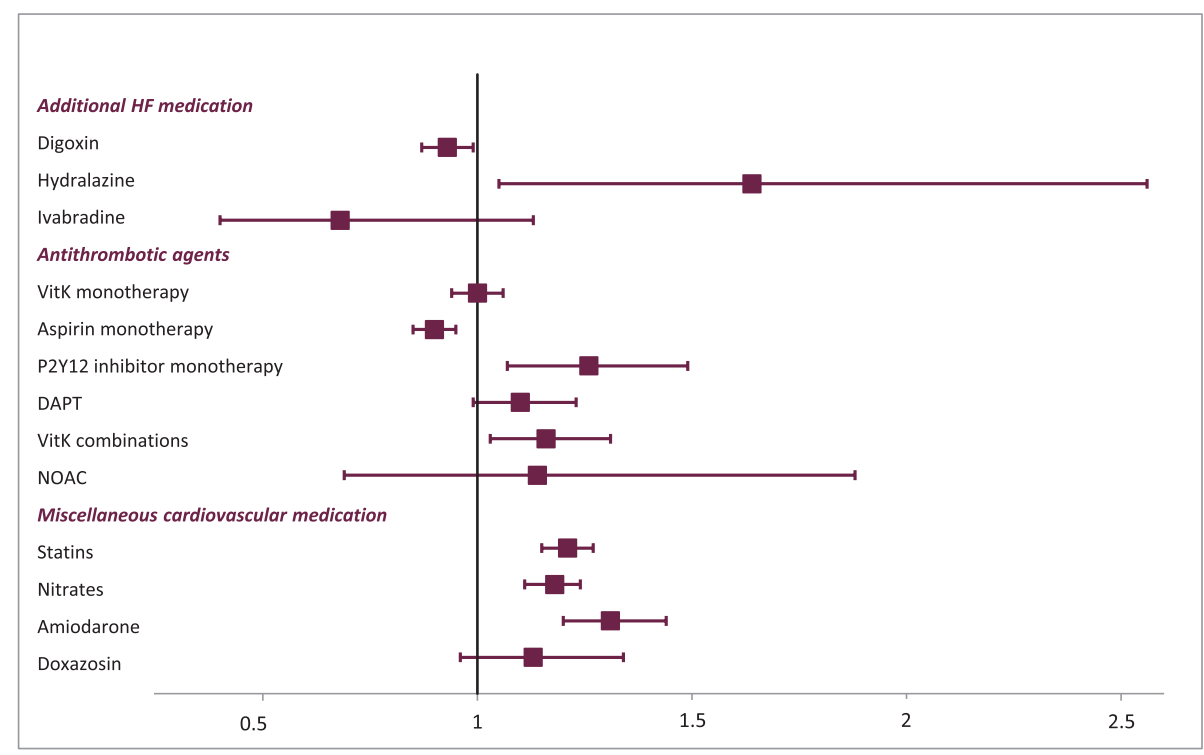

*HR versus non-use adjusted for age, gender, number of medications (excl particular medication), year of admission, propensity score of particular medication (based on baseline covariates and co-medication); DAPT: dual antiplatelet therapy (aspirin and P2Y12 inhibitor); VitK combinations: vitamin K antagonist and (aspirin and/or P2Y12 inhibitor); NOAC: non-vitamin K antagonist oral anticoagulant 
Table 2 Descriptive characteristics of heart failure readmission associated with cardiovascular medication

\begin{tabular}{|c|c|c|c|c|}
\hline Medication & $\begin{array}{l}\text { Number of } \\
\text { patients }(\%)\end{array}$ & $\begin{array}{l}\text { Number of patient } \\
\text { users }\end{array}$ & $\begin{array}{l}\text { s readmitted (\%) } \\
\text { non-users }\end{array}$ & $P$-value* \\
\hline \multicolumn{5}{|c|}{ Additional HF medication } \\
\hline Digoxin & 4826 (21.5\%) & $1378(28.6 \%)$ & 5335 (30.2\%) & 0.024 \\
\hline Hydralazine & $40(0.2 \%)$ & $20(50.0 \%)$ & $6693(29.8 \%)$ & 0.005 \\
\hline Ivabradine & $89(0.4 \%)$ & $15(16.9 \%)$ & $6698(29.9 \%)$ & 0.007 \\
\hline \multicolumn{5}{|l|}{ Antithrombotic agents } \\
\hline \multicolumn{5}{|l|}{ Monotherapy } \\
\hline Vitamin $\mathrm{K}$ antagonist & $6421(28.6 \%)$ & $2012(31.3 \%)$ & $4701(29.3 \%)$ & 0.002 \\
\hline Aspirin & $5941(26.4 \%)$ & $1702(28.6 \%)$ & $5011(30.3 \%)$ & 0.017 \\
\hline P2Y12 inhibitor & $410(1.8 \%)$ & $146(35.6 \%)$ & $6567(29.8 \%)$ & 0.010 \\
\hline \multicolumn{5}{|l|}{ Combination therapy } \\
\hline DAPT & $1096(4.9 \%)$ & $359(32.8 \%)$ & $6354(29.7 \%)$ & 0.032 \\
\hline VitK combinations & $825(3.7 \%)$ & $284(34.3 \%)$ & 6429 (29.7\%) & 0.004 \\
\hline \multicolumn{5}{|c|}{ Other antithrombotic agents } \\
\hline NOAC & $95(0.4 \%)$ & $17(17.9 \%)$ & $6696(29.9 \%)$ & 0.011 \\
\hline Heparin group & $209(0.9 \%)$ & $51(24.4 \%)$ & $6662(29.9 \%)$ & 0.083 \\
\hline Dipyridamole & $535(2.4 \%)$ & $148(27.7 \%)$ & $6565(29.9 \%)$ & 0.260 \\
\hline \multicolumn{5}{|c|}{ Miscellaneous cardiovascular medication } \\
\hline Statins & $8624(38.4 \%)$ & $2878(33.4 \%)$ & $3835(27.7 \%)$ & $P<0.001$ \\
\hline Ezetimibe & $249(1.1 \%)$ & $85(34.1 \%)$ & $6628(29.8 \%)$ & 0.139 \\
\hline Dihydropyridines & $2873(12.8 \%)$ & $891(31.0 \%)$ & $5822(29.7 \%)$ & 0.151 \\
\hline Verapamil & $805(3.6 \%)$ & $229(28.4 \%)$ & $6484(29.9 \%)$ & 0.370 \\
\hline Diltiazem & $567(2.5 \%)$ & $184(32.5 \%)$ & $6529(29.8 \%)$ & 0.173 \\
\hline Nitrates & $5873(26.1 \%)$ & $2031(34.6 \%)$ & $4682(28.2 \%)$ & $P<0.001$ \\
\hline Amiodarone & $1361(6.1 \%)$ & $546(40.1 \%)$ & $6167(29.2 \%)$ & $P<0.001$ \\
\hline Doxazosin & $418(1.9 \%)$ & 147 (32.5\%) & $6566(29.8 \%)$ & 0.017 \\
\hline
\end{tabular}

*P-value comparing users versus non-users of the specific medication based on Chi-square test; NOAC: non-vitamin K antagonist oral anticoagulant; DAPT: dual antiplatelet therapy (aspirin and P2Y12 inhibitor); VitK combinations: vitamin K antagonist and (aspirin and/or P2Y12 inhibitor) 
Table 3 Risk of readmission associated with cardiovascular medication

\begin{tabular}{|c|c|c|c|}
\hline Medication & $\begin{array}{l}\text { Number of } \\
\text { patients }(\%)\end{array}$ & $\begin{array}{l}\text { Unadjusted HR } \\
(95 \% \mathrm{CI})\end{array}$ & $\begin{array}{l}\text { Adjusted HR } \\
(95 \% \mathrm{Cl})^{*}\end{array}$ \\
\hline \multicolumn{4}{|l|}{ Additional HF medication } \\
\hline Digoxin & $4826(21.5 \%)$ & $0.93(0.88-0.99)$ & $0.93(0.87-0.99)$ \\
\hline Hydralazine & $40(0.2 \%)$ & $1.88(1.21-2.92)$ & $1.64(1.05-2.56)$ \\
\hline Ivabradine & $89(0.4 \%)$ & $0.68(0.41-1.13)$ & $0.68(0.40-1.13)$ \\
\hline \multicolumn{4}{|l|}{ Antithrombotic agents } \\
\hline Vitamin K antagonist monotherapy & $6421(28.6 \%)$ & $1.05(1.00-1.11)$ & $1.00(0.94-1.06)$ \\
\hline Aspirin monotherapy & $5941(26.4 \%)$ & $0.91(0.86-0.96)$ & $0.90(0.85-0.95)$ \\
\hline P2Y12 inhibitor monotherapy & $410(1.8 \%)$ & $1.35(1.14-1.59)$ & $1.26(1.07-1.49)$ \\
\hline DAPT & $1096(4.9 \%)$ & $1.17(1.05-1.30)$ & $1.10(0.99-1.23)$ \\
\hline VitK combinations & $825(3.7 \%)$ & $1.27(1.13-1.43)$ & $1.16(1.03-1.31)$ \\
\hline NOAC & $95(0.4 \%)$ & $0.85(0.53-1.38)$ & $1.14(0.69-1.88)$ \\
\hline \multicolumn{4}{|c|}{ Miscellaneous cardiovascular medication } \\
\hline Statins & $8624(38.4 \%)$ & $1.22(1.16-1.28)$ & $1.21(1.15-1.27)$ \\
\hline Nitrates & $5873(26.1 \%)$ & $1.30(1.23-1.37)$ & $1.18(1.11-1.24)$ \\
\hline Amiodarone & $1361(6.1 \%)$ & $1.44(1.32-1.57)$ & $1.31(1.20-1.44)$ \\
\hline Doxazosin & $418(1.9 \%)$ & $1.20(1.02-1.41)$ & $1.13(0.96-1.34)$ \\
\hline
\end{tabular}

DAPT: dual antiplatelet therapy (aspirin and P2Y12 inhibitor); VitK combinations: vitamin $\mathrm{K}$ antagonist and (aspirin and/or P2Y12 inhibitor); NOAC: non-vitamin K antagonist oral anticoagulant; HR: hazard ratio; ${ }^{*} \mathrm{HR}$ adjusted for age, gender, number of drugs (excl particular drug), year of admission, propensity score of particular medication (based on baseline covariates and co-medication)

\section{Additional HF medication}

In patients prescribed additional HF medication, compared to those that were not, the readmission rates were lower for digoxin (28.6\%) and particularly lower for ivabradine (16.9\%), see Table 2. In patients prescribed hydralazine the hazard rate for readmission was 1.9-fold increased compared to patients not prescribed hydralazine. Hydralazine and ivabradine are prescribed to few patients (40 and 89).

After adjusting for baseline characteristics and propensity score, based on baseline characteristics and co-medication to adjust for confounding by indication (Table 3), the use of digoxin was still associated with a lower risk of readmission (HRadj 0.93), as well as the risk for ivabradine although not significantly (HRadj 0.68). Patients on hydralazine still had an increased risk (HRadj 1.64).

The AUC was calculated to estimate the accuracy of the propensity score, i.e. how good the estimation of the risk of a certain patient to be prescribed a certain medication was. Estimates of the accuracy of the propensity score, the AUC, was 0.65 for digoxin, for hydralazine 0.87 , and for ivabradine 0.90 . 


\section{Antithrombotic agents}

In the category of antithrombotic agents, monotherapy with vitamin $\mathrm{K}$ antagonists or P2Y12 inhibitors as well as the use of combination therapy (DAPT and combinations with vitamin $\mathrm{K}$ antagonists), were all associated with an increased readmission rate above $31 \%$ (Table 2). Patients prescribed aspirin monotherapy and those on other antithrombotic agents (NOAC, heparin group and dipyridamole) had lower readmission rates compared to patients not using these medications, all beneath $29 \%$. Only vitamin K antagonist and aspirin monotherapy were prescribed to considerable percentage of patients ( $28.6 \%$ and $26.4 \%$ ), whereas the other antithrombotic agents were prescribed to less than $5 \%$.

Use of vitamin K antagonist monotherapy and DAPT (Table 3) was only associated with a higher risk of readmission in univariate analyses. However, the reduced risk of aspirin monotherapy and increased risk associated with the use of P2Y12 inhibitor monotherapy and vitamin $\mathrm{K}$ combinations remained in multivariable analyses. For NOACs the decreased risk disappeared.

AUC-values associated with the propensity scores for the various antithrombotic agents varied between 0.72 and 0.79 , except for the AUC for NOACs, which was 0.97 .

\section{Miscellaneous non-HF cardiovascular medication}

Statins, nitrates, amiodarone, and doxazosin were all associated with increased rates of readmission between $32.5 \%$ and $40.1 \%$ (Table 2). Calcium-channel blockers (dihydropyridines, verapamil and diltiazem) were not associated with increased readmission risks. The increased risk remained in the multivariable Cox model (Table 3 ) for statins, nitrates, and amiodarone. For doxazosin (418 patients) the hazard ratio appeared to be increased, although not significantly.

AUC-values varied between 0.72 and 0.76 , except for the AUC for amiodarone (1361 patients), which was 0.68 .

The analyses using propensity score trimming showed similar results, except for hydralazine, ivabradine and NOAC due to the low number of patients using this medication (data not shown).

\section{Discussion}

In our real-world, large, unselected group of patients the association between the use of additional HF medication and/or non-HF cardiovascular medication and HF readmission rates differs between medications. The use of digoxin and the use of aspirin monotherapy were associated with reduced readmission rates. The use of hydralazine, P2Y12 inhibitor monotherapy, combinations with vitamin $\mathrm{K}$ antagonist, statins, nitrates and amiodarone, respectively, were associated with increased readmission rates. The characteristics of our study cohort are comparable to other studies, which may imply that our results are representative for a typical HF population. ${ }^{6}$ 


\section{Additional HF medication}

About one fifth of the patients used digoxin. This is interesting because there is still controversy about this medication, which has market authorisation in the Netherlands since $1958 .^{9-11}$ In a retrospective analysis of 7788 patients in the DIG-trial' ${ }^{12}$, performed in the nineties, digoxin had the most positive effect on HF admission in patients with HFrEF, an intermediate effect in HF with mid-range ejection fraction (HFmrEF), and the smallest effect in HF with preserved ejection fraction (HFpEF). In 2015 a large-scale literature search ${ }^{13}$ was published, including studies from 1960 to July 2014 analysing treatment for HF or atrial fibrillation with digoxin compared with control (placebo or no treatment). In total 52 studies were systematically reviewed, comprising 621,845 patients. The main conclusion was that digoxin is not associated with mortality in randomised trials and a lower rate of hospital admissions across all study types. They also argue that treatment decisions should be based upon clinical trials instead of observational data, because it is not possible to adjust for prescription biases in observational data. In our study we attempted to adjust for confounding by indication and showed a limited, but potentially clinical significant lower rate in readmissions in patients prescribed digoxin. We might not have been able to adjust for confounding by indication fully, as the AUC associated with the probability of being prescribed digoxin was 0.65. The importance of digoxin however, as an addition in selected HF patients on top of core HF medication according to the therapeutic algorithm in the guidelines ${ }^{1,14,15}$, may be underestimated. Future clinical studies are needed to confirm this.

The combination of hydralazine and isosorbide dinitrate, and ivabradin were prescribed in few HF patients. Although, risks for readmission appear to be decreased, the related estimates should be considered inaccurate.

\section{Antithrombotic agents}

The use of antithrombotic agents in heart failure has been discussed for more than three decades. ${ }^{16-18}$ In the WATCH study ${ }^{19}$ in 1587 patients, with a follow-up of 16 months, fewer patients in the warfarin arm compared to the aspirin arm were admitted for HF $16.5 \%$ versus $22.2 \%$ ). However, when time to admission was considered, no differences were found. Also, for clopidogrel no differences were found compared to warfarin or aspirin. In a small study (580 patients) ${ }^{20}$ patients who received clopidogrel therapy had a lower rate of HF readmission than patients who did not receive clopidogrel therapy during 1 year of follow-up. Warfarin treatment did not have any effect on readmission during the first year in that study. Oral anticoagulants are not recommended in the guidelines ${ }^{1,15}$ other than in patients with atrial fibrillation. In a recent review ${ }^{21}$ this is confirmed, which is in line with our data.

The international guidelines ${ }^{1,15}$ state that there is no evidence on the benefits of antiplatelet medication (including aspirin) in patients with HF without accompanying coronary 
artery disease. However, we found a HRadj of hospital readmission for aspirin monotherapy of 0.90 , i.e. a decreased risk. Unfortunately we do not know whether patients on aspirin monotherapy in our study, $26.4 \%$ of the cohort, have coronary artery disease. The AUC of 0.79 associated with the probability of being prescribed aspirin monotherapy, makes it likely that we were able to adjust reasonably for confounding by indication.

In contrast to the decreased risk of aspirin, the increased risk of readmissions associated with P2Y12 inhibitor monotherapy (HRadj 1.26) is striking. P2Y12 inhibitors, especially clopidogrel, were in the Netherlands initially almost uniquely used in the post-treatment of acute coronary syndromes or post percutaneous coronary intervention-treatment, combined with aspirin and/or a vitamin K antagonist. Since 2011-2013 clopidogrel is increasingly replaced by ticagrelor and prasugrel for this indication because of higher effectivity. ${ }^{22}$ However, since 2013-2014 clopidogrel monotherapy is more often used instead of aspirin (with or without dipyridamole) as secondary prophylaxis for cerebrovascular incidents. From our data, aspirin monotherapy may be preferred to P2Y12 inhibitor monotherapy in order to lower the risk of HF readmissions in patients with HF, which depends on the indication of the prescription.

In our cohort, 1921 patients were prescribed DAPT (aspirin and P2Y12 inhibitor) or combinations with vitamin $\mathrm{K}$ antagonist (with aspirin and/or P2Y12 inhibitor). These patients had a considerably increased risk of HF readmission, although the HRadj for DAPT was not increased in the multivariable analysis. Ischaemic aetiology and atrial fibrillation adversely affect outcomes with regard to HF prognosis. ${ }^{23}$ Patients on vitamin $\mathrm{K}$ combinations or DAPT are usually still in the time-window for post-treatment with double or triple antithrombotic therapy after acute coronary syndrome or percutaneous coronary intervention. Deduced from our findings, the risk of HF readmission is especially increased in the period immediately following acute coronary syndromes or after percutaneous coronary intervention. So, these patients should be monitored closely.

\section{Miscellaneous cardiovascular medication}

According to the guidelines ${ }^{1,15}$ there is no evidence to support the initiation of statins in most patients with chronic HF. However, in patients who already receive a statin because of underlying coronary artery disease or hyperlipidaemia, this therapy should be continued. We observed a 1.2-fold increased risk of hospital readmission. Probably a considerable part of the users of statins in our cohort (8624 patients, 38.4\%) suffered from comorbidities that required the use of statins. Our results endorse the statement of the guidelines ${ }^{1,15}$ not to start a statin in HF patients without those comorbidities.

Less patients on verapamil were readmitted versus non-users. However, guidelines ${ }^{1,15}$ discourage the use of verapamil (and also diltiazem) in patients with $\mathrm{HFrEF}$, as this increases the risk of HF worsening and HF admission. This warrants further investigation. 
Nitrates are used by 5873 patients. As only 40 patients use hydralazine, by far the most of these 5873 patients are prescribed a nitrate because of angina or coronary artery disease. We found an almost 1.2-fold increased risk of readmission for nitrates. However, according to the ESC guideline', nitrates have been shown to be safe in HF. Recent findings of higher occurrence of ischemic events ${ }^{24}$ and decreased quality of life in HFpEF patients using isosorbide mononitrate versus placebo ${ }^{25}$ seem to be at odd with this guideline, and our results seem to support this.

The increased risk of readmission for amiodarone (HRadj 1.31) can be explained, as amiodarone is used in therapy-resistant arrhythmias, especially atrial fibrillation. According to the ESC guideline ${ }^{1}$ amiodarone should generally be avoided in patients with HFrEF and, although with less clinical evidence, in patients with HFpEF and HFmrEF, because of the high incidence of side-effects.

Doxazosin (418 patients) showed an increased risk of readmission, although this risk reduced somewhat and was no longer significant in the adjusted analysis. This increased HR matches the results of the ALLHAT-study ${ }^{26}$ that showed that a-receptor blockers, like doxazosin had a statistically significant $25 \%$ increase in the risk of combined cardiovascular disease events, including twice the risk of development of congestive heart failure, possibly caused by increasing plasma volume and plasma norepinephrine levels.

\section{Strengths and limitations}

A major strength of our study is the number of patients and the fact that not only the cardiovascular medication is available, but non-cardiovascular medications as well, which we used as a proxy for those often-recurring comorbidities.

One may expect confounding by indication, because prescription or withholding of medication at discharge is not done at random like in a clinical trial design. The prescription of a particular medication can result in a higher probability of readmission, but this can also be because patients that have a higher probability of readmission, due to more severity or comorbidities, are prescribed this specific medication. ${ }^{8}$ Although we did try to adjust for this phenomenon, called confounding by indication or confounding by severity, by using propensity scores, residual confounding may still be present. Especially as we calculated propensity scores using logistic regression analyses based on limited information on the patient and no information on HF etiology, comorbidities, left ventricular function, e.g. HFrEF or HFpEF or functional class (NYHA). To obtain a measure of the quality of the propensity scores, the AUC was calculated. As illustrated by a mean AUC of 0.79 , this approach was acceptable successful for most of the antithrombotic agents. The AUC associated with the propensity score for digoxin and amiodarone were moderate. The databases in the PHARMO Database Network contain no detailed information, in particular on the HF characteristics of the patient. Due to privacy legislation there was no option to 
retrieve this information. This information might have made our conclusions more robust.

Baseline characteristics of the study cohort, including the use of HF medication, are representative for a group of patients discharged after a first hospital admission. ${ }^{6}$ Because the patterns of comorbidities are similar in HFpEF and HFrEF, and despite the lack of information on the type of $\mathrm{HF}$, conclusions can be made. ${ }^{27}$ In fact, the aetiology of HFpEF is supposed to be more determined by comorbidities than in HFrEF and it is a strength therefore that information on the non-cardiovascular medications of the patients was available. As we focussed our study on readmissions for HF, we have no information on other causes for readmission, which would have been interesting to study as well.

\section{Conclusion}

We have investigated the association between additional HF medication and/or non-HF cardiovascular medication and readmission for $\mathrm{HF}$ in a real-world, large, unselected group of patients being discharged from hospital after a first HF admission. The position of digoxin in the category "other treatments with less certain benefits in symptomatic patients with HFrEF" in the guidelines may be an underestimation of its clinical importance. On account of the lower risk of HF readmission, aspirin monotherapy should perhaps be preferred to P2Y12 inhibitor monotherapy, which depends on the indication of the prescription. The risk of readmission for patients on statins, nitrates and amiodarone is increased, compared to patients not prescribed these medications.

\section{Supplementary Information}

Additional supporting information may be found online in the Supporting Information section at the end of this article.

Table S1. A complete table of AUCs and of HRadj with cardiovascular medication are shown in the supplementary Table S1.

\section{Acknowledgement}

The authors would like to thank all healthcare providers contributing information to the PHARMO Database Network. 


\section{References}

1. Ponikowski P, Voors AA, Anker SD, Bueno H, Cleland JG, Coats AJ, et al. 2016 ESC Guidelines for the diagnosis and treatment of acute and chronic heart failure: the task force for the diagnosis and treatment of acute and chronic heart failure of the European Society of Cardiology (ESC). Developed with the special contribution of the Heart Failure Association (HFA) of the ESC. Eur J Heart Fail 2016;18:891-975.

2. Tsuyuki RT, McKelvie RS, Arnold JM, Avezum A Jr., Barretto AC, Carvalho AC, et al. Acute precipitants of congestive heart failure exacerbations. Arch Intern Med 2001;161:2337-2342.

3. PHARMO Database Network. https://www. pharmo.nl/what-we-have/pharmo-databasenetwork/. Accessed 25 January 2019.

4. Herings RMC, Pedersen L. PharmacyBased Medical Record Linkage Systems. In: Pharmacoepidemiology. Wiley-Blackwell; 2012. p. 270-286.

5. van Herk-Sukel MP, van de Poll-Franse LV, Lemmens VE, Vreugdenhil G, Pruijt JF, Coebergh JW, et al. New opportunities for drug outcomes research in cancer patients: the linkage of the Eindhoven Cancer Registry and the PHARMO Record Linkage System. Eur J Cancer 2010;46:395-404.

6. Kruik-Kollöffel WJ, Linssen GCM, Kruik HJ, Movig KLL, Heintjes EM, van der Palen J. Effects of European Society of Cardiology guidelines on medication profiles after hospitalization for heart failure in 22,476 Dutch patients: from 2001 till 2015. Accepted for publication in Heart Fail Rev.

7. WHO ATC/DDD Index. https://www.whocc.no/ atc_ddd_index/. Accessed 25 January 2019.

8. Austin PC. An introduction to propensity score methods for reducing the effects of confounding in observational studies. Multivariate Behav Res 2011;46:399-424.

9. van Veldhuisen DJ, Rienstra M, van der Meer P. Value of digoxin in patients with heart failure: new pieces to the puzzle. Eur J Heart Fail 2018;20:1146-1147.

10. Upshaw JN, van KD, Konstam MA, Kent DM. Digoxin benefit varies by risk of heart failure hospitalization: applying the tufts MC HF risk model. Am J Med 2018;131:676-683.
11. Bavendiek U, Aguirre DL, Koch A, Bauersachs J. Assumption versus evidence: the case of digoxin in atrial fibrillation and heart failure. Eur Heart J 2017;38:2095-2099.

12. Abdul-Rahim AH, Shen $L$, Rush $C J$, Jhund PS, Lees KR, McMurray JJV. Effect of digoxin in patients with heart failure and mid-range (borderline) left ventricular ejection fraction. Eur J Heart Fail 2018;20:1139-1145.

13. Ziff OJ, Lane DA, Samra M, Griffith M, Kirchhof P, Lip GY, et al. Safety and efficacy of digoxin: systematic review and meta-analysis of observational and controlled trial data. BM 2015;351:h4451.

14. Cole GD, Francis DP. Trials are best, ignore the rest: safety and efficacy of digoxin. BMJ 2015;351:h4662.

15. Yancy CW, Jessup M, Bozkurt B, Butler J, Casey DE Jr., Drazner MH, et al. 2013 ACCF/ AHA guideline for the management of heart failure: a report of the American College of Cardiology Foundation/American Heart Association task force on practice guidelines. J Am Coll Cardiol 2013;62:e147-e239.

16. Homma S, Ye S. Stroke and anticoagulation in heart failure without atrial fibrillation: from risk to opportunity. Circulation 2015;131:14651467.

17. Prom R, Usedom JE, Dull RB. Antithrombotics in heart failure with reduced ejection fraction and normal sinus rhythm: an evidence appraisal. Ann Pharmacother 2014;48:226-237.

18. Yuan Z, Weinstein R, Zhang J, Cheng M, Griffin $\mathrm{G}$, Zolynas R, et al. Antithrombotic therapies in patients with heart failure: hypothesis formulation from a research database. Pharmacoepidemiol Drug Saf 2010;19:911920.

19. Massie BM, Collins JF, Ammon SE, Armstrong PW, Cleland JG, Ezekowitz M, et al. Randomized trial of warfarin, aspirin, and clopidogrel in patients with chronic heart failure: the warfarin and antiplatelet therapy in chronic heart failure (WATCH) trial. Circulation 2009;119:1616-1624.

20. Kozdag G, Yaymaci M, Ertas G, Celikyurt U, Sahin T, Kilic T, et al. Aspirin, clopidogrel, and warfarin use and outcomes in a cohort of 580 patients discharged after hospitalization for decompensated heart failure. Heart Vessels 2012;27:568-575. 
21. Siliste RN, Antohi EL, Pepoyan S, Nakou E, Vardas P. Anticoagulation in heart failure without atrial fibrillation: gaps and dilemmas in current clinical practice. Eur J Heart Fail 2018;20:978-988.

22. The Drug Information System of National Health Care Institute. https://www. gipdatabank.nl/. Accessed 25 January 2018.

23. Triposkiadis F, Giamouzis G, Parissis J, Starling $\mathrm{RC}$, Boudoulas $\mathrm{H}$, Skoularigis J, et al. Reframing the association and significance of comorbidities in heart failure. Eur J Heart Fail 2016;18:744-758.

24. Moreira-Silva S, Urbano J, Nogueira-Silva L, Bettencourt P, Pimenta J. Impact of chronic nitrate therapy in patients with ischemic heart failure. J Cardiovasc Pharmacol Ther 2016;21:466-470

25. Redfield MM, Anstrom KJ, Levine JA, Koepp $\mathrm{GA}$, Borlaug BA, Chen $\mathrm{HH}$, et al. Isosorbide mononitrate in heart failure with preserved ejection fraction. N Engl J Med 2015;373:23142324.

26. Major cardiovascular events in hypertensive patients randomized to doxazosin vs chlorthalidone: the antihypertensive and lipid-lowering treatment to prevent heart attack trial (ALLHAT). ALLHAT Collaborative Research Group. JAMA 2000;283:1967-1975.

27. Chamberlain AM, St Sauver JL, Gerber Y, Manemann SM, Boyd CM, Dunlay SM, et al. Multimorbidity in heart failure: a community perspective. Am J Med 2015;128:38-45. 


\section{Supplementary Information}

S1. Table S1 Risk of readmission associated with cardiovascular medication

\begin{tabular}{|c|c|c|c|}
\hline Medication & $\begin{array}{l}\text { Number of } \\
\text { patients }(\%)\end{array}$ & $\begin{array}{l}\text { Propensity } \\
\text { score AUC }\end{array}$ & $\begin{array}{l}\text { Adjusted HR } \\
(95 \% \mathrm{Cl})^{*}\end{array}$ \\
\hline \multicolumn{4}{|l|}{ Additional HF medication } \\
\hline Digoxin & $4826(21.5 \%)$ & 0.649 & $0.93(0.87-0.99)$ \\
\hline Hydralazine & $40(0.2 \%)$ & 0.871 & $1.64(1.05-2.56)$ \\
\hline Ivabradine & $89(0.4 \%)$ & 0.896 & $0.68(0.40-1.13)$ \\
\hline \multicolumn{4}{|l|}{ Antithrombotic agents } \\
\hline \multicolumn{4}{|l|}{ Monotherapy } \\
\hline Vitamin K antagonist monotherapy & $6421(28.6 \%)$ & 0.729 & $1.00(0.94-1.06)$ \\
\hline Aspirin monotherapy & $5941(26.4 \%)$ & 0.716 & $0.90(0.85-0.95)$ \\
\hline P2Y12 inhibitor monotherapy & $410(1.8 \%)$ & 0.787 & $1.26(1.07-1.49)$ \\
\hline \multicolumn{4}{|l|}{ Combination therapy } \\
\hline DAPT & $1096(4.9 \%)$ & 0.780 & $1.10(0.99-1.23)$ \\
\hline VitK combinations & $825(3.7 \%)$ & 0.751 & $1.16(1.03-1.31)$ \\
\hline \multicolumn{4}{|l|}{ Other antithrombotic agents } \\
\hline NOAC & $95(0.4 \%)$ & 0.972 & $1.14(0.69-1.88)$ \\
\hline Heparin group & 209 (0.9\%) & 0.772 & $0.95(0.72-1.25)$ \\
\hline Dipyridamole & $535(2.4 \%)$ & 0.799 & $1.01(0.86-1.20)$ \\
\hline \multicolumn{4}{|c|}{ Miscellaneous cardiovascular medication } \\
\hline Statins & $8624(38.4 \%)$ & 0.720 & $1.21(1.15-1.27)$ \\
\hline Ezetimibe & 249 (1.1\%) & 0.776 & $1.23(0.99-1.53)$ \\
\hline Dihydropyridines & $2873(12.8 \%)$ & 0.677 & $1.01(0.93-1.08)$ \\
\hline Verapamil & $805(3.6 \%)$ & 0.752 & $0.90(0.78-1.03)$ \\
\hline Diltiazem & $567(2.5 \%)$ & 0.786 & $1.00(0.86-1.16)$ \\
\hline Nitrates & $5873(26.1 \%)$ & 0.718 & $1.18(1.11-1.24)$ \\
\hline Amiodarone & $1361(6.1 \%)$ & 0.679 & $1.31(1.20-1.44)$ \\
\hline Doxazosin & 418 (1.9\%) & 0.757 & $1.13(0.96-1.34)$ \\
\hline
\end{tabular}

DAPT: dual antiplatelet therapy (aspirin and P2Y12 inhibitor); VitK combinations: vitamin K antagonist and (aspirin and/or P2Y12 inhibitor); NOAC: non-vitamin K antagonist oral anticoagulant; HR: hazard ratio; ${ }^{*} \mathrm{HR}$ adjusted for age, gender, number of drugs (excl particular drug), year of admission, propensity score of particular medication (based on baseline covariates and co-medication) 



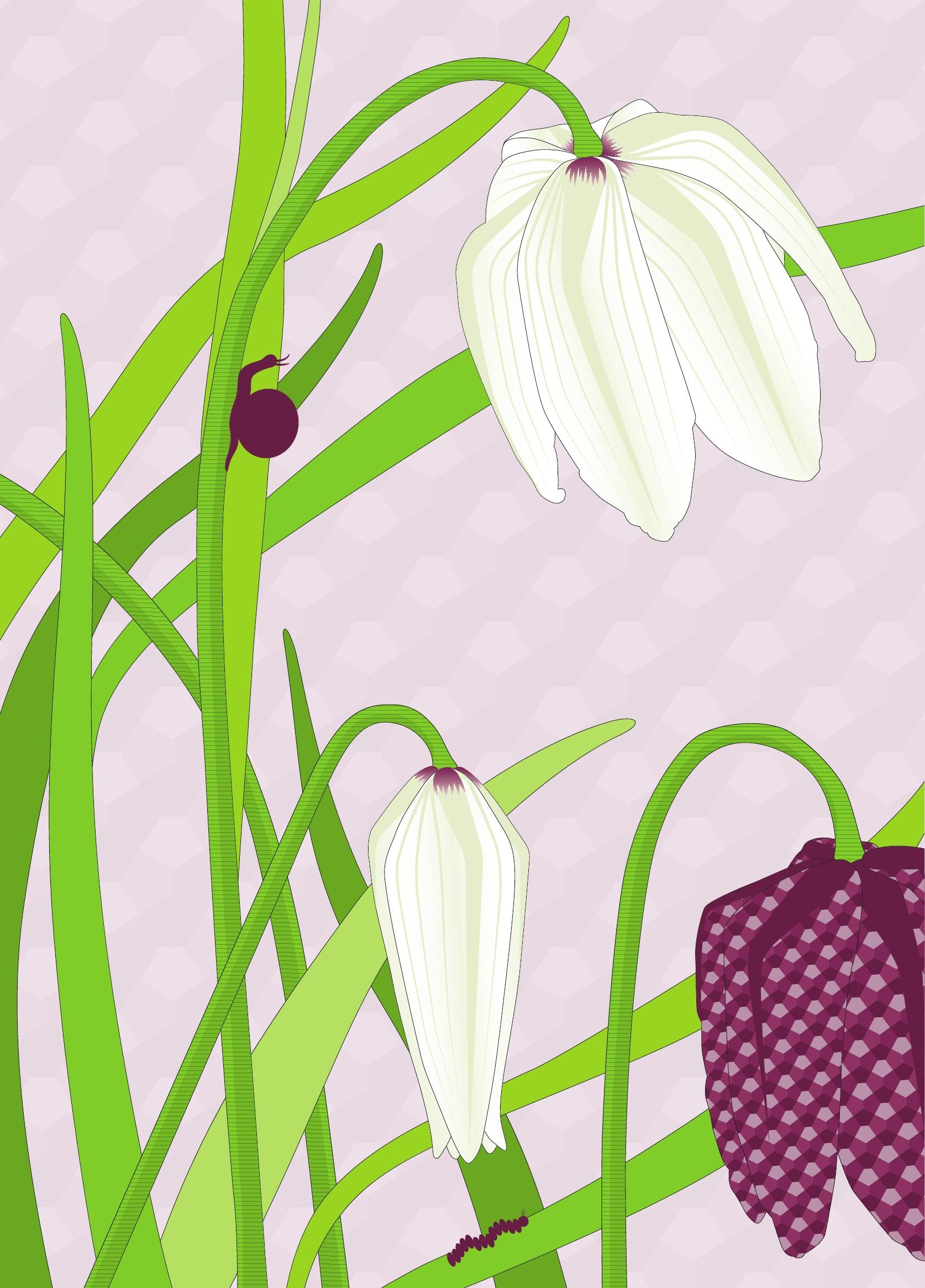




\section{Chapter 7}

Risk of readmission for heart failure associated with non-cardiovascular medication: an observational cohort study

Enriqueta Vallejo Yagüe* Willemien J. Kruik-Kollöffel*

Kris L.L. Movig Gerard C.M. Linssen Edith M. Heintjes Job van der Palen

*Both authors contributed equally

Submitted 


\section{Abstract}

\section{Objective}

This study aims to estimate the risk of readmission for heart failure (HF), associated with non-cardiovascular medication at hospital discharge from the index HF hospitalization.

\section{Study design and setting}

For this hypothesis generating study, data from 22,476 Dutch HF patients were randomly split into two data sets, one for model development and one for model validation. Medication at the index HF hospitalization was included in a multivariate Cox regression model to study the association between the treatment and the risk of readmission for HF.

\section{Results}

HF patients prescribed antigout preparations presented $25 \%$ increased risk of readmission. The use of insulin was associated with $18 \%$ higher risk of readmission versus non-exposed HF patients, but not versus HF patients with type 2 diabetes treated with other blood glucose lowering drugs. No association between the risk for readmission and NSAIDs was observed.

\section{Conclusion}

The pharmacotherapeutic treatment of comorbidities can influence the risk of readmission for HF. The results suggest the diabetes disease as responsible for the higher HF-readmission risk observed in patients prescribed insulin. The risk associated with antigout prescription, being either due to the condition intended to treat or to the medication, should be further investigated. 


\section{Introduction}

Although there have been improvements in prevention and treatment of heart failure $(\mathrm{HF})$, it is still a dramatically prevalent healthcare burden, and the high rate of hospital readmissions of patients remains a major concern. There are global efforts towards preventing $\mathrm{HF}$ and practice guidelines for management of the disease..$^{1-4}$ Special attention should be given to comorbidities, which are present in the majority of HF patients. Both the clinical characteristics and the pharmacological treatment of comorbidities may affect the HF therapy and the subsequent outcome. Comorbidities associated with worse outcome include e.g. hypertension, diabetes, obesity, hypothyroidism, chronic obstructive pulmonary disease, gout, arthritis, and anaemia. ${ }^{1,2,5,6}$

Several medical treatments of comorbidities are associated with higher cardiovascular risk and are not recommended in HF patients. For example, the use of thiazolidinediones and the use of non- steroid anti-inflammatory drugs (NSAIDs) may lead to an increased risk of HF hospitalization, and are therefore not recommended in HF patients. ${ }^{1}$ A specific question arises regarding the risk associated to non-cardiac medication or medication for comorbidities. However, not every medication has been studied in a real-world HF population. Thus, this study addressed the medication generally prescribed by physicians other than cardiologists, which may increase the probability of readmission for HF. This study aimed to generate new hypotheses using a statistical approach in order to provide new insights which may ultimately improve medical therapy of HF patients.

\section{Methods}

\section{Study population and data source}

Data from 22,476 Dutch HF patients ( $\geq 18$ years old) hospitalized for the first time for HF between January 2001 and December 2015 were obtained from the PHARMO Hospitalization Database, including hospital discharge records, and linked to the dispending data included in the Out-Patient Pharmacy Database of the PHARMO Database Network. This network includes drugs prescribed from primary and secondary care prescriptions and represents 3.8 million inhabitants throughout the Netherlands. HF was described by the International Classification of Diseases $9^{\text {th }}$ edition (ICD-9, code 428) and $10^{\text {th }}$ edition (ICD-10, code I50). The index admission for $\mathrm{HF}$ was preceded by a minimum of 3 years without hospitalization for $\mathrm{HF}$, looking at hospitalization records in the same hospital were the index HF took place. The follow-up time started at the time of discharge from the hospital (index admission). When more than one readmission followed the index admission, only the first one was included in the analyses (event). Every study patient was included in the analysis, independent of the follow-up time. Available subject's information included age, gender, year and duration of the HF index hospitalization, medication at the time of discharge (described by Anatomical Therapeutic Chemical Classification System, ATC code), and date of the readmission for HF (event). 


\section{Statistical analysis}

Analyses were conducted in either a) the total data set $(\mathrm{N}=22,476), \mathrm{b})$ the training set for model development $(\mathrm{N}=11,180)$, and $\mathrm{c})$ the validation set $(\mathrm{N}=11,296)$. Both the training and the validation set resulted from the random division of the total data set. The analyses were performed in the following phases (Figure 1): descriptive analyses ${ }^{\text {abc; }}$; data set division for split-half cross validation ${ }^{\text {a }}$, univariate analyses by Chi square and Kaplan-Meier ${ }^{\text {b }}$; multivariate analyses by Cox regression ${ }^{\text {b; }}$ bootstrapping ${ }^{\text {b }}$ implementation of the multivariate Cox regression model into the validation set'; sensitivity analyses and calculation of Harrell's C statistic ${ }^{\mathrm{bc}}$; exploratory analyses ${ }^{\mathrm{a}}$. In the training set, the medication present at the index hospital discharge was selected, based on univariate analyses and scientific rationale, and included in the multivariate Cox regression model. Subsequently, simplification of the model and bootstrapping were conducted. Two survival models were developed, either including or excluding cardiovascular drugs under ATC code C (Cardiovascular system) and B01 (Antithrombotic agents). Both survival Cox models were implemented in the validation set. Sensitivity analysis were performed to assess how modifying the follow-up time or the in- and exclusion criteria impacted the results. The analyses were performed for 3, 6, 12, and 24-month follow-up time, by excluding $<50$ years old patients, and excluding patients readmitted on the day of discharge.

Within this study, the hazard ratio (HR) of the Cox regression model without adjustment to cardiovascular medications is defined as $\mathrm{HR}$, and when adjusted to cardiovascular medication it is defined as $\mathrm{HR}_{\text {cadj" }}$

A detailed description of the methods is included as Supplementary Information (S1. Text) as well as the descriptive statistics from both training and validation sets (S2. Table) (S3. Table).

Statistical analyses were performed using IBM ${ }^{\circledR}$ SPSS Statistics 25.0.

\section{Exploratory analyses}

Following the observed effect of insulin on the risk of readmission for HF (see results and discussion), and being diabetes a known risk factor for HF, an exploratory analysis was performed in order to rule out the diabetes condition as the responsible cause for the observed effect. The type 2 diabetes (T2D) patients were identified as those treated with at least one blood glucose lowering drug different from insulin. Thus, the potential risk associated with insulin and other drugs used in diabetes was investigated in the 4,300 T2D patients. A detailed description is included in the Supplementary Information (S1. Text). 
Figure 1 Schema of the study methodology

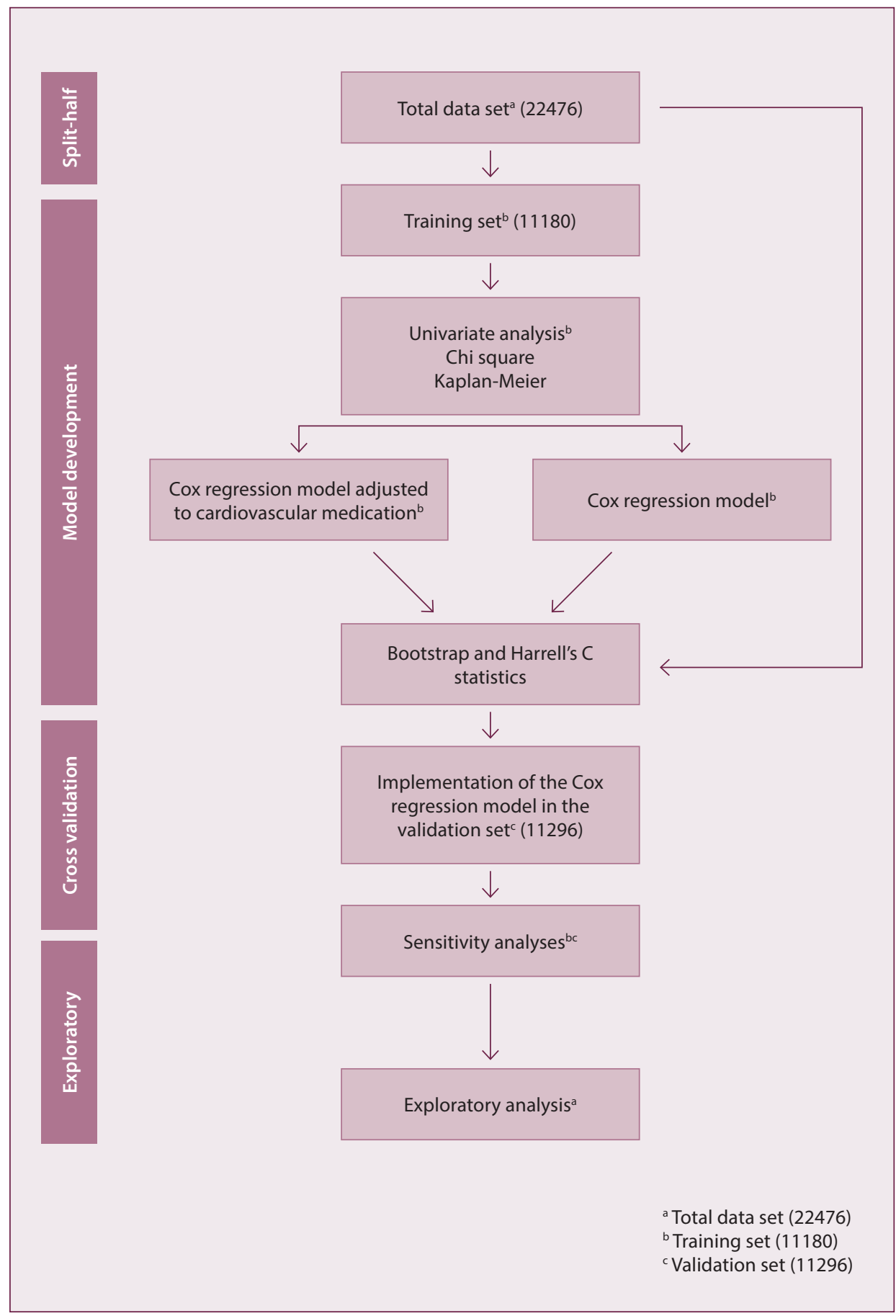




\section{Results}

The mean age of the patients at inclusion was 76.7 years (range 18-104), and $98 \%$ were $\geq 50$ years old. The median follow-up time was 2.5 years (range $0-15.7$ years). During the study period 6,725 (29.9\%) patients were readmitted for HF, with a median time-to-readmission of 7 months (range 0-14.3 years). The incidence rate of readmission using data from all 22,476 patients was 80 per 1,000 person years. Both the training set and the validation set had similar patient characteristics, follow-up time and time to readmission (Supplementary Information S2. Table).

\section{Multivariate analyses (Table 1)}

\section{Proton pump inhibitors (PPIs)}

Thirty-seven percent of the patients were prescribed PPIs. While a significant increase of $12 \%$ on the risk of readmission was observed in both training and validation sets, this risk was attenuated and no longer significant when adjusting for the cardiovascular medication.

\section{Antigout preparations}

The higher risk of readmission associated with antigout preparations was highly consistent, with $\mathrm{HR}$ of $1.36(95 \% \mathrm{Cl} 1.18-1.57)$ and $\mathrm{HR}_{\text {Cadj. }}$ of $1.25(95 \% \mathrm{Cl} 1.09-1.45)$ in the validation set.

\section{Drugs used in diabetes}

In the validation set 1,088 (10\%) patients were prescribed insulins and analogues for injection, and they presented an increased readmission risk (HR $1.26[95 \% \mathrm{Cl} 1.13-1.40]$ and $\mathrm{HR}_{\text {Cadj. }} 1.18$ [95\%Cl 1.06-1.32]).

The thiazolidinedione rosiglitazone, prescribed only up to 2010 due to marketing authorization withdrawal ${ }^{7}$, and the currently authorized pioglitazone, were included in the initial model but did not remain statistically significant during the development of the parsimonious model. Similarly, metformin, first line medication for T2D, ${ }^{8,9}$, generally associated with cardiovascular benefits ${ }^{10,11}$, and prescribed to $13.5 \%$ of the study population (training set), presented no significant contribution to the model. Therefore, these thiazolidinediones and metformin were removed from the model during the simplification steps. The sulfonylureas were studied as individual drugs, since it could be expected that the different generations of sulfonylureas differ in their safety profile. ${ }^{12}$ Tolbutamide, gliclazide, and glimepiride were associated with an elevated risk of readmission in the validation set, but only the effect of tolbutamide was consistent with the training set. Tolbutamide was associated with a $>20 \%$ increased risk of readmission in both sets. The number of patients prescribed dipeptidyl peptidase-4 (DDP-4) inhibitors was low and the result was highly variable between both data sets, with elevated bias in the bootstrap (bias -0.016). 


\section{NSAIDs}

Non-Steroidal Anti-Inflammatory and Anti-Rheumatic Drugs (NSAIDs) were studied in four groups, including acetic acid derivatives and related substances (e.g. indomethacin, diclofenac), oxicams, propionic acid derivatives (e.g. ibuprofen, naproxen), and coxibs. The propionic acid derivatives presented significant protection $\left(\mathrm{HR}_{\text {Cadj. }} 0.60(95 \% \mathrm{Cl}\right.$ 0.39-0.92) in the validation set, however without consistency to the training set. When combining all NSAIDs, the HR was $0.71(95 \% \mathrm{Cl} 0.58-0.86)$ and the $\mathrm{HR}_{\text {cadj. }}$ was $0.73(95 \% \mathrm{Cl} 0.59-0.88)$ in the validation set, and similar to the HR's 0.76 in the training set.

\section{Others}

Antipsychotics with known QT prolongation, did not significantly contribute to the risk of readmission for HF. Selective serotonin reuptake inhibitors indicated protection in the training set, but this effect was not confirmed in the validation set, nor in the sensitivity analyses. 


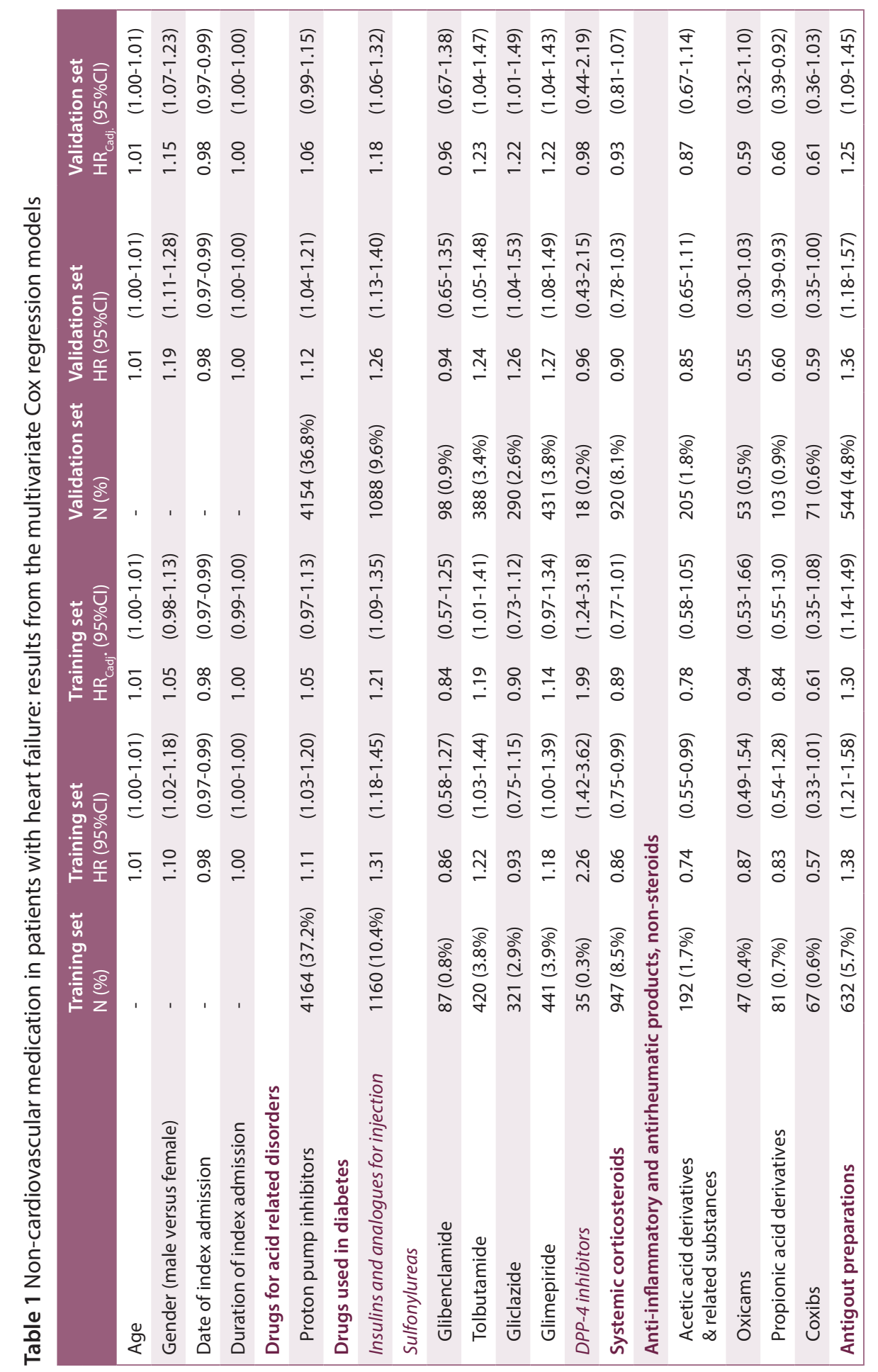




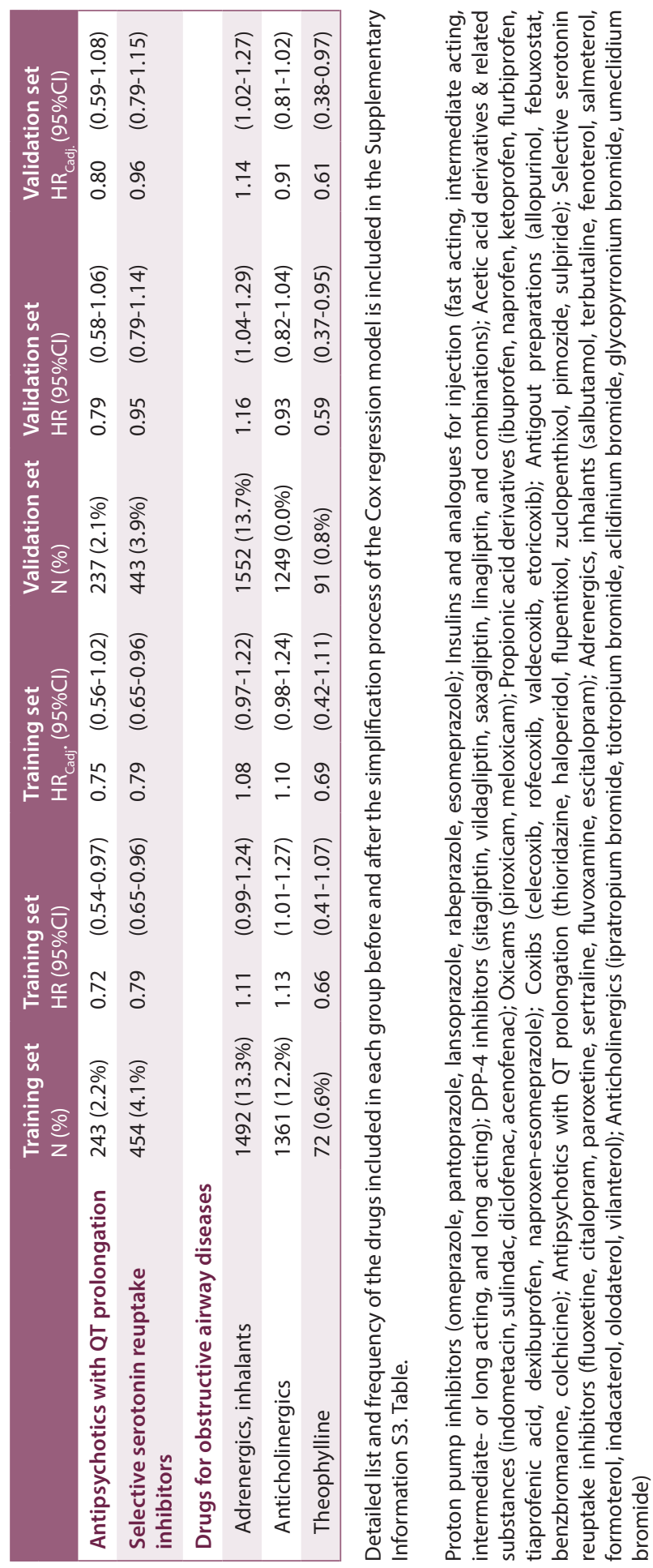




\section{Additional statistics}

The sensitivity analysis, with different follow-up times supported the risk associated to the gout medication, but showed less robustness with regard to the risk associated with insulin and analogues for injection. Results from bootstrapping, Harrell's C statistics and the sensitivity analyses are included as Supplementary Information (S4. Text) (S5. Table) (S6. Table)

\section{Exploratory analysis}

When investigating the association of insulin and analogues for injection, metformin, sulfonylureas, thiazolidinediones, and DDP-4 inhibitors, with the risk of readmission for HF of 4,300 T2D patients by Kaplan-Meier analysis, no significant associations were found. This result was confirmed by Cox regression. Only glibenclamide was associated with a lower risk of readmission (HR 0.74 [95\% Cl 0.56-0.98]), which was no longer significant when adjusting for cardiovascular medication.

\section{Discussion}

This observational cohort study aimed to provide new insights regarding the effects of non-cardiovascular medication on the risk of readmission of HF patients. The study results supported previous assumptions like the cardiac risk associated with patients prescribed antigout medication. However, the study did not confirm prior concerns about the cardiac risk associated to specific drugs used to treat diabetes ${ }^{1}$, and the use of NSAIDs in cardiology patients. ${ }^{1,13,14}$

\section{Proton pump inhibitors}

The observed increased risk associated with the use of PPIs disappeared when adjusting for cardiovascular drugs. PPIs are frequently used to prevent the gastrointestinal bleeding associated to the use of antiplatelet therapy, such as $\mathrm{P} 2 \mathrm{Y} 12$ receptor blocker (e.g. clopidogrel), in patients who have undergone stent placement or have suffered an acute coronary syndrome. This may suggest that the observed increased risk may be the consequence of PPIs prescription being a proxy of coronary artery disease. Based on this rationale, including the cardiovascular medication in the model may have corrected the confounding by indication. Additional research is needed, especially due to the high frequency of prescriptions of PPIs, and due to the controversial results from studies investigating the association between the concomitant use of PPIs and dual antiplatelet therapy (clopidogrel and salicylates) and higher cardiovascular risk. ${ }^{15}$

\section{Antigout preparations}

The $\geq 25 \%$ increased risk of readmission observed in patients prescribed antigout preparations, may well be due to the underlying abnormal levels of uric acid in blood. Gout 
disease, mainly characterized by constantly elevated levels of uric acid in the blood is associated with a higher risk of HF and worse outcome. ${ }^{16}$ Additionally, elevated uric acid is common in HF patients and it is a known side effect of diuretics, especially thiazides, a common treatment in symptomatic HF patients. ${ }^{1}$ Furthermore, coexisting impaired renal function may increase the incidence of gout. Therefore, this result may not reflect the risk associated to the medication itself, but to the condition intended to treat. Nevertheless, the high statistical significance and robustness of the result in the sensitivity analysis (Supplementary Information S6. Table), suggests the need to be aware of this associated risk.

\section{Drugs used in diabetes}

Diabetes is a risk factor of $\mathrm{HF}$, and poor glycaemic control and albuminuria are both associated with an increased risk of HF. ${ }^{17}$ In this study, one fourth of the study patients were prescribed diabetic treatment and being prescribed insulin and analogues for injection was associated with an increase of $18 \%$ on the risk of readmission. The diabetic condition could partly explain this increased risk, although one should consider that insulin induces sodium retention ${ }^{1,18}$, which may contribute to exacerbated fluid retention, resulting in worse cardiac outcome. Insulin, the main therapy of type 1 diabetes, is also frequently prescribed as second-line treatment in patients with T2D. ${ }^{19}$ In this study, insulin and analogues for injection did not present a significant impact on the risk of readmission versus other blood glucose lowering treatments in T2D patients. Thus, the exploratory analysis in the T2D population suggests that the risk observed in the main analysis may be the consequence of the lack of adjustment for comorbidities.

The main concern about the use of sulfonylureas is the risk of hypoglycaemia and changes in blood glucose, triggering vasoconstriction, platelet aggregation, and ischemia. ${ }^{12}$ In the general HF population, tolbutamide presented an increased risk ( $\geq 20 \%)$ of readmission in both data sets, which might be explained by the lower pancreatic affinity of tolbutamide, leading to higher binding to cardiac ATP-sensitive potassium channels. ${ }^{9,20}$ Gliclazide and glimepiride showed inconsistent effects between training and validation set, and only glibenclamide did not present significant effects in both data sets. Subsequently, when studying the T2D patients, being prescribed tolbutamide was no longer associated with an increased risk of readmission, and the use of glibenclamide reduced the risk of readmission (HR 0.74) and a similar but no longer significant effect when adjusting for cardiovascular medication. This result could initially suggest a potential benefit of using glibenclamide versus other sulfonylureas in HF patients with T2D. However, current recommendations of using other sulfonylureas such as gliclazide ${ }^{21}$ and glimepiride as better options in patients with cardiovascular risk ${ }^{9}$ may have influenced the physicians decision, especially when treating patients at higher risk. Thus, the result could be the consequence of the drug prescribed to less severe HF patients. Therefore, further study of the differences between 
sulfonylureas in HF patients is of interest, taken special care of patient profile and timing of treatment.

This study failed to confirm the known HF risk associated to thiazolidinediones, which cause sodium and water retention. ${ }^{18}$ Both rosiglitazone (up to 2010 ) and pioglitazone were hardly prescribed to the study patients, probably due to the European recommendation to avoid their use in HF patients. ' Therefore, the study result may be explained by channelling of the drug (prescribing or lack there-off to specific patient groups) causing the lack of statistical power.

\section{NSAIDs}

An interesting finding of this study is the beneficial trend observed in patients prescribed with NSAIDs, which is not in accordance with the issued warning on the use of NSAIDs, causing fluid retention, increasing the risk of myocardial infarction ${ }^{14}$, and being associated with various other cardiovascular adverse events. ${ }^{22}$ When assessing the association between specific groups within NSAIDs and the risk of readmission, the benefit was 'suggested' by the hazard ratio but without statistical significance. Only when every type of NSAID was included within the same group and the sample size sufficient for a higher statistical power, the HR was significantly below one. The majority of the NSAID use may have not been captured since it is available on prescription as well as an over-the-counter medication. Thus, this result should be taken with caution and it should be further investigated, especially because, if confirmed, the recommendation on the use of NSAIDs in HF may be expanded.

\section{Conclusion}

Prescribed antigout preparations at discharge after HF hospitalization was associated with a $25 \%$ increase in the risk of readmission. HF patients prescribed insulin presented a $18 \%$ higher risk of readmission versus other HF patients, but no additional risk against T2D HF patients treated with other blood glucose lowering drugs was observed. This finding suggests that diabetes is not only a risk factor for HF but also for readmissions for HF.

\section{Strengths and limitations}

Key strengths of the study are the large number of medications studied, as well as the use of observational data of a large group of HF patients, reflecting the real-world setting. Additionally, the consistency observed between the training and the validation sets supports the robustness of the study results.

A limitation of this study is the assumption that the medication at hospital discharge and the effect it exerts remain constant during the follow-up period. In order to investigate this assumption, sensitivity analyses were performed, modifying the follow-up time. An 
additional limitation was the lack of adjustment for unmeasured confounders, due to lack of clinical information regarding comorbidities. Thus, potential risk factors for HF hospitalization, could only be considered by proxy approach, using co-medications.

The low bias achieved in the bootstrap analyses showed statistical robustness of the model, although the low Harrell's C value obtained, defining the ability of the model to predict the outcome was poor. Since the study is performed only on patients with HF, and physicians prescribe medications applying their knowledge on contradictions and preferable treatment based on the patient's profile, it is assumed that the results may reflect fewer high risk medications in patients with a high risk of re-admission, a paradox that will influence the C-index directly. It is difficult to determine if channelling takes place in an observational dataset, and in what direction and to what extent it impacts on the results.

The medications classified as cardiovascular drugs, including antithrombotic agents were not discussed within this project, since it was out of the scope of the study. The used data was obtained from PHARMO, a nationwide database representative for the Netherlands. Thus, it is expected that the results of this study will be applicable to HF patients from the Dutch population, $>18$ years old.

\section{Acknowledgements}

The authors would like to thank all the healthcare providers contributing information to the Dutch PHARMO Database Network. The authors would like to thank the Medisch Spectrum Twente (MST), Enschede, the Netherlands, for providing the appropriate research environment. 


\section{References}

1. Ponikowski P, Voors AA, Anker SD, Bueno H, Cleland JGF, Coats AJS, et al. 2016 ESC Guidelines for the diagnosis and treatment of acute and chronic heart failure: The task force for the diagnosis and treatment of acute and chronic heart failure of the European Society of Cardiology (ESC)Developed with the special contribution of the Heart Failure Association (HFA) of the ESC. Eur Heart J 2016;37:21292200.

2. Atherton JJ, Sindone A, Pasquale CGD, Driscoll A, MacDonald PS, Hopper I, et al. National Heart Foundation of Australia and Cardiac Society of Australia and New Zealand: Guidelines for the prevention, detection, and management of heart failure in Australia 2018. Heart Lung Circ 2018;27:1123-1208.

3. Yancy CW, Jessup M, Bozkurt B, Butler J, Casey DE, Colvin MM, et al. 2017 ACC/AHA/ HFSA Focused update of the 2013 ACCF/ AHA Guideline for the management of heart failure: A report of the American College of Cardiology/American Heart Association task force on clinical practice guidelines and the Heart Failure Society of America. Circulation 2017;136:e137-161.

4. Hoes A, Voors A, Rutten F, Van Lieshout J, Janssen P, Walma E. NHG-Standaard Hartfalen (Tweede herziening). Huisarts Wet 2010:53(7):368-389. https://www.nhg. org/standaarden/volledig/nhg-standaardhartfalen. Accessed 23 January 2019.

5. Deursen VM van, Urso R, Laroche $C$, Damman K, Dahlström U, Tavazzi L, et al. Co-morbidities in patients with heart failure: an analysis of the European heart failure pilot survey. Eur J Heart Fail ;16:103-111.

6. Triposkiadis F, Giamouzis G, Parissis J, Starling RC, Boudoulas H, Skoularigis J, et al. Reframing the association and significance of $\mathrm{CO}^{-}$ morbidities in heart failure. Eur J Heart Fail 2016;18:744-758.

7. EMA Press officers. European Medicines Agency recommends suspension of Avandia, Avadament and Avaglim 2010.

8. Yandrapalli S, Jolly G, Horblitt A, Sanaani A, Aronow WS. Cardiovascular benefits and safety of non-insulin medications used in the treatment of type 2 diabetes mellitus. Postgrad Med 2017;129:811-821.
9. Azimova K, Juan ZS, Mukherjee D. Cardiovascular safety profile of currently available diabetic drugs. Ochsner J 2014;14:616-632.

10. Hippisley-Cox J, Coupland C. Diabetes treatments and risk of heart failure, cardiovascular disease, and all cause mortality: cohort study in primary care. BMJ 2016:i3477.

11. Khalaf KI, Taegtmeyer $\mathrm{H}$. After avandia: the use of antidiabetic drugs in patients with heart failure. Tex Heart Inst J 2012;39:174-178.

12. Kumar R, Kerins DM, Walther T. Cardiovascular safety of anti-diabetic drugs. Eur Heart J Cardiovasc Pharmacother 2016;2:32-43.

13. Center for Drug Evaluation and Research. Drug Safety and Availability - FDA Drug Safety Communication: Possible increased risk of fractures of the hip, wrist, and spine with the use of proton pump inhibitors. https://www. fda.gov/Drugs/DrugSafety/ucm213206.htm. Accessed 20 August 2018.

14. Center for Drug Evaluation and Research Drug Safety and Availability - FDA Drug Safety Communication: FDA strengthens warning that non-aspirin nonsteroidal antiinflammatory drugs (NSAIDs) can cause heart attacks or strokes. https://www.fda.gov/ Drugs/DrugSafety/ucm451800.htm. Accessed 23 January 2019.

15. Sherwood MW, Melloni C, Jones WS, Washam JB, Hasselblad V, Dolor RJ. Individual proton pump inhibitors and outcomes in patients with coronary artery disease on dual antiplatelet therapy: A systematic review. J Am Heart Assoc 2015;4.

16. Huang $\mathrm{H}$, Huang $B$, Li Y, Huang $Y$, Li J, Yao $\mathrm{H}$, et al. Uric acid and risk of heart failure: $\mathrm{a}$ systematic review and meta-analysis. Eur J Heart Fail 2014;16:15-24.

17. Rosengren A, Vestberg D, Svensson A-M, Kosiborod M, Clements M, Rawshani A, et al. Long-term excess risk of heart failure in people with type 1 diabetes: a prospective case-control study. Lancet Diabetes Endocrinol 2015;3:876-885.

18. Gilbert RE, Krum H. Heart failure in diabetes: effects of anti-hyperglycaemic drug therapy. Lancet 2015;385:2107-2117. 
19. Cosmi F, Shen L, Magnoli M, Abraham WT, Anand IS, Cleland JG, et al. Treatment with insulin is associated with worse outcome in patients with chronic heart failure and diabetes. Eur J Heart Fail 2018;20:888-895.

20. Bell DSH. Do sulfonylurea drugs increase the risk of cardiac events? CMAJ Can Med Assoc J 2006;174:185-186.

21. Rutten G, Nijpels G, Houweling S, van de Laar F, Bilo H, Holleman F, et al. NHG-Standaard Diabetes mellitus type 2 | (derde herziening). Huisarts Wet 2013;56(10):512-525. https:// www.nhg.org/standaarden/volledig/nhgstandaard-diabetes-mellitus-type-2. Accessed 23 January 2019.

22. Fanelli A, Ghisi D, Aprile PL, Lapi F. Cardiovascular and cerebrovascular risk with nonsteroidal anti-inflammatory drugs and cyclooxygenase 2 inhibitors: latest evidence and clinical implications. Ther Adv Drug Saf 2017;8:173-182. 


\section{Supplementary Information}

\section{S1 Text Statistical analysis}

The statistical analysis was performed using IBM ${ }^{\circledR}$ SPSS Statistics.

\section{Descriptive statistics}

The medications present at the hospital discharge, recorded by the ATC code, were grouped according to pharmacological characteristics. Descriptive statistics of more than 300 individual (fifth level ATC code) or grouped medications were studied. The studied medications belonged to the therapeutic groups mentioned on the Supplementary Information S2. Table. When grouping medications, the patients were grouped when prescribed to at least one of the drugs included in the group.

\section{Data division for split-half cross validation}

The complete data set (22,476 patients) was divided into two sets using randomized split set options from SPSS. A training set (11,180 subjects) was used to develop the study model, and a validation set (11,296 subjects) was used to asses model reproducibility. Descriptive statistics for both training and validation sets are shown in the Supplementary Information S2 Table.

\section{Univariate analysis (training set)}

The group or individual medications presenting significant results $(P<0.05)$ at chi-square analysis, were further analysed by Kaplan-Meier. The selection of variables was based on statistical measures, scientific interest and pharmacological reasoning. Variables with less than 10 exposed patients were not selected.

Based on the results of the univariate analyses and previous scientific knowledge, 27 non-cardiac medications (detailed and marked with a on Supplementary Information S3. Table) were selected for entering the next phase, the multivariate analysis.

\section{Multivariate analysis (training set)}

Multivariate Cox regression was designed including age, gender, date and duration of index admission, and the discharge medication suspected to have an impact on the time to readmission. Aiming to investigate medication for comorbidities that may have an impact on the outcome, the development of the survival model was initially performed excluding the drugs classified as cardiovascular system drugs, such as ATC code $C$ and antithrombotic agents (ATC code B01). Subsequently, the process was repeated including the cardiovascular system drugs and antithrombotic drugs for adjustment.

Simplification of the model, by removing variables showing no effect on time-to-event $(P>0.05)$, was performed following a statistical-stepwise method. Variables with non- 
significant contribution to the model were removed one by one, based on the change in -2 log likelihood. In a few cases, if there was scientific interest to further observe this variable, it was not removed. Two parallel simplification processes of the Cox regression model were performed, including and excluding adjustment for the cardiovascular system drugs.

Within this study, the hazard ratio (HR) of the cox regression model without adjustment to cardiovascular system medications is defined as $\mathrm{HR}$, and when adjusted to cardiovascular system medication is defined as $\mathrm{HR}_{\text {cadj. }}$ and it is corrected by including antithrombotic agents (P2Y12 inhibitors, salicylates), cardiac therapy (cardiac glycosides, antiarrhythmics, cardiac stimulants, vasodilators, and other cardiac medications), diuretics, beta-blocking agents, selective calcium channel blockers, agents acting on the renin-angiotensin system (ACE inhibitors, and angiotensin II antagonists), and lipid modifying agents (statins).

\section{Bootstrapping (training set)}

Bootstrapping was used for internal validation of the parsimonious Cox regression model.

\section{Harrel's C-statistics (training set and validation set)}

The goodness of fit of the model was measured using Harrel's C-statistic, calculated for both Cox regression models (with and without adjustment for cardiac medication) in both data sets.

Implementation of the multivariate Cox regression model into the validation set (validation set)

The two Cox regression models developed using the training set, either adjusting or not to cardiovascular system drugs, were implemented into the validation set.

Sensitivity analyses (validation set)

Sensitivity analyses were performed to assess how the findings were affected by limiting the time to readmission to $1,6,12$, and 24 months, or excluding the patients $<50$ years old, or excluding patients readmitted already on the same day of discharge.

\section{Exploratory analysis (validation set)}

Exploratory analysis was performed in type 2 diabetes (T2D) patients, identified as those patients treated with at least one blood glucose lowering drug different from insulin. This additional analysis was performed using the complete data set, selecting 4,300 T2D patients from the $22,476 \mathrm{HF}$ patients. The association of insulin and analogues for injection, metformin, sulfonylureas, thiazolidinediones, and dipeptidyl peptidase 4 (DDP-4) inhibitors, with the risk of readmission for HF was studied by Kaplan-Meier and Cox regression. This Cox regression included the same variables as in the two developed Cox models, plus every diabetes medication. 
S2 Table Descriptive statistics

\begin{tabular}{|llllllll|} 
& \multicolumn{2}{c}{$\begin{array}{c}\text { Training set [years] } \\
(11,180 \text { patients })\end{array}$} & \multicolumn{2}{c}{$\begin{array}{c}\text { Validation set [years] } \\
(11,296 \text { patients })\end{array}$} \\
& mean $(95 \% \mathrm{Cl})$ & median & range & mean $(95 \% \mathrm{Cl})$ & median & range \\
\hline Age & $76.8(76.6-77.0)$ & 79 & $18-104$ & $76.7(76.5-76.9)$ & 78 & $18-104$ \\
Follow-up time & $3.8(3.68-3.82)$ & 2.5 & $0-15.7$ & $3.7(3.63-3.77)$ & 2.4 & $0-15.7$ \\
$\begin{array}{l}\text { Time to readmission } \\
\text { (when readmission) }\end{array}$ & $1.4(1.37-1.50)$ & 0.6 & $0-13.4$ & $1.4(1.33-1.46)$ & 0.6 & $0-14.3$ \\
\hline
\end{tabular}

\begin{tabular}{|lllll|} 
& \multicolumn{2}{l}{ Training set } & \multicolumn{2}{l}{ Validation set } \\
& N & & N & \\
\hline Total & 11180 & $(100 \%)$ & 11296 & $(100 \%)$ \\
Date of the index admission & & & & \\
$2001-2004$ & 2632 & $(23.5 \%)$ & 2673 & $(23.7 \%)$ \\
$2005-2007$ & 2482 & $(22.2 \%)$ & 2537 & $(22.5 \%)$ \\
$2008-2010$ & 3246 & $(29.0 \%)$ & 3177 & $(28.1 \%)$ \\
$2011-2015$ & 2820 & $(25.2 \%)$ & 2909 & $(25.8 \%)$ \\
Gender & & & & \\
Men & 5460 & $(48.8 \%)$ & 5567 & $(49.3 \%)$ \\
Women & 5720 & $(51.2 \%)$ & 5729 & $(50.7 \%)$ \\
Age & & & & \\
$\leq 49$ & 221 & $(2.0 \%)$ & 247 & $(2.2 \%)$ \\
\hline $50-59$ & 671 & $(6.0 \%)$ & 599 & $(5.3 \%)$ \\
$60-69$ & 1587 & $(14.2 \%)$ & 1633 & $(14.5 \%)$ \\
$70-79$ & 3549 & $(31.7 \%)$ & 3620 & $(32.0 \%)$ \\
$80-89$ & 4193 & $(37.5 \%)$ & 4228 & $(37.4 \%)$ \\
$\geq 90$ & 959 & $(8.6 \%)$ & 969 & $(8.6 \%)$ \\
\hline
\end{tabular}




\begin{tabular}{|c|c|c|c|c|}
\hline \multirow[b]{2}{*}{ Drugs for acid related disorders [A02] } & \multicolumn{2}{|c|}{$\begin{array}{l}\text { Training set } \\
\mathbf{N}\end{array}$} & \multicolumn{2}{|c|}{$\begin{array}{l}\text { Validation set } \\
\mathbf{N}\end{array}$} \\
\hline & 4401 & $(39.4 \%)$ & 4384 & $(38.8 \%)$ \\
\hline Drugs used in diabetes [A10] & 2918 & $(26.1 \%)$ & 2808 & (24.9\%) \\
\hline Systemic corticosteroids [H02] & 947 & $(8.5 \%)$ & 920 & $(8.1 \%)$ \\
\hline Thyroid therapy [H03] & 738 & $(6.6 \%)$ & 785 & $(6.9 \%)$ \\
\hline Antibacterials for systemic use [J01] & 1340 & $(12.0 \%)$ & 1356 & $(12.0 \%)$ \\
\hline Immunosuppressants [L04] & 106 & $(0.9 \%)$ & 105 & $(0.9 \%)$ \\
\hline Anti-inflammatory \& antirheumatic products [M01] & 383 & $(3.4 \%)$ & 442 & $(3.9 \%)$ \\
\hline Antigout preparations [M04] & 632 & $(5.7 \%)$ & 544 & $(4.8 \%)$ \\
\hline Analgesics [N02] & 1602 & $(14.3 \%)$ & 1558 & $(13.8 \%)$ \\
\hline Antiepileptics [N03] & 421 & $(3.8 \%)$ & 391 & $(3.5 \%)$ \\
\hline Psycholeptics [N05] & 3018 & $(27.0 \%)$ & 3034 & $(26.9 \%)$ \\
\hline Psychoanaleptics [N06] & 986 & $(8.8 \%)$ & 1004 & $(8.9 \%)$ \\
\hline Drugs for obstructive airway disease [R03] & 2217 & $(19.8 \%)$ & 2294 & $(20.3 \%)$ \\
\hline Antithrombotic agents [B01] & 7436 & $(66.5 \%)$ & 7462 & (66.1\%) \\
\hline Cardiac therapy [C01] & 5218 & $(46.7 \%)$ & 5297 & $(46.9 \%)$ \\
\hline Antihypertensives [C02] & 251 & $(2.2 \%)$ & 271 & $(2.4 \%)$ \\
\hline Diuretics [C03] & 9219 & $(82.5 \%)$ & 9228 & $(81.7 \%)$ \\
\hline Peripheral vasodilators [C04] & 23 & $(0.2 \%)$ & 19 & $(0.2 \%)$ \\
\hline Vasoprotectives [C05] & 60 & $(0.5 \%)$ & 51 & $(0.5 \%)$ \\
\hline Beta blocking agents [C07] & 6692 & $(59.9 \%)$ & 6714 & $(59.4 \%)$ \\
\hline Calcium channel blockers [C08] & 2062 & $(18.4 \%)$ & 2121 & $(18.8 \%)$ \\
\hline Agents acting on the renin-angiotensin system [C09] & 7067 & $(63.2 \%)$ & 7052 & $(62.4 \%)$ \\
\hline Lipid modifying agents [C10] & 4344 & $(38.9 \%)$ & 4406 & $(39.0 \%)$ \\
\hline
\end{tabular}


S3 Table Additional description of main variables

\begin{tabular}{|c|c|c|c|c|}
\hline \multirow[b]{2}{*}{ Overall } & \multicolumn{2}{|c|}{$\begin{array}{l}\text { Training set } \\
\mathrm{N}\end{array}$} & \multicolumn{2}{|c|}{$\begin{array}{l}\text { Validation set } \\
\mathrm{N}\end{array}$} \\
\hline & 11180 & $(100 \%)$ & 11296 & (100\%) \\
\hline \multicolumn{5}{|l|}{ Drugs for acid related disorders } \\
\hline Proton pump inhibitors ${ }^{a b}$ & 4164 & $(37.2 \%)$ & 4154 & $(36.8 \%)$ \\
\hline Omeprazole & 1395 & (12.5\%) & 1410 & (12.5\%) \\
\hline Pantoprazole & 2037 & (18.2\%) & 2030 & (18.0\%) \\
\hline Lansoprazole & 33 & $(0.3 \%)$ & 35 & $(0.3 \%)$ \\
\hline Rabeprazole & 132 & $(1.2 \%)$ & 119 & $(1.1 \%)$ \\
\hline Esomeprazole & 657 & $(5.9 \%)$ & 639 & $(5.7 \%)$ \\
\hline Drugs used in diabetes & 2918 & $(26.1 \%)$ & 2808 & $(24.9 \%)$ \\
\hline Insulin and analogues for injection ${ }^{a b}$ & 1160 & $(10.4 \%)$ & 1088 & $(9.6 \%)$ \\
\hline Fast acting & 431 & $(3.9 \%)$ & 416 & $(3.7 \%)$ \\
\hline Intermediate acting & 176 & $(1.6 \%)$ & 166 & $(1.5 \%)$ \\
\hline Intermediate- or long-acting & 560 & $(5.0 \%)$ & 535 & $(4.6 \%)$ \\
\hline Long-acting & 344 & $(3.1 \%)$ & 308 & $(2.7 \%)$ \\
\hline \multicolumn{5}{|l|}{ Biguanide } \\
\hline Metformin ${ }^{a}$ & 1508 & $(13.5 \%)$ & 1430 & $(12.7 \%)$ \\
\hline Sulfonylureas & 1261 & $(11.3 \%)$ & 1199 & $(10.6 \%)$ \\
\hline Glibenclamide $^{\mathrm{ab}}$ & 87 & $(0.8 \%)$ & 98 & $(0.9 \%)$ \\
\hline Tolbutamide ${ }^{\mathrm{ab}}$ & 420 & $(3.8 \%)$ & 388 & $(3.4 \%)$ \\
\hline Gliclazide $^{\mathrm{ab}}$ & 321 & $(2.9 \%)$ & 290 & $(2.6 \%)$ \\
\hline Glimepiride $^{\mathrm{ab}}$ & 441 & $(3.9 \%)$ & 431 & $(3.8 \%)$ \\
\hline Thiazolidinediones & 87 & $(0.8 \%)$ & 74 & $(0.7 \%)$ \\
\hline Rosiglitazone $^{a}$ & 54 & $(0.5 \%)$ & 42 & $(0.4 \%)$ \\
\hline Pioglizatone $^{a}$ & 34 & $(0.3 \%)$ & 32 & $(0.3 \%)$ \\
\hline Dipeptidyl peptidase 4 (DPP-4) inhibitors ${ }^{a b}$ & 38 & $(0.3 \%)$ & 22 & $(0.2 \%)$ \\
\hline Sitagliptin & 19 & $(0.2 \%)$ & 10 & $(0.1 \%)$ \\
\hline Vildagliptin & 9 & $(0.1 \%)$ & 4 & $(0.0 \%)$ \\
\hline Saxagliptin & 2 & $(0.0 \%)$ & 1 & $(0.0 \%)$ \\
\hline Linagliptin & 7 & $(0.1 \%)$ & 4 & $(0.0 \%)$ \\
\hline DDP-4 inhibitor combinations & 3 & $(0.0 \%)$ & 5 & $(0.0 \%)$ \\
\hline Systemic corticosteroids ${ }^{\mathrm{ab}}$ & 947 & $(8.5 \%)$ & 920 & $(8.1 \%)$ \\
\hline Thyroid therapy ${ }^{a}$ & 738 & $(6.6 \%)$ & 785 & $(6.9 \%)$ \\
\hline Thyroid preparations, thyroid hormones & 649 & $(5.8 \%)$ & 693 & $(6.1 \%)$ \\
\hline Levothyroxine sodium & 648 & $(5.8 \%)$ & 692 & $(6.1 \%)$ \\
\hline Liothyronine sodium & 2 & $(0.0 \%)$ & 1 & $(0.0 \%)$ \\
\hline Thyroid gland preparations & 0 & $(0.0 \%)$ & 0 & $(0.0 \%)$ \\
\hline
\end{tabular}




\begin{tabular}{|c|c|c|c|c|}
\hline \multirow[b]{2}{*}{ Antithyroid preparations } & \multicolumn{2}{|c|}{$\begin{array}{l}\text { Training set } \\
\mathrm{N}\end{array}$} & \multicolumn{2}{|c|}{$\begin{array}{l}\text { Validation set } \\
\mathrm{N}\end{array}$} \\
\hline & 121 & $(1.1 \%)$ & 132 & $(1.2 \%)$ \\
\hline Propylthiouracil & 9 & $(1.1 \%)$ & 7 & $(0.1 \%)$ \\
\hline Carbimazole & 15 & $(0.1 \%)$ & 25 & $(0.2 \%)$ \\
\hline Thiamazole & 97 & $(0.9 \%)$ & 100 & $(0.9 \%)$ \\
\hline Immunosuppressants ${ }^{a}$ & 106 & $(0.9 \%)$ & 105 & $(0.9 \%)$ \\
\hline $\begin{array}{l}\text { Anti-inflammatory and } \\
\text { antirheumatic products non-steroids }\end{array}$ & 382 & $(3.5 \%)$ & 439 & $(3.9 \%)$ \\
\hline Acetic acid derivatives and related substances ${ }^{a b}$ & 192 & $(1.7 \%)$ & 205 & $(1.8 \%)$ \\
\hline Indometacin & 13 & $(0.1 \%)$ & 16 & $(0.1 \%)$ \\
\hline Sulindac & 3 & $(0.0 \%)$ & 6 & $(0.1 \%)$ \\
\hline Diclofenac & 125 & $(1.1 \%)$ & 143 & $(1.3 \%)$ \\
\hline Acenofenac & 1 & $(0.0 \%)$ & 3 & $(0.0 \%)$ \\
\hline Diclofenac, combinations & 52 & $(0.5 \%)$ & 37 & $(0.3 \%)$ \\
\hline Oxicams ${ }^{a b}$ & 47 & $(0.4 \%)$ & 53 & $(0.5 \%)$ \\
\hline Piroxicam & 8 & $(0.1 \%)$ & 2 & $(0.0 \%)$ \\
\hline Meloxicam & 39 & $(0.3 \%)$ & 50 & $(0.4 \%)$ \\
\hline Propionic acid derivatives ${ }^{a b}$ & 81 & $(0.7 \%)$ & 103 & $(0.9 \%)$ \\
\hline Ibuprofen & 36 & $(0.3 \%)$ & 50 & $(0.4 \%)$ \\
\hline Naprofen & 41 & $(0.4 \%)$ & 46 & $(0.4 \%)$ \\
\hline Ketoprofen & 4 & $(0.0 \%)$ & 4 & $(0.0 \%)$ \\
\hline Flurbiprofen & 0 & $(0.0 \%)$ & 1 & $(0.0 \%)$ \\
\hline Tiaprofenic acid & 0 & $(0.0 \%)$ & 2 & $(0.0 \%)$ \\
\hline Dexibuprofen & 1 & $(0.0 \%)$ & 0 & $(0.0 \%)$ \\
\hline \multicolumn{5}{|l|}{ Naproxen and esomeprazole } \\
\hline Coxibs $^{a b}$ & 67 & $(0.6 \%)$ & 71 & $(0.6 \%)$ \\
\hline Celecoxib & 16 & $(0.1 \%)$ & 24 & $(0.2 \%)$ \\
\hline Rofecoxib & 28 & $(0.3 \%)$ & 22 & $(0.2 \%)$ \\
\hline Valdecoxib & 0 & $(0.0 \%)$ & 1 & $(0.0 \%)$ \\
\hline Etoricoxib & 23 & $(0.2 \%)$ & 24 & $(0.2 \%)$ \\
\hline \multicolumn{5}{|l|}{ Other } \\
\hline Phenylbutarone & 0 & $(0.0 \%)$ & 2 & $(0.0 \%)$ \\
\hline Nabumetone & 3 & $(0.0 \%)$ & 8 & $(0.1 \%)$ \\
\hline Azapropazone & 0 & $(0.0 \%)$ & 1 & $(0.0 \%)$ \\
\hline Glucosamine & 0 & $(0.0 \%)$ & 0 & $(0.0 \%)$ \\
\hline Antigout preparations ${ }^{\mathrm{ab}}$ & 632 & $(5.7 \%)$ & 544 & $(4.8 \%)$ \\
\hline \multicolumn{5}{|l|}{ Preparations inhibiting uric acid production } \\
\hline Allopurinol & 463 & $(4.1 \%)$ & 408 & $(3.6 \%)$ \\
\hline Febuxostat & 1 & $(0.0 \%)$ & 0 & $(0.0 \%)$ \\
\hline
\end{tabular}




\begin{tabular}{|c|c|c|c|c|}
\hline & \multicolumn{2}{|c|}{$\begin{array}{l}\text { Training set } \\
\mathrm{N}\end{array}$} & \multicolumn{2}{|c|}{$\begin{array}{l}\text { Validation set } \\
\mathrm{N}\end{array}$} \\
\hline \multicolumn{5}{|l|}{ Preparations increasing uric acid excretion } \\
\hline Benzbromarone & 24 & $(0.2 \%)$ & 30 & $(0.3 \%)$ \\
\hline \multicolumn{5}{|l|}{ Preparations with no effect on uric acid metabolism } \\
\hline Colchicine & 224 & $(2.0 \%)$ & 161 & $(1.4 \%)$ \\
\hline \multicolumn{5}{|l|}{ Neurology medication } \\
\hline Antipsychotics with QT prolongation ${ }^{a b}$ & 243 & $(2.2 \%)$ & 237 & $(2.1 \%)$ \\
\hline Thioridazine & 5 & $(0.0 \%)$ & 1 & $(0.0 \%)$ \\
\hline Haloperidol & 219 & $(2.0 \%)$ & 222 & $(2.0 \%)$ \\
\hline Flupentixol & 1 & $(0.0 \%)$ & 3 & $(0.0 \%)$ \\
\hline Zuclopenthixol & 9 & $(0.1 \%)$ & 5 & $(0.0 \%)$ \\
\hline Pimozide & 8 & $(0.1 \%)$ & 3 & $(0.0 \%)$ \\
\hline Sulpiride & 1 & $(0.0 \%)$ & 3 & $(0.0 \%)$ \\
\hline \multicolumn{5}{|l|}{ Benzodiazepine derivatives } \\
\hline Lormetazepama & 120 & $(1.1 \%)$ & 111 & $(1.0 \%)$ \\
\hline Non-selective monoamine reuptake inhibitors ${ }^{a}$ & 259 & $(2.3 \%)$ & 272 & $(2.4 \%)$ \\
\hline Imipramine & 6 & $(0.1 \%)$ & 4 & $(0.0 \%)$ \\
\hline Clomipramine & 34 & $(0.3 \%)$ & 37 & $(0.3 \%)$ \\
\hline Amitriptyline & 161 & $(1.4 \%)$ & 179 & $(1.6 \%)$ \\
\hline Nortriptyline & 49 & $(0.4 \%)$ & 41 & $(0.4 \%)$ \\
\hline Doxepin & 4 & $(0.0 \%)$ & 5 & $(0.0 \%)$ \\
\hline Dosulepin & 1 & $(0.0 \%)$ & 3 & $(0.0 \%)$ \\
\hline Maprotiline & 5 & $(0.0 \%)$ & 4 & $(0.0 \%)$ \\
\hline Selective serotonin reuptake inhibitors ${ }^{a b}$ & 454 & $(4.1 \%)$ & 443 & $(3.9 \%)$ \\
\hline Fluoxetine & 37 & $(0.3 \%)$ & 29 & $(0.3 \%)$ \\
\hline Citalopram & 139 & $(1.2 \%)$ & 169 & $(1.5 \%)$ \\
\hline Paroxetine & 214 & $(1.9 \%)$ & 188 & $(1.7 \%)$ \\
\hline Sertraline & 33 & $(0.3 \%)$ & 27 & $(0.2 \%)$ \\
\hline Fluvoxamine & 21 & $(0.2 \%)$ & 23 & $(0.2 \%)$ \\
\hline Escitalopram & 10 & $(0.1 \%)$ & 9 & $(0.1 \%)$ \\
\hline \multicolumn{5}{|l|}{ Drugs for obstructive airway disease } \\
\hline Adrenergics, inhalants ${ }^{a b}$ & 1492 & $(13.3 \%)$ & 1552 & $(13.7 \%)$ \\
\hline Salbutamol & 448 & $(4.0 \%)$ & 492 & $(4.4 \%)$ \\
\hline Terbutaline & 23 & $(0.2 \%)$ & 23 & $(0.2 \%)$ \\
\hline Fenoterol & 108 & $(0.9 \%)$ & 83 & $(0.7 \%)$ \\
\hline Salbutamol and ipratropium bromide & 181 & $(1.6 \%)$ & 199 & $(1.8 \%)$ \\
\hline Salmeterol ${ }^{\mathrm{a}}$ & 615 & $(5.5 \%)$ & 667 & $(5.9 \%)$ \\
\hline Formoterol & 369 & $(3.3 \%)$ & 350 & $(3.1 \%)$ \\
\hline Indacaterol & 15 & $(0.2 \%)$ & 17 & $(0.1 \%)$ \\
\hline
\end{tabular}




\begin{tabular}{|c|c|c|c|c|}
\hline \multirow[b]{2}{*}{ Olodaterol } & \multicolumn{2}{|c|}{$\begin{array}{l}\text { Training set } \\
\mathrm{N}\end{array}$} & \multicolumn{2}{|c|}{$\begin{array}{l}\text { Validation set } \\
\mathrm{N}\end{array}$} \\
\hline & 1 & $(0.0 \%)$ & 0 & $(0.0 \%)$ \\
\hline Vilanterol & 0 & $(0.0 \%)$ & 0 & $(0.0 \%)$ \\
\hline Glucocorticoids $^{a}$ & 1168 & (10.4\%) & 1175 & $(10.4 \%)$ \\
\hline Beclometasone & 256 & $(2.3 \%)$ & 216 & $(1.9 \%)$ \\
\hline Budesonide & 268 & $(2.4 \%)$ & 268 & $(2.4 \%)$ \\
\hline Fluticasone & 653 & $(5.8 \%)$ & 698 & $(6.2 \%)$ \\
\hline Ciclesonide & 30 & $(0.3 \%)$ & 22 & $(20.0 \%)$ \\
\hline Anticholinergics ${ }^{a b}$ & 1361 & (12.2\%) & 1249 & \\
\hline Ipratropium bromide & 727 & $(6.5 \%)$ & 539 & $(4.8 \%)$ \\
\hline Tiotropium bromide & 666 & $(6.0 \%)$ & 737 & $(6.5 \%)$ \\
\hline Aclidinium bromide & 1 & $(0.0 \%)$ & 0 & $(0.0 \%)$ \\
\hline Glycopyrronium bromide & 11 & $(0.1 \%)$ & 7 & $(0.1 \%)$ \\
\hline Umeclidium bromide & 0 & $(0.0 \%)$ & & \\
\hline Adrenergics for systemic use ${ }^{a}$ & 12 & $(0.1 \%)$ & 9 & $(0.1 \%)$ \\
\hline Ephedrine & 1 & $(0.0 \%)$ & 0 & $(0.0 \%)$ \\
\hline Salbutamol & 4 & $(0.0 \%)$ & 2 & $(0.0 \%)$ \\
\hline Terbutaline & 7 & $(0.1 \%)$ & 7 & $(0.1 \%)$ \\
\hline Fenoterol & 0 & $(0.0 \%)$ & 0 & $(0.0 \%)$ \\
\hline Theophylline & 72 & $(0.6 \%)$ & 91 & $(0.8 \%)$ \\
\hline
\end{tabular}

${ }^{a}$ Non-cardiac medication included in the initial Cox regression model, prior to model simplification bNon-cardiac medication included in the final Cox regression model, after model simplification 


\section{S4 Text Bootstrapping, Harrell's C statistics, and sensitivity analysis}

\section{Results. Bootstrapping and Harrell's C statistics}

The low bias obtained when implementing the bootstrap of the Cox regression model indicated that the model was statistically robust. A bias higher than 0.015 was generally associated with lower exposed-group size and/or inconsistency in the results from the training and the validation sets. See Supplementary Information S5. Table.

Harrell's C statistic value from the Cox regression model in both sets was 0.55 without adjusting for cardiovascular system medication, and 0.58 when adjusting for it. The model including adjustment for cardiovascular system medication (Cadj.) could be considered a more optimal model based on the $C$ statistics, and its robustness was further confirmed by the sensitivity analyses.

\section{Results. Sensitivity analyses}

The final parsimonious Cox regression model was implemented in the training and validation sets limiting the follow-up time to 1, 6, 12, and 24 months, and obtaining similar point estimates of hazard ratios compared to the prior results of relevant variables. The difference between the $H R_{\text {cadj. }}$ and the limited follow-up time $H R_{\text {cadj. }}$ was $\leq \pm 0.3$ in the training set, with the exception of DDP-4 inhibitors, presenting $\mathrm{HR}_{\text {cadj }}$ difference $\leq \pm 0.5$. This correlates with the higher bias observed in this group (-0.02), probably due to the small group size $(\mathrm{N}=35)$. Results from sensitivity analyses in the validation set are shown in the Supplementary Information S6. Table.

When excluding the 221 patients $<50$ years old from the training set, the $\mathrm{HR}_{\text {cadj. }}$ from the non-cardiac medication varied $\leq \pm 0.03$ and the significance of the antipsychotics with prolonged QT dropped down to $P=0.045$. Following same procedure on the validation set, excluding 247 patients younger than 50 years old, the $\mathrm{HR}_{\text {cadj. }}$ varied $\leq \pm 0.04$.

73 Patients in the training set were readmitted on the day of discharge from the index hospitalization. Excluding these patients led to a $\mathrm{HR}_{\text {cadj. }}$ variability of the non-cardiac medication of $\leq \pm 0.05$, and the statistical significance was very similar. Similar consistency was observed when excluding the 73 patients readmitted on day 0 in the validation set, with the only remark that the significance value of gliclazide rose to $P=0.052$. 


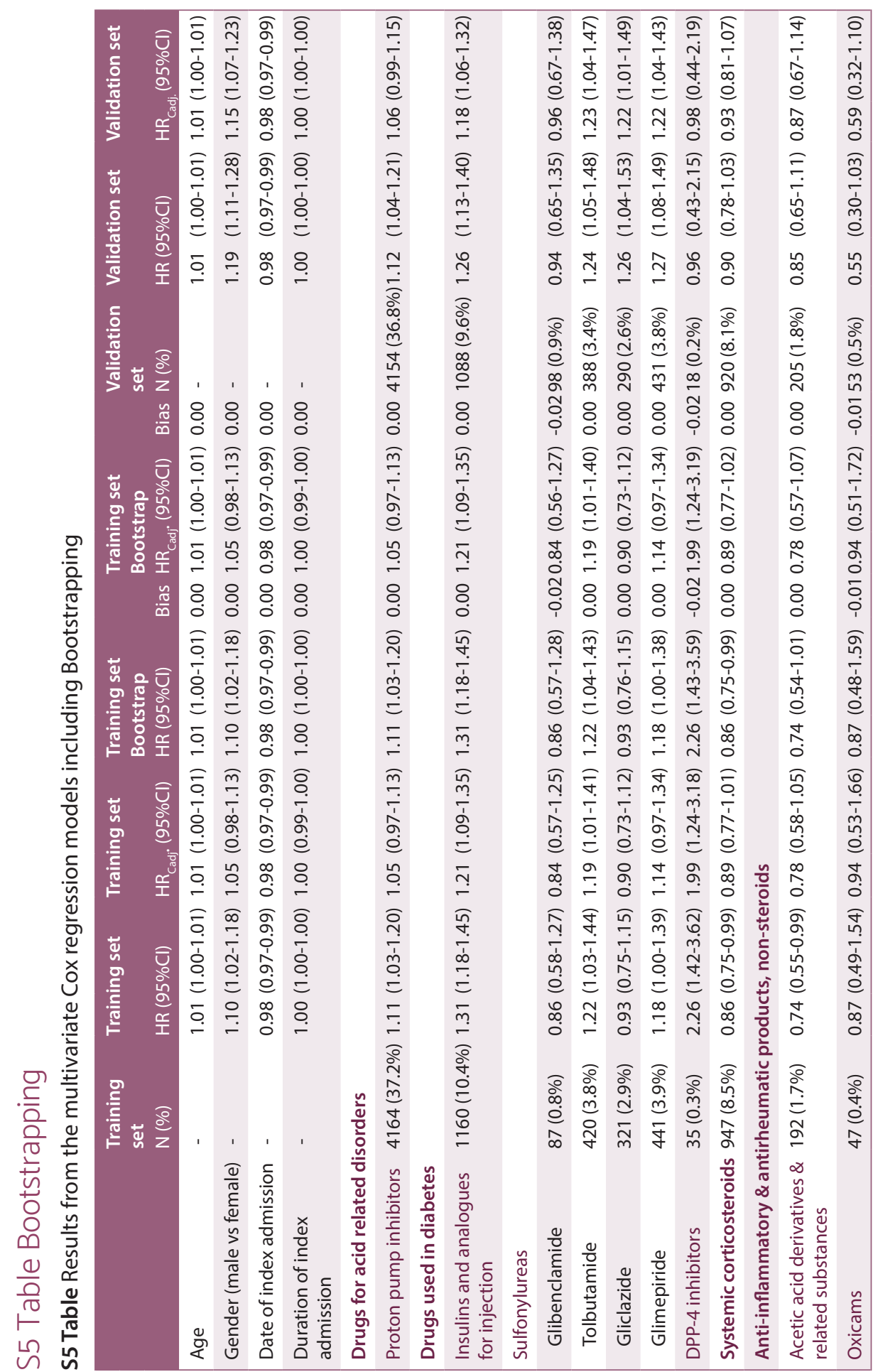



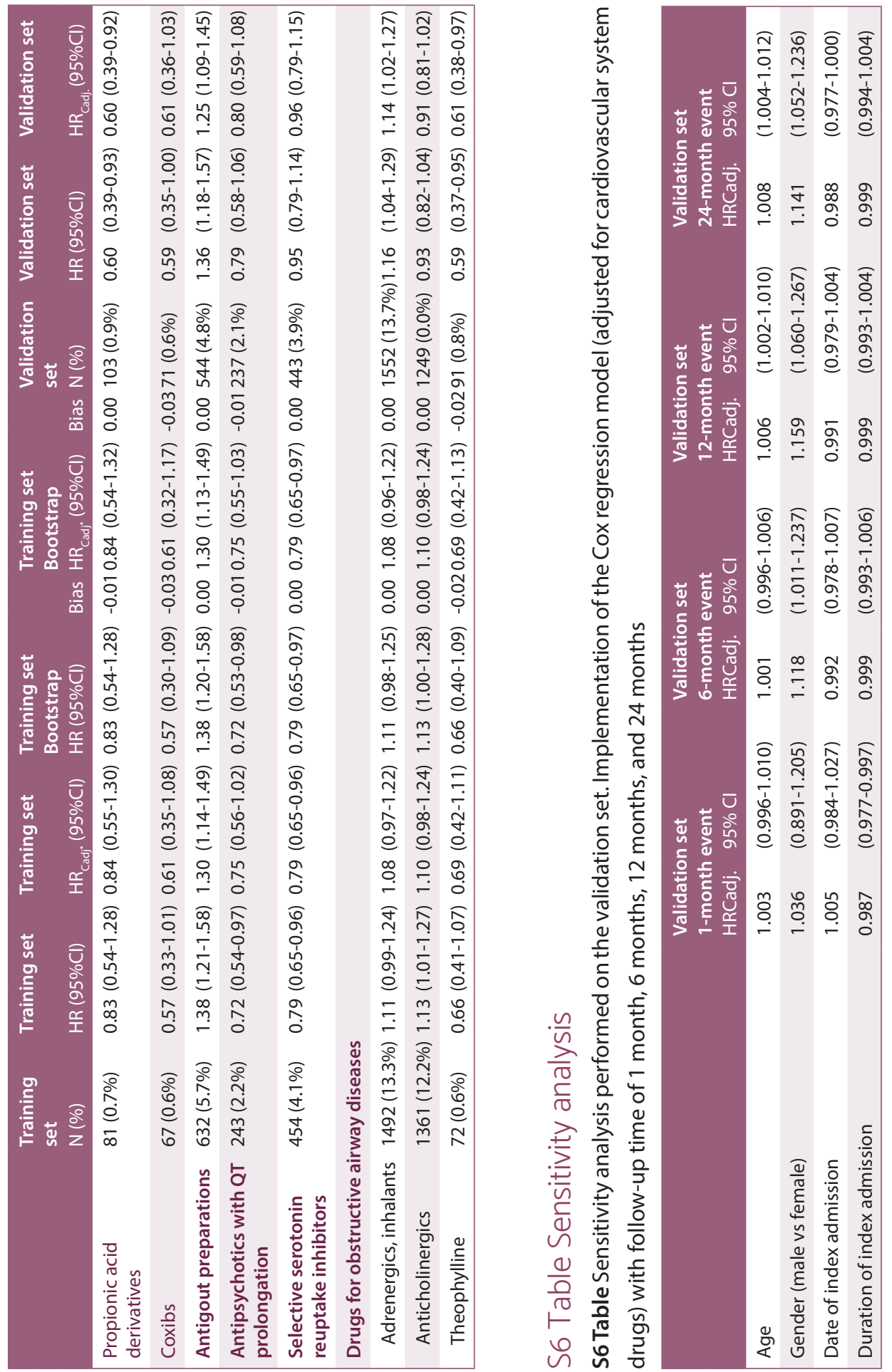


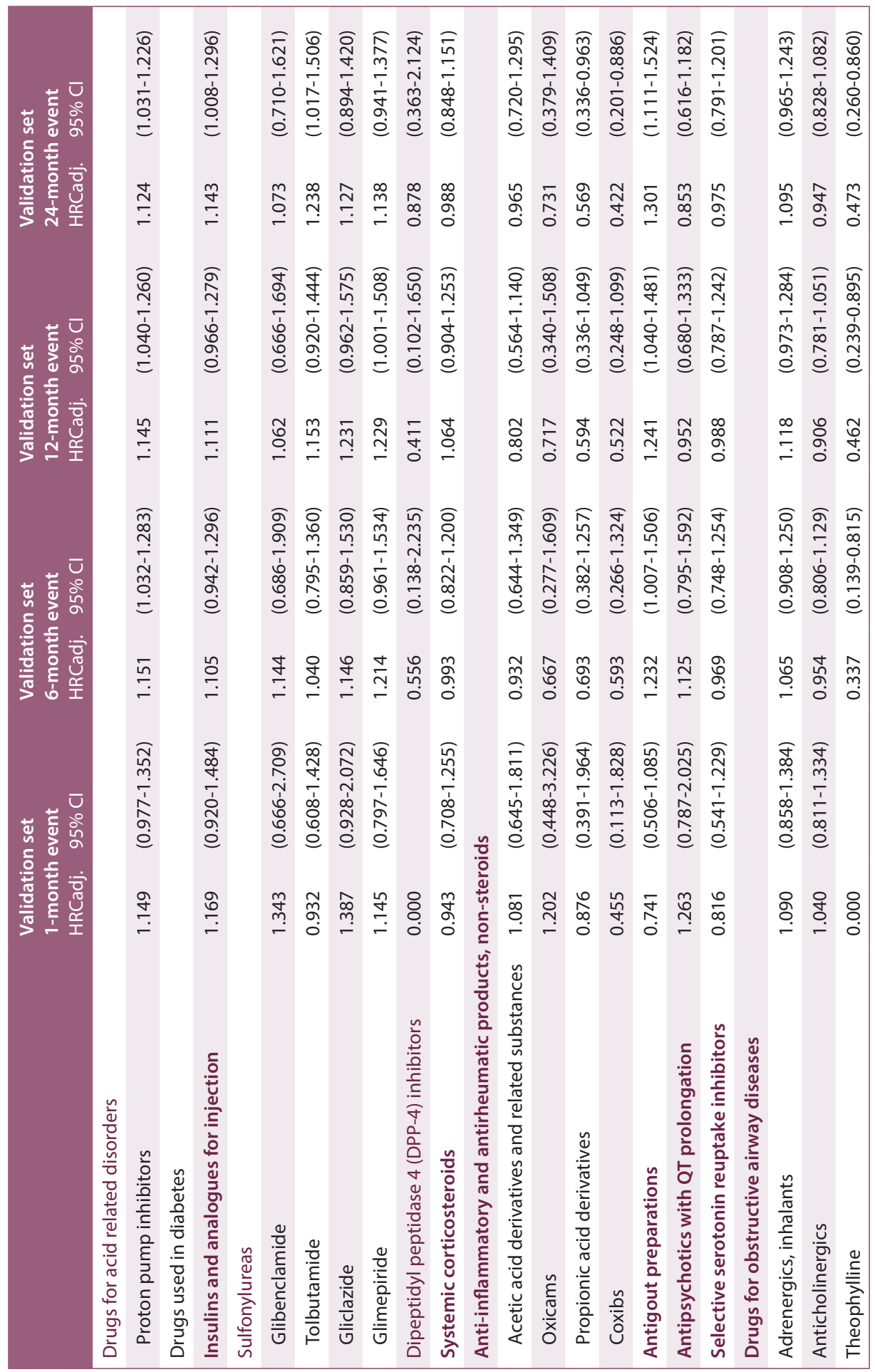




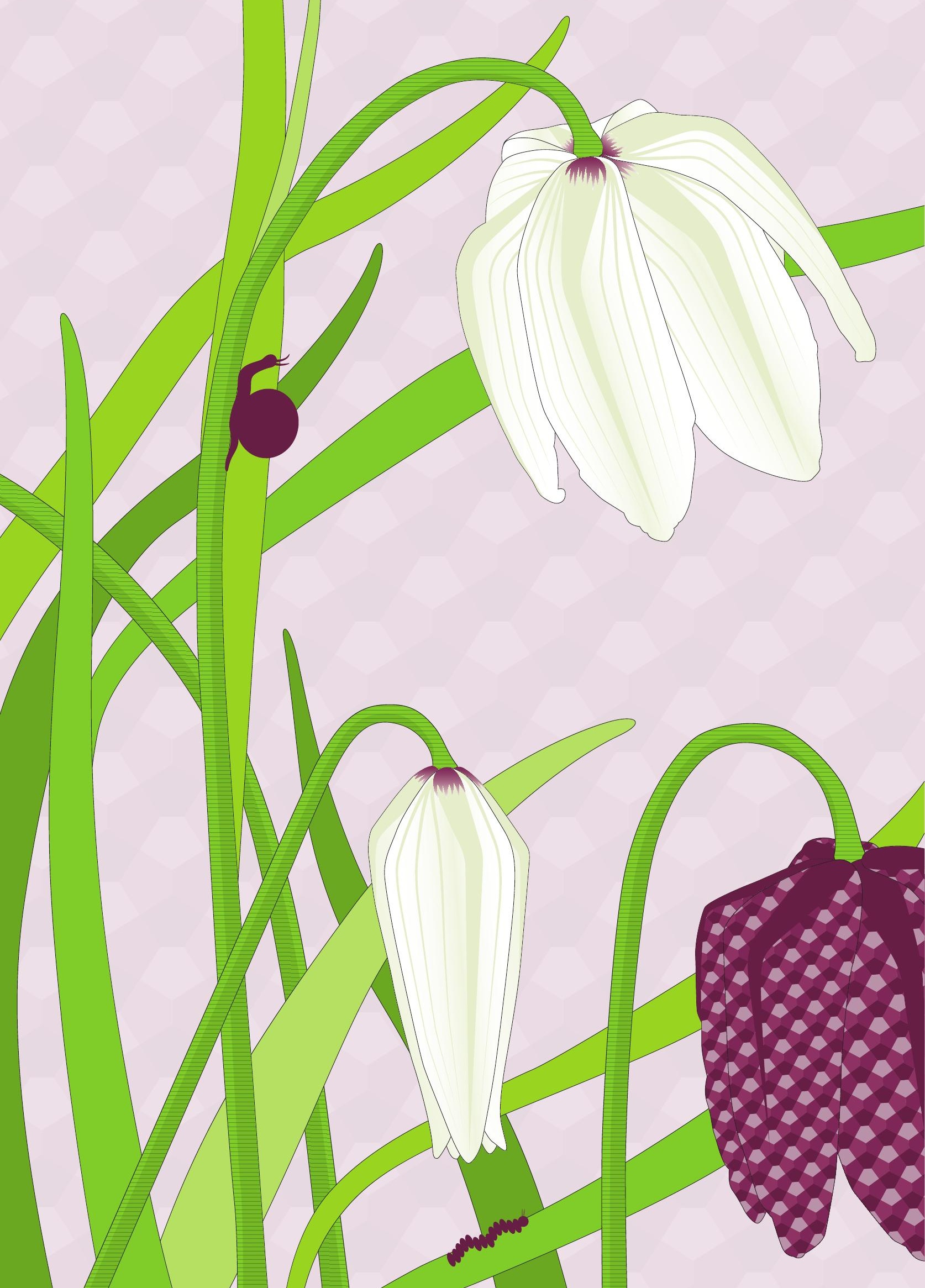




\section{Chapter 8}

General discussion 



\section{John Heart}

This is the story of Mr John Heart

John Heart is a 72-year old, retired bus driver from a medium-sized city in the Eastern part of the Netherlands. He enjoys playing tennis on the senior-mornings and drinking a few glasses of beer while playing dart with his friends in the local pub. A few years ago he stopped smoking because of his grandchildren. John has felt weary since a few weeks and thought he might get the flu. This morning he wakes up with chest pain radiating to his shoulder, he is sweating and feels a bit nauseous. His wife calls the emergency number of their general practitioner, who sends an ambulance to get John to the nearest hospital.

In the hospital the electrocardiogram shows myocardial ischaemia and elevated values of cardiac troponins. An immediate coronary angiography reveals occlusion of a left anterior descending coronary artery. Successful percutaneous coronary intervention (PCI) with two drug-eluting stents is performed. The cardiologist starts aspirin and clopidogrel to prevent stent thrombosis and a statin as secondary prophylaxis. John is prescribed a proton pump inhibitor (PPI) to prevent gastrointestinal side-effects by the combination of aspirin and clopidogrel. Dutifully John attends the heart revalidation course in his hospital.

A few years later Johns condition is declining. He experiences difficulties sleeping horizontally, both ankles swell during the day and he has gained weight. Ordinary physical activity results in undue breathlessness and fatigue. His general practitioner prescribes him some inhalation medication, considering his symptoms as lung problems because of his smoking history. However, his symptoms do not improve and he is referred to a cardiologist, who performs some laboratory testing, an electrocardiogram and echocardiography. John is diagnosed with heart failure (HF) with reduced ejection fraction. Medication is started according to the current guidelines and state of science.

Unfortunately a few years later John has to be admitted to the hospital because of decompensated HF. His medication is adjusted and he is referred to the outpatient HF clinic for pharmacological and non-pharmacological counselling and support. However, his situation slowly worsens over the years and during his last hospital admission the decision is made not to readmit him, but instead to focus on quality of life and give him palliative and supportive care at home.

\section{Clopidogrel and proton pump inhibitor}

Which PPI will the physician have prescribed to John?

The answer to this question is partly depending on the year Johns PCI takes place as we have demonstrated in Chapter 2 and 3. In 2009 and 2010 medicines regulatory authorities published official safety statements regarding the concomitant use of PPIs and clopidogrel. After the first statement at the end of May 2009 to avoid the combination of clopidogrel with a PPI ${ }^{1}$, we observed a temporary increase in histamine 2-receptor antagonists, less 
effective medication for gastroprotection, in new users as well as in patients already on a gastroprotective drug. After the adjusted statement in February $2010^{2}$ to avoid of the PPIs specifically (es)omeprazole, the contribution of (es)omeprazole was further diminished. Although changing drugs in general is a risk for therapy adherence, we observed that the advice of regulatory authorities was followed, albeit reluctantly and not fully, and more switches to "safe" PPIs were seen.

In the light of these safety communications, the physician and pharmacist had to choose the lesser of two evils. On the one hand switching the gastroprotection to a less effective one on the basis of doubtful scientific evidence and the burden of medication change, and on the other hand, medicolegal aspects and the theoretical risk of diminished effectivity of clopidogrel. Since the last communication by regulatory authorities, evidence for example from a large updated meta-analysis in 2015 has emerged with regard to the evidence of the interaction between clopidogrel and (es)omeprazole. ${ }^{3}$ Unfortunately, the information by the regulatory authorities has not been adapted, yet.

We suggested that lessons learned in this study should be applied to managing drug safety information in general. An official statement from regulatory authorities followed by a Direct Healthcare Professional Communications (DHPC) could have had more impact on prescribing behaviour if the scientific doubt was absent or negligible, the specialist associations had supported it, an alternative treatment had been available and actively promoted, and those statements were regularly updated to conform to new evidence. The current directive of June 2018 for DHPCs by the Dutch Medicines Evaluation Board (MEB) ${ }^{4}$ contains the following text: "If necessary, the professional organisations of the healthcare providers involved will be informed during the national implementation phase about a DHPC announced by the MEB. Depending on the set timelines, this takes place as soon as the English text is available, or when the Dutch translation becomes available. In this way, unambiguous communication can be prepared so that healthcare providers are informed of the relevant case as quickly as possible." In the case of valsartan (see General Introduction), at the end of 2018 for the first time, as far as the author knows, the MEB contacted the Dutch organisation of Pharmacists the day before the release of the DHPC to pre-inform them. We conclude that the adjusted directive is a step in the right direction, but not sufficient to close the gap between regulatory authorities and healthcare professionals and make a DHPC have an impact.

\section{Medication profile at discharge from hospital}

What about John's medication at discharge?

As discussed in the general introduction, a hospital admission for HF is a marker of poor prognosis. Disease-modifying medications, if not prescribed already, should be started during hospital admission: angiotensin-converting-enzyme inhibitors/angiotensin-receptor 
blockers, beta-blockers and mineralocorticoid-receptor antagonists in most patients. Diuretics are indispensable in the majority of the patients. The point of view on this cornerstone of HF medical therapy has evolved in the period since the first randomized clinical trial in 1987. ${ }^{5}$ Between the first guideline of the European Society of Cardiology (ESC) in $1997^{6}$ and the current one of $2016^{7}$, a lot of research has been performed, which results have led to changes in these guidelines.

In Chapter 4 we analysed to what extent the ESC guidelines influenced prescription behaviour for these four groups of medication at discharge after a first hospital admission for HF, between 2001 and 2015. Compliance with the ESC guidelines varied for the individual recommendations. Remarkably, there was no significant increase in mineralocorticoidreceptor antagonists prescriptions. At the same time developments were demonstrated, which were not instigated by the guidelines, like the shift from angiotensin-convertingenzyme inhibitors to angiotensin-receptor blockers.

In 2004 the concept of "mindlines" was introduced by Gabbay and le May ${ }^{8}$ based on thorough observations in two highly respected general practices. This showed that experienced clinicians rarely use explicit evidence from research, but mindlines instead off guidelines. These are "collectively reinforced, internalised, tacit guidelines", originated from the very complex system they work in. Mindlines are a professional's own mental guidelines derived from guidelines-in-the-head, but modified while learning lessons in daily work, experiences, contact with colleagues and patients, reading, understanding the local system, etc. Mindlines are "much more flexible, malleable, and complex than guidelines could ever be", this in contrast to the often black and white principles of guideline-makers and researchers. Implementation of guidelines is not a linear and rational process. The malleable nature of mindlines seems to be in contrast with the comparison made by Stone ${ }^{9}$ in the introduction of this thesis between guideline implementation and inertia "Matter will remain at rest or continue in uniform motion in the same straight line unless acted upon by some external force."

Ten years after the introduction of the concept of mindlines, research has been performed how the concept of mindlines has been taken forward since then. ${ }^{10}$ This qualitative type of research is unusual in the world of medical journals. However, this is probably the most appropriate way to investigate the way experienced clinicians use a vast array of cues in their decision making. ${ }^{11}$ Many of these cues are difficult to describe, let alone quantify, so that they can't contribute to statistical adjustments in observational studies. Real world data from registries like ours, or for example the CHECK-HF ${ }^{12}$, are suitable sources for this kind of research. Further research into the concept of mindlines and in general the way in which guidelines are adopted by professionals, might help to improve the implementation of guidelines, in which, as we have shown, there is room for optimisation. 


\section{Association between medication and readmission}

Is the readmission for John associated with his medication at discharge after his first admission? Patients discharged after a hospitalisation for HF have a high risk of HF readmission. In Chapters 5, 6, and 7 we investigated the association between various medication and the risk of HF readmission in a real-world, large, unselected group of patients being discharged from hospital after a first admission for HF.

At first, in Chapter 5 the core HF medication was investigated: angiotensin-convertingenzyme inhibitors/angiotensin-receptor blockers, beta-blockers and mineralocorticoidreceptor antagonists and diuretics. The evidence for the use of these classes of HF drugs, is based upon large randomized clinical trials. In our real-world data, however, carvedilol, mineralocorticoid-receptor antagonists and diuretics showed an increased risk of readmission. Only the prescription of selective beta-blockers with a market authorisation for HF (bisoprolol, metoprolol and nebivolol) resulted in a decreased risk of readmission. All risks were adjusted for comorbidities through the use of propensity scores. Based on our results, a selective beta-blocker should be preferred to the non-selective beta-blocker carvedilol. The choice for angiotensin-converting-enzyme inhibitors or angiotensin-receptor blockers seemed to match the respective patient profiles.

In Chapter 6 the association between additional HF medication and non-HF cardiovascular medication, and readmission for HF was investigated. Based on our results, the importance of digoxin as an addition in selected HF patients, on top of core HF medication according to the therapeutic algorithm in the guidelines, may be underestimated, because the risk of readmission is lower in users than in non-users. On account of the lower risk of HF readmission, aspirin monotherapy should be preferred to P2Y12 inhibitor monotherapy. This is in particular interesting because since 2013-2014 clopidogrel monotherapy (a P2Y12 inhibitor) is more and more used instead of aspirin (with or without dipyridamole) as secondary prophylaxis for cerebrovascular incidents. The risk of readmission for patients on statins, nitrates and amiodarone was increased compared to patients not prescribed these drugs.

The pharmacological treatment of comorbidities can influence the risk for readmission for HF. In Chapter 7 a hypothesis generating study is presented into the association between non-cardiovascular medication and readmissions for HF. The association with readmission was in some cases in accordance with what is known already, but also some unexpected observations were made, like the absence of an association between the use of nonsteroidal anti-inflammatory drugs and readmission. Different sulfonylureas presented a diverse effect on the risk of readmission with $\mathrm{HF}$, not always consistent with existing evidence. HF patients prescribed antigout preparations presented an increased risk of readmission and should therefore be monitored more intensively, irrespective whether the use of this medication is a disease severity marker or a true risk factor. The use of insulin 
was associated with a higher risk of readmission vs non-exposed HF patients However, the risk of readmission was not increased for insulin in HF patients with type 2 diabetes treated with other blood glucose lowering drugs. Although internal and external validation showed statistical robustness of the model, the results have to be considered as hypothesis generating.

The research described in Chapter 5, 6 and 7 demonstrates the value of research from real world data to generate real world evidence or at least food for thought.

\section{Benefit of the clinical pharmacist for cardiovascular patients}

At the end of this thesis, some extra words might be said to address the role of the clinical pharmacist. In 2014 the American College of Clinical Pharmacy ${ }^{13}$ published a guideline titled "Standards of practice for clinical pharmacists" in which the clinical pharmacist is positioned in a team, to work in collaboration with other health care providers to deliver comprehensive medication management that optimizes patient outcomes". The Dutch Association of Hospital Pharmacists (NVZA) has published a statement on the clinical pharmacist in specialized patient care $^{14}$ in September 2017. The American College of Cardiology published in 2015 a Joint Council Perspectives paper on the role of the clinical pharmacist in the care of patients with cardiovascular disease. ${ }^{15}$ They note that clinical pharmacists are underutilised and "have a substantial effect in a wide variety of roles in inpatient and ambulatory settings, largely through optimization of drug use, avoidance of adverse drug events, and transitional care activities focusing on medication reconciliation and patient education". With the highest level of recommendation and evidence, the European $\mathrm{HF}$ guideline ${ }^{7}$ recommends that patients with $\mathrm{HF}$ are enrolled in a multidisciplinary care management programme to reduce the risk of HF hospitalization and mortality, and pharmacists should contribute to these programmes. So, there are policy statements and documents on point of view, but what can be done in practice?

Once a patient like John is being admitted to the hospital, medication reconciliation has to be performed to establish which medication a patient uses at home. Pharmacy-led medication reconciliation interventions were found to be an effective strategy to reduce medication discrepancies ${ }^{16}$, while others emphasize the fact that most of the identified discrepancies had no clinical significance. ${ }^{17}$ The primary goal is to compose a correct medication list, but this moment might also be used to review the medication of the patient and point out potential medication related problems. ${ }^{18}$

Some research has been performed on the effectiveness of involvement of a pharmacist at discharge to assist in an adequate transfer of information with regard to the patient's medication. For example a pharmacist delivered intervention in patients admitted for acute coronary syndromes or acute decompensated $\mathrm{HF}^{19}$ failed to show a decrease in the number of clinically important medication errors, which were present in one half of 
the patients after discharge. Opposite are the results from a study into a pharmacist-led, multidisciplinary transitional care clinic for HF patients, which was able to decrease the percentage of patients readmitted within 30 days from 19\% to $9 \%{ }^{20}$ More research is sought-after into the role of a pharmacist at discharge.

In various situations the role of a clinical pharmacist in a multidisciplinary team has been described. The role of a clinical pharmacist in antibiotic stewardship might be the most well-known ${ }^{21}$ and is even required by the Dutch national authorities. Research has also been performed into the role of the clinical pharmacist in a nephrology unit ${ }^{22}$ and oncology. ${ }^{23}$ In cardiology there are opportunities in antithrombotic stewardship. For example: during and after admission ${ }^{24}$, in the format of a combined haemostatic and antithrombotic stewardship ${ }^{25}$ or around direct oral anticoagulants. ${ }^{26}$

HF patients are especially suited to a multidisciplinary team approach, as they are at high risk of medication related problems. They often have multiple comorbidities, are older and the management of HF involves a variety of medications to be prescribed. ${ }^{27,28}$ Polypharmacy can lead to drug-drug interactions and poor adherence. The HARM-wrestling Task Force demonstrated that seven pharmacologically predictable adverse drug events associated with ten drug classes were responsible for more than half of all potentially preventable hospital admissions in the IPCI and HARM studies. ${ }^{29}$ Gastrointestinal and other bleedings were the most frequent adverse drug events, followed by disturbances of diabetes mellitus control, electrolyte disturbances, fractures, renal insufficiency and HF. Tools are necessary to detect patients most at risk. Some of these risk factors are known, like age, number of drugs and comorbidities, but we are still in need of a workable prediction model. The RxRisk comorbidity index, recently introduced, offers an interesting possibility to estimate the disease burden. ${ }^{30}$

A large variety of modes for pharmacists to contribute to the care of patients with HF are described: drug interaction screening, patient education, medication safety, pharmacokinetic assessment, etc. ${ }^{31}$ Some of these efforts are evidence-based..$^{32}$ The PHARM-CHF trial $^{33}$ is designed to test whether an interdisciplinary pharmacy-based intervention can safely improve medication adherence and will estimate the potential impact on clinical endpoints. The pilot study showed reduced systolic blood pressure in the intervention group as indicator for improved medication adherence.

Intelligent clinical rules designed by pharmacists can support the medication surveillance, combining old-school medication signals with other information available in the electronic patient dossier, like laboratory values and weight of the patient. Such clinical rules can become clinical decision support systems if they are directed at the prescriber. For example if (es)omeprazol is added to clopidogrel, to inform the prescriber of the theoretical, potential interaction and to offer an alternative in an easy accessible way. Another opportunity arises when a patient is discharged from the hospital after decompensated HF. 
A clinical rule could check whether all necessary drugs are present in the medication list of the patient. If one or more are absent, the rule gives a suitable suggestion for a drug to be prescribed. Such a clinical rule is a good example of a cooperation of the HF specialist and the clinical pharmacist to design a rule which improves quality of care in an efficient way.

As the 2016 ESC guideline7 states "In the year 2016, no one would any longer dispute that, by applying all evidence-based discoveries, HF is now becoming a preventable and treatable disease." However, despite this quite positive statement, there comes a time, when the palliative phase starts for a patient like John. In contrast to, for example oncology patients, patients with $\mathrm{HF}$ and their physician tend to maintain a too positive perspective on the nearby future. ${ }^{34-36}$ The position statement of the Heart Failure Association on Advanced Heart Failure focusses on what can and should be done for about 22 pages, while only the last short section is spent on palliative care and what should be refrained from. ${ }^{37}$ In the Netherlands we are blessed to have access to a dedicated, multidisciplinary guideline on palliative care for heart failure patients NYHA class III and IV. ${ }^{38}$ Care at home with a multidisciplinary team approach for HF patients has proven to improve patientcentred outcomes. ${ }^{39} \mathrm{~A}$ pharmacist can have a role in providing necessary medication, like intravenous diuretics in some patients or medication for palliative sedation on others, and advice on what medication might be stopped.

\section{To conclude}

The main objective of this thesis was to search for opportunities for improvement of cardiovascular pharmacotherapy based on evidence from real-world observational data. The title, "Guidelines: friend or foe", reflects the delicate balance for guidelines to persevere. A balance which has been described excellently in 1955 by Glanville Williams: "It must be remembered that rules and institutions are of far less importance than the mode and spirit in which they are administered".40 


\section{References}

1. European Medicines Agency (EMA). News and press release archive. Public statement on possible interaction between clopidogrel and proton pump inhibitors, May 29, 2009. http://www.ema.europa.eu/ema/ index.jsp?curl=pages/news_and_events/ news/2009/11/news_detail_000194. jsp\&mid=WC0b01ac058004d5c1. Accessed 4 February 2017.

2. European Medicines Agency (EMA). News and press release archive. "Public statement on interaction between clopidogrel and proton-pump inhibitors", March 17, 2010: http://www.ema.europa.eu/ema/ index.jsp?curl=pages/news_and_events/ news/2010/03/news_detail_001008. jsp\&mid=WC0b01ac058004d5c1. Accessed 4 February 2017.

3. Cardoso RN, Benjo AM, DiNicolantonio JJ, Garcia DC, Macedo FY, El-Hayek G, et al. Incidence of cardiovascular events and gastrointestinal bleeding in patients receiving clopidogrel with and without proton pump inhibitors: an updated meta-analysis. Open Heart 2015;2(1):e000248.

4. College ter Beoordeling van Geneesmiddelen. MEB 44: Direct Healthcare Professional Communication. https://english.cbg-meb.nl/ topics/mah-direct-healthcare-professionalcommunication-dhpc/documents/policydocuments/2019/01/01/meb-44-directhealthcare-professional-communicationsdhpcs. Accessed 1 February 2019.

5. The CONSENSUS trial study group. Effects of enalapril on mortality in severe congestive heart failure. Results of the cooperative North Scandinavian enalapril survival study (CONSENSUS). N Engl J Med 1987;316:1429-1435.

6. Task force of the working group on heart failure of the European Society of Cardiology. The treatment of heart failure. Eur Heart J 1997;18(5):736-753.

7. Ponikowski P, Voors AA, Anker SD, Bueno H, Cleland JG, Coats AJ, et al. 2016 ESC Guidelines for the diagnosis and treatment of acute and chronic heart failure: The task force for the diagnosis and treatment of acute and chronic heart failure of the European Society of Cardiology (ESC). Developed with the special contribution of the Heart Failure Association (HFA) of the ESC. Eur J Heart Fail 2016;18(8):891-975.
8. Gabbay J, le May A. Evidence based guidelines or collectively constructed "mindlines?" Ethnographic study of knowledge management in primary care. BMJ 2004;329(7473):1013.

9. Clement Stone quotes. AZQuotes. http:// www.azquotes.com/quote/776478. Accessed 1 February 2019.

10. Wieringa S, Greenhalgh T. 10 years of mindlines: a systematic review and commentary. Implement Sci 2015;10:45.

11. Cole GD, Francis DP. Trials are best, ignore the rest: safety and efficacy of digoxin. BMJ 2015;351:h4662.

12. Brunner-La Rocca HP, Linssen GC, Smeele FJ, van Drimmelen AA, Schaafsma HJ, Westendorp $\mathrm{PH}$, et al. Contemporary drug treatment of chronic heart failure with reduced ejection fraction: the $\mathrm{CHECK}-\mathrm{HF}$ registry. JACC Heart Fail 2019;7(1):13-21.

13. American College of Clinical Pharmacy. Standards of practice for clinical pharmacists. Pharmacotherapy 2014;34(8):794-797.

14. Nederlandse Vereniging van Ziekenhuisapothekers. Visiedocument Behandelaarschap. NVZA, september 2017.

15. Dunn SP, Birtcher KK, Beavers CJ, Baker WL, Brouse SD, Page RL $2^{\text {nd }}$, et al. The role of the clinical pharmacist in the care of patients with cardiovascular disease. J Am Coll Cardiol 2015;66(19):2129-2139.

16. Mekonnen AB, McLachlan AJ, Brien JA. Effectiveness of pharmacist-led medication reconciliation programmes on clinical outcomes at hospital transitions: a systematic review and meta-analysis. BMJ Open 2016;6(2):e010003.

17. Kwan JL, Lo L, Sampson M, Shojania KG. Medication reconciliation during transitions of care as a patient safety strategy: a systematic review. Ann Intern Med. 2013;158(5 Pt 2):397403.

18. Mongaret $C$, Quillet $P$, Vo TH, Aubert $L$, Fourgeaud M, Michelet-Huot E, et al. Predictive factors for clinically significant pharmacist interventions at hospital admission. Medicine (Baltimore) 2018;97(9):e9865.

19. Kripalani S, Roumie CL, Dalal AK, Cawthon C, Businger A, Eden SK, et al. Effect of 
a pharmacist intervention on clinically important medication errors after hospital discharge: a randomized trial. Ann Intern Med. 2012;157(1):1-10.

20. Milfred-LaForest SK, Gee JA, Pugacz AM, Piña IL, Hoover DM, Wenzell RC, et al. Heart failure transitions of care: A pharmacist-led postdischarge pilot experience. Prog Cardiovasc Dis 2017;60(2):249-258.

21. Parente DM, Morton J. Role of the pharmacist in antimicrobial stewardship. Med Clin North Am 2018;102(5):929-936.

22. Chen CC, Hsiao FY, Shen LJ, Wu CC. The costsaving effect and prevention of medication errors by clinical pharmacist intervention in a nephrology unit. Medicine (Baltimore) 2017;96(34):e7883.

23. Walko C, Kiel PJ, Kolesar J. Precision medicine in oncology: New practice models and roles for oncology pharmacists. Am J Health Syst Pharm 2016;73(23):1935-1942.

24. Dreijer AR, Kruip MJ, Diepstraten J, Polinder S, Brouwer R, Leebeek FW, et al. Antithrombotic stewardship: a multidisciplinary team approach towards improving antithrombotic therapy outcomes during and after hospitalisation: a study protocol. BMJ Open 2016;6(12):e011537.

25. Reardon DP, Atay JK, Ashley SW, Churchill WW, Berliner N, Connors JM. Implementation of a Hemostatic and Antithrombotic Stewardship program. J Thromb Thrombolysis 2015;40(3):379-382.

26. Uppuluri EM, McComb MN, Shapiro NL. Implementation of a direct oral anticoagulation screening service at a large academic medical center provided by a pharmacist-managed antithrombosis clinic as a method to expand antithrombotic stewardship efforts. J Pharm Pract 2018:897190018799200.

27. Triposkiadis F, Giamouzis G, Parissis J, Starling $\mathrm{RC}$, Boudoulas $\mathrm{H}$, Skoularigis J, et al. Reframing the association and significance of comorbidities in heart failure. Eur J Heart Fail 2016;18(7):744-758.

28. Page RL 2nd, O'Bryant CL, Cheng D, Dow TJ, Ky B, Stein CM, et al. Drugs that may cause or exacerbate heart failure: A scientific statement from the American Heart Association. Circulation 2016;134(6):e32-69.
29. Warlé-van Herwaarden MF, Kramers C, Sturkenboom MC, van den Bemt PM, De Smet PA. Targeting outpatient drug safety: recommendations of the Dutch HARM-Wrestling Task Force. Drug Saf 2012;35(3):245-259.

30. Pratt NL, Kerr M, Barratt JD, Kemp-Casey A, Kalisch Ellett LM, Ramsay E. The validity of the Rx-Risk comorbidity index using medicines mapped to the anatomical therapeutic chemical (ATC) Classification System. BMJ Open 2018;8(4):e021122.

31. Stough WG, Patterson JH. Role and value of clinical pharmacy in heart failure management. Clin Pharmacol Ther 2017;102(2):209-212.

32. Jaarsma T. Health care professionals in a heart failure team. Eur J Heart Fail 2005;7(3):343-349.

33. Laufs U, Griese-Mammen N, Krueger K, Wachter A, Anker SD, Koehler F, et al. Pharmacy-based interdisciplinary program for patients with chronic heart failure (PHARM$\mathrm{CHF}$ ): rationale and design of a randomized controlled trial, and results of the pilot study. Eur J Heart Fail 2018;20(9):1350-1359.

34. Geijteman ECT. Denying the inevitability of death. Eur J Heart Fail 2018;20(5):835-836.

35. Woldman S. Heart failure management-time to change our script on prognosis? Eur J Heart Fail 2018;20(5):837-838.

36. Jaarsma T, van der Wal M, Hjelmfors L, Strömberg A. Talking about palliative care in heart failure. Eur J Heart Fail 2018;20(9):1348-1349.

37. Crespo-Leiro MG, Metra M, Lund LH, Milicic D, Costanzo MR, Filippatos G, et al. Advanced heart failure: a position statement of the Heart Failure Association of the European Society of Cardiology. Eur J Heart Fail 2018;20(11):15051535.

38. Integraal Kankercentrum Nederland. Palliatieve zorg bij hartfalen, third edition. Utrecht, Februari 2018. https://www.pallialine. $\mathrm{nl} /$ hartfalen.

39. Diop MS, Rudolph JL, Zimmerman KM, Richter MA, Skarf LM. Palliative Care interventions for patients with heart failure: A systematic review and meta-analysis. J Palliat Med 2017;20(1):84-92.

40. The proof of guilt, a study of the English criminal trial. Williams G. Stevens \& Sons Limited, London, 1955. 


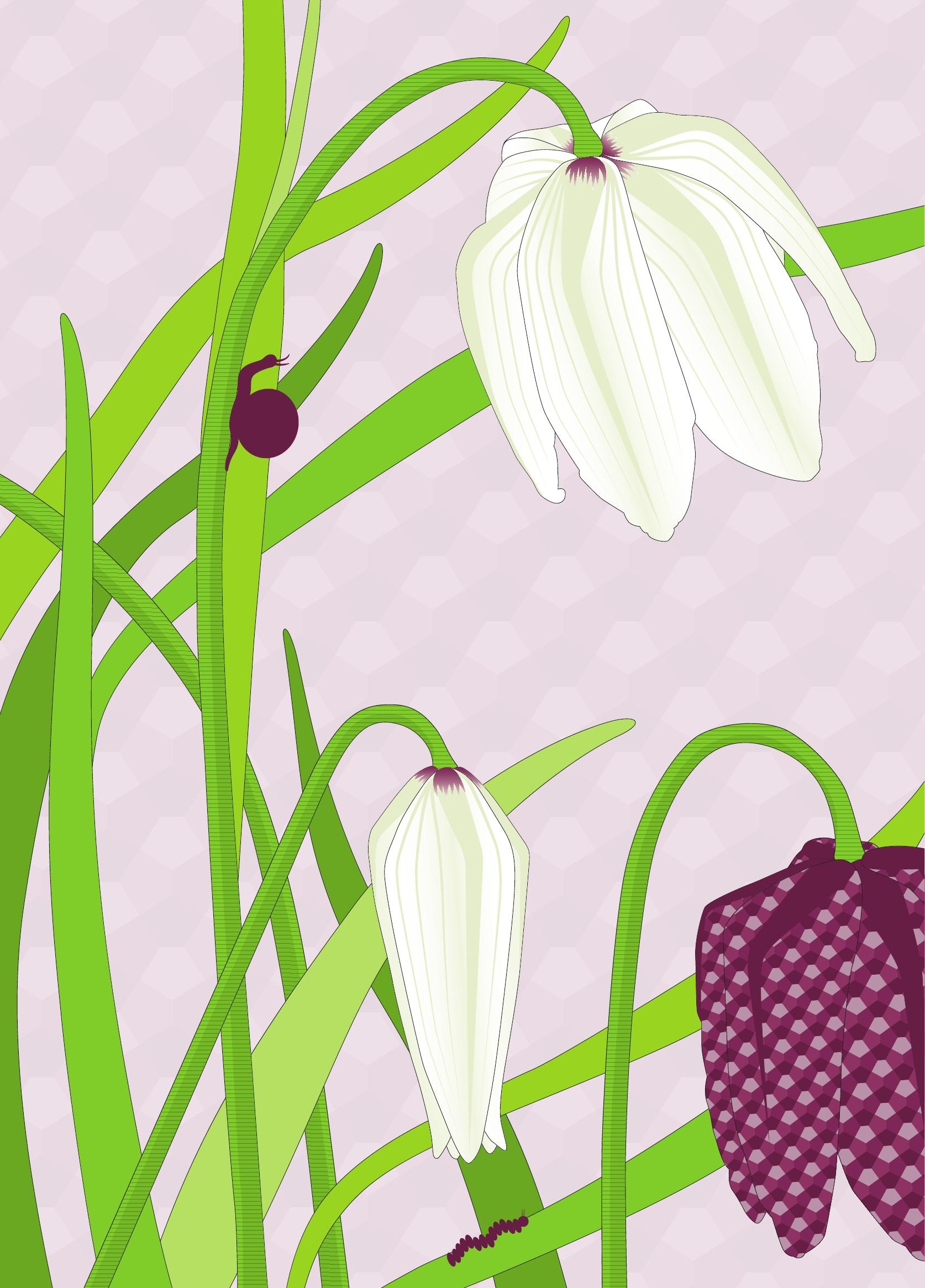




\section{Chapter 9}

Summaries

Summary

Nederlandse samenvatting

Samenvatting voor het publiek 



\section{Summary}

Since ever increasing numbers of clinical research studies are published, the need for guidelines on how to make choices in everyday patient care is obvious. The evidence from clinical research is simply too much to take control of for an individual health care professional. Guidelines play an important role in health care in the pharmacotherapeutic treatment of patients. Guidelines can, just as their name suggest, be a guide in the treatment of patients. On the other hand guidelines can feel as a too strict regimen, an iron corset, hindering professional freedom. Once guidelines become a way to rebuke an individual health care professional for not "staying on the right path", guidelines become a foe instead of a friend. In the general introduction of this thesis (Chapter 1) we described this delicate dilemma. Furthermore, we described the advantages and disadvantages of real-world data and realworld evidence. These two themes, guidelines and real-world evidence from real-world data, formed the starting point of this thesis.

In Chapter $\mathbf{2}$ and $\mathbf{3}$ we investigated the association between prescription behaviour related to gastroprotective drugs and communications regarding the interaction between clopidogrel and proton pump inhibitors. After the first statement by regulatory authorities in June 2009, to avoid combinations of clopidogrel with a proton pump inhibitor, we found in new users as well as in prevalent users of gastroprotective drugs a steep increase in histamine 2-receptor antagonists, peaking at $25 \%$ in new users. As histamine 2-receptor antagonists are less effective in gastroprotection, those patients were at risk of gastrointestinal events. This effect for histamine 2-receptor antagonists faded away after a few months. In February 2010 an adjusted statement was published to avoid only the combination with (es)omeprazole. We then found a decrease of almost $12 \%$ for (es)omeprazole and an increase of $16 \%$ for other proton pump inhibitors in new users of gastroprotective drugs. However, still $22.6 \%$ of the patients started on (es)omeprazole, exposing those patients to a theoretical risk of diminished efficacy of clopidogrel. Not keeping to this official statements could be caused by the doubtful scientific evidence pertaining to this alleged interaction. The same trends could be demonstrated in prevalent users, although less pronounced, as can be expected, because in prevalent users the gastroprotective drug has to be changed when starting clopidogrel. A change in medication is, after all, a risk for reduced adherence.

In Chapter 4 we reviewed the penetration of European guidelines for heart failure on the basis of the prescription of evidence-based medication in a large cohort of patients at discharge after a first hospital admission for heart failure. The setting was in the Netherlands between 2001 and 2015, a period in which major progress was made in the treatment of heart failure. Compliance with these guidelines varied for the individual recommendations. Remarkably, there was no significant increase in mineralocorticoid-receptor antagonist prescriptions. At the same time developments were demonstrated, which were not instigated by the guidelines, like the shift from angiotensin-converting-enzyme inhibitor to 
angiotensin-receptor blocker. Although the exact heart failure classification of our patients was unknown, and assuming a relatively stable case-mix, our data provide insight into "real-world" pharmacological management of patients following a hospital admission for heart failure. Insight into the implementation of current guidelines can help to ameliorate the implementation of future guidelines.

Patients discharged after a first hospitalisation for heart failure have a high risk of a heart failure readmission. In Chapters 5, 6, and 7 we investigated the association between medication, prescribed at discharge, and the risk of a heart failure readmission in a realworld, large, unselected group of patients.

At first, in Chapter 5 the core heart failure medication was investigated: angiotensinconverting-enzyme inhibitors/angiotensin-receptor blockers, beta-blockers, mineralocorticoid-receptor antagonists and diuretics. The evidence for the use of these classes of heart failure drugs comes from large randomized clinical trials. In our real-world data, however, carvedilol, mineralocorticoid-receptor antagonists and diuretics showed an increased risk of readmission, respectively 1.25-fold, 1.09-fold and 1.14-fold. Only the prescription of selective beta-blockers with a market authorisation for heart failure (bisoprolol, metoprolol and nebivolol) resulted in a decreased risk of readmission with a hazard ratio of 0.94 . All risks were adjusted for comorbidities through the use of propensity scores. Based on our results, a selective beta-blocker should be preferred to the nonselective beta-blocker carvedilol. The choice for angiotensin-converting-enzyme inhibitors or angiotensin-receptor blockers seemed to match the respective patient profiles.

In Chapter 6 the association between additional heart failure medication and nonheart failure cardiovascular medication, and readmission for heart failure was investigated. According to the therapeutic algorithm in the guidelines, digoxin can be prescribed as an addition on top of core heart failure medication in selected heart failure patients. Based on our results, however, the clinical importance of digoxin may be underestimated, because the risk of readmission is 0.93 -fold lower in users than in non-users. On account of the lower risk of heart failure readmission, aspirin monotherapy (hazard ratio 0.90) should be preferred to P2Y12 inhibitor monotherapy (hazard ratio 1.26). This is particularly interesting because since 2013-2014 clopidogrel monotherapy (a P2Y12 inhibitor) is more and more used instead of aspirin (with or without dipyridamole) as secondary prophylaxis for cerebrovascular incidents. The risk of readmission for patients on statins, nitrates and amiodarone was increased compared to patients not prescribed these drugs, respectively 1.21-fold, 1.18-fold and 1.31-fold. The increased risk of readmission might be explained by the comorbidities these drugs are prescribed for.

The pharmacological treatment of comorbidities can influence the risk for readmission for heart failure. In Chapter 7 a hypothesis generating study is presented into the association between non-cardiovascular medication and readmissions for heart failure. The association 
with readmission was in some cases in accordance with what is known already. However, also some unexpected observations were made, like the absence of an association between the use of non-steroidal anti-inflammatory drugs and readmission. Different sulfonylureas presented diverse effect on the risk of readmission with heart failure, not always consistent with existing evidence. Heart failure patients prescribed antigout preparations presented an increased risk of readmission and should therefore be monitored more intensively, irrespective whether the use of this medication is a disease severity marker or a true risk factor. The use of insulin was associated with a higher risk of readmission versus heart failure patients not using insulin. However, the risk of readmission was not increased for insulin in heart failure patients with type 2 diabetes compared to those treated with other blood glucose lowering drugs only. Although internal and external validation showed statistical robustness of the model, the results have to be considered as hypothesis generating.

In the general discussion (Chapter 8) we tried to bring back the evidence from our two large cohorts, respectively 39,496 and 22,476 patients, to what it means for an individual, fictional patient called John. The benefit of the clinical pharmacist for cardiovascular patients is described as well. 


\section{Nederlandse samenvatting}

Richtlijnen die het keuzeproces in de dagelijkse patiëntenzorg ondersteunen zijn noodzakelijk om de stijgende aantallen publicaties met resultaten uit klinische onderzoek het hoofd te kunnen bieden. De hoeveelheid bewijs die voortkomt uit klinisch onderzoek is eenvoudigweg te veel om door een individuele professional in de gezondheidszorg te kunnen beheersen. In de gezondheidszorg spelen richtlijnen een belangrijke rol in de medicamenteuze behandeling van patiënten. Richtlijnen kunnen, precies zoals het woord al aangeeft, richting geven aan de behandeling van patiënten. Aan de andere kant kunnen richtlijnen aanvoelen als een te strak keurslijf, een harnas, dat de professionele vrijheid belemmert. Zodra richtlijnen gebruikt worden om een individuele professional in de gezondheidszorg terecht te wijzen omdat deze niet "op het rechte pad" blijft, worden richtlijnen een vijand in plaats van een vriend. In de algemene introductie van dit proefschrift (Hoofdstuk 1) beschreven we dit delicate evenwicht. Tevens beschreven we de voor- en nadelen van "real-world data" en "real-world evidence": het verzamelen van data uit "de echte wereld", als tegenovergestelde van data uit klinisch onderzoek, en bewijs dat daaruit voortkomt. Deze twee thema's, richtlijnen en "real-world evidence" op basis van "real-world data", vormden het startpunt van dit proefschrift.

In Hoofdstuk 2 en $\mathbf{3}$ onderzochten we het verband tussen voorschrijfgedrag van maagbeschermende medicatie en officiële berichtgevingen betreffende de interactie tussen clopidogrel en protonpompremmers. Na de eerste berichtgeving van registratie-autoriteiten in juni 2009, om de combinatie van clopidogrel en protonpompremmer te vermijden, vonden we een sterke toename van het gebruik van $\mathrm{H} 2$-antagonisten zowel in nieuwe gebruikers, met een piek tot $25 \%$ van deze gebruikers, als in patiënten die voorheen al maagbeschermende middelen gebruikten. Aangezien $\mathrm{H} 2$-antagonisten minder effectieve maagbeschermende middelen zijn, lopen deze patiënten een risico op maagbloedingen en in mindere mate bloedingen in de darm. Deze toename in het voorschrijven van $\mathrm{H} 2$-antagonisten verdween na enige maanden. In februari 2010 werd een aangepaste berichtgeving gepubliceerd waarin geadviseerd werd om alleen de combinatie met (es)omeprazol te vermijden. Hierop toonden we bij nieuwe gebruikers van maagbeschermende middelen een daling van bijna $12 \%$ aan voor (es)omeprazol en een toename van $16 \%$ voor andere protonpompremmers. Echter, nog steeds startte $22.6 \%$ van de patiënten met (es)omeprazol, waardoor deze patiënten werden blootgesteld aan een theoretisch risico op een verminderde effectiviteit van clopidogrel. Dezelfde trends konden worden aangetoond in patiënten die reeds maagbeschermende medicatie gebruikten, hoewel minder uitgesproken, zoals te verwachten, aangezien bij deze patiënten de maagbeschermende medicatie aangepast zou moeten worden bij de start van clopidogrel. Een medicatiewijziging vormt immers een risico op verminderde therapietrouw. Het feit dat men de officiële berichtgevingen slechts in beperkte mate opvolgde kan veroorzaakt zijn door het twijfelachtige wetenschappelijke bewijs voor deze veronderstelde interactie. 
In Hoofdstuk 4 onderzochten we in welke mate de Europese richtlijnen voor hartfalen hebben geleid tot het voorschrijven van evidence-based medicatie in een grote groep patiënten bij ontslag na een eerste ziekenhuisopname voor hartfalen. Wij onderzochten dit Nederlandse cohort met behulp van een grote PHARMO database tussen 2001 en 2015, een periode waarin grote voortgang werd geboekt in de behandeling van hartfalen. Het nakomen van de richtlijnen verschilde per aanbeveling. Opvallend was de afwezigheid van een significante toename in het voorschrijven van mineralocorticoïde-receptor antagonisten. Tegelijkertijd toonden wij ontwikkelingen aan die niet in de richtlijnen stonden, bijvoorbeeld de verschuiving van angiotensine-converting-enzym remmers naar angiotensinereceptorblokkers. Hoewel de hartfalenclassificatie van onze patiënten onbekend was, verschaffen onze data, uitgaande van een relatief stabiele case-mix, inzicht in "realworld" medicamenteuze behandeling van patiënten na een ziekenhuisopname voor hartfalen. Inzicht in de implementatie van huidige richtlijnen kan helpen om de implementatie van toekomstige richtlijnen te verbeteren.

Een opname voor hartfalen markeert een verslechtering van de prognose en patiënten na een eerste ziekenhuisopname voor hartfalen hebben een groot risico op een heropname voor hartfalen. In de Hoofdstukken 5, 6 en 7 onderzochten we de associatie tussen medicatie voorgeschreven bij ontslag en het risico op een heropname voor hartfalen in een "real-world", grote, niet geselecteerde patiëntengroep.

Allereerst werden in Hoofdstuk $\mathbf{5}$ de groepen geneesmiddelen onderzocht die de kern vormen voor de behandeling van hartfalen: diuretica, bètablokkers, angiotensineconverting-enzym remmers/angiotensinereceptorblokkers en mineralocorticoïde-receptor antagonisten. Het bewijs voor het gebruik van deze klassen van hartfalenmiddelen is geleverd door grote gerandomiseerde klinische trials. In ons "real-world" cohort, lieten carvedilol (een bètablokker), mineralocorticoïde-receptor antagonisten en diuretica een verhoogde kans zien op een heropname, respectievelijk met een factor 1.25, 1.09 en 1.14. Alleen het voorschrijven van selectieve bètablokkers met een registratie voor hartfalen (bisoprolol, metoprolol en nebivolol) resulteerde in een verlaagde kans op heropname met een hazard ratio van 0.94 . Alle risico's werden gecorrigeerd voor comorbiditeiten door gebruik te maken van propensity scores. Op basis van onze resultaten zou een selectieve bètablokker de voorkeur hebben boven de niet-selectieve bètablokker carvedilol. De keuze voor angiotensine-converting-enzym remmers of angiotensinereceptorblokkers lijkt te passen bij de respectievelijke patiëntprofielen.

In Hoofdstuk 6 werd de associatie onderzocht tussen een heropname voor hartfalen en de additionele hartfalenmiddelen en de cardiovasculaire middelen die niet bij hartfalen worden toegepast. Volgens het behandelschema in de richtlijnen kan digoxine worden voorgeschreven aan geselecteerde patiënten, bovenop de geneesmiddelen die de kern vormen van de hartfalenbehandeling. Op basis van onze resultaten zou gesteld kunnen worden dat 
het klinische belang van digoxine wordt onderschat, omdat het risico op heropnames een factor 0.93 lager was in gebruikers ten opzichte van niet-gebruikers. Kijkend naar het lagere risico op heropname voor hartfalen, zou acetylsalicylzuur monotherapie (hazard ratio 0.90) de voorkeur moeten krijgen boven monotherapie meteen P2Y12-remmer (hazard ratio 1.26). Dit is in het bijzonder interessant, omdat sinds 2013-2014 monotherapie met clopidogrel (een P2Y12-remmer), meer en meer wordt gebruikt in plaats van acetylsalicylzuur (met of zonder dipyridamol) als secundaire profylaxe bij cerebrovasculaire incidenten. Het risico voor een heropname was verhoogd voor patiënten die statines (hazard ratio 1.21), nitraten (hazard ratio 1.18) of amiodaron (hazard ratio 1.31) gebruikten. Het verhoogde risico op een heropname voor deze middelen kan mogelijk verklaard worden door de comorbiditeiten waarvoor deze middelen worden voorgeschreven.

De medicamenteuze behandeling van comorbiditeiten kan het risico op een heropname voor hartfalen beïnvloeden. In Hoofdstuk 7 presenteerden we een hypothese-genererende studie waarin we de associatie tussen niet-cardiovasculaire medicatie en de kans op een heropname voor hartfalen onderzochten. In sommige gevallen bleek de associatie met heropname in overeenstemming met wat we al weten. Echter, ook enkele onverwachte bevindingen werden gedaan, zoals de afwezigheid van een associatie tussen het gebruik van niet-steroïdale anti-inflammatoire geneesmiddelen (NSAID's) en heropname. De verschillende sulfonylureumderivaten laten een verschillend effect zien op het risico op heropname voor hartfalen, niet altijd in overeenstemming met het bestaande bewijs. Hartfalenpatiënten aan wie middelen tegen jicht zijn voorgeschreven hebben een verhoogd risico op een heropname en dienen daarom intensiever bewaakt te worden, onafhankelijk van de vraag of het gebruik van deze medicatie een kenmerk is van de ernst van de ziekte, of een echte risicofactor. Het gebruik van insuline was geassocieerd met een verhoogd risico op heropname ten opzichte van patiënten die geen insuline gebruiken. Echter, het heropnamerisico van insuline was niet toegenomen bij hartfalenpatiënten met diabetes type 2 in vergelijking met patiënten die alleen andere bloedsuikerverlagende middelen gebruiken. Hoewel interne en externe validatie de statistische robuustheid van het model aantoonden, dienen onze resultaten als hypothese-genererend te worden beschouwd.

Het bewijs dat we verzameld hebben in onze 2 grote patiënten cohorten, respectievelijk 39.496 en 22.476 patiënten, probeerden we in de algemene discussie (Hoofdstuk 8) te vertalen naar een individuele, fictieve patiënt, genaamd John. De toegevoegde waarde van de ziekenhuisapotheker voor cardiovasculaire patiënten wordt hier eveneens beschreven. 


\section{Samenvatting voor het publiek}

In dit proefschrift beschrijven we het onderzoek dat we hebben uitgevoerd in 2 databases met vele duizenden patiënten. Om het belang voor een enkele patiënt te laten zien, stellen we in de discussie een bedachte patiënt voor, met de naam John Heart ("Jan van 't Hart").

John Heart is een gepensioneerde buschauffeur uit Twente. Hij speelt tennis op de seniorenochtend en drinkt graag een biertje met wat vrienden tijdens het darten in een café. Een paar jaar geleden is hij gestopt met roken, omdat hij kleinkinderen kreeg. John voelde zich al een paar dagen niet lekker en dacht dat hij de griep zou gaan krijgen. Vanochtend werd hij wakker met een pijn die uitstraalde naar zijn schouder. Hij zweet en is wat misselijk. Zijn vrouw belt het spoednummer van de huisarts, omdat ze de signalen van een hartinfarct ("hartaanval") denkt te herkennen. De huisarts stuurt een ambulance, die John snel naar het ziekenhuis brengt.

In het ziekenhuis wordt een hartfilmpje gemaakt en bloed afgenomen. Hij heeft inderdaad een hartinfarct. John gaat door naar de behandelkamer en daar wordt met een ballonnetje de vernauwing in het bloedvat van het hart open gemaakt. Er worden ook 2 stents geplaatst, kleine buisjes die voorkomen dat de wand van het bloedvat direct weer terugveert en verstopt. De cardioloog (arts gespecialiseerd in hartziekten) geeft John een recept met acetylsalicylzuur en clopidogrel om ervoor te zorgen dat het bloedvat op die plek niet opnieuw dicht gaat zitten. Dit zijn twee geneesmiddelen die ervoor zorgen dat het bloed minder snel stolt. Helaas geven ze daardoor ook een verhoogde kans op een maagbloeding. John krijgt een maagbeschermer om deze bijwerking te voorkomen. John volgt braaf het hartrevalidatie programma.

In 2009 en 2010 kwamen er officiële berichten van de overheid, dat de combinatie van clopidogrel en sommige maagbeschermers slecht zou zijn. Door de maagbeschermer zou clopidogrel misschien minder goed kunnen werken. Onze patiënt, John, zou dan opnieuw een hartinfarct kunnen krijgen. Cardiologen en apothekers stonden voor een lastige keus. Het is immers niet de bedoeling dat clopidogrel minder goed werkt. Toch wil je ook niet dat John een maagbloeding krijgt door slechtere (of geen) maagbescherming. Wij keken in een database met bijna 40.000 patiënten die tussen 2008 en 2011 gestart waren met clopidogrel. Niet bij alle patiënten bleken de officiële adviezen op te zijn gevolgd. We denken dat dit onder andere kwam doordat artsen en apothekers twijfelden of de berichten wel juist waren. Het zou goed zijn als officiële instanties beter in gesprek zouden gaan met artsen en apothekers voordat ze een officieel advies uitbrengen, was één van onze conclusies uit dit onderzoek.

Een paar jaar later gaat het toch wat minder goed met John. Hij heeft een extra kussen nodig om te kunnen slapen, zijn enkels zwellen op in de loop van de dag en hij is wat zwaarder geworden. John is snel buiten adem en moe bij gewone activiteiten zoals de dagelijkse boodschappen. 
Zijn huisarts denkt eerst dat hij last heeft van zijn longen omdat John jaren heeft gerookt. Hij krijgt daarvoor wat geneesmiddelen. Het gaat helaas niet beter met hem en hij wordt doorgestuurd naar een cardioloog. Er wordt onderzoek gedaan en John blijkt hartfalen te hebben. Zijn hart pompt niet genoeg bloed rond. Hij krijgt de gebruikelijke geneesmiddelen voor hartfalen.

Wereldwijd wordt veel onderzoek gedaan naar hartfalen. Deskundigen bestuderen alle resultaten en kijken of de behandeling van patiënten moet worden aangepast. Nederlandse patiënten worden behandeld volgens Europese richtlijnen, die gemiddeld eens per 4 jaar worden aangepast. Wij kregen een database met een groep van ruim 22.000 patiënten, zoals John, die opgenomen zijn geweest in het ziekenhuis tussen 2001 en 2015. We onderzochten of we de veranderingen in de Europese richtlijnen konden terugvinden in de geneesmiddelen die deze patiënten bij ontslag voorgeschreven kregen. Alserveranderingen in de richtlijnen zijn, verwacht je immers dat je dat terugziet in de behandeling van patiënten. Sommige veranderingen in richtlijnen waren goed in de dagelijkse praktijk te zien. Voor andere richtlijnen was dat minder het geval. Deze informatie kan ons helpen om in de toekomst ervoor te zorgen dat nieuwe richtlijnen nog beter worden opgevolgd.

Helaas moet John een paar jaar later in het ziekenhuis worden opgenomen omdat het niet goed gaat met zijn hartfalen. Zijn geneesmiddelen worden aangepast en hij wordt doorgestuurd naar de hartfalenpoli. Het team van de hartfalenpoli helpt hem met zijn geneesmiddelen, maar ook met bewegen, voeding, en dergelijke. In de loop der jaren gaat zijn toestand langzaam achteruit. Tijdens de laatste opname in het ziekenhuis wordt besloten hem niet meer op te nemen, maar hem vooral nog zo veel mogelijk te laten genieten van de rest van zijn leven en thuis maximale steun te geven.

Een ziekenhuisopname voor hartfalen is een slecht teken. Daarna gaat het vaak een stuk slechter met de patiënt en moet ook nog al eens opnieuw opgenomen worden. In dezelfde grote database met hartfalenpatiënten hebben we gekeken of het wat uitmaakt voor zo'n nieuwe opname welke geneesmiddelen een patiënt gebruikt. Allereerst hebben we gekeken naar de echte hartfalen geneesmiddelen, de "harde kern". Deze geneesmiddelen worden door veel van de patiënten zoals John gebruikt. In onderzoek waren deze geneesmiddelen effectief, maar wij wilden weten of ze dat ook in de dagelijkse praktijk waren. Die effectiviteit bleek op die manier toch lastig aan te tonen. We hebben vervolgens gekeken of andere geneesmiddelen een effect hadden op de kans dat een patiënt opnieuw opgenomen zou moeten worden. Zo hebben we gekeken naar de reserve-geneesmiddelen voor hartfalen en de geneesmiddelen die wel door een cardioloog worden gegeven, maar voor iets anders dan hartfalen. Ten slotte hebben we gekeken naar de geneesmiddelen die 
niet door een cardioloog worden gegeven aan patiënten. Bijvoorbeeld een geneesmiddel tegen jicht, zou best een grotere kans op een nieuwe hartfalenopname kunnen geven.

We hopen dat de onderzoeken die we hebben gedaan de zorg voor een hartpatiënt zoals John kunnen verbeteren en dat de ziekenhuisapotheker daaraan een bijdrage kan leveren. 


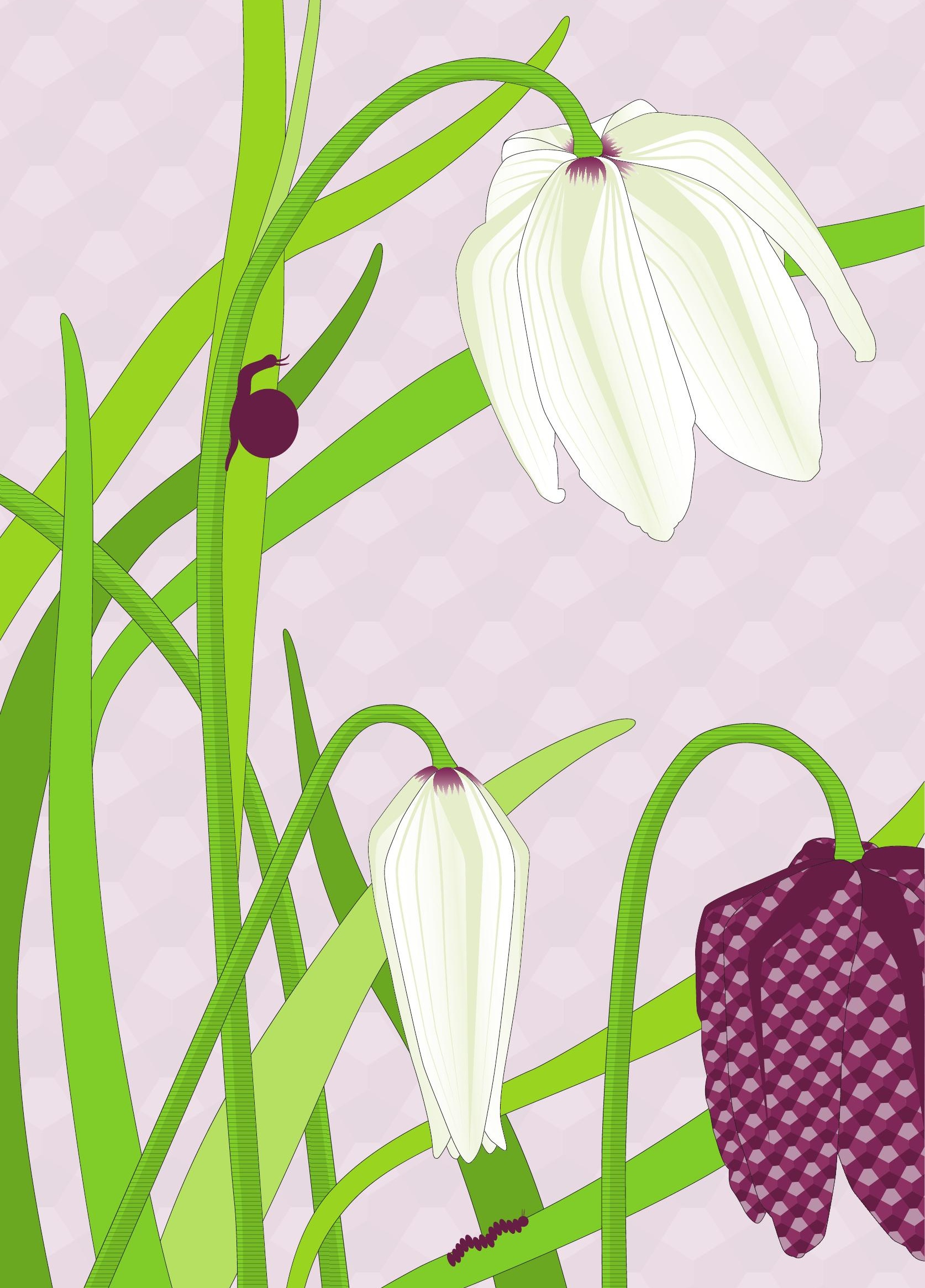




\title{
Chapter 10
}

Appendices

\author{
Dankwoord \\ Curriculum vitae \\ List of publications \\ Bij de voorpagina
}





\section{Dankwoord}

Als mens en professional word je gevormd door alles wat je op je levenspad tegenkomt. Soms zorgen toevallige ontmoetingen ervoor dat je op een pad terecht komt waarvan je niet had gedacht dat je het ooit zou belopen. Dit promotie-traject was voor mij zo'n pad. Ik ben trots en blij, en toch ook wel een beetje opgelucht, dat ik nu het einde van dit pad heb bereikt. Dank dus, aan iedereen die -soms onbewust- op één of andere manier een bijdrage heeft geleverd aan de totstandkoming van dit proefschrift.

In het bijzonder wil ik hartelijk bedanken mijn promotieteam, dat mij heeft geholpen dit pad te belopen en het eindpunt te bereiken. Zonder de enthousiaste, motiverende coaching van jou, Job, was er misschien helemaal geen proefschrift geweest. Zeker was het, dat dit traject minder leuk geweest zou zijn: ik kwam meestal (in gedachten!) huppelend van onze afspraken vandaan. Ook Kris en Gerard, mijn copromotoren, jullie hebben je best gedaan mij op het juiste pad te houden en duwtjes in de goede richting te geven. Kris bescheiden, op de achtergrond, maar als het nodig was, was je er. Gerard stapte wat later in, bewaakte de cardiologische kant van het onderzoek- en schrijfwerk. Job, jij zei eens: "de promovendus kiest het promotieteam". Ik denk dat ik goed gekozen heb!

Geachte leden van de promotiecommissie, uw inbreng door mijn proefschrift te beoordelen en deel te nemen aan mijn oppositie, is niet alleen noodzakelijk, maar wordt door mij ook op prijs gesteld. Dank daarvoor.

Myrthe, Edith, Carine en Enriqueta, co-onderzoekers en co-auteurs. Ik heb jullie inbreng bij het uitvoeren, afronden en opschrijven van de verschillende onderzoeken zeer gewaardeerd. Jullie waren soms irritant gedetailleerd, maar dit heeft wel de kwaliteit van het geleverde werk in positieve zin beïnvloed. Enriqueta: muchas gracias por la buena cooperación.

Vele mensen hebben in dit traject met mij meegedacht, meegeleefd en meegelachen. Allen dank. Een opsomming zal altijd iemand tekort doen, toch wil ik Leonora, Jesse, Marloes en Jacqueline met name noemen.

De collega's binnen de vakgroep ZGT-SXB, inclusief de "extended" vakgroep Anet, Frank en Susan, dank voor jullie warme belangstelling en ondersteuning. Elkaar helpen bij tegenslagen en samen successen vieren. Zullen we nog één of twee promoties afspreken in de komende vijf jaar? Dank ook aan alle andere medewerkers van beide apotheken. Jullie vonden mijn promotie-hobby maar wat vreemd, ik stop er nu mee. 
Regine, we kennen elkaar sinds 1987 en hadden -ook toen al- een klik. Toen we samen in Enschede terecht kwamen, werden we vriendinnen. We hebben veel met elkaar gemeen en kunnen elkaar steunen zowel in werk als privé. Ik vind het heel fijn jou naast me te hebben als paranimf.

Chris, Jorien, Nel en de rest van de familie, we hebben heel wat met elkaar meegemaakt de afgelopen jaren. Dieptepunten, maar gelukkig ook hoogtepunten. Voor mij is dit proefschrift een hoogtepunt en ik dank jullie voor jullie steun en aanwezigheid. Het is nu tijd voor een feestje!

Lieve ouders, in de aanloop naar dit proefschrift zijn jullie beide overleden. Mam, bij je uitvaart zei dominee Florus dat het geluk van je kinderen, jouw geluk was: je zou gelukkig geweest zijn! Je was, pap, apetrots dat mijn "stukjes" toch nog tot een "boekje" zouden leiden. Ik had jullie zo graag nog bij ons gehad. Dank voor jullie onvoorwaardelijke liefde.

Coen en Bouwen, van "monstertjes" zijn jullie jong-volwassen mannen geworden. Ik ben trots op jullie en dankbaar voor jullie steun, ook al konden jullie de eerste jaren niet helemaal overzien waar mijn onderzoek toe zou kunnen leiden. Eerlijk gezegd, wist ik dat ook niet precies. Ik wens jullie net zo veel plezier in je toekomstige vak als ik in het mijne heb.

Last but not least, allerliefste Joost, ook aan jou ben ik veel dank verschuldigd. Dat ik jou op mijn pad tegen ben gekomen heeft een belangrijke rol gespeeld in de totstandkoming van dit boekje. Je stimuleert me om het beste uit mezelf te halen en mijn dromen waar te maken. Ik hoop dat we samen heel oud mogen worden en misschien, Joost, gaan we nog een keer samen op vakantie naar de Loire? 


\section{Curriculum Vitae}

Willemien Kruik-Kollöffel werd geboren op 5 april 1965 in Utrecht en groeide op in het nabij gelegen dorp Vleuten. Ze rondde in 1983 haar middelbare school opleiding af aan het Christelijk Gymnasium te Utrecht. In 1983 startte Willemien met de studie farmacie aan de Universiteit van Utrecht. Na het behalen van het doctoraalexamen in 1988, vervolgde ze haar studie en slaagde voor het apothekersexamen in 1990.

In 1992 begon ze de specialisatie tot ziekenhuisapotheker in het toenmalige Twenteborg Ziekenhuis te Almelo. Na werkervaring op te hebben gedaan in diverse ziekenhuizen in Nederland, werkt ze sinds 2016 in de ziekenhuisapotheek van de Saxenburgh Groep in Hardenberg (RegioApotheek Vechtdal) en de Ziekenhuisgroep Twente, met ziekenhuizen in Almelo en Hengelo.

Een breed scala aan ervaringen opgedaan in meer dan 30 jaar, vormde de basis waaruit het onderzoek in dit proefschrift is ontstaan. Een extra-curriculaire onderzoekstage gedurende het zomerreces van de universiteit, leidde tot de eerste publicaties van Willemien. De cirkel van het onderzoek werd rond gemaakt door het winnen van de Twenteborg Plus Prijs in de categorie wetenschappelijk in 1996 en afgelopen herfst de ZGT onderzoeksprijs. Daarnaast heeft ze in die periode van 30 jaar vanzelfsprekend ook andere professionele en bestuurlijke vaardigheden ontwikkeld, zoals tijdens haar studententijd door het bestuurslidmaatschap van de Algemene Nederlandse Pharmaceutische Studentenvereniging en een aanvullend doctoraalexamen voortgezette bedrijfseconomie aan de rechtenfaculteit. In de jaren die volgden was ze onder andere plaatsvervangend opleider, lid van het stafbestuur en had Willemien een aanstelling als coördinator patiëntveiligheid in één van de ziekenhuizen waarin ze werkzaam was.

Willemien is getrouwd met Joost en heeft twee zonen, Coen en Bouwen.

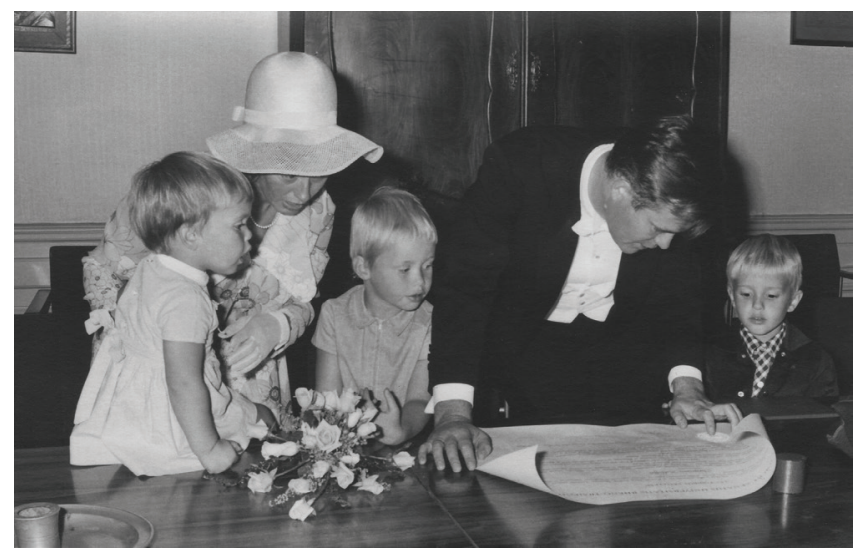




\section{List of publications}

\section{Included in this thesis}

- Kruik-Kollöffel WJ, Linssen GCM, Kruik HJ, Movig KLL, Heintjes EM, van der Palen J. Effects of European Society of Cardiology guidelines on medication profiles after hospitalization for heart failure in 22,476 Dutch patients: from 2001 till 2015. Heart Fail Rev, online first 8 March 2019, doi: 10.1007/s10741-019-09777-2.

- Kruik-Kollöffel WJ, van der Palen J, van Herk-Sukel MPP, Kruik HJ, Movig KLL. Decrease in switches to "unsafe" proton pump inhibitors after communications about interactions with clopidogrel prescription behaviour for gastroprotective drugs in new users as a result of communications regarding clopidogrel - proton pump inhibitor interaction. Clinical Drug Investigation 2017;37(8):787-794.

- Kruik-KollöffelWJ, van der Palen J, Kruik HJ, van Herk-Sukel MPP, Movig KLL. Prescription behaviour for gastroprotective drugs in new users as a result of communications regarding clopidogrel - proton pump inhibitor interaction. Pharma Res Per 2016;4(4):e00242.

\section{Not included in this thesis}

- Van der Elst KCM, Oortgiesen BE, Kruik-Kollöffel WJ, Hoogendoorn M, Hofma SH, van Roon EN. Noodzaak en nadelen van protonpompremmers bij clopidogrel monotherapie. Accepted for publication in Ned Tijdschr Geneeskd.

- Nygård P, Jansman FG, Kruik-Kollöffel WJ, Barnaart AF, Brouwers JR. Effects of short-term addition of NSAID to diuretics and/or RAAS-inhibitors on blood pressure and renal function. Int J Clin Pharm 2012;34:468-474.

- Nygård P, Saleem R, Jansman FGA, Kruik-Kollöffel WJ, Barnaart AFW, Brouwers JRBL. Effect van kortdurend postoperatief gebruik van NSAID's op bloeddruk en nierfunctie bij gelijktijdig gebruik van diuretica en/of RAAS-remmers. PW Wetenschappelijk Platform 2010;4(9):148-150.

- Kruik-Kollöffel WJ, Van Berlo-van de Laar IRF, Van den Broek E, Meulenhoff AMC, Ploeger B. Steunpunt en elektronisch voorschrijven. Samen nog beter. Pharm Weekbl 2005; 140(20): 662-664.

- Boom FA, Bouwman-Boer Y, Kruik-Kollöffel WJ, Pluim MAL, Rendering JA, Simons KA. Hoofdstuk GMP-Ziekenhuisfarmacie herzien. Verantwoordelijkheid voor aseptische handelingen buiten de ziekenhuisapotheek. Pharm Weekbl 2005;140(11):350-352.

- De Vries F, Kruik-Kollöffel WJ. Verminderde afweer en immuunrespons. Influenza vaccinatie tijdens behandeling met cytostatica. Pharm Weekbl 2003;138(20):658-663.

- Kollöffel WJ, Boom FA. Het productdossier van de gestandaardiseerde bereiding. Theorie en praktijk. Pharm Weekbl 2000;135(38):1426-1431. 
- Kollöffel WJ, Boom FA. Het productdossier van de gestandaardiseerde bereiding. Farmacotherapeutische kwaliteit en rationaliteit. Pharm Weekbl 2000;135(1):25-28.

- Kruik-Kollöffel WJ, Schüsler-van Hees MTIW. FPZ-Standaard Hypertensie. WINAp, Den Haag, mei 1998.

- Kruik HJ, Kollöffel WJ, Verheugt FWA. Streptokinase. In: Becker RC, ed. Textbook of coronary thrombosis and thrombolysis. Massachusetts: Kluwer Academic Publishers, 1997:239-242.

- Kollöffel WJ, Weekers LEA, Goldhoorn PB. Pharmacokinetics of propylene glycol after rectal administration. Pharm World Sci 1996;18(3):109-1013.

- Kollöffel WJ, Driessen FGWHM, Goldhoorn PB. Plasma-concentration profiles after rectal administration of a solution of paracetamol in children. Pharm World Sci 1996;18(3):105-108.

- Kollöffel WJ, Driessen FGWHM, Goldhoorn PB. Rectal administration of paracetamol: a comparison of a solution and suppositories in adult volunteers. Pharm World Sci 1996;18(1):26-29.

- Kruik HJ, KollöffelWJ, Verheugt FWA. Dexrazoxane en de preventie van cardiomyopathie door doxorubicine. Cardiologie 1996;3(4):154-156.

- Kollöffel WJ, Kaan JA. Toxoplasmose. Pharm Weekbl 1995;130(1):10-15.

- Kollöffel WJ, de Vroom TE, Weekers LEA, Woittiez AJJ. Severe cutaneous side effects of peripheral infusions with Carbicarb ${ }^{\circ}$ half strength. Intensive Care Med 1994;20(7):531.

- Kollöffel WJ. Postoperatieve pijnbestrijding bij kinderen. Pharm Weekbl 1993;128(21):635-643.

- Leufkens HGM, Herings RMC, Kollöffel WJ, Bakker A. Concomitant drug use among patients on cardiac glycosides. Int J of Risk \& Safety in Med 1992;2:11-20.

- Kollöffel WJ, Leufkens HGM, Voesten MTPJ, Bakker A. Apotel: een inventarisatie van het telefoonverkeer tussen apotheek en arts. Pharm Weekbl 1990;125(20):486-490. 


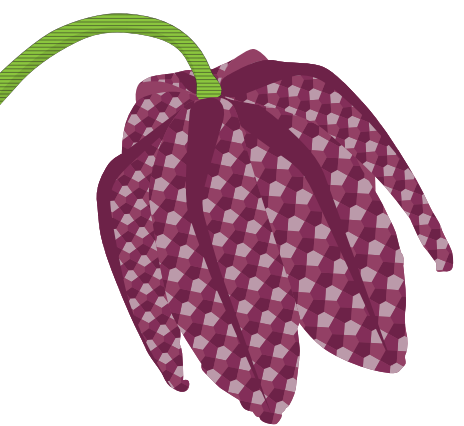

\section{Bij de voorpagina}

De kievitsbloem (Fritillaria meleagris) is een in het wild zeer zeldzaam voorkomend bolgewas. De plant doet er acht jaar over om in bloei te komen. Ze kan slecht tegen veranderingen aan het grondwaterpeil en is op de meeste plaatsen al voor de Tweede Wereldoorlog uitgestorven. De belangrijkste groeiplaats van de wilde kievitsbloem is langs de oevers van de Overijsselse Vecht en het Zwarte Water bij Zwolle. Ongeveer tachtig procent van de Nederlandse wilde kievitsbloemen staat hier.

In Wierden staat jaarlijks in mei een veldje vol kievitsbloemen langs een fietspad van ons huis naar de voormalige basisschool van de kinderen. De planten overleefden een grondige renovatie van het fietspad. Het is mooi om te zien dat zo'n zeldzame plant met uniek uiterlijk zo dichtbij gewoon in je eigen woonplaats kan groeien en bloeien. 

